\title{
The Surface Chemistry of Cerium Oxide
}

\author{
David R. Mullins* \\ Chemical Sciences Division \\ Oak Ridge National Laboratory \\ Oak Ridge, TN 37831-6201
}

This manuscript has been authored by UT-Battelle, LLC under Contract No. DE-AC05-00OR22725 with the U.S. Department of Energy. The United States Government retains and the publisher, by accepting the article for publication, acknowledges that the United States Government retains a non-exclusive, paid-up, irrevocable, worldwide license to publish or reproduce the published form of this manuscript, or allow others to do so, for United States Government purposes. The Department of Energy will provide public access to these results of federally sponsored research in accordance with the DOE Public Access Plan (http://energy.gov/downloads/doe-public-access-plan).

${ }^{*}$ Corresponding Author:

David R. Mullins

Oak Ridge National Laboratory

PO Box 2008, MS 6201

Oak Ridge, TN 37831-6201

e-mail: mullinsdr@ornl.gov

phone: 865-574-2796

FAX: 865-241-5252 


\begin{abstract}
This review covers the structure of, and chemical reactions on, well-defined cerium oxide surfaces. Ceria, or mixed oxides containing ceria, are critical components in automotive threeway catalysts due to their well-known oxygen storage capacity. Ceria is also emerging as an important material in a number of other catalytic processes, particularly those involving organic oxygenates and the water-gas shift reaction. Ceria's acid-base properties, and thus its catalytic behavior, are closely related to its surface structure where different oxygen anion and cerium cation environments are present on the low-index structural faces. The actual structure of these various faces has been the focus of a number of theoretical and experimental investigations. Ceria is also easily reducible from $\mathrm{CeO}_{2}$ to $\mathrm{CeO}_{2-x}$. The presence of oxygen vacancies on the surface often dramatically alters the adsorption and subsequent reactions of various adsorbates, either on a clean surface or on metal particles supported on the surface. Most surface science studies have been conducted on the surfaces of thin-films rather than on the surfaces of bulk single crystal oxides. The growth, characterization and properties of these thinfilms are also examined.
\end{abstract}




\section{List of abbreviations}

$\begin{array}{ll}\text { AP-XPS } & \text { Ambient pressure x-ray photoelectron spectroscopy } \\ \text { AR-MSRI } & \text { Angle resolved mass spectrometry of recoiled ions } \\ \text { DFT } & \text { Density functional theory } \\ \text { DRS } & \text { Direct recoil spectroscopy } \\ \text { FTIR } & \text { Fourier transform infrared spectroscopy } \\ \text { GGA } & \text { Generalized gradient approximation } \\ \text { HREELS } & \text { High resolution electron energy loss spectroscopy } \\ \text { LEED } & \text { Low energy electron diffraction } \\ \text { LEEM } & \text { Low energy electron microscopy } \\ \text { LEIS } & \text { Low energy ion scattering } \\ \text { LCVD } & \text { Laser chemical vapor deposition } \\ \text { MOCVD } & \text { Metalorganic chemical vapor deposition } \\ \text { NC-AFM } & \text { Non-contact atomic force microscopy } \\ \text { NC-SFM } & \text { Non-contact scanning force microscopy } \\ \text { NEXAFS } & \text { Near-edge x-ray absorption fine structure } \\ \text { PEEM } & \text { Photoemission electron microscopy } \\ \text { PLD } & \text { Pulsed laser deposition } \\ \text { RAIRS } & \text { Reflection }- \text { absorption infrared spectroscopy } \\ \text { RBS } & \text { Rutherford back scattering } \\ \text { RER } & \text { Resonant enhancement ratio } \\ \text { RHEED } & \text { Reflection high energy electron diffraction } \\ \text { RPES } & \text { Resonant photoelectron spectroscopy } \\ \text { SMSI } & \text { Strong metal support interaction } \\ \text { STM } & \text { Scanning tunneling microscopy } \\ \text { SXPS } & \text { Soft x-ray photoelectron spectroscopy } \\ \text { TDS } & \text { Thermal desorption spectroscopy } \\ \text { TPD } & \text { Temperature programmed desorption } \\ \text { WGS } & \text { Water-gas shift reaction } \\ \text { XPS } & \text { X-ray photoelectron spectroscopy } \\ \text { XRD } & \text { X-ray diffraction } \\ \text { YSZ } & \text { Yttria-stabilized zirconia } \\ & \end{array}$




\section{1 - Introduction}

The fundamental interest in and commercial applications of cerium oxide as a catalytic material have accelerated rapidly in recent years. This progression has been tracked from the seminal review article by Alessandro Trovarelli in 1996[1] through two subsequent books in 2002[2] and 2013[3]. In the most recent volume Delgado et al identified many catalytic applications of ceria-based materials.[4] These include pollution abatement, steam and dry reforming of hydrocarbons and oxygenates, $\mathrm{CO}$ oxidation and preferential $\mathrm{CO}$ oxidation in the presence of $\mathrm{H}_{2}$ (PROX), water-gas shift (WGS), conversion of syngas to alcohols, C-C coupling, aldol condensations, partial oxidation and selective hydrogenation. Organic syntheses catalyzed by ceria that involve more complex reactants and products have been reviewed by Vivier and Duprez.[5] Of these various applications the use of ceria, or mixed oxides containing ceria, in automotive three-way catalysts (TWC) has been the most widespread and technologically successful.[4]

In a classic overview of organic reactions on metal oxide surfaces, Barteau identified three key concepts for understanding the surface chemistry of metal oxides.[6] These are: (1) the coordination environment of the surface atoms; (2) the redox properties of the oxide; and (3) the oxidation state of the surface. With respect to these three concepts cerium oxide is an ideal material for testing and understanding the influence of these characteristics. As will be discussed below, as a cubic material cerium oxide has a relatively simple structure. However each of its stable, low-index crystallographic faces exposes $\mathrm{Ce}$ cations and $\mathrm{O}$ anions with different numbers of coordination vacancies. Ceria is easily reducible, as evidenced by its use as an oxygen storage material in three way catalysts. Calculations have indicated that the oxygen vacancy formation energy, which is related to the reducibility, is approximately $30 \%$ lower on ceria surfaces compared to bulk.[7-9] This suggests that reactions that involve the exchange of $\mathrm{O}$ between adsorbates and the surface may occur readily on ceria surfaces. Further, these calculations indicate that the O-vacancy formation energy will vary from face to face. Therefore oxidation and reduction reactions are likely to be different on the different faces. Finally, when $O$ vacancies are created, two of the Ce cations adjacent to the vacancy change from $\mathrm{Ce}^{4+}$ to $\mathrm{Ce}^{3+}$. As will be shown, adsorption and reaction on reduced ceria surfaces may differ dramatically from the chemistry of the same adsorbate on a fully oxidized $\mathrm{CeO}_{2}$ surface.

It has been frequently demonstrated that the "surface science approach", i.e. experiments on a well characterized, single crystal surface in an ultrahigh vacuum environment, has been invaluable for understanding the fundamental interactions between adsorbates and surfaces. However, surface science studies on cerium oxide have only recently been coming 
into their own. As noted in one of the first reviews of the surface science of ceria, up to 1998 there were only a handful of references related to surface science studies on ceria.[10] While the number of papers has been growing, there have been no comprehensive reviews in the past decade. We note that several more limited reviews have included ceria within an overview of the chemistry on a number of oxides.[11,12]

Computational studies on ceria had been limited by the inability of traditional DFT methods to adequately describe adsorption and reaction on metal oxides containing unoccupied f-orbitals. Recent advances have largely overcome this barrier and there are several excellent reviews covering computational studies on ceria. $[9,13]$

Following a brief description of the experimental and computational methods that have been used to study the chemistry on ceria (Section 2), the structural properties of $\mathrm{CeO}_{2}(111)$, $\mathrm{CeO}_{2}(110)$ and $\mathrm{CeO}_{2}(100)$ will be discussed in detail (Section 3) since they are critical for understanding the chemical behavior of these surfaces. Most experimental studies on ceria surfaces have been conducted on cerium oxide thin films deposited on other substrates. There have been a number of different deposition methods and substrates and these will be discussed in Section 4. The two largest sections of this review will cover adsorption of various molecules on clean ceria surfaces (Section 5) and on metals supported on ceria surfaces (Section 6). Section 6 will begin with an overview of the characterization of different metals on ceria in the absence of adsorbates.

\section{2 - Experimental Methods}

The methods used to study adsorption and reaction on cerium oxide surfaces can be grouped into four general areas; structural characterization, spectroscopic techniques, reaction analysis, and theoretical / computational methods. Structure / function relationships are inherently important for understanding the reaction behavior on ceria surfaces. Therefore it is essential to characterize the structure of the various ceria surfaces that are examined. In certain instances it is also possible to ascertain by microscopy or spectroscopy the adsorption site and/or orientation of adsorbed species on the surface. Spectroscopic techniques are primarily used to identify adsorbed species and to determine the oxidation state of the $\mathrm{Ce}$ in the substrate. Analysis of products that leave the surface directly relates to the catalytic properties of the substrate. Computational methods have been used to determine the structure and properties of the clean surfaces, the stability, nature and adsorption sites of adsorbates on the surface, and the reaction pathways from gas phase reactants through adsorbed intermediates to desorbed products. 


\section{1 - Structural Characterization}

Although it's primarily a bulk characterization technique, $x$-ray diffraction (XRD) has been used to study cerium oxide thin films. Polar and azimuthal scans have demonstrated that films grown on single crystal substrates are predominantly single crystal with their surface normal aligned to expose a specific low-index crystal plane and their azimuths aligned along a specific direction with respect to the single crystal substrate.[14,15] Rutherford backscattering (RBS) has also been used to ascertain the quality of single crystalline films. [14]

Reflection high-energy electron diffraction (RHEED) provides more surface-specific information. [14] The nature of the diffraction pattern, i.e. spots vs. streaks, provides an indication of the roughness of the surface. The azimuthal dependence of the diffraction pattern confirms that the surface lattice is aligned in a manner consistent with the bulk orientation revealed by XRD.

Low-energy electron diffraction (LEED) produces an indication of the order and symmetry of the atoms on the surface. In principle more sophisticated methods such as spot profile analysis (SPA) LEED or LEED-IV could be applied to obtain a more precise determination of structure, relaxation and disorder but these have not been applied to cerium oxide surfaces. Low-energy electron microscopy (LEEM) and photoemission electron microscopy (PEEM) provide video images of surface structure during the growth of ceria films at nanometer resolution.[16] Application of LEED can be hampered by the insulating nature of the substrate that can cause charging and disrupt the low-energy electrons' flight. This can be overcome by using higher energy incident beams[14], reducing the ceria slightly to improve conductivity[17] or studying thin films on conducting substrates.

Several atomic scattering techniques have been used to study ceria surfaces. Direct recoil spectroscopy (DRS) [14], angle resolved mass spectrometry of recoiled ions (ARMSRI)[18] and low-energy alkali ion scattering (LEIS)[19,20] provide highly surface sensitive information regarding surface structure and composition. Angular variations resulting from shadowing and blocking effects of surface atoms can be modeled for different surface structures and compared to experimental results. Charging does not affect the results in these methods due to either collecting both charged species and neutrals in DRS and AR-MSRI or due to the low neutralization probability of scattered alkali ions.

All of these methods provide area-averaged indications of the surface structure. Scanning probe microscopy produces atomic scale, local information regarding surface structure. Scanning tunneling microscopy (STM) has been performed on the (111)[17], (100)[21] 
and (110)[22] faces of bulk cerium oxide. The very low conductivity of stoichiometric $\mathrm{CeO}_{2}$ necessitated performing these experiments at either elevated temperatures, very low tunneling current or at a very small degree of reduction, $\mathrm{CeO}_{1.99}(111)$. An alternative approach for imaging insulating, bulk $\mathrm{CeO}_{2}(111)$ surfaces at lower temperatures was to use non-contact atomic force microscopy (NC-AFM)[23-25] / scanning force microscopy (NC-SFM)[26-29]. The low conductivity problem in applying STM to stoichiometric $\mathrm{CeO}_{2}$ can also be overcome by studying thin films of ceria supported on a conducting substrate. This approach has been widely applied.[30-37].

\section{2 - Spectroscopic Methods}

One of the most important characteristics of cerium oxide is the oxidation state of the $\mathrm{Ce}$ cation. The most commonly used method for determining the $\mathrm{Ce}$ oxidation state is measurement of the Ce $3 d$ core level by x-ray photoelectron spectroscopy (XPS).[38-43] As shown in Figure 1 the Ce $3 d$ XPS spectra are complex. The spectra for fully oxidized $\mathrm{CeO}_{2}(111)$ / $\mathrm{Ce}^{4+}$ and fully reduced $\mathrm{Ce}$ (III) oxide / $\mathrm{Ce}^{3+}$ contain six and four peaks, respectively, rather than two each due to spin-orbit splitting as might be expected for the $3 \mathrm{~d}$ core-level. The peaks labeled V'" and U'" are associated with the Ce $3 d^{9} \mathrm{O} 2 \mathrm{p}^{6} \mathrm{Ce} 4 \mathrm{f}^{0}$ final state with a spin-orbit splitting of $16.5 \mathrm{eV}$. The additional peaks result from so-called "shake-down" states where electrons are transferred from the $\mathrm{O} 2 \mathrm{p}$ level to the $\mathrm{Ce} 4 \mathrm{f}$ level in the excited state. [44,45] $\mathrm{A}$ quantitative estimate of the degree of reduction can be obtained from fitting a linear combination of the spectra from the reference materials as shown by the dotted line in Figure 1. This fit indicates that the partially reduced material is $30 \% \mathrm{Ce}^{3+}$ or $\mathrm{CeO}_{1.85}$. Although the fit in Figure 1 looks reasonable it has been suggested that the relative intensities of the peaks do not remain constant if the ceria is partially reduced.[40] If the line shapes and intensities are not constant the spectrum would need to be fit with ten peaks to determine the relative composition of $\mathrm{Ce}^{4+}$ and $\mathrm{Ce}^{3+}$.

The Ce $4 d$ core level spectra show a similar dependence on the Ce oxidation state as shown in Figure 2. Although the intensity of these spectra is much smaller than the $\mathrm{Ce} 3 \mathrm{~d}$ spectra when using a laboratory $\mathrm{Mg} \mathrm{ka}$ or $\mathrm{Al}$ ka excitation source[42], the intensity is much greater when excited with a lower photon energy as might occur using a synchrotron light source.[43] Assignments of the peaks in the Ce 4d spectra are even more complex than those for the $\mathrm{Ce} 3 \mathrm{~d}$ spectra because in addition to spin-orbit splitting and shake-down effects, multiplet splitting occurs due to a coupling of an unpaired electron in the $\mathrm{Ce} 4 \mathrm{~d}$ final state with an electron in the Ce $4 \mathrm{f}$ level.[46,47] Again the highest binding energy peaks, X'" and W'", are associated 
with the simplest final state, $\mathrm{Ce} 4 d^{9} \mathrm{O} 2 \mathrm{p}^{6} \mathrm{Ce} 4 \mathrm{f}^{0}$. The spin-orbit splitting is much smaller for $\mathrm{Ce}$ $4 \mathrm{~d}, 3.3 \mathrm{eV}$, compared to $16.5 \mathrm{eV}$ for the $\mathrm{Ce} 3 \mathrm{~d}$ spectrum. As shown by the dotted line in Figure $2 b$, a reasonable fit can be obtained in the $\mathrm{Ce} 4 \mathrm{~d}$ spectrum for a partially reduced $\mathrm{CeO}_{2-\mathrm{x}}$ sample from a linear combination of spectra from the reference materials.

A third approach for determining the Ce oxidation state using photoemission is from valence band spectra. Here the analysis should be straight forward since the intensity of the $\mathrm{Ce}$ $4 \mathrm{f}$ level should give a direct indication of the occupancy of this state and thus the presence of $\mathrm{Ce}^{3+}$. Using standard laboratory excitation such as Hel or Hell the $\mathrm{Ce} 4 \mathrm{f}$ photoemission is not very intense.[38] The intensity of the $\mathrm{Ce} 4 \mathrm{f}$ as well as the $\mathrm{O} 2 \mathrm{p}$ features are resonantly enhanced using photon energies at the Ce 4d (Ce $\left.N_{\text {IV }}\right)$ edge near 120 eV.[48,49] Matolin et al have applied this technique extensively to study the oxidation, reduction and charge transfer on cerium oxide thin films[50-54] and nanoparticles.[55,56] They have called this method resonant photoelectron spectroscopy (RPES). As shown in Figure 3 the maximum intensity for the Ce $4 f$ peak at $1.4 \mathrm{eV}$ binding energy occurs at an excitation of $121.4 \mathrm{eV}$ while the maximum in the hybridized $\mathrm{O} 2 \mathrm{p}$ feature associated with $\mathrm{Ce}^{4+}$ near $4 \mathrm{eV}$ binding energy occurs at an excitation energy of $124.8 \mathrm{eV}$. Matolin et al have defined resonant enhancement factors $\left(\mathrm{D}\left(\mathrm{Ce}^{4+}\right)\right.$ and $\mathrm{D}\left(\mathrm{Ce}^{3+}\right)$ in Figure 3) which are the differences in the $\mathrm{O} 2 \mathrm{p}$ and $\mathrm{Ce} 4 \mathrm{f}$ peak intensities on and off resonance.[57] The ratio of $\mathrm{D}\left(\mathrm{Ce}^{3+}\right) / \mathrm{D}\left(\mathrm{Ce}^{4+}\right)$ has been called the resonant enhancement ratio (RER) and is proportional to the percentage of $\mathrm{Ce}^{3+}$ in the sample. This method is advantageous compared to the measurement of $\mathrm{Ce} 3 \mathrm{~d}$ or $\mathrm{Ce} 4 \mathrm{~d}$ level spectra in that it has very high count rates enabling rapid data acquisition, it has a large contrast for samples with only a small variation in Ce oxidation state and it is very surface sensitive since the kinetic energy of the valence electrons, ca. $120 \mathrm{eV}$, is near the minimum in the mean free path curve for electrons in solids.[58] It should also be noted that the intensity of the Ce $4 \mathrm{f}$ peak is enhanced at excitation energies above the resonance maximum and therefore could be used to obtain the $\mathrm{Ce}^{3+}$ concentration provided suitable reference standards are also measured.[43]

XPS has also been used extensively to study adsorbates on cerium oxide surfaces.[5966] To a lesser extent valence level photoemission has also been used to study adsorbates on ceria surfaces.[15,67] The use of synchrotron radiation has been termed soft $x$-ray photoelectron spectroscopy (sXPS). Using synchrotron radiation as an excitation source has many advantages compared to a standard laboratory excitation source. A synchrotron light source has much higher photon flux / brightness compared to a laboratory source. This is typically accomplished without sacrificing photon energy resolution. The excitation energy is also tunable. This enables high surface sensitivity as a lower kinetic energy of the emitted 
electron minimizes the electron mean free path. This is particularly evident when studying the $O$ 1s core-level where the photoemission from a monolayer or less of $O$ in an adsorbate has intensity similar to the emission from the $\mathrm{O}$ in the $\mathrm{CeO}_{x}$ substrate.[15,68] In addition the photoemission cross section increases exponentially as the excitation energy gets closer to the ionization energy.[69] We have found that the excitation "sweet spot" is ca. $100 \mathrm{eV}$ above the nominal binding energy of the element being studied. This provides a balance between cross section, surface sensitivity and the intense, rapidly rising background that occurs at low photoelectron kinetic energies.

Synchrotron radiation is also used to perform $\mathrm{x}$-ray absorption spectroscopy. X-ray absorption spectroscopy of adsorbed species using soft $x$-ray excitation is called near-edge $x$ ray absorption fine structure (NEXAFS).[70] This technique can provide more precise molecular level identification than core level SXPS, for example differentiating formate, (HCOO-), from carbonate, $\left(\mathrm{CO}_{3}\right)^{2-},[71]$ or carbonate from $\mathrm{CO}_{2}$.[72] It can also provide information regarding adsorbate orientation.[72]

Vibrational spectroscopy can be conducted using high resolution electron energy loss spectroscopy (HREELS)[73]and reflection-absorption infrared spectroscopy (RAIRS).[74] The use of HREELS is complicated by the non-conducting nature of the ceria substrate and the intense phonon modes that dominate the spectra which require deconvolution algorithms to remove them from the spectrum. Its application has been limited.[75,76] Infrared spectra provide precise identification of adsorbed species[77] and also information regarding the surface adsorption site.[62,78,79] The sensitivity is enhanced by reflection of the IR beam from a metal surface[80], therefore the technique is more widely applied on thin ceria films supported on metal surfaces. RAIRS also has the advantage that it can be conducted at elevated pressures as opposed to in a vacuum environment generally required for electron spectroscopy. Thus it can be applied under realistic reaction conditions. Recent advances in ambient pressure XPS (AP-XPS) will make core-level photoemission more readily applicable for studying surface reactions at elevated pressures.[81]

\section{3 - Reaction Methods}

The most common method for determining the reaction products from adsorbates on ceria surfaces is temperature programmed desorption (TPD), also called thermal desorption spectroscopy (TDS).[82] In this technique one or more reactants are adsorbed on a surface and then a linear temperature ramp is applied to the sample while the desorbing, gas phase products are monitored by a mass spectrometer. This method has been widely applied to 
studying reactions on cerium oxide surfaces as is evident in later sections of this report. Two potential difficulties in applying TPD to oxide materials are mounting the sample and accurately recording the sample temperature. Support wires and thermocouples cannot be directly spotwelded to oxide substrates. However, if ceria films are grown on metal substrates spot-welding can be used. Mounting $\mathrm{CeO}_{2}$ single crystals or ceria films grown on oxide supports requires either support on some sort of metallic holder[83] or the use of ceramic cement to attach the sample to support wires.[19] The thermocouple needs to be attached directly to the oxide sample, typically using ceramic cement, as significant temperature gradients can occur between metal supports and the oxide sample.

The reactivity of ceria surfaces can also be monitored under dynamic conditions. In these experiments the sample is constantly exposed to the reactants rather than exposing the surface to only a monolayer of reactants and then evacuating the chamber. The reactant pressure might be either relatively low, $10^{-5}-10^{-6}$ torr, $[84,85]$ or at elevated pressures greater than 1 torr.[86,87] The products can be monitored either by a mass spectrometer or, in the case of experiments at elevated pressures, a gas chromatograph. Further, the experiments can be conducted at constant temperature and pressure, in which case kinetic parameters can be extracted, or as the sample temperature is ramped.

\section{4- Computational Methods}

Two extensive reviews of the computational approaches applied to cerium oxide have been produced by Sauer, et al.[9,13] The earlier paper placed the theoretical work on cerium oxide, a rare earth oxide, in context with similar calculations conducted on transition metal oxides. The latter work focused solely on cerium oxide. As with most computational work applied to solid surfaces and reactants on solid surfaces, the vast majority of theoretical work on cerium oxide has been performed within the framework of density functional theory (DFT). The greatest limitation to the application of standard DFT to cerium oxide has been an accurate description of reduced $\mathrm{CeO}_{2-x}$. The two electrons released to the surface through the removal of neutral $1 / 2 \mathrm{O}_{2}$ are deposited in the $4 \mathrm{f}$ level of cerium. DFT delocalizes these electrons through the $\mathrm{Ce}$ in the substrate producing a fractional occupation of the $4 \mathrm{f}$ orbital with a metallic ground state.[13] There have been two approaches to correcting the DFT calculations; a) correction of the on-site Coulomb correlation through a Hubbard U-term (known as DFT+U), or b) the use of hybrid functionals which add a fraction of the Fock exchange energy to the DFT exchange energy.[9] The DFT+U approach has been the most widely applied because the use of hybrid functionals is comparatively computationally expensive. One significant limitation of the $D F T+U$ 
method noted by Paier, et al is that energy diagrams for catalytic reactions on ceria will be too exothermic when ceria is reduced and too endothermic when ceria is re-oxidized.[9]

\section{3 - Structure}

Fully oxidized $\mathrm{CeO}_{2}$ has the fluorite $\left(\mathrm{CaF}_{2}\right)$ crystal structure, space group Fm3m.[88] As shown in Figure 4 the Ce cations are arranged in a face-centered cubic structure with the $\mathrm{O}$ anions embedded within the unit cell in a simple cubic arrangement. The lattice constant of the cubic unit cell is $0.541 \mathrm{~nm}$. The Ce cations are bonded to eight $O$ nearest neighbors while the $O$ anions are tertrahedrally bonded to four Ce nearest neighbors. Note that although the $\mathrm{Ce}$ occupy FCC-like sites they are not close-packed with respect to their Ce nearest neighbors.

The stable form of the fully reduced sesquioxide, $\mathrm{Ce}_{2} \mathrm{O}_{3}$, is hexagonal, space group $P 3$ $\mathrm{ml}$. In this structure the Ce cations are coordinated to seven $\mathrm{O}$ anions, with four oxygens closer than the other three. However, it has been well-established that intermediate compositions of $\mathrm{CeO}_{2-\mathrm{x}}$ with $0.5<\mathrm{x} \leq 0$ have a structure based on a fluorite lattice with the Ce retaining near FCC-like positions and O-vacancies either randomly distributed or ordered depending on composition and temperature.[89-91] The limiting structure for fluorite-based $\mathrm{Ce}_{2} \mathrm{O}_{3}$ is $\mathrm{BCC}$-type $\mathrm{C}$ or bixbyite, space group la3. This has a very large unit cell with $32 \mathrm{Ce}$ atoms and $48 \mathrm{O}$ atoms. The Ce are coordinated to six $\mathrm{O}$.

In this review we will be considering the low-index faces of $\mathrm{CeO}_{2}$, i.e. (111), (110) and (100). These three surfaces are prototypical examples of three types of ionic crystal surfaces whose stability was considered by Tasker.[92] $\mathrm{CeO}_{2}(110)$ is a Type 1 surface with each layer having zero charge due to a stoichiometric balance of anions and cations in each plane (Figure 5). $\mathrm{CeO}_{2}(111)$ is a Type 2 surface. Each plane is charged but the repeat unit consists of three planes in a symmetrical configuration resulting in no net dipole moment perpendicular to the surface (Figure 6). Type 1 and Type 2 surfaces should have relatively low surface energies and should produce surfaces with only modest relaxations compared to a bulk truncation. A bulk truncation along $\mathrm{CeO}_{2}(100)$ creates a Type 3 surface. This surface has alternately charged planes with a repeat unit of only two planes producing a dipole moment perpendicular to the surface (Figure 7a). Such a surface would have a nearly infinite free energy and therefore will require a major reconstruction compared to the bulk. A straight-forward way to eliminate the dipole moment is to remove half of the ions from one layer and move them to the opposing face as shown in Figure 7b. An alternative way of envisioning this structure is that it is similar to a Type 2 structure, i.e. a three-layer repeat unit A-B-A-A-B-A-, except that the interior layers of $O$ are interlaced / co-planar. 
There have been many computational studies on the structure and stabilities of these three low-index surfaces of $\mathrm{CeO}_{2} \cdot[7,93-101]$ While the methods and absolute results may vary, the general consensus is that stability of these three surfaces runs in the order $(111)>(110)>$ (100). The surface energies are stabilized by relaxation with a contraction between the first and second layers. The degree of relaxation runs in the reverse order of the surface energies with the $\mathrm{O}$ anions on the surface of $\mathrm{CeO}_{2}(100)$ contracting the most and those on $\mathrm{CeO}_{2}(111)$ the least. Calculations on $\mathrm{CeO}_{2}(110)$ have indicated that the $\mathrm{Ce}$ contracts more than the $\mathrm{O}$ creating a ripple in the top layer.[95,97] Calculations of $\mathrm{CeO}_{2}(100)$ have started with a model where half of the $O$ is removed from the top surface and placed on the bottom surface in order to eliminate the diploe normal to the surface. $[93,95,97,100]$ Most have assumed the so-called "checkboard" arrangement of $\mathrm{O}$ as shown in Figure 7b. Skorodumova et al tested other arrangements of $O$ and determined that the checkerboard arrangement was the most stable. [95] However the energy difference between different arrangements was small suggesting that deviations from a perfect geometry could easily occur.

Experimental studies of $\mathrm{CeO}_{2}(111)$ by LEED[17,36,37,102], ion scattering[20] and STM / AFM[17,24-27,34,36,37,103,104] are consistent with the structure shown in Figure 6. Ion scattering established that the surface was terminated by O.[20] This was corroborated by scanning probe microscopy studies where vacancies are observed suggesting that the surface is terminated by $\mathrm{O}$. Figure 8 demonstrates various features on a $\mathrm{CeO}_{2}(111)$ revealed by scanning force microscopy.[104] Figure 8 a shows a relatively wide area image, $(100 \times 100) \mathrm{nm}^{2}$. The surface is not perfectly flat but is composed of stacked terraces. This structure has been observed on both a single crystal surface, as in Figure $8 \mathrm{a}$, and on $\mathrm{CeO}_{2}(111)$ thin films (Figure 9a). A line scan across the terraces, Figure $8 \mathrm{~b}$, indicates that each terrace is $0.31 \mathrm{~nm}$ tall corresponding to an O-Ce-O tri-layer as shown in the sideview at the bottom of Figure 6. Atomic resolution shown in Figure $8 \mathrm{c}$ demonstrates that the surface has the ideal geometry as shown in Figure $8 \mathrm{~d}$ and Figure 6. Finally the terrace edges are predominantly oriented along (110) and (001) directions creating hexagonal structures (Figure 8i and 8ii) and corners with $120^{\circ}$ angles.

Nörenberg and Briggs conducted LEED, RHEED and STM studies on single crystal $\mathrm{CeO}_{2}(110)$.[22] LEED and RHEED indicated a (2x1) reconstruction. STM showed lines running in the [11 0] direction separated by $1.1 \mathrm{~nm}$. Referring to Figure 5 these lines run along the rows of Ce cations. The separation is equal to twice the distance between Ce rows in the [100] direction. Similar STM structures were observed on the structurally isomorphic $\mathrm{UO}_{2}(110)$ surface. [105] Muggelberg et al ascribed the STM structure to a missing row reconstruction of the $\mathrm{UO}_{2}(110)$ surface. When the $\mathrm{CeO}_{2}(110)$ surface was annealed to $1030^{\circ} \mathrm{C}$ the surface 
facetted. RHEED patterns recorded along the [11 0] azimuth revealed streaks tilted by $35^{\circ}$. This is the angle between the (110) plane and the (111) and (111) planes. STM images revealed ridges running along the [11 0] direction that were $2.5 \mathrm{~nm}$ high and separated by $8-10 \mathrm{~nm}$. These results indicate faceting into (111) and (111) planes.

The structural characterizations of the $\mathrm{CeO}_{2}(100)$ surface have not been definitive. Square, (1x1) LEED patterns have been published from $\mathrm{CeO}_{2}(100)$ grown on $\mathrm{Pd}(100)[106]$ and on $\mathrm{SrTiO}_{3}(100)$.[14] Conceivably the surface terminations shown in Figure $7 \mathrm{a}$ and $7 \mathrm{~b}$ would produce different LEED patterns, i.e. $p(1 \times 1)$ vs. $c(2 \times 2)$. However these authors made no claim as to surface termination. Overbury et al performed angle resolved low energy alkali ion scattering experiments.[19] They concluded that the $\mathrm{CeO}_{2}(100)$ surface had a bulk termination with roughly $50 \% \mathrm{Ce}$ ions on the surface and $50 \% \mathrm{O}$ ions on the surface. Kim et al used direct recoil spectroscopy (DRS) / low energy ion scattering of $\mathrm{Kr}$ and concluded that the $\mathrm{CeO}_{2}(100)$ surface was predominantly terminated by O.[14] Herman then used mass spectroscopy of recoiled ions (MSRI) and concluded that the structure depicted in Figure $7 \mathrm{~b}$ was the most consistent with his results.[18] Yang et al imaged $\mathrm{CeO}_{2}(100)$ grown on oxidized $\mathrm{Cu}(111)$ by STM.[107] They observed step heights and atom spacing consistent with either Figure 7a or 7b. However they were using a positive sample bias which imaged the Ce cations. Therefore they couldn't say anything about the termination or $\mathrm{O}$ structure.

Nörenberg and Harding produced STM images of single crystal $\mathrm{CeO}_{2}(100)$ at elevated temperatures.[21] They observed lines running in the [011] direction. Atomic resolution along the lines had a spacing of $0.38 \mathrm{~nm}$ and the spacing between lines was $1.1 \mathrm{~nm}$. These are equivalent to the spacing between $\mathrm{O}$ ions in the [011] direction in Figure $7 \mathrm{~b}$ and three times this spacing in the orthogonal direction. They called this fully oxidized surface a $\sqrt{2} / 2(3 \times 1) R 45^{\circ}$ reconstruction. Based on the calculations they concluded that the surface was terminated by $\mathrm{O}$. Their proposed structure was essentially equivalent to that shown in Figure $7 \mathrm{~b}$. The superstructure observed in the STM was due to small differences in the $O$ height, i.e. a ripple, on the surface.

A high resolution electron microscopy study was conducted on $\mathrm{CeO}_{2}$ nanocubes that had an edge length of ca. $20 \mathrm{~nm}$.[108] Lin et al observed a variety of terminations on the (100) surfaces of these cubes. The $\mathrm{CeO}_{2}(100)$ surface had regions of $\mathrm{Ce}, \mathrm{O}$ and $\mathrm{CeO}$ termination. They also noted a pronounced tendency for atoms to hop along these surfaces.

A precise model for the $\mathrm{CeO}_{2}(100)$ surface may not exist due to small energetic differences between different structures allowing a variety of terminations that may be in constant flux. However, an important result is that the surface is not terminated by a solid layer 
of $\mathrm{Ce}$ or $\mathrm{O}$ as depicted in Figure 7a. Therefore a variety of $\mathrm{O}$ and $\mathrm{Ce}$ ions are exposed that have two, or more, coordination vacancies.

Both theoretical[8,9,13,93,97,100,109,110] and experimental[24,25,27,110-112] studies of the structure of reduced ceria surfaces have primarily focused on very low degrees of reduction, frequently single oxygen vacancies. O vacancies produce a reconstruction / relaxation around the vacancy with the remaining $O$ ions that surround the vacancy displaced from their bulk termination positions. Multiple vacancies have been shown to organize into triangles and lines on $\mathrm{CeO}_{2}(111)$. Nörenberg and Harding have reported a series of reconstructed STM and LEED images on $\mathrm{CeO}_{2-x}(100)$ with up to $75 \%$ of the surface $\mathrm{O}$ removed from Figure $7 \mathrm{a}$ (50\% removed from Figure 7b).[21] They proposed a series of structures resulting from an ordering of vacancies and a repositioning of the remaining $\mathrm{O}$ atoms on the surface. No long range order, either by LEED or STM, has been reported on other reduced, lowindex surfaces.

\section{4 - Cerium Oxide Thin Films}

While there have been some studies of the adsorption and reaction of molecules on single crystal cerium oxide surfaces[75,83,113,114] the majority of studies have been conducted on cerium oxide thin films grown on a variety of substrates. In Section 4.1 the various methods that have been used to grow cerium oxide thin films will be described followed examples of specific crystallographic faces in subsequent sections. These sections will focus on studies where ceria films were grown and characterized. Adsorption studies on these surfaces will be covered in later sections.

\section{1 - Methods}

The production of a cerium oxide thin film requires the deposition of a Ce-containing precursor onto a dissimilar substrate. Organometallic precursors have been used in a process known as metalorganic chemical vapor deposition (MOCVD).[115,116] The solid molecular precursor is heated until a vapor is formed which is then transported by a carrier gas to the substrate. The transport lines are heated as well to prevent condensation. The precursor molecules are deposited on a heated substrate where they decompose in the presence of $\mathrm{O}_{2}$ to create a ceria film. A variation of this method is to irradiate the substrate with a continuous wave infrared laser during deposition in a process termed laser chemical vapor deposition (LCVD).[117-119] The laser irradiation was found to enhance the growth rate of the films compared to the non-laser assisted MOCVD. 
Inorganic precursors can also be used to deposit Ce on a substrate in a process known as spray pyrolysis. Cerium acetylacetonate[120] or cerium nitrate[121,122] were dissolved in water or an ethanol/water solution. The solution was then nebulized and sprayed onto the substrate. The deposited precursor was then thermally decomposed in air to produce the cerium oxide film.

Cerium oxide can be directly deposited from a $\mathrm{CeO}_{2}$ target. $\mathrm{CeO}_{2}$ is highly refractory so extraordinary means are needed to vaporize the target. E-beam heating[123-125], pulsed laser deposition (PLD)[15,19] and r.f. magnetron sputtering[126] have been used to ablate the ceria targets. Typically this has been conducted in an $\mathrm{O}_{2}$ atmosphere to ensure complete oxidation of the deposited film.

The most common method of creating cerium oxide thin films is to start with cerium metal. Cerium is readily oxidized upon exposure to air and cannot be readily formed into wires as with many transition metals. Cerium can be evaporated by resistive heating in a Ta or W boat[20,37,127] or by e-beam heating[14,33,106,128]. Typically $\mathrm{Ce}$ is deposited in an oxidizing atmosphere such $\mathrm{O}_{2},[20]$ atomic $\mathrm{O}[33]$ or an $\mathrm{O}$ plasma[14] to produce $\mathrm{CeO}_{2}$ on the substrate through reactive deposition. However there have been some cases where $\mathrm{Ce}$ was deposited directly on the surface followed by $\mathrm{O}_{2}$ treatment to oxidize the Ce.[31,102,129]

In all of these methods the growth conditions have proven to be critical in determining the quality of the deposited film as will be discussed below.

$4.2-\mathrm{CeO}_{2}(111)$

The majority of work on cerium oxide thin films have utilized the $\mathrm{CeO}_{2}(111)$ surface. One approach for creating a highly ordered ceria thin film is epitaxial growth of ceria on a single crystal substrate where the desired $\mathrm{CeO}_{2}$ surface orientation has a good lattice match with the substrate. The cubic fluorite structure of $\mathrm{CeO}_{2}$ has an excellent lattice match to the cubic diamond structure of $\mathrm{Si}, \Delta \mathrm{a} / \mathrm{a}=0.35 \%$. Epitaxial films of $\mathrm{CeO}_{2}(111)$ have been grown on $\mathrm{Si}(111)$ by PLD[130] and e-beam evaporation[123] of $\mathrm{CeO}_{2}$ targets. The deposition was not performed in an $\mathrm{O}_{2}$ ambient in order to avoid oxidation of the Si substrate.

$\mathrm{CeO}_{2}(111)$ has been grown on cubic yttria-stabilized $\mathrm{ZrO}_{2}(111)$ (YSZ(111)).[131-133] There is a $5.3 \%$ lattice mismatch between ceria and zirconia. However, it has been suggested that structural modifications such as dislocations, vacancies, interstitials and substitutions at the interface can reduce this misfit to ca. 1\%.[134] Dmowski, et al suggested that strain due to the lattice mismatch is relieved by the formation of islands on the substrate separated by grain boundaries.[131] Maicaneanu, et al and Dmowski, et al cautioned that the catalytic properties of 
these films are likely influenced by the structural defects and/or less stable surfaces between grains. Therefore the use of films grown on YSZ may not reflect the chemistry that occurs on other thin films surfaces or bulk single crystal terminations.

Most $\mathrm{CeO}_{2}(111)$ films have been produced by evaporating $\mathrm{Ce}$ metal in an $\mathrm{O}_{2}$ background onto the close-packed planes of $h c p(0001)$ or $f c c(111)$ single crystal metal surfaces. $\mathrm{CeO}_{2}(111)$ has been grown on $\mathrm{Pd}(111)[129]$, $\mathrm{Pt}(111)[33,124,135], \mathrm{Rh}(111)[35,36]$, $\mathrm{Ru}(0001)[16,20,37], \mathrm{Cu}(111)[32,53,102,107,136,137], \mathrm{Ni}(111)$ [20], and $\mathrm{Au}(111)[31]$. Figure 9 shows STM images from a $3 \mathrm{~nm}$ thick $\mathrm{CeO}_{2}$ (111) film grown on $\mathrm{Ru}(0001)$.[34] A relatively large area image, Figure 9a, shows that the $\mathrm{CeO}_{2}(111)$ forms stacks of terraces up to several hundred $\mathrm{nm}$ in diameter. This morphology is similar to what was observed on single crystal $\mathrm{CeO}_{2}(111)$ (Figure 8a). [104] The inset shows the hexagonal $\mathrm{p}(1.4 \times 1.4)$ LEED pattern of $\mathrm{CeO}_{2}(111)$ relative to the $\mathrm{p}(1 \times 1)$ LEED pattern of $\mathrm{Ru}(0001)$. Figure $9 \mathrm{~b}$ shows the atomic resolution of the $\mathrm{CeO}_{2}(111)$ surface demonstrating the hexagonal ordering of the surface as well as isolated vacancies and defects.

It is perhaps surprising that the ceria not only forms well-ordered $\mathrm{CeO}_{2}(111)$ but that the films are azimuthally aligned with the single crystal substrates as demonstrated by LEED and angle resolved low energy ion scattering. [20] The lattice mismatch between the $\mathrm{CeO}_{2}(111)$ film and the metallic single crystal substrates ranges from 40\%-50\%. Figure 10 shows STM images of a sub-monolayer film of $\mathrm{CeO}_{2}(111)$ deposited on $\mathrm{Rh}(111)$.[35] The inset in Figure 10a shows a LEED pattern containing both the $p(1 \times 1) \mathrm{Rh}(111)$ spots and the $\mathrm{p}(1.4 \times 1.4) \mathrm{CeO}_{2}(111)$ spots. The spots observed in the STM image in Figure 10c are from the Ce cations. The spacing and symmetry are consistent with a $\mathrm{CeO}_{2}(111)$ surface. A unique feature at this submonolayer coverage is the larger area superstructure evident in the lines produced in Figures $10 \mathrm{~b}$ and 10c. These lines form a coincidence with the $\mathrm{Rh}(111)$ sublattice such that $5 \times \mathrm{a}_{(\mathrm{CeO}(111))}$ $=7 \times \mathrm{a}_{(\mathrm{Rh}(111))}$. There is evidently a strong interaction between the $\mathrm{CeO}_{2}$ and the $\mathrm{Rh}$ that pins the oxide film at these coincidence points. A similar pattern for sub-monolayer ceria films has been observed on $\mathrm{Cu}(111)[32]$ and $\mathrm{Ru}(0001)$ (unpublished results).

Some care must be exercised in the formation and treatment of these films on some surfaces due to the interaction between the ceria and the substrate. Alexandrou and Nix reported that $\mathrm{CeO}_{2}$ (111) films on $\mathrm{Pd}(111)$ decomposed at $600^{\circ} \mathrm{C}$ via diffusion of $\mathrm{Ce}$ and $\mathrm{O}$ into the substrate.[129] Ceria films on $\mathrm{Ni}(111)$ lost a small amount of $\mathrm{O}$ following annealing at $700 \mathrm{~K}$ and lost $25 \%$ of their $\mathrm{O}$ at $1000 \mathrm{~K}$.[20] The loss of $\mathrm{O}$ from the ceria is thought to be due to the formation of $\mathrm{NiO}$. Annealing $\mathrm{CeO}_{2}$ (111) films on $\mathrm{Pt}(111)$ in vacuum above $1000 \mathrm{~K}$ also results in reduction of the ceria.[33,41,124] It was also more difficult to produce fully oxidized ceria films at 
sub-monolayer coverages of ceria. On $\mathrm{Pt}(111)$ it was suggested that the reduction / decomposition was due to the formation of Pt-Ce alloys.[41] A similar behavior was observed on $\mathrm{Rh}(111)$.[36] $\mathrm{CeO}_{2}$ (111) films grown on $\mathrm{Cu}(111)$ by deposition of $\mathrm{Ce}$ in $\mathrm{O}_{2}$ at $520 \mathrm{~K}$ were stable up to $970 \mathrm{~K}$ in UHV but reduced at $1070 \mathrm{~K} .[137]$

Various recipes have been proposed to improve the quality of the films, i.e. produce larger terraces with fewer defects. In general it appears that flatter films with wider terraces and fewer defects are produced by depositing Ce metal in an oxidizing environment while the substrate is maintained at elevated temperature. However, Staudt et al have reported that a continuous $\mathrm{CeO}_{2}(111)$ layer, as opposed to the stacks of plates depicted in Figure 9a, can be produced through a kinetically limited growth process of $\mathrm{Ce}$ in $\mathrm{O}_{2}$ at $100 \mathrm{~K}$ followed by annealing in $\mathrm{O}_{2}$ to $770 \mathrm{~K}$.[136] Thicker films can be created by sequential homoepitaxial deposition and annealing steps.

\section{$4.3-\mathrm{CeO}_{2}(100)$}

$\mathrm{CeO}_{2}$ has a good lattice match with $\mathrm{SrTiO}_{3}$ however epitaxy is achieved by rotating the $\mathrm{CeO}_{2}$ surface azimuthally relative to the $\mathrm{SrTiO}_{3}$ substrate. $\mathrm{CeO}_{2}(100)$ has a $2 \%$ lattice mismatch with $\mathrm{SrTiO}_{3}(100)$ if the surfaces are rotated $45^{\circ}$ with respect to each other so that [011] II [001]. $\mathrm{CeO}_{2}(100)$ has been grown on $\mathrm{SrTiO}_{3}(100)$ by e-beam evaporation of Ce metal in an oxygen plasma[14] and by PLD of a $\mathrm{CeO}_{2}$ target.[19]

$\mathrm{CeO}_{2}(100)$ has been deposited on R-cut $\alpha-\mathrm{Al}_{2} \mathrm{O}_{3}$ which exposes the (11 02) surface. The ceria was deposited by magnetron sputtering[126] or e-beam deposition[106] of $\mathrm{CeO}_{2}$ and laser assisted chemical vapor deposition (LCVD).[119] $\mathrm{CeO}_{2}(100)$ was also grown on polycrystalline $\mathrm{Al}_{2} \mathrm{O}_{3}[118]$ and amorphous $\mathrm{SiO}_{2}[117]$ by LCVD. However, although these films grew preferentially along the (100) direction they had a granular, columnar morphology with pyramidal caps that exposed (111) microfacets.

As noted above, $\mathrm{CeO}_{2}$ has an excellent lattice match with Si. However, ceria thin films on $\mathrm{Si}(100)$ generally produced $\mathrm{CeO}_{2}(110)$ surfaces.[138-142] Growth of $\mathrm{CeO}_{2}(100)$ could be induced by biasing the $\mathrm{Si}(100)$ substrate during deposition by magnetron sputtering[143] or by irradiating the $\mathrm{Si}(100)$ substrate with an electron beam during deposition.[144]

There have only been a few reported examples of growing $\mathrm{CeO}_{2}(100)$ on the four-fold symmetric faces of fcc (100) metals. Tian et al deposited ceria films on $\operatorname{Pd}(100)$ by e-beam evaporation.[106] They produced $\mathrm{CeO}_{2}(100)$ if they used a $\mathrm{CeO}_{2}$ source. However, multitwinned $\mathrm{CeO}_{2}(111)$ films were produced if they deposited Ce metal in an $\mathrm{O}_{2}$ atmosphere. We obtained similar results evaporating $\mathrm{Ce}$ metal from a resistively heated source in an $\mathrm{O}_{2}$ 
background on $\mathrm{Pd}(100)$ and $\mathrm{Pt}(100)$ (unpublished results). Interestingly, the $\mathrm{CeO}_{2}(111)$ films produced following evaporation from a metallic Ce source demonstrated azimuthal registry with the (100) substrates producing 12 or 24 spot LEED patterns indicating $\mathrm{CeO}_{2}(111)$ domains rotated $0^{\circ}, 45^{\circ}, 90^{\circ}$ and $135^{\circ}$ with respect to the $\mathrm{Pd}(100)$ substrate.

$\mathrm{CeO}_{2}(100)$ was deposited by oxidative e-beam deposition of $\mathrm{Ce}$ metal on $\mathrm{Ni}$ foil that had been rolled to produce biaxially textured $\mathrm{Ni}(100)$ surface.[128] $\mathrm{CeO}_{2}(100)$ was also deposited by MOCVD on polycrystalline Hastelloy C276, a Ni-based multi-element alloy.[116] These studies were conducted with the goal of producing a $\mathrm{CeO}_{2}$ buffer layer between metallic tape or wirelike substrates and high Tc metal oxide super conductors.

The results obtained with $\mathrm{SrTiO}_{3}(100), \mathrm{Pd}(100), \mathrm{Pt}(100)$ and biaxally textured $\mathrm{Ni}(100)$ suggest that the adsorption strength between the $\mathrm{O}$ in the film and substrate is a critical factor in determining whether film's structure is determined by the structure of the substrate or whether it forms the lower surface energy $\mathrm{CeO}_{2}(111)$ structure.

As noted above, $\mathrm{CeO}_{2}(100)$ has also been deposited on $\mathrm{YSZ}(100)$ with the same caveats mentioned previously regarding unique surface chemical properties related to defects and grain boundaries. [131]

\section{$4.4-\mathrm{CeO}_{2}(110)$}

In principle $\mathrm{CeO}_{2}(110)$ can be grown on $\mathrm{SrTiO}_{3}(110)$ if the two surfaces are rotated by $90^{\circ}$ relative to each other so that [100] II [01 1]. As with $\mathrm{CeO}_{2}(100) / \mathrm{SrTiO}_{3}(100)$ the two lattices would have a $2 \%$ lattice mismatch. Growth of this film has not yet been reported. $\mathrm{CeO}_{2}(110)$ was grown on $\mathrm{SrTiO}_{3}(211)$.[43] This is a stepped surface with two-dimensional symmetry where the spacing between the $\mathrm{O}$ ions in the short direction has a good lattice match to $\mathrm{CeO}_{2}(110)$. $\mathrm{CeO}_{2}(110)$ was also grown on $\mathrm{Si}(100)[138,140-142]$ and on $\mathrm{YSZ}(110)$. [131]

While there have been a number of reports of computational studies of adsorption and reaction on the $\mathrm{CeO}_{2}(110)$ surface there have not yet been any experimental studies reported.

\section{5 - Adsorption on clean surfaces}

\section{1 - Inorganic molecules}

\subsection{1 $-\mathrm{H}_{2}$ and $\mathrm{H}$}

$\mathrm{H}_{2}$ can reduce $\mathrm{CeO}_{2}$ powders at elevated temperatures at atmospheric pressure.[145,146] However, the consistent experimental observation on flat $\mathrm{CeO}_{\mathrm{x}}$ surfaces under UHV conditions is that $\mathrm{H}_{2}$ does not adsorb nor react.[19,147,148] This is despite 
theoretical calculations that indicate that $\mathrm{H}_{2}$ will adsorb and dissociate exothermically on $\mathrm{CeO}_{2}(111)$ and $\mathrm{CeO}_{2}(110) \cdot[99,149]$

Exposure of stoichiometric $\mathrm{CeO}_{2}(111)$ to atomic $\mathrm{D}$ at $115 \mathrm{~K}$ produces -OD on the surface at low exposure.[148] This process leads to the reduction of $\mathrm{Ce}^{4+}$ to $\mathrm{Ce}^{3+}$. At higher exposure (> $50 \mathrm{~L}$ ) water is observed in $\mathrm{O}$ 1s XPS indicating that $\mathrm{D}(\mathrm{g})$ impinging on the surface reacted with $O D$ to produce chemisorbed $D_{2} \mathrm{O}$. The OD disproportionated to produce $\mathrm{D}_{2} \mathrm{O}(\mathrm{g})$ between $200 \mathrm{~K}$ and $600 \mathrm{~K}$. The chemisorbed water desorbed in a relatively sharp peak near 200 $\mathrm{K} . \mathrm{D}_{2}$ desorbed in a broad, weak feature between $400 \mathrm{~K}$ and $500 \mathrm{~K}$. On reduced $\mathrm{CeO}_{2-\mathrm{x}}(111)$ exposure to $D(g)$ again produced $O D$ on the surface but the tendency to form $D_{2} O(a)$ at higher exposures decreased as the surface became more reduced. The OD adsorbed on the reduced $\mathrm{CeO}_{2-x}(111)$ surface was stabilized compared to that on a fully oxidized $\mathrm{CeO}_{2}(111)$ surface. Water and $D_{2}$ both desorbed near $570 \mathrm{~K}$. These observations are supported by DFT calculations which determined exothermic adsorption of $\mathrm{H}(\mathrm{g})$ on the surface $\mathrm{O}$ anions on $\mathrm{CeO}_{2}(111)$ and $\mathrm{CeO}_{2}(110)$ accompanied by the reduction of the neighboring Ce cations.[150] Ultra accelerated quantum chemical molecular dynamics simulations indicated that $\mathrm{H}(\mathrm{g})$ will initially form $\mathrm{OH}$ on the $\mathrm{CeO}_{2}(111)$ and (110) surfaces followed by reaction with additional $\mathrm{H}(\mathrm{g})$ to produce $\mathrm{H}_{2} \mathrm{O}(\mathrm{a}) \cdot[151]$

\section{$5.1 .2-\mathrm{O}_{2}$}

One of the principle applications of $\mathrm{CeO}_{2}$ is as an oxygen storage material in automotive exhaust catalysts.[4] In this capacity the ceria acts as a buffer to supply $\mathrm{O}$ during fuel-rich $/ \mathrm{O}_{2}$ deficient periods of engine operation, and conversely remove $\mathrm{O}$ when there is an excess of $\mathrm{O}_{2}$ in the exhaust stream. It is believed that oxidation reactions over ceria surfaces occur through a Mars van Krevelen mechanism wherein an adsorbate reacts with $\mathrm{O}$ contained in the substrate and this $O$ is subsequently replenished by $O_{2}$ from the gas phase.[152,153] As such it is important to understand both the adsorption and dissociation of $\mathrm{O}_{2}$ with ceria surfaces and the desorption of $\mathrm{O}_{2}$ from oxidized ceria.

It has been shown that the oxidation of Ce metal proceeds at below $300 \mathrm{~K}$ through the formation of $\mathrm{Ce}_{2} \mathrm{O}_{3}$ which is then capped by a thin layer of $\mathrm{CeO}_{2}$ on the surface.[154-156] Heating a polycrystalline sample that was capped with a layer of $\mathrm{CeO}_{2}$ to $600 \mathrm{~K}$ resulted in a reduction of the surface to $\mathrm{Ce}_{2} \mathrm{O}_{3}$ based on $\mathrm{Ce} 3 \mathrm{~d}$ and $\mathrm{Ce} 4 \mathrm{~d}$ XPS.[43] Conversely, a $\mathrm{CeO}_{2}(100)$ surface that was reduced by $\mathrm{Ar}^{+}$ion sputtering at $300 \mathrm{~K}$ showed partial re-oxidation when it was heated to $600 \mathrm{~K}$ in vacuum.[19] These two results are indicative of $\mathrm{O}$ re-distribution between the surface and the bulk below $600 \mathrm{~K}$. 
Wu et al studied the adsorption of $\mathrm{O}_{2}$ on ceria nanoshapes.[157] Nanorods, nanocubes and nano-octadra are believed to expose primarily $\{110\}+\{100\},\{100\}$ and $\{111\}$ faces, respectively.[157] Using Raman spectroscopy they observed superoxo $\left(\mathrm{O}_{2}{ }^{-}\right)$and peroxo $\left(\mathrm{O}_{2}{ }^{2-}\right)$ species on the reduced $\mathrm{CeO}_{2-x}$ surfaces. The same species were also observed on reduced, non-shape-specific $\mathrm{CeO}_{2-x}$ powders.[158] These species dissociated into lattice $\mathrm{O}^{2-}$ and reoxidized the surface. The reaction pathway was:

(1) $\mathrm{O}_{2}(\mathrm{~g}) \rightarrow \mathrm{O}_{2}^{-}(\mathrm{a}) \rightarrow \mathrm{O}_{2}{ }^{2-}(\mathrm{a}) \rightarrow 2 \mathrm{O}^{2-}(\mathrm{I})$

In addition to the dissociation, approximately $20 \%$ of the adsorbed oxygen desorbed as $\mathrm{O}_{2}$. This occurred through disproportionation reactions.

(2) $\mathrm{O}_{2}^{-}(\mathrm{a})+\mathrm{O}_{2}^{-}(\mathrm{a}) \rightarrow \mathrm{O}_{2}{ }^{2-}(\mathrm{a})+\mathrm{O}_{2}(\mathrm{~g})$

(3) $\mathrm{O}_{2}^{2-}(\mathrm{a})+\mathrm{O}_{2}{ }^{2-}(\mathrm{a}) \rightarrow 2 \mathrm{O}^{2-}(\mathrm{I})+\mathrm{O}_{2}(\mathrm{~g})$

The $\mathrm{O}_{2}$ desorption occurs at a lower temperature on the nanocubes, ca. $340 \mathrm{~K}$, than on the nanorods, ca. $470 \mathrm{~K}$. The temperature dependent Raman spectroscopy further indicated that the superoxo species disappeared before the peroxo species.

DFT calculations on stoichiometric $\mathrm{CeO}_{2}(111)$ indicated that the adsorption of $\mathrm{O}_{2}$ was endothermic.[158] DFT $+U$ calculations on partially reduced $\mathrm{CeO}_{2-x}(111)$ indicated that the superoxo species was weakly bound to the O-vacancy $(-0.30$ to $-0.38 \mathrm{eV})$ and the peroxo species is more strongly bound $(-2.80$ to $-3.25 \mathrm{eV})$.[159] Similar calculations on partially reduced $\mathrm{CeO}_{2-\chi}(110)$ and $\mathrm{CeO}_{2-x}(100)$ surfaces reported only the peroxo species with adsorption energies of $-2.05 \mathrm{eV}$ and $-2.02 \mathrm{eV}$, respectively.[160]

Putna et al observed desorption of $\mathrm{O}_{2}$ between $800 \mathrm{~K}$ and $1200 \mathrm{~K}$ from ceria films deposited on $\mathrm{\alpha}-\mathrm{Al}_{2} \mathrm{O}_{3}(0001)$ whereas no $\mathrm{O}_{2}$ desorbed below $1300 \mathrm{~K}$ from single crystal $\mathrm{CeO}_{2}(111)$.[161] This suggests that the morphology and defect structure of the ceria surface further influences the adsorption and desorption of $\mathrm{O}_{2}$.

\subsection{3 $-\mathrm{H}_{2} \mathrm{O}$}

Water is ubiquitous in many catalytic reactions either as a reactant, product, solvent or simply a spectator present in the atmosphere. It is also the simplest example of a molecule 
possessing the hydroxyl moiety, $\mathrm{R}-\mathrm{OH}$, and its interactions with ceria surfaces provide important information for understanding the adsorption and reaction of more complicated molecules such as alcohols and carboxylic acids.

Experimental studies of water adsorption on stoichiometric $\mathrm{CeO}_{2}(111)$ and $\mathrm{CeO}_{2}(100)$ have concluded that the water adsorbs molecularly, dissociatively or a mixture of both.[15,51,68,133,148,162-164] Computational studies of water adsorption on $\mathrm{CeO}_{2}(111)$ have been contradictory. Watkins et al.[149] concluded water will dissociate while Fronzi et al.[165] and Marrocchelli and Yildiz[166] concluded it would not. Molinari et al. compared water adsorption on $\mathrm{CeO}_{2}(111)$, (100) and (110) using DFT-GGA+U calculations.[167] They concluded that dissociation was favored over molecular adsorption, and the dissociated state was the most stable on the $\mathrm{CeO}_{2}(100)$ surface. They also reported that molecular adsorption becomes more favorable as the water coverage increases. Fernández-Torre et al compared calculations using a number of different approximations for handling exchange and correlation within DFT and concluded that there was very little difference between the dissociated species and molecular water in the lowest energy configuration.[168]

The primary method for differentiating molecular water from dissociated $-\mathrm{OH}$ on the surface has been $O$ 1s XPS data.[15,51,68,133,148,162-164] As shown in Figure 11a, water adsorption on $\mathrm{CeO}_{2}(111)$ and $\mathrm{CeO}_{2}(100)$ near $200 \mathrm{~K}$ results in three $\mathrm{O}$ 1s peaks. The lowest binding energy peak at $530.5 \mathrm{eV}$ is from the lattice $\mathrm{O}$ in $\mathrm{CeO}_{2}$. The highest binding energy peak near $534.4 \mathrm{eV}$ is associated with molecular water. This water could either be chemisorbed water or multilayer / physisorbed water. Since the spectra were recorded above $180 \mathrm{~K}$ this feature is unlikely associated with multilayer water since multilayer water has generally been reported to desorb between $150 \mathrm{~K}$ and $170 \mathrm{~K}$.[169] The intermediate feature near $532 \mathrm{eV}$ has generally been assigned to $-\mathrm{OH}$ although it has also been assigned to chemisorbed water[68] or a combination of $-\mathrm{OH}$ and chemisorbed water.[162] Valence level photoelectron spectra have demonstrated that the feature near $532 \mathrm{eV}$ is associated with $-\mathrm{OH}$ and not $\mathrm{H}_{2} \mathrm{O}$.[15] The $\mathrm{O}$ 1s spectra from water on $\mathrm{CeO}_{2}(111)$ (black curve) indicates a nearly equal amount of molecular water and $-\mathrm{OH}$ which is consistent with calculations that indicate little energetic difference between molecular and dissociative adsorption. The $\mathrm{O}$ 1s spectra from water on $\mathrm{CeO}_{2}(100)$ (blue curve) indicates that the water predominantly dissociated on this surface which is consistent with Molinari et al's calculations.[167]

The TPD following water adsorption at $180 \mathrm{~K}$ on oxidized $\mathrm{CeO}_{2}(111)$ and $\mathrm{CeO}_{2}(100)$ are very different as shown in Figure $11 \mathrm{~b}$. On $\mathrm{CeO}_{2}(111)$ the water mostly desorbs in a single, sharp feature near $200 \mathrm{~K} \cdot[15,68,133,148] \mathrm{On} \mathrm{CeO}_{2}(100)$ the water desorption extends from near 200 
$\mathrm{K}$ to beyond $500 \mathrm{~K} .[15]$ The principal conclusion from these results is that hydroxyls are more stable on oxidized $\mathrm{CeO}_{2}(100)$ than on $\mathrm{CeO}_{2}(111)$. This result is reasonable if we consider how the dissociated water would fill the coordination vacancies indicated in the surface structures shown in Figures 6 and $7 \mathrm{~b}$. On $\mathrm{CeO}_{2}(111)$ the $\mathrm{Ce}$ and the $\mathrm{O}$ each have a single coordination vacancy whereas on $\mathrm{CeO}_{2}(100)$ these surface ions each have two coordination vacancies. $\mathrm{OH}$ $+\mathrm{H}$ are most stable when they bond to the more under-coordinated surface species. This intuitive conclusion is supported by the calculations of Molinari et al.[167] They reported that the dissociated state was most stable on $\mathrm{CeO}_{2}(100)$.

Chen et al compared hydroxyls formed when water adsorbed on $\mathrm{CeO}_{2}(111)$ with hydroxyls formed by exposure to atomic D. [148] In this case the hydroxyls adsorb in two different configurations. Following water dissociation the hydroxyls populate a mixture of threefold sites originally occupied by the surface $O$ and singly coordinated sites atop the second layer $\mathrm{Ce}$. When the surface is exposed to atomic $\mathrm{D}$, all of the $-\mathrm{OD}$ occupies the three-fold adsorption sites. When $D_{2} O$ was adsorbed, rather than atomic $D$, the water desorbed in a manner similar to that shown by the black curve in Figure 11b. When the surface was exposed to atomic $D$, the water initially desorbed at low exposure of $\mathrm{D}$ in a broad feature from $200 \mathrm{~K}$ to $600 \mathrm{~K}$. At high $\mathrm{D}$ exposure a more pronounced peak appeared near $200 \mathrm{~K}$. In combination with their $\mathrm{O}$ 1s data they concluded that the broad desorption was due to disproportionation of hydroxyls on the surface producing $\mathrm{D}_{2} \mathrm{O}$ and an O-vacancy. The peak near $200 \mathrm{~K}$ was produced by reaction between $-O D$ and impinging $D$ that produced chemisorbed water at low temperature.

There have been two experimental studies of water adsorption on oxidized $\mathrm{CeO}_{2}(100)$. Herman et al. concluded that water adsorbed both molecularly and dissociatively and that all of the water desorbed below 350 K.[163] As shown by the blue lines in Figure 11b, Mullins and Albrecht reported water desorption extending to nearly 600 K.[15]

Ceria is known for its ability to liberate $\mathrm{O}$ through the reduction of $\mathrm{Ce}^{4+}$ to $\mathrm{Ce}^{3+}$. When this occurs on $\mathrm{CeO}_{2-x}(111)$, the O-vacancies create $\mathrm{Ce}$ cations with two coordination vacancies and a three-fold hollow adsorption site.[103] Experiment[15,51,68,148,162,164] and theory[149,165-167] have generally concluded that the presence of vacancies on $\mathrm{CeO}_{2-x}(111)$ promotes and stabilizes the dissociation of water. As shown in Figure 12a there is considerably more $-\mathrm{OH}$ on $\mathrm{CeO}_{1.7}(111)$ than on $\mathrm{CeO}_{2}(111)$ (Figure 11a). The hydroxyls are stable to above $500 \mathrm{~K}$ compared to oxidized $\mathrm{CeO}_{2}(111)$ where they mostly disappear by $250 \mathrm{~K}$. $[15,51,68,148]$ As seen in Figure $12 \mathrm{~b}$, reaction between hydroxyls on $\mathrm{CeO}_{1.7}(111)$ results primarily in $\mathrm{H}_{2}$ desorption. $[15,68,148]$ Henderson et al. observed no $\mathrm{H}_{2}$ desorption from reduced $\mathrm{CeO}_{2-x}(111)$ and $\mathrm{Ce} 3 \mathrm{~d}$ XPS indicated further reduction of the $\mathrm{Ce}$ in response to water adsorption.[133] One 
possible explanation for the differences reported by Henderson et al and these other studies is the nature of the $\mathrm{CeO}_{2-x}(111)$ films. Henderson et al grew their films on yttrium-stabilized $\mathrm{ZrO}_{2}(111)$ (YSZ). The other films were grown on $\mathrm{Ru}(0001)[15,68]$ or $\mathrm{Cu}(111) \cdot[51,148]$ Ferrizz et. al. have reported that ceria films grown on $Y S Z(100)$ showed greater reducibility than films grown on $\alpha-\mathrm{Al}_{2} \mathrm{O}_{3}(0001)$.[170] The source of the enhanced reducibility on YSZ was unclear; but if a similar effect is occurring on $Y S Z(111)$, this enhanced reducibility presumably indicates a lower O-vacancy formation energy, thereby producing a smaller driving force to re-oxidize a reduced surface through water decomposition. Enhanced reducibility of $\mathrm{CeO}_{2}(111)$ grown on YSZ may also explain why Henderson et al. were able to reduce their films by annealing to 830 $\mathrm{K}$, whereas other authors have reported thermal reduction only at much higher temperatures. $[23,111]$

The desorption of primarily $\mathrm{H}_{2}$ from water adsorbed on reduced $\mathrm{CeO}_{1.7}(111)$ is in contrast to the desorption from reduced $\mathrm{CeO}_{1.7}(100)$ where the primary desorption channel is still recombination to produce water with only a small amount of $\mathrm{H}_{2}$ formation (Figure 12b). The vacancy formation energy is higher on $\mathrm{CeO}_{2}(111)$ than on $\mathrm{CeO}_{2}(100) \cdot[7,8]$ Therefore it would be anticipated that the driving force for filling the vacancy would be greatest on $\mathrm{CeO}_{2-\mathrm{x}}(111)$.

\subsection{4 $-\mathrm{CO}$ and $\mathrm{CO}_{2}$}

$\mathrm{CO}$ can reduce ceria powder and nanocrystals at elevated temperatures producing $\mathrm{CO}_{2}$ and $\mathrm{CeO}_{2-x}$. The oxidation of $\mathrm{CO}$ is also one of the reactions promoted by ceria in automotive exhaust catalysts and in the water-gas shift reaction.[4] However, as with $\mathrm{H}_{2}$, $\mathrm{CO}$ does not adsorb on either $\mathrm{CeO}_{2}(111)$ or $\mathrm{CeO}_{2}(100)$ in UHV.[171-173] Weak adsorption of $\mathrm{CO}$ on the different faces of $\mathrm{CeO}_{2}$ is consistent with numerous calculations which have found that the adsorption energy is ca. $0.2 \mathrm{eV}$.[174-180] Several authors have calculated exothermic reaction energies greater than $2 \mathrm{eV}$ for the formation of carbonate from $\mathrm{CO}$ on $\mathrm{CeO}_{2}(110)[175,178-180]$ Nolan and Watson further determined that carbonate formation would be more exothermic on $\mathrm{CeO}_{2}(100)$, $-3.2 \mathrm{eV}$, than on $\mathrm{CeO}_{2}(110),-1.95 \mathrm{eV} .[180]$ To date there have been no measurements of $\mathrm{CO}$ adsorption on $\mathrm{CeO}_{2}(110)$. Stubenrauch and Vohs have reported that $\mathrm{CO}$ does not adsorb on single crystal $\mathrm{CeO}_{2}(100)$ at $300 \mathrm{~K}[171]$ and we have obtained unpublished results that indicate that ca. $0.1 \mathrm{ML}$ of $\mathrm{CO}$ adsorbs on a $\mathrm{CeO}_{2}(100)$ thin film at $100 \mathrm{~K}$ that then fully desorbs by $200 \mathrm{~K}$.

$\mathrm{CO}_{2}$ adsorption and activation offers a number of intriguing applications. $\mathrm{CO}_{2}$ adsorption could provide a means to capture and sequester this greenhouse gas from the atmosphere. 
Activation of $\mathrm{CO}_{2}$ to release $\mathrm{O}$ could conceivably be used as an oxidant in organic oxidation reactions and produce $\mathrm{CO}$ as a syngas reactant for further synthesis reactions.

Senanayake and Mullins observed that $\mathrm{CO}_{2}$ interacts weakly with stoichiometric $\mathrm{CeO}_{2}(111)$.[71] At $90 \mathrm{~K} \mathrm{CO}_{2}$ primarily physisorbed and then desorbed by $150 \mathrm{~K}$. A small amount of carbonate was formed that persisted up to $300 \mathrm{~K}$. Senanayake et al studied $\mathrm{CO}_{2}$ on reduced $\mathrm{CeO}_{2-x}$ clusters on $\mathrm{Au}(111)$ and observed similar behavior with a small amount of carbonate formed at low temperature that persisted up to $300 \mathrm{~K}$. Neither paper reported whether the $\mathrm{CO}_{2}$ simply desorbed as $\mathrm{CO}_{2}$ or whether on the reduced surface it was reduced to $\mathrm{CO}$ leaving the $\mathrm{O}$ with the ceria. In two papers Lykhach et al[181] and Staudt et al[182] examined the re-oxidation of reduced $\mathrm{CeO}_{2-x}(111)$ grown on $\mathrm{Cu}(111)$. Only a small amount of carbonate and carboxylate were observed in the $\mathrm{C}$ 1s and $\mathrm{O}$ 1s spectra[181] however a significant amount of $\mathrm{Ce}^{3+}$ was oxidized to $\mathrm{Ce}^{4+}$.

A more recent study of $\mathrm{CO}_{2}$ on $\mathrm{CeO}_{x}(100)$ has revealed a much stronger interaction of $\mathrm{CO}_{2}$ with both the oxidized and reduced surfaces.[72] Figure 13 shows the $\mathrm{CO}_{2}$ TPD from stoichiometric $\mathrm{CeO}_{2}(100)$ (black line) and reduced $\mathrm{CeO}_{1.7}(100)$ (blue line) following $\mathrm{CO}_{2}$ exposure at $180 \mathrm{~K}$. On the oxidized surface the $\mathrm{CO}_{2}$ desorbs in a series of peaks at $230 \mathrm{~K}, 410$ $\mathrm{K}, 510 \mathrm{~K}$ and $655 \mathrm{~K}$. The rising tail above $750 \mathrm{~K}$ resulted from desorption from the sample holder. $\mathrm{C}$ 1s XPS and $\mathrm{C}$ k-edge NEXAFS spectra indicate that the $\mathrm{CO}_{2}$ is adsorbed as carbonate throughout the entire range. The $230 \mathrm{~K}$ peak conceivably corresponds to the weak $\mathrm{CO}_{2}$ adsorption observed on $\mathrm{CeO}_{2}(111)$.[71] $\mathrm{A}$ unique feature that was revealed in the $\mathrm{C}$ k-edge NEXAFS spectra is that the molecular plane of the carbonate is oriented parallel to the $\mathrm{CeO}_{2}(100)$ surface (Figure 14). DFT+U calculations were conducted on possible adsorption states for the carbonate and the most stable configuration was a tri-dentate species where the $\mathrm{C}$ in the $\mathrm{CO}_{2}$ bonded to a surface $\mathrm{O}$ and the $\mathrm{O}$ in the $\mathrm{CO}_{2}$ bonded in bridge sites to surface $\mathrm{Ce}$. This species is shown in the inset in Figure 14. The adsorption energy for this carbonate was $1.93 \mathrm{eV}$. When the $\mathrm{CeO}_{2}(100)$ surface is reduced to $\mathrm{CeO}_{1.7}(100)$ the low temperature $\mathrm{CO}_{2}$ desorption is largely suppressed and the carbonate is stabilized producing a prominent peak at $765 \mathrm{~K}$ (Figure 13, blue line). No CO desorbed from either the oxidized or reduced surface and the $\mathrm{Ce} 4 \mathrm{f}$ peak intensity didn't change on the reduced surface indicating that $\mathrm{CO}_{2}$ did not reoxidize the $\mathrm{CeO}_{1.7}(100)$ surface.

Hahn et al investigated the adsorption of $\mathrm{CO}_{2}$ on a stoichiometric $\mathrm{CeO}_{2}(111)$ surface using DFT and DFT+U calculations.[183] They found that a monodentate carbonate species was the most stable configuration but was weakly adsorbed with an average binding energy of ca. $-0.3 \mathrm{eV}$ for both methods. They didn't examine adsorption on a reduced surface. Cheng et al 
have studied $\mathrm{CO}_{2}$ adsorption on oxidized and reduced $\mathrm{CeO}_{\mathrm{X}}(110)$ using the $\mathrm{DFT}+\mathrm{U}$ formalism.[184] Eleven different configurations were examined for $\mathrm{CO}_{2}$ adsorbed on the stoichiometric $\mathrm{CeO}_{2}(110)$ surface. The most stable configuration had the $\mathrm{CO}_{2}$ molecule bridging between $\mathrm{Ce}^{4+}$ cations with an adsorption energy of $-0.26 \mathrm{eV}$. The $\mathrm{C}=\mathrm{O}$ bond distance and the distance between the $\mathrm{CO}_{2}$ molecule and the surface indicated that the molecule was physisorbed as $\mathrm{CO}_{2}$ and did not form a carbonate. They considered two different models for the reduced $\mathrm{CeO}_{2-x}(110)$ surface. In one an in-plane O-vacancy was formed by simply removing an $O$ from the surface. In the other a split vacancy was produced when an $O$ adjacent to the initial vacancy shifts toward that vacancy into a bridge site between two Ce cations. $\mathrm{CO}_{2}$ bonds to the surface with the in-plane vacancy as a carboxylate with the $\mathrm{C}$ and one $\mathrm{O}$ atom in the molecule bonding to two $\mathrm{Ce}$ cations (Figure 15a). The adsorption energy is $-1.04 \mathrm{eV} . \mathrm{CO}_{2}$ adsorption on a surface with the split vacancy forms a monodentate carbonate (Figure 15b) and has a more stable adsorption energy of $-1.22 \mathrm{eV}$.

\section{$5.1 .5-N O_{x}$}

The adsorption and reaction of nitrogen oxides $\left(\mathrm{NO}_{x}\right)$, i.e. $\mathrm{N}_{2} \mathrm{O}, \mathrm{NO}$ and $\mathrm{NO}_{2}$, were among the first adsorbate systems investigated on ceria surfaces. This was because of ceria's application in automotive exhaust catalysts and the further potential for ceria in $\mathrm{NO}_{x}$ remediation.

Ferriz et al reported that $\mathrm{NO}$ did not adsorb at $300 \mathrm{~K}$ on a stoichiometric $\mathrm{CeO}_{2}(111)$ single crystal or on $\mathrm{CeO}_{2}$ grown on $\mathrm{a}-\mathrm{Al}_{2} \mathrm{O}_{3}(0001)$.[185] Overbury et al also observed that $\mathrm{NO}$ did not adsorb on $\mathrm{CeO}_{2}(100)$ at $160 \mathrm{~K}$ or $300 \mathrm{~K}[19]$ but adsorbed weakly at $90 \mathrm{~K}$ on oxidized $\mathrm{CeO}_{2}(111) / \mathrm{Ru}(0001)$.[59] As shown at the bottom of Figure 16 most of the NO desorbs as NO below $200 \mathrm{~K}$ with small amounts of $\mathrm{N}_{2}$ and $\mathrm{N}_{2} \mathrm{O}$ desorbing in the same temperature range. The broad NO desorption between $300 \mathrm{~K}$ and $400 \mathrm{~K}$ was ascribed primarily to $\mathrm{NO}$ adsorbed on the sample holder and on the back of the $\mathrm{Ru}(0001)$ crystal. This weak adsorption on the oxidized surface is consistent with the calculations of Yang et al who reported that NO adsorbs atop the $\mathrm{Ce}^{4+}$ cation on $\mathrm{CeO}_{2}(111)$ with an adsorption energy of only $-0.1 \mathrm{eV}$. $\mathrm{N} 1 \mathrm{~s}$ XPS indicates that at $90 \mathrm{~K}$ the $\mathrm{NO}$ adsorbs on $\mathrm{CeO}_{2}(111)$ as $\mathrm{N}_{2} \mathrm{O}$ and $\left[\mathrm{NO}_{2}\right]^{-}$as shown in Figure 17a. These may be slightly more stable surface products that were not explored in the calculations of Yang et al.

Both Ferriz et al[185] and Overbury et al[19,59] reported that NO adsorbs more strongly on reduced $\mathrm{CeO}_{2-x}$. These observations on low-index, low-surface area $\mathrm{CeO}_{2-x}$ surfaces confirm the work by Daturi et al which correlated catalytic deNO $\mathrm{N}_{\mathrm{x}}$ activity on ceria powders with $\mathrm{O}$ vacancy concentration on the ceria surface.[186] Ferriz et al observed only $\mathrm{N}_{2}$ desorption 
following $\mathrm{NO}$ adsorption at $300 \mathrm{~K}$ on reduced $\mathrm{CeO}_{2} / \alpha-\mathrm{Al}_{2} \mathrm{O}_{3}(0001)$. The $\mathrm{N}_{2}$ desorption profile varied depending on how they prepared their reduced surface. A film that was grown in a lower $\mathrm{O}_{2}$ ambient pressure resulted in a sharp $\mathrm{N}_{2}$ desorption between $300 \mathrm{~K}$ and $400 \mathrm{~K}$. A fully oxidized film that was sputtered to preferentially remove $\mathrm{O}$ produced a broad $\mathrm{N}_{2}$ desorption that extended from $400 \mathrm{~K}$ to $800 \mathrm{~K}$. Overbury et al observed a variety of desorption products and the product distribution varied depending on adsorption temperature.[59] As shown in the top of Figure 16, following adsorption at $90 \mathrm{~K} \mathrm{NO}, \mathrm{N}_{2}$ and $\mathrm{N}_{2} \mathrm{O}$ are produced primarily below $200 \mathrm{~K}$ with additional $\mathrm{NO}$ and $\mathrm{N}_{2}$ desorbing between $200 \mathrm{~K}$ and $400 \mathrm{~K}$. When the adsorption temperature is raised to $150 \mathrm{~K}$ the low temperature desorption is suppressed and additional $\mathrm{N}_{2}$ desorption is observed near $350 \mathrm{~K}$. When the adsorption temperature is increased to $400 \mathrm{~K}$, which is above where most products were observed following adsorption at lower temperatures, new desorption features appear with a substantial amount of $\mathrm{N}_{2}$ as well as $\mathrm{NO}$ desorbing in a pair of peaks at $500 \mathrm{~K}$ and $740 \mathrm{~K}$.

The $N$ 1s XPS spectra reveal how the surface species differ following adsorption at different temperatures on reduced $\mathrm{CeO}_{2-x}(111)$ (Figure 17b). Following adsorption at $90 \mathrm{~K}$ two stable surface species are observed; $\mathrm{N}_{2} \mathrm{O}$ with its two inequivalent nitrogens producing a doublet at $404.6 \mathrm{eV}$ and $408.3 \mathrm{eV}$, and $\mathrm{NO}^{-}$at $402.6 \mathrm{eV}$. These species mostly desorb and produce the products observed below $200 \mathrm{~K}$. When the adsorption temperature was raised to $145 \mathrm{~K}$ the $\mathrm{N}_{2} \mathrm{O}$ surface species is suppressed and the $\mathrm{NO}$ adsorbs almost exclusively as $\mathrm{NO}$. As the adsorption temperature is raised further new surface species appear and at $350 \mathrm{~K}$ nitride, $\mathrm{N}^{3-}$, is nearly the only species evident. These results suggest that the decomposition of $\mathrm{NO}$ leads to $\mathrm{N}_{2}$ and $\mathrm{NO}$ desorption between $200 \mathrm{~K}$ and $400 \mathrm{~K}$. Decomposition of $\mathrm{N}^{3-}$ produces the products at $500 \mathrm{~K}$ and $740 \mathrm{~K}$. Ferriz et al conjectured that the $\mathrm{CeO}_{2-\mathrm{x}} / \mathrm{a}-\mathrm{Al}_{2} \mathrm{O}_{3}(0001)$ grown in a lower oxygen pressure was less reduced than the sputtered $\mathrm{CeO}_{2-x} / \alpha-\mathrm{Al}_{2} \mathrm{O}_{3}(0001)$ film. [185] The less highly reduced film produced primarily $\mathrm{NO}^{-}$that decomposed to $\mathrm{N}_{2}$ below $400 \mathrm{~K}$ whereas the more highly reduced film resulted in nitride formation that decomposed between $400 \mathrm{~K}$ and $800 \mathrm{~K}$.

Yang et al calculated that the adsorption energy of $\mathrm{NO}$ on a reduced $\mathrm{CeO}_{2-\mathrm{x}(111)}$ surface will be an order of magnitude greater than on the oxidized surface.[187] The most stable configuration is with the $\mathrm{O}$ end down filling the $\mathrm{O}$-vacancy on the reduced surface. They report that the decomposition of $2 \mathrm{NO}(\mathrm{a})-\mathrm{CeO}_{2-x}$ to $\mathrm{N}_{2}$ plus re-oxidized $\mathrm{CeO}_{2}$ is thermodynamically favorable. Overbury et al noted that $\mathrm{NO}$ in fact re-oxidizes $\mathrm{CeO}_{2-x}(111)$ at $300 \mathrm{~K}$ based on $\mathrm{Ce} 4 \mathrm{~d}$ XPS.[59] However, the ceria became less oxidized upon annealing to $500 \mathrm{~K}$. This was ascribed to $O$ transport from the surface into the bulk. Interestingly, Berner et al did not observe re- 
oxidation of reduced $\mathrm{CeO}_{2-\mathrm{x}} / \mathrm{Pt}(111)$ following exposure to $\mathrm{NO}$ at either $300 \mathrm{~K}$ or $400 \mathrm{~K}$.[67] They attribute the lack of re-oxidation compared to the results of Overbury et al to a different morphology of the ceria. They propose that in their system the ceria forms islands with the reduced $\mathrm{Ce}^{3+}$ sites situated and conceivably stabilized at the $\mathrm{Pt} /$ ceria interface.

$\mathrm{NO}_{2}$ is an aggressive oxidant and is generally more effective than even $\mathrm{O}_{2}$. Berners et al observed that $\mathrm{NO}_{2}$ oxidized reduced $\mathrm{CeO}_{2-\mathrm{x}} / \mathrm{Pt}(111)$ whereas $\mathrm{NO}$ did not.[67] Rodriguez et al reported $\mathrm{NO}_{2}$ forms nitrate, $\left[\mathrm{NO}_{3}\right]^{-}$, at $300 \mathrm{~K}$ on polycrystalline $\mathrm{CeO}_{2}$ films deposited on $\mathrm{Pt}(111)$.[188] Namai et al did not observe any adsorbates following $\mathrm{NO}_{2}$ exposure on single crystal $\mathrm{CeO}_{2}(111)$ at room temperature using non-contact atomic force microscopy.[113] On lightly reduced $\mathrm{CeO}_{2-\mathrm{x}}(111)$ they observed that the O-vacancies were healed following $\mathrm{NO}_{2}$ exposure which they attributed to the reaction of $\mathrm{NO}_{2}$ with the vacancy to produce $\mathrm{NO}$ gas. They also observed adsorbed features that they assigned to $\left[\mathrm{NO}_{3}\right]^{-}$. When reduced $\mathrm{CeO}_{2-\mathrm{x}} / \mathrm{Pt}(111)$ was exposed to $\mathrm{NO}_{2}$ Rodriguez et al observed adsorbed $\mathrm{NO}$ and $\mathrm{N}$ (possibly nitride) as well as nitrate.[188] Nolan et al have calculated the structures of the adsorbed species for $\mathrm{NO}_{2}$ on reduced $\mathrm{CeO}_{2-\mathrm{x}}(111)$, (110) and (100).[189] They determined that $\mathrm{NO}_{2}$ adsorbs as $\left[\mathrm{NO}_{2}\right]^{-}$on all three surfaces. They do not report the formation of $\left[\mathrm{NO}_{3}\right]^{-}$nor the cleavage of an $\mathrm{N}-\mathrm{O}$ bond which they conclude must be an activated process that could occur between $300 \mathrm{~K}$ and $400 \mathrm{~K}$.

$\mathrm{N}_{2} \mathrm{O}$ was studied on a sputter reduced $\mathrm{CeO}_{2-x}(100)$ film. The dominant surface species at $100 \mathrm{~K}$ was $\mathrm{N}_{2} \mathrm{O}$ with a small amount of $\mathrm{NO}^{-}$.[59] Evolution of $\mathrm{N}_{2}$ was observed during exposure to $\mathrm{N}_{2} \mathrm{O}$ at $90 \mathrm{~K}$ which is consistent with the formation of $\mathrm{NO}^{-}$. The adsorbed $\mathrm{N}_{2} \mathrm{O}$ desorbs by $150 \mathrm{~K}$ with a small amount of $\mathrm{N}_{2}$ produced as well. Müller et al have calculated the adsorption of $\mathrm{N}_{2} \mathrm{O}$ on stoichiometric $\mathrm{CeO}_{2}(111)$ using a number of different formalisms.[190] The molecule always adsorbs linearly on a $\mathrm{Ce}^{4+}$ cation but the calculations differ as to whether it adsorbs with an $\mathrm{O}$ or a $\mathrm{N}$ bound to the cerium depending on the method used. In any case the adsorption is weak with an adsorption interaction of only $-0.2 \mathrm{eV}$ to $-0.3 \mathrm{eV}$. They cite experimental vibrational data that indicate that the preferred orientation is with the $O$ toward the cerium.

\subsection{6 $-\mathrm{SO}_{2}$ and $\mathrm{H}_{2} \mathrm{~S}$}

The finite concentration of sulfur containing molecules in fossil fuels leads to the formation of sulfur oxides $\left(\mathrm{SO}_{x}\right)$ in the exhaust. Adsorption of these gases leads to loss of oxygen storage capacity in the cerium oxide in automotive catalytic convertors. However, high affinity for $\mathrm{SO}_{x}$ could be exploited by trapping sulfur in the effluent. 
Two studies examined the adsorption of $\mathrm{SO}_{2}$ on cerium oxide thin films and arrived at different conclusions. Overbury et al used well-characterized $\mathrm{CeO}_{2}(111) / \mathrm{Ru}(0001)$ and concluded that $\mathrm{SO}_{2}$ adsorbed as $\mathrm{SO}_{3}{ }^{2-}$ on the fully oxidized surface at temperatures from $100 \mathrm{~K}$ - 600 K.[191] Based on S 2p XPS it was concluded that the $\mathrm{SO}_{2}$ adsorbed through a Lewis acid - base interaction at the basic $\mathrm{O}^{2-}$ surface sites. The adsorbate desorbed as $\mathrm{SO}_{2}$ over this entire range with major desorption peaks near $200 \mathrm{~K}$ and $400 \mathrm{~K}$. There was no evidence of either oxidation to $\mathrm{SO}_{4}{ }^{2-}$ or reduction to $\mathrm{SO}^{2-}$ or $\mathrm{S}^{2-}$. These results were consistent with an earlier study by Waqif et al on $\mathrm{CeO}_{2}$ powders where they observed by vibrational spectroscopy that only sulfite formed following room temperature exposure to $\mathrm{SO}_{2}$.[192] Sulfate formation occurred after exposure at $673 \mathrm{~K}$ and was promoted by simultaneous exposure to $\mathrm{O}_{2}$. Contrary to these reports, Rodriguez et al found that $\mathrm{SO}_{2}$ adsorbed almost exclusively as $\mathrm{SO}_{4}{ }^{2-}$ on fully oxidized, polycrystalline $\mathrm{CeO}_{2} / \mathrm{Pt}(111)$.[193]

Perhaps in an effort to resolve this discrepancy a number of other investigators performed additional experiments that investigated additional parameters in the interaction between $\mathrm{SO}_{2}$ and ceria. Smirnov et al studied $\mathrm{SO}_{2}$ adsorption on polycrystalline $\mathrm{CeO}_{2}$ deposited on $\mathrm{Al}_{2} \mathrm{O}_{3}$ using an $\mathrm{SO}_{2}$ pressure of 2.5 mbar.[194] They observed sulfite formation at temperature below $473 \mathrm{~K}$ and sulfate formation above $573 \mathrm{~K}$. When an equal pressure of $\mathrm{O}_{2}$ was added to the $\mathrm{SO}_{2}$ exposure sulfite formation was suppressed at the lower temperatures but sulfate still only appeared at the higher temperatures. The sulfate formation was enhanced by the addition of $\mathrm{O}_{2}$ at the higher temperatures, however. Ferriz et al used polycrystalline ceria films deposited by spray pyrolysis on Ta foil, used for TPD measurements, and by Ce vapor deposition in an $\mathrm{O}_{2}$ ambient onto a $\mathrm{Mo}(100)$, used for XPS measurements. Following $\mathrm{SO}_{2}$ exposure at $298 \mathrm{~K}$ a prominent $\mathrm{SO}_{2}$ desorption peak was observed near $473 \mathrm{~K}$.[195] This is similar to the $\mathrm{SO}_{2}$ desorption reported by Overbury et al.[191] However, distinct $\mathrm{SO}_{2}$ desorption peaks were also observed between $800 \mathrm{~K}$ and $1000 \mathrm{~K}$ that were not seen by Overbury et al. When the $\mathrm{SO}_{2}$ exposure temperature was increased to $573 \mathrm{~K}$ the higher temperature peak increased in intensity and the lower temperature peak was suppressed. The S $2 p$ XPS indicated that the $\mathrm{SO}_{2}$ adsorbed predominantly as sulfite at $298 \mathrm{~K}$ but some of this transformed to sulfate as the sample was heated. Heating to $923 \mathrm{~K}$ further transformed the sulfate into sulfide. Similar results were obtained regardless of whether the $\mathrm{SO}_{2}$ was co-exposed with $\mathrm{O}_{2}$ or by itself.

Most recently, Happel et al studied $\mathrm{SO}_{2}$ on well-characterized $\mathrm{CeO}_{2}(111) / \mathrm{Cu}(111)$.[196] Their S $2 p$ XPS results, shown in Figure 18a, indicate that sulfite is the primary surface species at $300 \mathrm{~K}$. As the sample was heated some of the sulfur was reduced to $S^{0}$ and $S^{2-}$. No sulfate was observed at any temperature. 
The consensus is that sulfite is the primary species adsorbed at room temperature and below. Elevated temperature, co-exposed $\mathrm{O}_{2}$ and perhaps surface heterogeneity appear to promote sulfate formation. This is consistent with the DFT-U calculations conducted by Lu et al.[197] $\mathrm{SO}_{3}{ }^{2-}$ was determined to be the most stable species on $\mathrm{CeO}_{2}(111)$ whereas $\mathrm{SO}_{4}{ }^{2-}$ was also formed on $\mathrm{CeO}_{2}(110)$. This difference was attributed to the spacing between $\mathrm{O}^{2-}$ anions on the two surfaces. Sulfites formed by attaching to a single $\mathrm{O}^{2-}$ anion in a monodentate configuration. On $\mathrm{CeO}_{2}(110)$ sulfates formed by bridging between two $\mathrm{O}^{2-}$ anions. The spacing between the $\mathrm{O}^{2-}$ anions is too great on $\mathrm{CeO}_{2}(111)$ for this two occur. A stable sulfate configuration can occur on $\mathrm{CeO}_{2}(111)$ if the sulfite extracts an $\mathrm{O}$ from the surface to create $\mathrm{SO}_{4}{ }^{2-}$. This is an activated process which is consistent with the observation that sulfate formation generally requires elevated temperature. The cases where sulfate was observed at lower temperatures may be related to heterogeneous surfaces that were not exclusively $\mathrm{CeO}_{2}(111)$.

Adsorption on a reduced $\mathrm{CeO}_{2-x}$ surface promotes reduction of the $\mathrm{SO}_{2}$. As shown in Figure $18 \mathrm{~b}$ the $\mathrm{SO}_{2}$ again adsorbs on $\mathrm{CeO}_{2-x}(111) / \mathrm{Cu}(111)$ primarily as $\mathrm{SO}_{3}{ }^{2-}$ at $300 \mathrm{~K}$ but $\mathrm{S}$ $2 p$ features that can be assigned to $\mathrm{SO}_{2}^{-}, \mathrm{S}^{0}$ and $\mathrm{S}^{2-}$ are also apparent. As the sample is annealed most of these species convert to the sulfide. Overbury et al observed that there were virtually no products desorbed from a heavily reduced $\mathrm{CeO}_{2-\mathrm{x}}$ (111) surface following $\mathrm{SO}_{2}$ exposure. In Figure 18b sulfide is identified at two slightly different binding energies; surface sulfide occurs at $160.7 \mathrm{eV}$ and bulk sulfide is at $161.3 \mathrm{eV}$. The surface sulfide transforms into a bulk sulfide at elevated temperature. Overbury et al observed that upon annealing to $1000 \mathrm{~K}$ the $S 2 p$ signal mostly disappeared as the $S$ diffused away from the near-surface region sampled by the sXPS.[191] Happel et al[196] and Overbury et al[191] both observed that $\mathrm{Ce}^{3+}$ oxidized to $\mathrm{Ce}^{4+}$ as sulfur was reduced from $\mathrm{S}^{4+}$ to $\mathrm{S}^{2-}$. Using $\mathrm{DFT}+\mathrm{U}$ calculations Kullgren et al concluded that $\mathrm{SO}_{2}$ adsorption will lead to sulfide formation on reduced $\mathrm{CeO}_{2-x}(111)$ but will still lead to sulfate formation on $\mathrm{CeO}_{2-x}(110)$.[198]

$\mathrm{H}_{2} \mathrm{~S}$ provides additional insight into the interaction of S-containing species with ceria surfaces. It is also a close analog to water and the adsorption and dissociation of $\mathrm{H}_{2} \mathrm{O}$ and $\mathrm{H}_{2} \mathrm{~S}$ on $\mathrm{CeO}_{2}(111)$ have been compared computationally.[166,199] Unlike $\mathrm{SO}_{2}, \mathrm{H}_{2} \mathrm{~S}$ interacts with $\mathrm{CeO}_{2}(111)$ as a Lewis base with the basic $\mathrm{S}$ atom bonding to the acidic $\mathrm{Ce}^{4+}$ cation. As shown in Figure 19a the $\mathrm{S} 2 \mathrm{p}$ XPS indicates the presence of $\mathrm{H}_{2} \mathrm{~S}$ on the ceria surface from $100 \mathrm{~K}-150$ $\mathrm{K}$ but none at $200 \mathrm{~K}$.[200] In addition to $\mathrm{H}_{2} \mathrm{~S}$ the $\mathrm{S} 2 \mathrm{p}$ spectrum also indicates $-\mathrm{SH}$. The intensities of both the $\mathrm{H}_{2} \mathrm{~S}$ and $-\mathrm{SH}$ decrease as the sample is annealed from $100 \mathrm{~K}$ to $200 \mathrm{~K}$. This is consistent with TPD spectra that show $\mathrm{H}_{2} \mathrm{~S}$ desorption at ca. $165 \mathrm{~K}$ from oxidized 
$\mathrm{CeO}_{2}(111)$.[200] As can be seen in Figure 19b, O 1s spectra recorded at the same temperatures as the $S 2 p$ spectra indicate the formation of $\mathrm{H}_{2} \mathrm{O}$ and $-\mathrm{OH}$ on the $\mathrm{CeO}_{2}(111)$ surface. These are formed from the dissociated $\mathrm{H}$ from the $\mathrm{H}_{2} \mathrm{~S}$ bonding with the surface $\mathrm{O}$ on the ceria. TPD spectra show water desorption occurring from $200 \mathrm{~K}$ to $400 \mathrm{~K}$ as these react and desorb from the surface. The presence of both $-\mathrm{SH}$ and $-\mathrm{OH}$ therefore leads to competitive reaction pathways producing $\mathrm{H}_{2} \mathrm{~S}$ and $\mathrm{H}_{2} \mathrm{O}$. As the reactions between $-\mathrm{SH}$ and $-\mathrm{OH}$ proceed as the surface is heated the $S$ is transformed into surface sulfide. The binding energy is consistent with the surface sulfide observed during $\mathrm{SO}_{2}$ decomposition in Figure 18a.

The calculations of Chen et al[199] and Marrocchelli and Yildiz[166] are consistent with the observed experiments with $\mathrm{H}_{2} \mathrm{~S}$ adsorbing weakly molecularly and progressing through more stable $-\mathrm{SH}$ and $\mathrm{S}$ adsorption species. Note that the $\mathrm{S} 2 \mathrm{p}$ spectra at $200 \mathrm{~K}$ and above do not give any indication of $\mathrm{SO}_{x}$ species on the surface. Chen et al found that $-\mathrm{SH}$ is most stable when bound atop a surface $\mathrm{O}$ whereas Marrocchelli and Yildiz determined that the most stable configuration for $-\mathrm{SH}$ was atop the $\mathrm{Ce}$. Chen et al further reported that desorption of $\mathrm{SO}_{2}$ is favorable whereas Marrocchelli and Yildiz determined that formation of $\mathrm{H}_{2}(\mathrm{~g}), \mathrm{H}_{2} \mathrm{O}(\mathrm{g})$ and $\mathrm{SO}_{2}(\mathrm{~g})$ were all equally unfavorable. Marrocchelli and Yildiz suggested that the formation of $\mathrm{SO}_{2}$ was disfavored due to the high vacancy formation energy in $\mathrm{CeO}_{2}(111)$. The formation of $\mathrm{H}_{2} \mathrm{O}$ was slightly exothermic when the $S$ filled the vacancy created by the $\mathrm{H}_{2} \mathrm{O}$ formation but that there was a large activation barrier in this step.

When the ceria surface is partially reduced considerably more $\mathrm{H}_{2} \mathrm{~S}$ adsorbs on the surface and decomposition to $-\mathrm{SH}$ and $\mathrm{S}$ is observed at $100 \mathrm{~K}$.[200] TPD spectra show that $\mathrm{H}_{2} \mathrm{O}$ desorbs near $580 \mathrm{~K}$ when the ceria is $20 \%$ reduced $\left(\mathrm{CeO}_{1.9}(111)\right)$, reaches a maximum intensity when the ceria is $50 \%$ reduced $\left(\mathrm{CeO}_{1.75}(111)\right)$ and then decreases in intensity at higher degrees of reduction.[200] $\mathrm{H}_{2}$ desorption occurs at $580 \mathrm{~K}$ when the degree of reduction is greater than $50 \%$ and increases at the expense of $\mathrm{H}_{2} \mathrm{O}$ formation at higher degrees of reduction. Marrocchelli and Yildiz determined that while $\mathrm{H}_{2}(\mathrm{~g})$ may be thermodynamically more favorable than $\mathrm{H}_{2} \mathrm{O}(\mathrm{g})$, it has a significantly higher activation barrier and thus would not be anticipated.[166] They ascribe the transition from $\mathrm{H}_{2} \mathrm{O}$ formation to $\mathrm{H}_{2}$ to increasing difficulty to remove $\mathrm{O}$ from the surface as the ceria becomes more reduced.

The production of water at elevated temperature from $\mathrm{H}_{2} \mathrm{~S}$ on partially reduced $\mathrm{CeO}_{2}$. $x(111)$ is in contrast to the behavior of $\mathrm{H}_{2} \mathrm{O}$ where $\mathrm{H}_{2}$ desorption is almost exclusively observed at elevated temperature with little $\mathrm{H}_{2} \mathrm{O}$.[68,148] Mullins and $\mathrm{McD}$ Donald attributed the difference between $\mathrm{H}_{2} \mathrm{~S}$ and $\mathrm{H}_{2} \mathrm{O}$ to the ability of $\mathrm{O}$ to diffuse into the bulk compared to S.[200] At the temperature where $-\mathrm{OH}$ reacts, i.e. near $580 \mathrm{~K}$, the $\mathrm{O}$ can diffuse into the bulk[68] whereas $\mathrm{S}$ 
moves from the surface to the bulk at higher temperatures.[63,191,200] The stability of $S$ on the surface makes the surface more oxidized and thus makes it easier to remove the $O$.

\section{2 - Organic Molecules}

Organic molecules appear to require a functional group containing a heteroatom such as $\mathrm{N}, \mathrm{O}, \mathrm{S}$, etc. in order to adsorb and react on ceria surfaces under UHV conditions. Nonfunctionalized organic molecules have not been extensively studied. It was reported that ethylene desorbs molecularly below $150 \mathrm{~K}$ on $\mathrm{CeO}_{2}(111)$.[201] Ethylene was also studied on $\mathrm{Rh}$ / $\mathrm{CeO}_{2}$ / YSZ(100).[202] While the authors didn't explicitly report the ethylene interaction with a clean ceria surface, the results were interpreted in terms of ethylene adsorption on the Rh particles. Vile' et al reported the selective hydrogenation of alkynes to olefins at high conversion over polycrystalline ceria powders.[203] Carrasco et al investigated this system computationally examining the hydrogenation of acetylene to ethylene over $\mathrm{CeO}_{2}(111)$ by DFT.[204] They determined that $\beta-\mathrm{C}_{2} \mathrm{H}_{2}$ radical species adsorb on-top of surface oxygen atoms leading to $\mathrm{C}_{2} \mathrm{H}_{3}$ species. This species has a lower activation barrier leading to gas phase $\mathrm{C}_{2} \mathrm{H}_{4}$ compared to the formation of a $\beta-\mathrm{C}_{2} \mathrm{H}_{4}$ radical that would lead to more highly hydrogenated products.

Of the functionalized molecules the oxygenates; alcohols, aldehydes, ketones, ethers and carboxylic acids, have been by far the most investigated. There have been several reviews covering adsorption and reaction of some of these molecules.[11,12,205] In Section 5.2.1 the adsorption and reaction of these molecules will be covered more extensively. In Section 5.2.2 organic adsorbates containing other functional groups will be reviewed.

\subsection{1 - Oxygenates}

\subsubsection{Alcohols}

Methanol has been the most extensively investigated organic oxygenate on ceria surfaces. This is because, as stated by Badlani and Wachs, "methanol is a 'smart' chemical probe molecule that can provide fundamental information about the number of surface active sites, the nature of surface active sites, the decomposition temperature of surface methoxy intermediates and the quantitative TOF values for methanol oxidation for pure metal oxide catalysts."[206] It therefore serves as an ideal probe for comparing ceria surfaces to the surfaces of other oxides and differentiating the adsorption and reaction characteristics between different ceria surfaces. The chemically important reaction for the adsorption of methanol on ceria is the formation of methoxy and hydroxyl:[11,12,83,102,207,208] 
(4) $\mathrm{CH}_{3} \mathrm{O}-\mathrm{H}+\mathrm{CeO}_{2} \rightarrow \mathrm{CH}_{3} \mathrm{O}-\mathrm{Ce}+\mathrm{H}-\mathrm{O}(\ell)$

The methoxy species can be differentiated spectroscopically from the alcohol based on the C $1 \mathrm{~s}$, and especially the $\mathrm{O} 1 \mathrm{~s}$, binding energies.[50,208]

In contrast, calculations by Mei et al have indicated that the most stable dissociative state on stoichiometric $\mathrm{CeO}_{2}(111)$ involves cleavage of a $\mathrm{C}-\mathrm{H}$ bond and the formation of a $\mathrm{C}$ $\mathrm{O}(\ell)$ bond. [209] In a subsequent publication these authors indicated that O-H cleavage may be kinetically favored due to much lower activation barrier compared to $\mathrm{C}-\mathrm{H}$ cleavage, resulting in adsorbed species that agree with experimental observations.[210]

The concentration of methoxy on the surface thus determines the number of surface active sites on that surface. Based on $\mathrm{C}$ 1s photoemission the methoxy coverage on $\mathrm{CeO}_{2}(111)$ is $7 \mathrm{~nm}^{-2}$ at $200 \mathrm{~K}$. [208] The Ce cation density on $\mathrm{CeO}_{2}(111)$ is $7.9 \mathrm{~nm}^{-2}$ therefore the methoxy coverage is ca. $0.9 \mathrm{ML}$. The methoxy coverage drops steadily as the sample is heated and methanol recombines and desorbs. The coverage is ca. $3 \mathrm{~nm}^{-2}$ at $373 \mathrm{~K}$. This is consistent with the methoxy coverage on ceria powder which was $4.2 \mu$ mole $\mathrm{m}^{-2}$ at $100^{\circ} \mathrm{C}$ which is equivalent to $2.5 \mathrm{~nm}^{-2}$.[206] The methoxy coverage on $\mathrm{CeO}_{2}(100)$ is ca. $10 \mathrm{~nm}^{-2}$ at $200 \mathrm{~K} .[205,211]$ On $\mathrm{CeO}_{2}(100)$ the density of bridge sites between Ce cations is $6.8 \mathrm{~nm}^{-2}$ (Figure 7b). While the match is not perfect, the maximum methoxy coverage which occurs near $200 \mathrm{~K}$ on $\mathrm{CeO}_{2}(111)$ and $\mathrm{CeO}_{2}(100)$ is nearly $1 \mathrm{ML}$.

The TPD following methanol adsorption on $\mathrm{CeO}_{2}(111)$ and $\mathrm{CeO}_{2}(100)$ is shown in Figure 20.[205] On $\mathrm{CeO}_{2}(111)$ water and methanol are the primary products and they desorb between $200 \mathrm{~K}$ and $300 \mathrm{~K}$ (Figure 20, black lines). This demonstrates that even though the initial coverage of methoxy is high the methoxys and hydroxyls are unstable on this surface and recombine. It is important to note, however, that a competing reaction in this temperature range is the disproportionation of hydroxyls to produce water and a vacancy.

(5) $\mathrm{H}-\mathrm{O}(\ell)+\mathrm{H}-\mathrm{O}(\ell) \rightarrow \mathrm{H}_{2} \mathrm{O}(\mathrm{g})+\mathrm{O}(\ell)+\mathrm{V}_{\mathrm{O}}$

Where $V_{O}$ is an oxygen vacancy. Isotopic labeling experiments with $\mathrm{Ce}^{18} \mathrm{O}_{2}(111)$ demonstrated that the water produced near $200 \mathrm{~K}$ contained lattice O.[208] The desorption of methanol between $200 \mathrm{~K}$ and $300 \mathrm{~K}$ is consistent with the decrease in methoxy coverage as the sample is annealed. The only reaction products at higher temperature result from the disproportionation of methoxy at ca. $560 \mathrm{~K}$. 
(6) $\mathrm{CH}_{3} \mathrm{O}-\mathrm{Ce}+\mathrm{CH}_{3} \mathrm{O}-\mathrm{Ce} \rightarrow \mathrm{CH}_{3} \mathrm{OH}(\mathrm{g})+\mathrm{CH}_{2} \mathrm{O}(\mathrm{g})+2 \mathrm{Ce}$

This suggests that $\mathrm{CeO}_{2}(111)$ is primarily a redox type catalyst. Badlani and Wachs reached a similar conclusion on $\mathrm{CeO}_{2}$ powder.[206] They also reported a similar decomposition temperature, $573 \mathrm{~K}$. Methanol is an excellent reductant for $\mathrm{CeO}_{2}(111)$ since the $\mathrm{O}: \mathrm{C}$ ratio averaged over the products, $\mathrm{CH}_{3} \mathrm{OH}, \mathrm{CH}_{2} \mathrm{O}$ and $\mathrm{H}_{2} \mathrm{O}$, is greater than $\mathrm{O}: \mathrm{C}$ ratio in the reactant.

Methanol recombination and water formation are also evident on $\mathrm{CeO}_{2}(100)$ (Figure 20, blue lines). The water desorption extends to a much higher temperature and does not spike as much near $200 \mathrm{~K}$ compared to $\mathrm{CeO}_{2}(111)$. The methanol desorption behaves similarly. This demonstrates that methoxy and hydroxyl are both more stable on $\mathrm{CeO}_{2}(100)$ than on $\mathrm{CeO}_{2}(111)$. Methanol and formaldehyde desorption through methoxy disproportionation occur at the same temperature as on $\mathrm{CeO}_{2}(111)$ but have a greater intensity, consistent with the significantly greater methoxy coverage on $\mathrm{CeO}_{2}(100)$ at the reaction temperature.[211] $\mathrm{CO}$, $\mathrm{CO}_{2}, \mathrm{H}_{2}$, and $\mathrm{H}_{2} \mathrm{O}$ are also produced near $600 \mathrm{~K}$. These products are indicative of a basic reaction mechanism.[206,212] The basic O anions on the surface dehydrogenate the methyl group in the methoxy.

When the ceria surfaces are reduced O-vacancies are created on the surface. On $\mathrm{CeO}_{2}$ $x(111)$ this introduces three-fold adsorption sites between the Ce cations, equivalent to the sites occupied by the surface $O$ in Figure 6 , in addition to the on-top adsorption sites. Adsorption at these sites is much more stable as can be seen by the decrease of water and methanol desorption below $300 \mathrm{~K}$ on reduced $\mathrm{CeO}_{2-\mathrm{x}}(111)$ (Figure 21, black lines). This is also consistent with what was observed following water adsorption (compare Figure 11b and 12b, black lines) where reduction of the substrate attenuated the water desorption at low temperature. The methoxy is stable until about $660 \mathrm{~K}$ where it decomposes to produce $\mathrm{CH}_{2} \mathrm{O}, \mathrm{CH}_{3} \mathrm{OH}, \mathrm{CO}, \mathrm{H}_{2}$ and $\mathrm{CO}_{2}$. This demonstrates a transition from redox to basic behavior. The decomposition temperature shifts to higher temperature indicating a greater stability for the methoxy species. An important feature to note is the two peaks in the $\mathrm{H}_{2}$ desorption. Isotopic labeling using $\mathrm{CH}_{3} \mathrm{OD}$ demonstrated that the first peak at ca. $550 \mathrm{~K}$ resulted from the reaction between hydroxyls on the surface while the second peak resulted from the dehydrogenation of the methyl in the methoxy.[208] The desorption temperature due to hydroxyl recombination is consistent with what was observed when water was adsorbed on reduced $\mathrm{CeO}_{2-x}(111)$ (Figure 12b).

The effect that reduction has on the reaction of methanol on $\mathrm{CeO}_{2-x}(100)$ is not nearly as dramatic as the effect on $\mathrm{CeO}_{2-\mathrm{x}}(111)$. There is a slight decrease in the water and methanol desorption between $200 \mathrm{~K}$ and $500 \mathrm{~K}$. There is also a small increase, ca. $25 \mathrm{~K}$, in the $\mathrm{CO}$ and $\mathrm{H}_{2}$ 
desorption temperature. The formaldehyde formation is greatly diminished, however. Ferrizz et al reported similar behavior for methanol adsorbed on oxidized and reduced $\mathrm{CeO}_{x}(100)$ grown on YSZ(100).[83] Note that on $\mathrm{CeO}_{2-\mathrm{x}}(100)$ there is only a single $\mathrm{H}_{2}$ desorption peak. Although isotopic labeling has not been performed presumably the hydroxyl reaction is similar to what was observed for water; specifically, the hydroxyls primarily react to form water and only a relatively small amount produce $\mathrm{H}_{2}$. Therefore the $\mathrm{H}_{2}$ desorption peak mostly results from methoxy decomposition.

It's clear that O-vacancies increase the number of adsorption sites on the ceria surfaces, particularly on $\mathrm{CeO}_{2-\mathrm{x}}(111) .[83,208]$ It has been argued, however, that O-vacancies are necessary for methanol adsorption and methoxy formation on $\mathrm{CeO}_{x}(111) \cdot[12,83]$ Ferriz et al reported that less than $0.08 \mathrm{ML}\left(0.6 \mathrm{~nm}^{-2}\right)$ adsorbed on fully oxidized single crystal $\mathrm{CeO}_{2}(111)$ at $300 \mathrm{~K}$.[83] It has also been observed by noncontact AFM that methoxy on $\mathrm{CeO}_{2}(111)$ adsorbs in O-vacancy sites and methoxy in the on-top sites has not been observed.[113] Other experimental reports, as well as the results presented above, appear to indicate that methanol will adsorb and dissociate on the fully oxidized $\mathrm{CeO}_{2}(111)$ surface.[50,208] There are several possible explanations for reconciling these observations. Calculations have shown that methoxy is weakly stable in the on-top site on $\mathrm{CeO}_{2}(111)$.[207] This weak adsorption is consistent with the methanol desorption between $200 \mathrm{~K}$ and $300 \mathrm{~K}$. As demonstrated by water adsorption on oxidized and reduced $\mathrm{CeO}_{x}(111)$, hydroxyl adsorbed in a vacancy is relatively stable while hydroxyl adsorbed on top of a Ce cation is unstable.[15,51] This is evident from the water TPD spectra shown in Figure 11b. Likewise, based on calculations, methoxy is more stable in a vacancy compared to the on-top adsorption site.[207] If the methoxy and the hydroxyl were able to exchange adsorption sites following methanol adsorption at $180 \mathrm{~K}$, as shown in (7), this would stabilize the methoxy and destabilize the hydroxyl.

7)
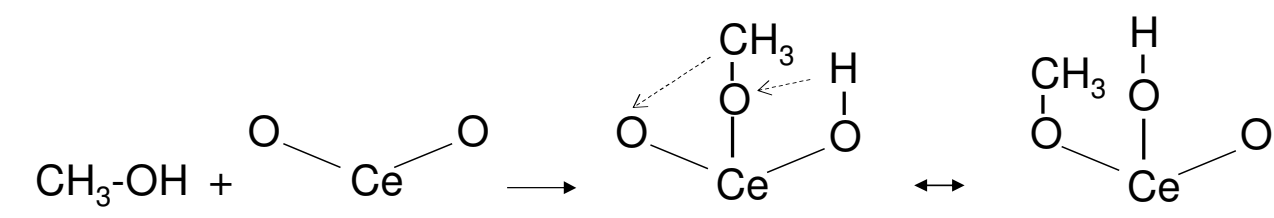

This mechanism not only stabilizes the methoxy but also helps explain the water desorption at low temperature. This also places the methoxy in a vacancy site as observed by AFM. The removal of $\mathrm{H}$ through the desorption of water may also help to stabilize the methoxy regardless of its adsorption site. If the methoxy doesn't have a $\mathrm{H}$ to recombine with it will be stranded on the surface until it can decompose or react with another methoxy and 
disproportionate at higher temperatures. It isn't clear why more activity wasn't observed by Ferriz et al.[83] The adsorption of methanol was conducted at $300 \mathrm{~K}$ by Ferriz et al but at $90 \mathrm{~K}$ by Mullins et al [208] and $110 \mathrm{~K}$ by Matolin et al [50]. Perhaps the weakly bound dissociative state recombines and desorbs too quickly to react with the surface at $300 \mathrm{~K}$. It's also possible that the reactivity is different on the $\mathrm{CeO}_{2}(111)$ single crystal compared to the $\mathrm{CeO}_{2}(111)$ thin films although no obvious differences are evident in the STM and AFM images from these different surfaces.

Longer chain alcohols such as ethanol, 1-propanol and 2-propanol also adsorb on ceria surfaces by dissociating at the $\mathrm{Ce} / \mathrm{O}$ acid-base pair sites. $\mathrm{C}$ 1s XPS indicates that the alkoxy coverage formed from the longer chain alcohols is the same as the methoxy coverage created by methanol adsorption.[205,213] This is consistent with what has been observed on powder samples where methanol, ethanol and propanol produce the same coverages.[214] The coverage is therefore determined by the interaction of the alcohol with the surface adsorption sites and not by adsorbate-adsorbate interactions.

The introduction of a C-C bond into the alcohol opens up new possibilities for the reaction products. The product distribution is again used to characterize the acidic or basic nature of the substrate.[214] Dehydration to produce alkenes and water (8) occurs on acidic / redox oxides and dehydrogenation to produce ketones or aldehydes (9) occurs on basic oxides. While ethanol, 1-propanol and 2-propanol follow similar reaction pathways, 2-propanol tends to produce the cleanest results following exclusively one pathway or the other on most oxides.[213,214]

(8) $\left(\mathrm{CH}_{3}\right)_{2} \mathrm{CHOH}+\mathrm{CeO}_{2} \rightarrow \mathrm{CH}_{3} \mathrm{CH}=\mathrm{CH}_{2}+\mathrm{H}_{2} \mathrm{O}+\mathrm{CeO}_{2}$

dehydration

(9) $\left(\mathrm{CH}_{3}\right)_{2} \mathrm{CHOH}+\mathrm{CeO}_{2} \rightarrow\left(\mathrm{CH}_{3}\right)_{2} \mathrm{C}=\mathrm{O}+\mathrm{H}_{2}+\mathrm{CeO}_{2}$

dehydrogenation

We note, however, that these reaction descriptions are an oversimplification since they do not explicitly indicate how the $\mathrm{O}$ in the ceria may be involved. For example, on an oxidized surface the water from dehydration may incorporate $O$ from the substrate followed by deoxygenation of the adsorbate to replenish the $O$ in the substrate. The net reaction is dehydration as shown in (8) but the $\mathrm{O}$ in the $\mathrm{H}_{2} \mathrm{O}$ does not come from the alcohol. Alternatively dehydration may lead to propylene as a product but, if the substrate is initially reduced, the $\mathrm{O}$ from the propoxide may re-oxidize the substrate and $\mathrm{H}_{2}$ will be produced rather than $\mathrm{H}_{2} \mathrm{O}$. 
The adsorption of 2-propanol at $180 \mathrm{~K}$ on oxidized $\mathrm{CeO}_{2}(111)$ and $\mathrm{CeO}_{2}(100)$ leads to water and alcohol desorption between $200 \mathrm{~K}$ and $450 \mathrm{~K}$ that is similar to what was observed for methanol (Figure 20).[205] On $\mathrm{CeO}_{2}(111)$ water and 2-propanol desorb in a single, well-defined peak near $225 \mathrm{~K}$. On $\mathrm{CeO}_{2}(100)$ the low-temperature water and 2-propanol desorption is broad, extending to almost $500 \mathrm{~K}$.

On $\mathrm{CeO}_{2}(111)$ propylene is essentially the only hydrocarbon product and desorbs at 585 K.[205,213] There are trace amounts of acetone and 2-propanol desorbing between $500 \mathrm{~K}$ and $550 \mathrm{~K} . \mathrm{H}$ is liberated when propoxy decomposes to propylene. This $\mathrm{H}$ desorbs as $\mathrm{H}_{2}$ and does not react with the substrate to produce $\mathrm{H}_{2} \mathrm{O}$. This exemplifies the complex nature of this dehydration reaction as described above. Water is produced at $225 \mathrm{~K}$ from a reaction between the $\mathrm{H}$ in the alcohol and $\mathrm{O}$ in the substrate. The lattice $\mathrm{O}$ is replenished by the propoxy when it decomposes at $585 \mathrm{~K}$. The net reaction is still predominantly dehydration. Because the Obalance between the reactant and products is effectively equal, 2-propanol is a poor reductant for $\mathrm{CeO}_{2}(111)$.

Propylene is still the dominant product on $\mathrm{CeO}_{2}(100)$ but a significant amount of acetone and 2-propanol are produced at $550 \mathrm{~K}$ as well.[205] As with methanol, the reaction behavior of 2-propanol indicates that $\mathrm{CeO}_{2}(100)$ exhibits basic properties as well as redox character. Unlike methanol the decomposition of the propoxy intermediate leads exclusively to $\mathrm{H}_{2} \mathrm{O}$ with no $\mathrm{H}_{2}$ produced. In this case the surface is not O-starved since the propoxy can supply the $O$. We can surmise that the water that is produced between $200 \mathrm{~K}$ and $500 \mathrm{~K}$ results from a reaction between hydroxyls on the surface as in water and methanol, while the water produced near 585 $\mathrm{K}$ incorporates the $\mathrm{H}$ and $\mathrm{O}$ from the propoxy intermediate. $\mathrm{C}-\mathrm{C}$ bond cleavage is also indicated as both $\mathrm{CO}$ and $\mathrm{CO}_{2}$ are produced. 2-propanol acts as a reductant on $\mathrm{CeO}_{2}(100)$ since although propylene is produced, O-rich products such as water, acetone, $\mathrm{CO}$ and $\mathrm{CO}_{2}$ contain more $\mathrm{O}$ relative to $\mathrm{C}$ than the 2-propanol reactant.

Propylene is the only C-containing product, other than recombination to 2-propanol, following adsorption on reduced $\mathrm{CeO}_{2-x}(111)$ and $\mathrm{CeO}_{2-x}(100) \cdot[205,213]$ Here the substrate characteristics appear to differ from what was observed with methanol. The reaction of methanol indicated that reduction of the ceria appeared to make the surface more basic as the product distribution moved away from formaldehyde and toward CO. With 2-propanol the surface appears to be more acidic / redox as a) acetone is eliminated on $\mathrm{CeO}_{2-x}(100)$ and b) the propylene product is produced at lower temperature on $\mathrm{CeO}_{2-x}(111)$ than on $\mathrm{CeO}_{2}(111)$. The primary difference between methanol and 2-propanol is likely the ability to break the C-O bond in 2-propanol. The branching between the ketone and the olefin reflects a competition between 
cleaving the O-Ce bond and breaking the $\mathrm{O}-\mathrm{C}$ bond. On the reduced surfaces $\mathrm{O}-\mathrm{C}$ bond cleavage is clearly favored. In methanol C-O cleavage may occur by C-C coupling, methane formation or $\mathrm{CH}_{\mathrm{x}}$ radical ejection. No products from any of these pathways were detected from either $\mathrm{CeO}_{2-\mathrm{x}}(111)$ or $\mathrm{CeO}_{2-\mathrm{x}}(100)$, although these products have been observed from other oxide surfaces.[11] Interestingly, the $\mathrm{H}$ from the 2-propanol decomposition was again incorporated in $\mathrm{H}_{2}$ on $\mathrm{CeO}_{2-\mathrm{x}}(111)$ and $\mathrm{H}_{2} \mathrm{O}$ on $\mathrm{CeO}_{2-\mathrm{x}}(100)$. As a result 2-propanol acts as an oxidant on $\mathrm{CeO}_{2-x}(111)$ but has no effect on the oxidation state of $\mathrm{CeO}_{2-x}(100)$.

The adsorption and reaction of the $\mathrm{C}_{2}$-diol, ethylene glycol, was studied on oxidized and reduced $\mathrm{CeO}_{x}(111)$.[215] As with the mono-alcohols this diol reacts with the surface by cleaving an $\mathrm{O}-\mathrm{H}$ bond producing an alkoxy and a hydroxyl on the surface. $\mathrm{O}$ 1s photoemission indicated that at $190 \mathrm{~K}$ the molecule initially adsorbed through only one of the alcohol groups, i.e. alkoxy and alcohol were evident in the photoemission spectrum. Also in a manner similar to the monoalcohols, glycol recombination and water desorption occurred as the sample was heated to 250 K. O vacancies and adsorption sites that were created upon annealing enabled dissociation and adsorption of the alcohol at the other end of the molecule creating adsorbed ethylenedioxy, $\mathrm{OCH}_{2} \mathrm{CH}_{2} \mathrm{O}$-. On the oxidized $\mathrm{CeO}_{2}(111)$ surface this intermediate followed two reaction pathways; C-O bond cleavage and rearrangement resulting in acetaldehyde desorption, and C$\mathrm{C}$ bond cleavage to produce adsorbed formate. The formate ultimately decomposed to produce water and $\mathrm{CO}$. On reduced $\mathrm{CeO}_{2-\mathrm{x}}(111)$ the ethylenedioxy intermediate also underwent $\mathrm{C}-\mathrm{O}$ bond cleavage to produce acetaldehyde but also produced a stable enolate, $-\mathrm{O}-\mathrm{CH}=\mathrm{CH}_{2}$. This species underwent further $\mathrm{C}-\mathrm{O}$ bond cleavage to produce ethylene and acetylene in a manner similar to the adsorption and reaction of acetaldehyde on reduced $\mathrm{CeO}_{2-\mathrm{x}}(111)$ (see section 5.2.1.3).[216]

Ceria powders are known to selectively produce unsaturated alcohols from larger diols such as 1,3-propanediol and 1,3-butanediol.[217] This would result from the dehydration at one end of the diol leaving the alcohol at the other end intact. However, a computational analysis of the reaction of 1,3-butanediol on $\mathrm{CeO}_{x}(111)$ using density functional theory produced an entirely different reaction model compared to those discussed above.[218,219] In this model the $-\mathrm{OH}$ groups interact with the surface without dissociation while a $\mathrm{H}$ on the methylene in the 2-position was abstracted by the substrate. The reaction was completed by the cleavage of an $-\mathrm{OH}$ from the intermediate producing water and an unsaturated alcohol. To our knowledge this mechanism has not been substantiated by experimental observations.

\subsubsection{2 - Carboxylic Acids}


The adsorption and reaction of carboxylic acids has also been used as a probe of acid base properties on oxides.[6] As with the alcohols, the acids easily deprotonate to form carboxylate upon adsorption. Dehydration products are favored on acidic substrates while dehydrogenation occurs on basic substrates. The products for these two reaction pathways are very clear for formic acid where dehydration leads to $\mathrm{CO}$ plus water while dehydrogenation produces $\mathrm{CO}_{2}$ and $\mathrm{H}_{2}$. For acetic acid dehydration leads to ketene, $\mathrm{CH}_{2}=\mathrm{C}=\mathrm{O}$. Dehydrogenation leads to total decomposition products such as $\mathrm{CO}_{2}$ and $\mathrm{CO}$.

Formic acid adsorption and reaction has been studied on $\mathrm{CeO}_{2}(111)[62,71,75,78]$ and on $\mathrm{CeO}_{2}(100)$.[75] Formic acid formed a more stable adsorbed species on $\mathrm{CeO}_{2}(111)$ than methanol. This was ascribed to the increased acidity of formic acid compared to methanol. On the basis of C 1s XPS, C k-edge NEXAFS and vibrational spectroscopy it was determined that formic acid dissociated into formate and $\mathrm{H}$ depositing the proton on a surface $\mathrm{O}$ forming a hydroxyl. The splitting between the symmetric and asymmetric O-C-O stretching frequencies, $v_{\mathrm{s}}(\mathrm{OCO})$ and $v_{\mathrm{a}}(\mathrm{OCO})$, in the vibrational spectra of the adsorbed formate have been used to determine the nature of the formate adsorption site.[220-222] A small value for the splitting, e.g. less than $200 \mathrm{~cm}^{-1}$, was attributed to a bidentate configuration whereas a splitting significantly greater than $200 \mathrm{~cm}^{-1}$ was attributed to a monodentate configuration. The vibrational frequencies reported for formate on $\mathrm{CeO}_{2}(111)$ are in general agreement however the splitting between $v_{\mathrm{s}}(\mathrm{OCO})$ and $v_{\mathrm{a}}(\mathrm{OCO})$ fall into a "gray area" with values of $220 \mathrm{~cm}^{-1}$ [75], $217 \mathrm{~cm}^{-1}-$ $232 \mathrm{~cm}^{-1}$ [78] and $196 \mathrm{~cm}^{-1}-275 \mathrm{~cm}^{-1}$ [62]. Gordon et al noted that in addition to the adsorbate bonding geometry the splitting could also be influenced by co-adsorbed $\mathrm{H}$ and the detailed nature of the adsorption site. [78] On the basis of DFT calculations and surface selection rules, they argued that the formate adsorbed in a bidentate configuration.

The reaction products following formic acid adsorption on oxidized and reduced $\mathrm{CeO}_{X}(111)$ are shown in Figure 22 (a) and (c). [62] All of the studies that reported TPD results for formic acid on $\mathrm{CeO}_{2}(111)$ have qualitatively agreed; the principal product is $\mathrm{CO}$ along with $\mathrm{CO}_{2}$ and water with a small amount of formaldehyde.[62,71,75] Senanayake et al and Lykhach et al also reported desorption of $\mathrm{H}_{2}$ with the latter additionally observing methane. The details are quite different between the various studies, however. Stubenrauch et al reported that all of the products desorbed at nearly same temperature in a single symmetric peak near $610 \mathrm{~K}$. [75] Lykhach et al reported much more complex desorption spectra, as shown in Figure 22 (a), and a slightly lower nominal decomposition temperature. [62] The desorption spectra reported by Senanayake and Mullins clearly divided the decomposition into two regions; $\mathrm{CO}_{2}$ and $\mathrm{H}_{2}$ near $350 \mathrm{~K}$ and $\mathrm{CO}$ above $400 \mathrm{~K}$. [71] In addition, they noted a water desorption peak near $300 \mathrm{~K}$ as 
did Lykhach et al. By using isotopically labeled $\mathrm{Ce}^{18} \mathrm{O}_{2}(111)$ Senanayake and Mullins determined that the water at $300 \mathrm{~K}$ resulted from the disproportionation of surface hydroxyls. When methanol is adsorbed on $\mathrm{CeO}_{2}(111)$ this reaction occurs near $220 \mathrm{~K}$.[208] On the basis of DFT calculations Gordon et al determined that $-\mathrm{OH}$ is stabilized when located near co-adsorbed formate on $\mathrm{CeO}_{2}(111)$. [78]

On reduced $\mathrm{CeO}_{2-\mathrm{x}}(111)$ the decomposition of formate results in more $\mathrm{CO}$ and $\mathrm{H}_{2}$ and a significant decrease in $\mathrm{CO}_{2}$ (Figure $22(\mathrm{c})$ ). [62,71] As with methanol, this indicates that reduced $\mathrm{CeO}_{2-\mathrm{x}}(111)$ is more basic than oxidized $\mathrm{CeO}_{2}(111)$, and that the reduced surface competes with the desorption products for $O$.

Stubenrauch et al determined that formic acid behaved largely the same on $\mathrm{CeO}_{2}(100)$ compared to $\mathrm{CeO}_{2}(111)$. The $\mathrm{CO} / \mathrm{CO}_{2}$ product ratio was slightly greater on $\mathrm{CeO}_{2}(100)$ as was the formate decomposition temperature.

Acetic acid also dissociates and adsorbs as acetate and hydroxyl on $\mathrm{CeO}_{2}(111)$ and $\mathrm{CeO}_{2}(100)$, [75] [205] and the carboxylate coverage is similar to what was obtained from formic acid. The TPD from acetic acid on oxidized and reduced $\mathrm{CeO}_{X}(111)$ and $\mathrm{CeO}_{X}(100)$ is shown in Figure $23(\mathrm{~A})$ and $(\mathrm{B})$, respectively. On $\mathrm{CeO}_{2}(111)$ (Figure $23(\mathrm{~A})$, black lines) the primary reaction products are ketene, water, $\mathrm{CO}$ and $\mathrm{CO}_{2}$. This result is very consistent with what was reported by Stubenrauch et al on $\mathrm{CeO}_{2}(111)$ [75] and indicates a mixture of dehydration / acidic and dehydrogenation / basic behavior. The water desorption peak near $300 \mathrm{~K}$ is similar to what was observed with formic acid and suggests stabilization of the surface $-\mathrm{OH}$ by the coadsorbed acetate. In addition to these principal products there are several minor products such as acetone, acetylene and the recombination of $-\mathrm{OH}$ plus acetate to produce acetic acid at ca. $500 \mathrm{~K}$. Acetone is the result of the ketonization reaction which in addition to acetone produces $\mathrm{CO}_{2}$ plus water. It has been suggested that this reaction requires two acetates bound to the same metal cation.[6] Presumably this can only occur at defect sites on fully oxidized $\mathrm{CeO}_{2}(111)$ which may explain why it is only a minor product.

On $\mathrm{CeO}_{2}(100)$ (Figure 23(A), blue lines) the ketene production is dramatically decreased while the $\mathrm{CO}_{2}$ formation is increased compared to $\mathrm{CeO}_{2}(111)$. This is consistent with what was observed for 2-propanol where the dehydration pathway is less favored on the (100) surface. Stubenrauch et al also studied acetic acid on $\mathrm{CeO}_{2}(100)$ and reported very different results.[75] They found that ketene formation was essentially the same as on $\mathrm{CeO}_{2}(111)$ except for an increase in desorption temperature. They also report that formic acid produced a higher $\mathrm{CO} /$ $\mathrm{CO}_{2}$ product ratio on $\mathrm{CeO}_{2}(100)$ than on $\mathrm{CeO}_{2}(111)$, indicating that the $\mathrm{CeO}_{2}(100)$ surface is less basic than $\mathrm{CeO}_{2}(111)$. 
Reduction of the ceria surfaces has a dramatic effect as shown in Figure 23(B). The intensity of the C-containing products is greatly diminished with only small amounts of $\mathrm{CO}, \mathrm{CO}_{2}$, ketene and acetylene evident. Note that although reduction presumably increases the number of multiply-under-coordinated cation sites on both surfaces, acetone formation is largely eliminated. This is because re-oxidation of the reduced ceria inhibits competing reaction pathways where the products contain $\mathrm{O}$.

XPS indicates that more than $50 \%$ of the $C$ from the acetic acid is left on the surface as graphitic-like $\mathrm{C}$ after TPD to $800 \mathrm{~K}$. This is perhaps surprising since the $\mathrm{O}$ content in the acetic acid is higher than that in ethanol or 2-propanol which react cleanly on the reduced surfaces. Acetic acid produces very stable surface species that remain on the surface until they dehydrogenate to produce $\mathrm{H}_{2}$ and $\mathrm{H}_{2} \mathrm{O}$ on $\mathrm{CeO}_{2-x}(111)$ and $\mathrm{CeO}_{2-x}(100)$, respectively and deoxygenate to re-oxidized the substrate. This leaves the remaining $C$ fragments few options to desorb as stable products.

\subsubsection{3 - Aldehydes, Ketones and Ethers}

Aldehydes, ketones and ethers represent a different class of adsorbates compared to alcohols and carboxylic acids. They cannot deprotonate and attach to acid-base sites on the surface as a Brønsted acid as is the case with alcohols and carboxylic acids. They can act as a Lewis base with the lone-pair electrons on the $O$ interacting with cationic Lewis acid sites or they can break a $\mathrm{C}-\mathrm{O}$ bond so that the $\mathrm{C}$ can react with a surface $\mathrm{O}$. The interaction of formaldehyde,[223] acetaldehyde[216], acetone,[224], dimethylether and diethylether[225] with stoichiometric $\mathrm{CeO}_{2}(111)$ is weak. The parent molecules desorb molecularly between $200 \mathrm{~K}$ and $225 \mathrm{~K}$. The TPD for acetaldehyde on $\mathrm{CeO}_{2}(111)$ is shown by the black lines in Figure 24 .

Acetaldehyde adsorption on $\mathrm{CeO}_{2}(100)$ is much stronger than on $\mathrm{CeO}_{2}(111)$.[61] The acetaldehyde desorption extends from $200 \mathrm{~K}$ to above $400 \mathrm{~K}$. In addition to the parent molecule, above $400 \mathrm{~K}$ additional products are observed. Total decomposition to $\mathrm{CO}, \mathrm{CO}_{2}$ and $\mathrm{H}_{2} \mathrm{O}$ is the principal pathway with a small amount of dehydration to produce acetylene at $700 \mathrm{~K}$. In addition a notable product is the small amount of crotonaldehyde that is evident at $430 \mathrm{~K}$. This is the result of the aldol condensation coupling reaction between two acetaldehyde molecules.[6] The adsorption and reaction on $\mathrm{CeO}_{2}(100)$ is consistent with trends previously observed for the other oxygenates. Specifically, stronger adsorption results from a greater number of coordination vacancies around the $\mathrm{Ce}$ cation on $\mathrm{CeO}_{2}(100)$ compared to $\mathrm{CeO}_{2}(111)$. The $\mathrm{CO}$ and $\mathrm{CO}_{2}$ products result from dehydrogenation of the adsorbed acetaldehyde by the basic $\mathrm{O}$ 
anions. The water desorption results from the relative ease with which the $\mathrm{H}$ reacts with the surface $\mathrm{O}$.

Introduction of surface vacancies in reduced $\mathrm{CeO}_{2-x}(111)$ has a dramatic effect on the adsorption and reaction of formaldehyde,[223] acetaldehyde[216] and acetone[224]. These carbonyl-containing molecules now adsorb strongly on the $\mathrm{CeO}_{2-\mathrm{x}}(111)$ surface. In addition to to desorbing non-dissociatively, formaldehyde decomposes into $\mathrm{CO}$ and $\mathrm{H}_{2}$. As dioxymethylene (see below) is heated on reduced $\mathrm{CeO}_{2-\mathrm{x}}(111)$ it disproportionates into methoxy and formate. [223] These surface species then go on to react in the same manner as if they had been formed from methanol[208] and formic acid.[71] They decompose into formaldehyde, $\mathrm{CO}$ and $\mathrm{H}_{2}$.

Acetaldehyde produces ethylene, acetylene and $\mathrm{H}_{2}$ on $\mathrm{CeO}_{2-x}(111)$ (Figure 24, blue lines). The desorption of the parent molecule also changes. The low temperature desorption near $220 \mathrm{~K}$ is suppressed and two new peaks appear near $400 \mathrm{~K}$ and between $500 \mathrm{~K}$ and 650 $\mathrm{K}$.216] In a similar manner, acetone desorbs as molecular acetone near $500 \mathrm{~K}$ and also decomposes into propyne, $\mathrm{H}_{2}$ and CO.[224]

Acetaldehyde adsorbed on reduced $\mathrm{CeO}_{2-x}(100)$ desorbs from $200 \mathrm{~K}$ to $600 \mathrm{~K}$ with no significant new peaks as on $\mathrm{CeO}_{2-\mathrm{x}}(111)$.[61] $\mathrm{CO}, \mathrm{CO}_{2}$ and crotonaldehyde formation are eliminated and $\mathrm{H}_{2}$ desorption replaces $\mathrm{H}_{2} \mathrm{O}$. Ethylene is produced at about the same temperature as on $\mathrm{CeO}_{2-\mathrm{x}}(111)$. XPS indicates that almost $40 \%$ of the $\mathrm{C}$ in the adsorbed acetaldehyde remains on the $\mathrm{CeO}_{2-x}(100)$ surface as graphitic-like $\mathrm{C}$ at $800 \mathrm{~K}$.

The adsorption states and reactions pathways for these carbonyl-containing molecules on ceria surfaces are complex. As shown below for acetone, the molecule can adsorb nondissociatively on oxide surfaces either through the $O$ lone as an $\eta^{1}$ - monoxy species (a) or react with a surface $O$ to create an $\eta^{2}$ - dioxy species (b).[226]

(a)<smiles></smiles>

(b)<smiles>CC(C)(O[Ge])O[Ge]</smiles>

These two species are indistinguishable in C 1s XPS.[216,223,224] However they can be differentiated in C k-edge NEXAFS based on the presence or absence of the $C=O \pi^{*}$ resonance. It was determined that formaldehyde adsorbs on oxidized $\mathrm{CeO}_{2}(111)$ as $\eta^{2}-$ dioxymethylene due to the absence of the $\mathrm{C}=\mathrm{O} \pi^{*}$ resonance. [223] DFT calculations found a similar result.[227] However, acetaldehyde and acetone both adsorbed in the $\eta^{1}$ - monoxy 
configuration. [216,224] Vibrational spectroscopy and DFT calculations confirmed this result for acetaldehyde.[77] On reduced $\mathrm{CeO}_{2-x}(111)$ these compounds all adsorb as $\eta^{2}$ - dioxys.

In addition to the inability to differentiate between the $\eta^{1}$ - carbonyl species and the $\eta^{2}-$ dioxy species in the $C$ 1s spectra, it was observed that the carbonyl compounds were sensitive to $\mathrm{x}$-ray induced dissociation whereby $\mathrm{H}$ was ejected and surface carboxylates were produced. Therefore, when using XPS to analyze carbonyl-containing oxygenates on ceria surfaces care must be exercised to limit $x$-ray exposure. Possible $x$-ray damage must tested by varying $x$-ray exposure and analyzing various sample positions.[216,223,224]

The reaction pathway for acetaldehyde and acetone on reduced $\mathrm{CeO}_{2-\mathrm{x}}(111)$ is different from that of formaldehyde. These molecules dehydrogenate to form an enolate as shown below for acetaldehyde.

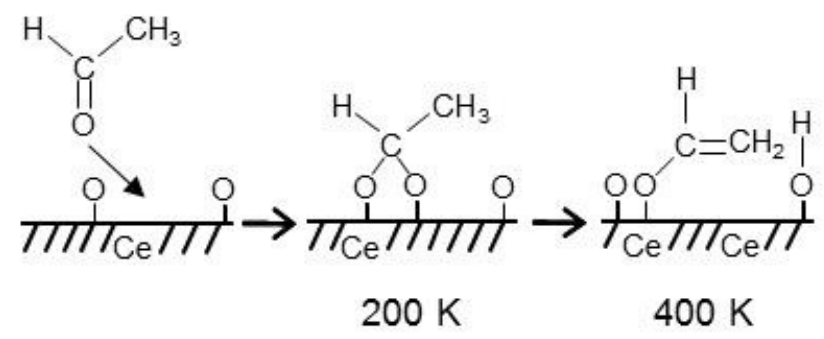

Figure 25 shows two spectroscopic pieces of evidence for this transformation. In the $\mathrm{C}$ 1s XPS there is a shift from a binding energy indicative of two C-O bonds, i.e. carbonyl or dioxy, to a position indicative of a single $\mathrm{C}-\mathrm{O}$ bond, i.e. alkoxy. The peak at $284.8 \mathrm{eV}$ in the $\mathrm{C}$ k-edge NEXAFS spectrum at $450 \mathrm{~K}$ is indicative of a $\mathrm{C}=\mathrm{C}$ double bond. Note that the peaks at $284.8 \mathrm{eV}$ and $286.5 \mathrm{eV}$ are both related to the $\mathrm{C}=\mathrm{C}$ bond. The peak at lower photon energy is at the $=\mathrm{CH}_{2}$ end while the peak at higher photon energy is at the $\mathrm{OCH}=$ end.[228] FTIR and DFT calculations confirm this result.[77] The enolate is also formed on oxidized and reduced $\mathrm{CeO}_{x}(100)$.[61] On reduced $\mathrm{CeO}_{2-\mathrm{x}}(111)$ re-hydrogenation of the enolate above $400 \mathrm{~K}$ leads to acetaldehyde desorption. C-O bond cleavage along with hydrogenation at the carbonyl C produces ethylene while additional dehydrogenation leads to acetylene. On $\mathrm{CeO}_{x}(100)$ further dehydrogenation and $\mathrm{C}-\mathrm{C}$ bond cleavage also occurs leading to $\mathrm{CO}, \mathrm{CO}_{2}$ and $\mathrm{C}$ deposited on the surface.

Vibrational spectroscopy and DFT calculations have shed additional light on the first acetaldehyde desorption peak near $400 \mathrm{~K}$ on $\mathrm{CeO}_{2-x}(111)$ (Figure 24, blue line). [77] This desorption feature results from the decomposition of a dimer formed from the coupling of the carbonyl $\mathrm{O}$ and the acyl $\mathrm{C}$ of two acetaldehyde molecules. 
As noted at the beginning of this section, dimethyl ether and diethyl ether interact weakly and do not decompose on either oxidized or reduced $\mathrm{CeO}_{x}(111)$.[225] Co-adsorption of diethyl ether with $-\mathrm{OH}$ on reduced $\mathrm{CeO}_{2-x}(111)$ resulted in decomposition of the ether into ethoxy and formate. A similar decomposition did not occur for dimethyl ether suggesting that dissociation of the $\mathrm{C}-\mathrm{O}$ bond requires the presence of $\beta$-hydrogen.

\subsection{2 - Other organic molecules}

\subsubsection{1 - Methanethiol}

Methanethiol, $\mathrm{CH}_{3} \mathrm{SH}$, is the S-containing analog of methanol, $\mathrm{CH}_{3} \mathrm{OH}$. The $\mathrm{C}$ and $\mathrm{S}$ coverage at $150 \mathrm{~K}$ on oxidized $\mathrm{CeO}_{2}(111)$ is similar to the $\mathrm{C}$ and adsorbate $\mathrm{O}$ coverage following methanol exposure.[229] However, whereas methanol almost totally decomposes into methoxy and $-\mathrm{OH}$ below $200 \mathrm{~K}$, only $40 \%$ of the thiol decomposes into $\mathrm{CH}_{3} \mathrm{~S}$ - plus $-\mathrm{OH}$. More than $90 \%$ of the chemisorbed thiol desorbs molecularly below $300 \mathrm{~K}$. The remainder produces a small amount of methane leaving $S$ on the surface. This decomposition of the thiol was attributed to reaction at step sites and defects.

Adsorption of methanethiol on reduced $\mathrm{CeO}_{1.75}(111)$ was more similar to methanol compared to the fully oxidized surface in that it dissociated almost exclusively into $\mathrm{CH}_{3} \mathrm{~S}$ - plus $\mathrm{OH}$ below $200 \mathrm{~K}$. The thiolate and hydroxyl were relatively stable with only a small amount of recombination to produce methanethiol below $300 \mathrm{~K}$. The major reaction product was methane at $600 \mathrm{~K}$ along with small amounts of $\mathrm{CH}_{3} \mathrm{SH}, \mathrm{CH}_{2} \mathrm{O}$ and $\mathrm{H}_{2} \mathrm{O}$. Unlike the decomposition of $\mathrm{CH}_{3} \mathrm{OH}$ on reduced $\mathrm{CeO}_{2-x}(111), \mathrm{H}_{2}$ was largely absent from the products. As with the reaction of $\mathrm{H}_{2} \mathrm{~S}[200]$ and $\mathrm{SO}_{2}[191]$ on reduced $\mathrm{CeO}_{2-x}(111)$, the decomposition of methanethiol left a considerable amount of $S$ on the surface. This sulfur diffused into the bulk above $800 \mathrm{~K}$ rather than desorbing in S-containing products.

\subsubsection{3 - Dimethyl methylphosphonate}

Dimethyl methylphosphonate (DMMP, $\left.\left(\mathrm{CH}_{3} \mathrm{O}\right)_{2} \mathrm{PO}\left(\mathrm{CH}_{3}\right)\right)$ is frequently used as a simulant molecule for organophosphorous nerve agents because DMMP is nontoxic but has structural similarities to the nerve agents. DMMP readily adsorbs and reacts on oxidized and reduced $\mathrm{CeO}_{X}(111)$. The reaction pathway has been determined through a combination of TPD, sXPS and FTIR.[230] As shown in Figure 26, DMMP initially adsorbs at $200 \mathrm{~K}$ through the lone pair electrons on the $O$ in a manner similar to acetaldehyde and acetone. As the sample is heated a $\mathrm{P}-\mathrm{O}$ bond is cleaved to one of the methoxy groups forming methoxy methylphosphonate (MMP) 
and methoxy on the surface. The bonding of the MMP intermediate appears to be more analogous to a carboxylate than it does to an $\eta^{2}$ - dioxy. As the methoxy species decompose the reaction products resemble those from methanol adsorption on $\mathrm{CeO}_{2}(111)$ [208] with $\mathrm{CH}_{3} \mathrm{OH}$ and $\mathrm{CH}_{2} \mathrm{O}$ desorbing between $400 \mathrm{~K}$ and $500 \mathrm{~K}$. The other methoxy group eventually cleaves from the MMP and reacts on the surface leaving methylphosphonate (MP). The C-P bond is tenacious and doesn't break until above $700 \mathrm{~K}$ where it also reacts with the surface to produce formaldehyde and water. The formation of $\mathrm{CH}_{3} \mathrm{OH}, \mathrm{CH}_{2} \mathrm{O}$ and $\mathrm{H}_{2} \mathrm{O}$ results in the reduction of the ceria. $\mathrm{PO}_{\mathrm{X}}$ species remain on the surface even up to $900 \mathrm{~K}$ and decrease the ability of the $\mathrm{CeO}_{X}(111)$ surface to react with DMMP in subsequent adsorption / reaction cycles. However, some activity remains even up to seven adsorption cycles.

The adsorption and reaction of DMMP on reduced $\mathrm{CeO}_{2-\mathrm{x}}(111)$ follows a similar pathway with progressive cleavage of methoxy groups and eventual cleavage of the methyl group. As with methanol, reduced $\mathrm{CeO}_{2-x}(111)$ shifts the reaction products toward $\mathrm{CO}$ and $\mathrm{H}_{2}$ formation as the surface becomes more effective at dehydrogenating the adsorbed species.

\section{6 - Metal particles supported on ceria surfaces}

This section will first consider the structure of metal particles on ceria surfaces. To date the only experimental studies have been conducted on $\mathrm{CeO}_{2}(111)$ surfaces although there have been some computational studies on other surfaces.

This section will then be followed by a discussion of the reactions of various molecules on these metal loaded surfaces. As in Section 5 the discussion will be divided by different molecules or classes of molecules rather than by the type of metal.

\section{1 - Structure of metals on ceria surfaces}

Metal atoms and clusters display both relatively weak interactions with ceria surfaces but also strong interactions in some cases; up to and including the formation of mixed metal oxides with the ceria substrate. Figures 27 and 28 show examples of weak and strong interactions, respectively. Figure 27 shows an STM image of Au deposited on $\mathrm{CeO}_{2}(111)$ at 300 K.[231] The $\mathrm{Au}$ particles nucleate at step edges and defect sites on the oxidized surface. Alternatively in Figure $28 \mathrm{Ni}$ clusters are shown decorating the $\mathrm{CeO}_{2}(111)$ terraces with no significant preference for the step edges.[232] $\mathrm{Ag}[233,234], \mathrm{Au}[37,235]$ and $\mathrm{Rh}[34]$ have been reported to adsorb primarily at step edges and defects. It was noted that $\mathrm{Rh}$ decorates the edges at low coverages but populates the terraces more uniformly at high coverages. Au adsorbs on the terraces, with no preference for edges and defects, when deposited at $10 \mathrm{~K} .[236] \mathrm{Ni}[232,237]$ 
and $\mathrm{Pt}[238]$ cover the $\mathrm{CeO}_{2}(111)$ terraces uniformly. Zhou et al reported that Pd had a partial preference for decorating step edges on fully oxidized $\mathrm{CeO}_{2}(111)[34,173]$ whereas Wilson and co-workers indicated that $\mathrm{Pd}$ nanoparticles uniformly covered the terraces on partially reduced $\mathrm{CeO}_{2-\mathrm{x}}(111)$.[239] Finally, Al[240], Ga[241], Mg[181], Sn[55], Ti[242], V[243] and W[244] are all either heavily oxidized by the $O$ in the ceria or formed mixed metal oxides with the ceria substrate.

There have been more DFT calculations reporting the adsorption of metals on $\mathrm{CeO}_{2}(111)$ and $\mathrm{CeO}_{2}(110)$ than there have been experimental observations. Adsorption sites, energies and charge transfer behavior have been reported for $\mathrm{Ag}$ [233,245-247], $\mathrm{Au}$ [245-253], $\mathrm{Cu}[245-247,254-256], \mathrm{Ni}[254], \operatorname{Pd}[239,257-259], \operatorname{Pt}[258,260-262]$ and $\operatorname{Rh}[258,259,263]$. The adsorption of single metal atoms has generally found an affinity between the admetal and surface $\mathrm{O}$ with a preference for adsorption in the $\mathrm{CeO}_{2}(111)$ or $\mathrm{CeO}_{2}(110) \mathrm{O}-\mathrm{O}$ bridge site, and occasionally the $\mathrm{O}$ three-fold hollow site on $\mathrm{CeO}_{2}(111)$ or the $\mathrm{O}$ a-top site. Adsorption in a hollow site above a second layer Ce cation has been energetically unfavorable. In a few cases clusters of metal atoms have been studied. In most cases the clusters form three dimensional structures that maximize the metal-metal bonds. The trend is that while metal to surface interactions are favorable, metal-metal interactions are more energetically stable. This was demonstrated in the microcalorimetry work of Farmer et al where they observed that the heat of adsorption for $\mathrm{Ag}$ on $\mathrm{CeO}_{2-\mathrm{x}}(111)$ was initially near $200 \mathrm{~kJ} / \mathrm{mole}$ and grew to $285 \mathrm{~kJ} / \mathrm{mole}$ at high coverage.[234] They noted, however, that the initial heat of adsorption for $\mathrm{Ag}$ on $\mathrm{CeO}_{2-\mathrm{x}}(111)$ was greater than that for $\mathrm{Ag}$ on $\mathrm{MgO}(100)[264,265]$ indicating a stronger metal-surface interaction.

In general, calculations have determined that there is an electron transfer from the adsorbed metal atoms/particles to the ceria surface resulting in a small positive charge on the admetal and a reduction of the $\mathrm{Ce}^{4+}$ cations. Experimentally reduction of the $\mathrm{Ce}$ has been reported in the $\mathrm{Ce} 3 \mathrm{~d}$, Ce $4 \mathrm{~d}$ and $\mathrm{Ce} 4 \mathrm{f}$ photoemission following metal adsorption.[54,233235,237-239,260,266-270]. Despite an indication of a reduction of the Ce, oxidation of the admetal has generally not been observed except in cases of $O$ transfer from the substrate to the admetal or where mixed metal oxide formation occurs between the admetal and the ceria. Small positive binding energy shifts relative to the bulk metal peak position have been attributed to final state effects associated with small metal particles.[271]

Strong metal-support interaction (SMSI), i.e. encapsulation of the metal nanoparticle by the ceria substrate, was reported for $\mathrm{Pt}$ on reduced $\mathrm{CeO}_{2-\mathrm{x}}(111)$.[172] This occurred when $\mathrm{Pt}$ on reduced $\mathrm{CeO}_{2-\mathrm{x}}(111)$ was annealed to $900 \mathrm{~K}$ in vacuum as indicated by a decrease in the $\mathrm{Pt} 4 \mathrm{f}$ 
XPS intensity and poisoning of subsequent CO adsorption due to the encapsulation. The SMSI effect was reversed following oxidation at $600 \mathrm{~K}$.

\section{2 - Adsorption / Reaction on metals supported on ceria surfaces}

\section{$6.2 .1-\mathrm{CO}$}

Two aspects of the interaction of $\mathrm{CO}$ with metals supported on cerium oxides surfaces have been studied; the standard UHV adsorption/desorption phenomena as measured by XPS, vibrational spectroscopy and TPD, and reaction behavior, specifically CO oxidation and the water-gas shift reaction. The WGS reaction will be considered in Section 6.2.3.

On fully oxidized $\mathrm{CeO}_{2}$ the adsorption and desorption of $\mathrm{CO}$ largely resembles what has been observed on pure, unsupported metals or metals supported on less reactive oxide substrates such as $\mathrm{SiO}_{2}$ or $\mathrm{Al}_{2} \mathrm{O}_{3}$, i.e. the ceria substrate has little effect on the adsorption/desorption of $\mathrm{CO}$. This is true on $\mathrm{Au}[272], \operatorname{Pd}[173,272-274], \operatorname{Pt}[121,172,275]$ and $\mathrm{Rh}[76,170,171,276-279]$. One major difference for some of these metals supported on $\mathrm{CeO}_{2}$ compared to the unsupported metals is the production of $\mathrm{CO}_{2}$ during TPD from Pt[172,275] and $\mathrm{Rh}[170,171,276-278]$. The $\mathrm{CO}_{2}$ was produced by $\mathrm{CO}$ reacting with $\mathrm{O}$ from the ceria. Isotopic labeling also indicated that in some cases the $\mathrm{CO}$ adsorbed on the metal particles exchanged $\mathrm{O}$ with the ceria substrate without necessarily reacting to form $\mathrm{CO}_{2} \cdot[171-173]$ The $\mathrm{CO}_{2}$ formation was face-specific. $\mathrm{Rh}$ on $\mathrm{CeO}_{2}(111)$ produced $\mathrm{CO}_{2}$ whereas $\mathrm{Rh}$ on $\mathrm{CeO}_{2}(100)$ did not.[171] Further, the ability of the ceria substrate to donate $\mathrm{O}$ to the $\mathrm{CO}$ was inhibited by annealing the ceria to elevated temperatures.[277,278]

The participation of the $\mathrm{O}$ from the ceria substrate was also demonstrated in $\mathrm{CO}$ oxidation reactions on $\mathrm{Pd}[280,281]$, $\mathrm{Pt}[280,282]$ and $\mathrm{Rh}[276,277]$. On pure metal surfaces the $\mathrm{CO}$ oxidation rate is inversely related to the $\mathrm{CO}$ pressure as $\mathrm{CO}$ adsorption poisons the $\mathrm{O}$ adsorption sites on the metal. In the presence of the ceria substrate however, a second $\mathrm{CO}$ mechanism is evident where the rate is zero-order in $\mathrm{CO}$ pressure. This is attributed to $\mathrm{CO}$ reacting with $\mathrm{O}$ in the substrate. $\mathrm{CO}$ oxidation on $\mathrm{Au}$ nanoclusters on $\mathrm{CeO}_{2}(111)$ has also been examined by DFT. On fully oxidized stepped- $\mathrm{CeO}_{2}(111) \mathrm{Kim}$ and Henkelman determined that $\mathrm{O}$ in the ceria at the step edges reacted favorably with $\mathrm{CO}$ adsorbed on the Au.[283] The same authors also studied $\mathrm{CO}$ oxidation over $\mathrm{Au}$ on partially reduced $\mathrm{CeO}_{2-x}(111)$.[284] In that study they determined that $\mathrm{O}_{2}$ adsorbed at the interface between the $\mathrm{Au}$ nanoparticle and an $\mathrm{O}$ vacancy in the ceria led to a favorable pathway for oxidiation.

A dramatic effect was observed when $\mathrm{CO}$ was adsorbed on $\mathrm{Rh}$ supported on reduced $\mathrm{CeO}_{2-\mathrm{x}}(111)$. The $\mathrm{CO}$ dissociated into $\mathrm{C}$ and $\mathrm{O}$. As shown in Figure 29 a new, high temperature 
$\mathrm{CO}$ desorption state appears in the TPD of $\mathrm{CO} / \mathrm{Rh} / \mathrm{CeO}_{2-x}(111)$.[76] The isotopic labeling indicates that the high temperature $\mathrm{CO}$ state contained $\mathrm{O}$ obtained from the $\mathrm{CeO}_{2-x}(111)$ substrate. The $\mathrm{C} 1 \mathrm{~s}$ core level sXPS, Figure 30 , shows that the $\mathrm{CO}$ decomposes between $300 \mathrm{~K}$ and $500 \mathrm{~K}$ on $\mathrm{Rh} / \mathrm{CeO}_{2-\mathrm{x}}(111)$.[279] $\mathrm{CO}$ decomposition has also been observed on highly stepped vicinal $R h(331), R h(755)[285]$ and $R h(210)[286]$ and on $R h$ particles on thin film $\mathrm{Al}_{2} \mathrm{O}_{3}$.[287,288] In those cases the decomposition was related to the $\mathrm{Rh}$ structure and was promoted at under-coordinated edge sites. For $\mathrm{Rh}$ on reduced $\mathrm{CeO}_{2-x}(111)$ the degree of decomposition was not related to the Rh coverage or particle size but was directly correlated to the degree of ceria reduction.[279] The most likely explanation is that the CO dissociation is activated at the Rh-ceria interface and is related to O-vacancies in the ceria.

Small amounts of $\mathrm{CO}$ dissociation were also observed on $\mathrm{Pd}[173]$ and $\mathrm{Pt}[172]$ on reduced $\mathrm{CeO}_{2-x}(111)$ but the degree of dissociation was less than $10 \%$. Other types of metalsupport interactions were evident for $\mathrm{CO}$ adsorbed on $\mathrm{Pt} / \mathrm{CeO}_{2-\mathrm{x}}(111)$.[172] As noted above, when $\mathrm{Pt} / \mathrm{CeO}_{2-\mathrm{x}}(111)$ was annealed above $900 \mathrm{~K}$ the $\mathrm{Pt}$ became encapsulated by the ceria and all $\mathrm{CO}$ adsorption was suppressed. On $\mathrm{Pt} / \mathrm{CeO}_{2-\mathrm{x}}(111)$ samples that were not annealed to high temperatures there were low temperature $\mathrm{CO}$ desorption states observed between $180 \mathrm{~K}$ and $220 \mathrm{~K}$. A possible explanation is that the $\mathrm{CO}$ is adsorbed as a carbonyl on very small $\mathrm{Pt}$ particles. Low temperature $\mathrm{CO}$ desorption was also observed from small $\mathrm{Pd}$ particles on $\mathrm{Al}_{2} \mathrm{O}_{3}$.[289] This low temperature $\mathrm{CO}$ desorption was attributed to the decomposition of $\mathrm{Pd}$ carbonyl species. Low temperature $\mathrm{CO}$ desorption also occurred when $\mathrm{CO}$ was co-adsorbed with $\mathrm{O}_{2}$ on $\mathrm{Rh} / \mathrm{CeO}_{2}(111)$.[290] It was proposed the $\mathrm{CO}+\mathrm{O}$ dispersed the Rh clusters and produced Rh - gem-dicarbonyl species on the surface. An alternative explanation for the low temperature desorption of $\mathrm{CO}$ on $\mathrm{Pt} / \mathrm{CeO}_{2-x}(111)$ is electron transfer from $\mathrm{Ce}^{3+}$ to the $\mathrm{Pt}$. It has been shown on $\mathrm{Pt} / \mathrm{TiO}_{2}$ that dopants in the titania can weaken the CO-Pt adsorption strength through electron transfer to the Pt.[291]

\section{$6.2 .2-N O$}

$\mathrm{NO}$ adsorption and decomposition was studied on $\mathrm{Pd}$, $\mathrm{Pt}$ and $\mathrm{Rh}$ on $\mathrm{CeO}_{2}$ surfaces. In the absence of an oxide support NO has been shown to adsorb both molecularly and dissociatively on all three metals. However the degree of dissociation, and hence the propensity to recombine and desorb as $\mathrm{N}_{2}$, has been found to be highly structure sensitive. NO produces little or no $\mathrm{N}_{2}$ on the low index $\operatorname{Pd}(111), \operatorname{Pd}(100)$ and $\mathrm{Pd}(110)$ surfaces.[292,293] NO adsorption on the more highly stepped $\mathrm{Pd}(311)$ produces considerable $\mathrm{N}_{2}$ however.[293] NO produces no $\mathrm{N}_{2}$ on $\mathrm{Pt}(111)$, a small amount on $\mathrm{Pt}(110)$ and nearly $50 \%$ of the adsorbed $\mathrm{NO}$ produces $\mathrm{N}_{2}$ on 
Pt(100).[294] On Pt(410) over $90 \%$ of the NO decomposes. NO on Rh is somewhat more complex in that all faces of $\mathrm{Rh}$ are highly active for NO decomposition. However, the temperature at which $\mathrm{NO}$ decomposes is lower on $\mathrm{Rh}(100)$ than on $\mathrm{Rh}(111)$.[295] The dissociation of $\mathrm{NO}$ on Rh surfaces is self-poisoning. The degree of dissociation decreases as the NO coverage increases. Multiple sites are necessary for NO decomposition and these can be blocked by other NO molecules or by decomposition products.

NO decomposition was studied on $\mathrm{Pd}[147]$ and $\mathrm{Pt}[121]$ supported on amorphous $\mathrm{CeO}_{2}$ films. $\mathrm{NO}$ on $\mathrm{Pd} / \mathrm{CeO}_{2}$ produced predominantly $\mathrm{N}_{2}$. The authors compared this to $\mathrm{Pd} / \mathrm{Al}_{2} \mathrm{O}_{3}$ where the $\mathrm{NO}$ mostly desorbed molecularly. The differences in behavior between $\mathrm{Pd} / \mathrm{CeO}$ and $\mathrm{Pd} / \mathrm{Al}_{2} \mathrm{O}_{3}$ are not entirely clear however the results on $\mathrm{Pd}$ single crystals suggests that there may be a morphological difference between the Pd particles on the two oxide surfaces. If the ceria was reduced prior to NO adsorption the resulting TPD spectrum was qualitatively similar to that which results from $\mathrm{Pd}$ on oxidized ceria with respect to desorption temperatures and product distribution. However the overall intensity increased suggesting that the NO adsorbed on the reduced ceria as well as on the Pd but ultimately reacted on the $\mathrm{Pd}$. $\mathrm{NO}$ adsorption on $\mathrm{Pt} / \mathrm{CeO}_{2}$ resulted in predominantly $\mathrm{N}_{2}$ desorption.[121] Unlike $\mathrm{Pd}$, the results for $\mathrm{Pt} / \mathrm{CeO}_{2}$ were similar to those for $\mathrm{Pt} / \mathrm{Al}_{2} \mathrm{O}_{3}$.[296] This suggests that the Pt morphology was similar on the two oxides. The authors suggest that the propensity for NO decomposition was related to the particulate nature of the Pt particles compared to the flat, single crystal surfaces.

The desorption of $\mathrm{N}_{2}$ and $\mathrm{NO}$ from $\mathrm{NO} / \mathrm{Rh} / \mathrm{CeO}_{2}(111)$ [297] resembles that from $\mathrm{NO} / \mathrm{Rh}(111) .[298]$ This indicates that there is little interaction between the $\mathrm{Rh}$ and the $\mathrm{CeO}_{2}(111)$ substrate. However reduction of the ceria substrate increases the amount of $\mathrm{N}_{2}$ that desorbs and totally suppresses the NO desorption for degrees of reduction greater than $40 \%$ $\mathrm{Ce}^{3+}\left(\mathrm{CeO}_{1.8}(111)\right)$. Further, at any given temperature from $250 \mathrm{~K}$ to $350 \mathrm{~K}$ the degree of dissociation of NO on the Rh particles, as measured by $\mathrm{N}$ 1s SXPS, was greater on reduced $\mathrm{CeO}_{2-x}(111)$ than on oxidized $\mathrm{CeO}_{2}(111)$.[297] Overbury et al suggested three possible mechanisms for the enhanced $\mathrm{NO}$ dissociation on $\mathrm{Rh} / \mathrm{CeO}_{2-x}(111)$; i) electron transfer from $\mathrm{Ce}^{3+}$ to $R h$, ii) $O$ spillover from the $R h$ to the reduced ceria, and iii) morphological differences between the Rh particles on the oxidized and the reduced ceria. RPES experiments indicate that the $\mathrm{Ce}^{3+}$ concentration increases, rather than decreases, following Rh deposition, even on initially partially reduced $\mathrm{CeO}_{2-x}(111)$, however the effect is greater on initially oxidized ceria.[269] Therefore electron transfer to the $\mathrm{Rh}$ is unlikely the cause of enhanced dissociation on $\mathrm{Rh} / \mathrm{CeO}_{2-x}(111)$. 
Since NO dissociation on $\mathrm{Rh}$ is self-inhibiting, spillover of $\mathrm{O}$ from the $\mathrm{Rh}$ surface to $\mathrm{CeO}_{2-x}$ would remove $\mathrm{O}$ from the $\mathrm{Rh}$ and would conceivably eliminate the inhibiting effect of the O. Two observations eliminated this possibility, however. When the NO coverage was reduced to $35 \%$ of its saturation coverage on the Rh particles the NO dissociation was still greater on $\mathrm{Rh} / \mathrm{CeO}_{2-x}(111)$ than on $\mathrm{Rh} / \mathrm{CeO}_{2}(111)$.[299] On $\mathrm{Rh}(111)$ it was shown that at reduced $\mathrm{NO}$ coverage the inhibition effect disappeared. [298] Further, in another experiment, $\mathrm{Rh} / \mathrm{CeO}_{2-x}(111)$ was exposed to $\mathrm{H}_{2} \mathrm{O}$ which dissociated on the ceria surface filling the $\mathrm{O}$ vacancies. The $\mathrm{NO}$ dissociation on the hydroxylated $\mathrm{Rh} / \mathrm{CeO}_{2-\mathrm{x}}(111)$ was the same as on the hydroxyl-free surface indicating the $O$ vacancies on the ceria did not enhance dissociation.[299]

STM measurements indicate similar growth of Rh particles on oxidized and reduced surfaces.[34] These measurements did not provide atomic level information however, so it isn't known what surface planes are exposed, or whether the particles have a different degree of step and kink sites, on a reduced surface compared to the oxidized surface. Since NO dissociation is greater on $\mathrm{Rh}(110)[300]$ and $\mathrm{Rh}(100)[301]$ than on $\mathrm{Rh}(111)[298]$ it's possible that atomic level morphological differences are responsible for the enhanced dissociation on $\mathrm{Rh} / \mathrm{CeO}_{2-\mathrm{x}}(111)$.

NO was also co-adsorbed with $\mathrm{CO}$ [302] or $\mathrm{C}_{2} \mathrm{H}_{4}$ [201] on $\mathrm{Rh} / \mathrm{CeO}_{x}(111)$. These coadsorbates are particularly relevant in relation to the reduction of $\mathrm{NO}_{\mathrm{x}}$ in automotive exhaust. The reaction between $\mathrm{CO}$ and NO on Rh has been studied by a number of authors[303-308] and the broader literature has been reviewed by Zhdanov and Kasemo.[309] When CO and NO are co-adsorbed on $\mathrm{Rh} / \mathrm{CeO}_{2}(111)$ the interaction is as has been observed on the Rh metal surfaces. [302] $\mathrm{CO}$ reacts with $\mathrm{O}$ from the dissociated $\mathrm{NO}$ to produce $\mathrm{CO}_{2}$ and the $\mathrm{N}$ atoms combine to produce $\mathrm{N}_{2}$. The only surface species observed are $\mathrm{CO}, \mathrm{NO}, \mathrm{N}$ and O. When $\mathrm{CO}$ and $\mathrm{NO}$ are co-adsorbed on reduced $\mathrm{Rh} / \mathrm{CeO}_{2-x}(111)$ new reaction pathways are observed. These new pathways result from a) the depletion of $O$ on the $R$ h due to spillover of $O$ from $R h$ to $\mathrm{CeO}_{2-x}(111)$ following $\mathrm{NO}$ dissociation and $\mathrm{b}$ ) the dissociation of $\mathrm{CO}$ on reduced $\mathrm{Rh} / \mathrm{CeO}_{2-x}(111)$ at elevated temperatures (see Sec. 6.2.1). The depletion of $O$ on the $R$ h leads to the formation of OCN through the reaction of $\mathrm{CO}+\mathrm{N}$. The $\mathrm{OCN}$ decomposes into gas phase $\mathrm{CO}+\mathrm{N}_{2}$. The dissociation of $\mathrm{CO}$ into $\mathrm{C}+\mathrm{O}$ leads to the formation of $\mathrm{C}_{X} \mathrm{~N}_{Y}$ fragments on the Rh particles. These eventually decompose at high temperatures leading to $\mathrm{N}_{2}$ and $\mathrm{CO}$ through the reaction of $\mathrm{C}$ on the $\mathrm{Rh}$ and $\mathrm{O}$ in the ceria. Notably no $\mathrm{CO}_{2}$ is produced from $\mathrm{CO}+\mathrm{NO}$ on $\mathrm{Rh} / \mathrm{CeO}_{2-\mathrm{x}}(111)$. The re-oxidation of the ceria inhibits the reaction between $\mathrm{CO}$ and $\mathrm{O}$ on the $\mathrm{Rh}$.

$\mathrm{C}_{2} \mathrm{H}_{4}+\mathrm{NO}$ have also been investigated on $\mathrm{Rh} / \mathrm{CeO}_{x}(111)$.[201] As discussed in Section 6.2.6, the $\mathrm{C}_{2} \mathrm{H}_{4}$ decomposes to produce $\mathrm{C}+\mathrm{H}$ on the Rh. These react to produce $\mathrm{H}_{2}$, through 
reaction between the $\mathrm{H}$, and $\mathrm{CO}$, through $\mathrm{C}$ reaction with the ceria. The $\mathrm{H}$ does not react with the ceria to form water.[170,201] van Hardeveld et al studied the reaction between $\mathrm{C}_{2} \mathrm{H}_{4}$ and $\mathrm{NO}$ on $\mathrm{Rh}(111)$.[310] Individually $\mathrm{C}_{2} \mathrm{H}_{4}$ and $\mathrm{NO}$ produce $\mathrm{C}$ and $\mathrm{H}_{2}$, or $\mathrm{NO}$ and $\mathrm{N}_{2}$, respectively. Reactions between $\mathrm{C}_{2} \mathrm{H}_{4}$ and $\mathrm{NO}$ produced $\mathrm{H}_{2} \mathrm{O}, \mathrm{CO}, \mathrm{CO}_{2}$ and $\mathrm{HCN}$. The same products were observed on $\mathrm{Rh} / \mathrm{CeO}_{2}(111)$ except there was no $\mathrm{H}_{2}$ or $\mathrm{HCN}$. In comparison with the reaction of $\mathrm{C}_{2} \mathrm{H}_{4}$ by itself on $\mathrm{Rh} / \mathrm{CeO}_{2}(111)$, it is clear that the $\mathrm{H}_{2} \mathrm{O}$ and $\mathrm{CO}_{2}$ result from a reaction between $\mathrm{C}_{2} \mathrm{H}_{4}$ and the $\mathrm{O}$ from the $\mathrm{NO}$ on the $\mathrm{Rh}$ nanoparticles. The absence of $\mathrm{H}_{2}$ apparently resulted from the relative coverage of $\mathrm{C}_{2} \mathrm{H}_{4}$ and $\mathrm{NO}$ so that all of the $\mathrm{H}$ was consumed by the $\mathrm{O}$ from the NO. No $C_{X} N_{Y}$ intermediates were detected on the Rh. The $C$ was more reactive with $O$ on the $\mathrm{Rh}$ and $\mathrm{O}$ in the ceria than it was with $\mathrm{N}$. The absence of $\mathrm{C}_{X} \mathrm{~N}_{Y}$ intermediates resulted in no $\mathrm{HCN}$ products. When $\mathrm{C}_{2} \mathrm{H}_{4}$ and $\mathrm{NO}$ were co-adsorbed on reduced $\mathrm{Rh} / \mathrm{CeO}_{2-x}(111)$ the $\mathrm{O}$ was removed from the $\mathrm{Rh}$ by reduced ceria. This eliminated $\mathrm{H}_{2} \mathrm{O}$ and $\mathrm{CO}_{2}$ formation. The absence of these reaction channels, i.e. the reaction of $\mathrm{C}$ or $\mathrm{H}$ with $\mathrm{O}$, resulted in $\mathrm{H}_{2}$ and $\mathrm{NH}_{3}$ formation at low temperatures. $\mathrm{C}_{X} \mathrm{~N}_{Y}$ intermediates were now detected on the $\mathrm{Rh}$ at higher temperatures but these ultimately decomposed leading to $\mathrm{N}_{2}$ and $\mathrm{CO}$ through the reaction of $\mathrm{C}$ with the ceria.

\subsection{3 - Water and the Water-Gas Shift Reaction}

Water was studied experimentally on $\mathrm{Rh} / \mathrm{CeO}_{x}(111) .[68]$ Water adsorbs weakly on oxidized $\mathrm{CeO}_{2}(111)[15,68]$ and on $\mathrm{Rh}(111)$ and polycrystalline Rh.[311] Therefore it isn't too surprising that water adsorption on $\mathrm{Rh} / \mathrm{CeO}_{2}(111)$ showed little difference compared to water on $\mathrm{CeO}_{2}(111)$. Chen et al calculated that water adsorbed on $\mathrm{Rh} / \mathrm{CeO}_{2}(111)$ was slightly more stable than water adsorbed on $\mathrm{CeO}_{2}(111)$.[312] This may be evident in a slight broadening of the $\mathrm{H}_{2} \mathrm{O}$ desorption toward higher temperatures on $\mathrm{Rh} / \mathrm{CeO}_{2}(111)$ but the effect is not substantial.[68] When $\mathrm{H}_{2} \mathrm{O}$ was adsorbed on reduced $\mathrm{Rh} / \mathrm{CeO}_{2-\mathrm{x}}(111)$ there was a new $\mathrm{H}_{2}$ desorption state between $250 \mathrm{~K}$ and $300 \mathrm{~K}$ and the high temperature $\mathrm{H}_{2}$ desorption state near $600 \mathrm{~K}$ from $\mathrm{H}_{2} \mathrm{O}$ on $\mathrm{CeO}_{2-x}(111)$ (see Figure 12) shifted to lower temperature. The Rh facilitated the disproportionation of $-\mathrm{OH}$ on the oxide surface to produce $\mathrm{H}_{2}$. The persistence of two $\mathrm{H}_{2}$ desorption features may be due to $-\mathrm{OH}$ located near the $\mathrm{Rh} / \mathrm{CeO}_{2-x}(111)$ interface (the low temperature peak) and $-\mathrm{OH}$ located away from the interface that diffused to the $\mathrm{Rh}$ at higher temperature.

Much of the interest in water adsorption on $\mathrm{M} / \mathrm{CeO}$ stems from research in the watergas shift reaction (WGS).

$$
\text { (10) } \mathrm{CO}+\mathrm{H}_{2} \mathrm{O} \rightarrow \mathrm{CO}_{2}+\mathrm{H}_{2}
$$


Studies have determined that $\mathrm{CeO}_{2}(111)$ without supported metal is inactive for WGS.[65,266,313] The WGS activity increases substantially for $\mathrm{Cu}$ [313], $\mathrm{Au}[313,314]$, Ni[266] and Pt[65] supported on ceria. The WGS activity is optimal at submonolayer coverages of the metals indicating that reaction likely occurs at the interface between the oxide support and metal nanoparticles.

Co-adsorption of $\mathrm{CO}$ and $\mathrm{H}_{2} \mathrm{O}$ was studied on $\mathrm{Rh} / \mathrm{CeO}_{x}(111)$.[68] Any interaction between $\mathrm{CO}$ and $\mathrm{H}_{2} \mathrm{O}$ was presumed to be bi-functional, i.e. water adsorbed on the ceria and $\mathrm{CO}$ adsorbed on the Rh, since CO does not adsorb on the ceria[171,279,315] and water doesn't adsorb on Rh above $300 \mathrm{~K}[311]$ in UHV. Since water also desorbs at low temperature from oxidized $\mathrm{CeO}_{2}(111)$ the $\mathrm{CO}$ and $\mathrm{H}_{2} \mathrm{O}$ were co-adsorbed on $\mathrm{Rh} / \mathrm{CeO}_{2-x}(111)$. No $\mathrm{CO}_{2}$ was observed during thermal desorption indicating that WGS did not occur in the UHV co-adsorption experiment. However, co-adsorption of $\mathrm{CO}$ and $\mathrm{H}_{2} \mathrm{O}$ affects the desorption of $\mathrm{H}_{2}$ and $\mathrm{CO}$ compared to $\mathrm{H}_{2} \mathrm{O}$ or $\mathrm{CO}$ adsorbed individually. Molecular $\mathrm{CO}$ adsorbed on the Rh inhibits $\mathrm{H}_{2}$ desorption near $300 \mathrm{~K}$ suggesting that the $\mathrm{CO}$ blocks the reaction of $-\mathrm{OH}$ at the ceria/Rh interface. $\mathrm{CO}$ on reduced $\mathrm{Rh} / \mathrm{CeO}_{2-\mathrm{x}}(111)$ dissociates above $300 \mathrm{~K}$. The co-adsorbed water does not inhibit the dissociation. However the recombination of $\mathrm{C}+\mathrm{O}$ to desorb as $\mathrm{CO}$ occurs at a slightly lower temperature when the ceria is covered by $-\mathrm{OH}$. Since isotopic labeling experiments indicated that $\mathrm{C}$ is reacting with $\mathrm{O}$ on the ceria[76] the presence of $-\mathrm{OH}$ enhances the reactivity between the $\mathrm{C}$ and the oxide.

The adsorption of water on various $\mathrm{M} / \mathrm{CeO}_{2}(111)$ surfaces has been studied computationally, particularly as it relates to the WGS reaction. In many of these studies a consistent observation was that the dissociation of water was the rate limiting step in the WGS reaction. On $\mathrm{Cu}_{4}$ clusters on $\mathrm{CeO}_{2}(111)$ Yang et al determined that $\mathrm{Cu}_{4}$ becomes positively charged which promotes the dissociation of $\mathrm{H}_{2} \mathrm{O}$.[256] Liu and Rodriguez studied $\mathrm{Cu}_{29}$ and $\mathrm{Au}_{29}$ clusters.[316] Water dissociation was found to be more favorable at the edges and corners of the nanoparticles. It wasn't clear what synergistic effect the ceria surface played in the process. On a $\mathrm{Rh}_{4}$ cluster on $\mathrm{CeO}_{2}(111)$ Chen et al determined that both $\mathrm{CO}$ and $\mathrm{H}_{2} \mathrm{O}$ adsorbed on the Rh.[312] Dissociation of the water led to the formation of a carboxyl intermediate ( $\mathrm{Rh}-\mathrm{COOH})$ which then decomposed to $\mathrm{CO}_{2}$ and $\mathrm{H}$. Finally, Bruix et al [65] and Senanayake et al [317] reported a "new type of strong metal-support interaction" for $\mathrm{Pt}$ and $\mathrm{Ni}$ nanoparticles on $\mathrm{CeO}_{2}(111)$. DFT calculations and valance photoemission indicated a smaller density of Pt $5 \mathrm{~d}$ or $\mathrm{Ni} 3 \mathrm{~d}$ states near the Fermi level compared to bulk metallic Pt or Ni. These nanoparticles enhanced the ability to adsorb and dissociate water relative to the bulk metals. This unique 
property of small metallic clusters was consistent with experimental observations that submonolayer amounts of $\mathrm{Pt}, \mathrm{Au}, \mathrm{Cu}$ and Ni promoted the WGS reaction.

\subsection{4 - Alcohols and Formic Acid}

The adsorption of methanol on $\mathrm{Rh} / \mathrm{CeO}_{X}(111)$ [318] produces desorption features that are different from methanol on either $\mathrm{CeO}_{x}(111)[83,205,208], \mathrm{Rh}(111)[319]$ or $\mathrm{Rh}(100)$.[320] Methanol dissociates and adsorbs as $\mathrm{H}$ and methoxy on both the ceria surface and $\mathrm{Rh}$ particles. The TPD spectra in Figure 31 can be interpreted in terms of methoxy decomposing on the Rh particles and methoxy adsorbing on the ceria and then reacting at the $\mathrm{Rh} / \mathrm{CeO}_{\mathrm{x}}(111)$ interface. The $\mathrm{H}_{2}$ desorption below $300 \mathrm{~K}$ and the $\mathrm{CO}$ desorption near $500 \mathrm{~K}$ are consistent with what has been observed following methanol adsorption on $\mathrm{Rh}(111))$ [319] and $\mathrm{Rh}(100)$.[320] Methanol adsorbed on Rh-free ceria disproportionates to formaldehyde and methanol near $600 \mathrm{~K}$ (Figure 20). When $\mathrm{Rh}$ is present the formaldehyde formation is completely suppressed and only $\mathrm{CO}$ and $\mathrm{H}_{2}$ are produced. The $\mathrm{CO}$ and $\mathrm{H}_{2}$ associated with the methoxy adsorbed on the ceria are produced at a lower temperature than where formaldehyde and methanol are produced on clean ceria. These results indicate that the methoxy on the ceria is reacting at the $\mathrm{Rh} /$ ceria interface. The reaction kinetics do not depend on the amount of Rh present nor the size of the Rh particles. A single, sharp $\mathrm{CO}$ desorption peak, coincident with a sharp $\mathrm{H}_{2}$ peak, indicates that all of the methoxy on the ceria is reacting at the $\mathrm{Rh} /$ ceria interface. TPD and $\mathrm{C}$ 1s sXPS indicate that at low methanol exposures all of the methanol adsorbs and reacts on the $\mathrm{Rh}$ nanoparticles. This is evidence of the so-called "capture zone" effect[321,322] where methanol that has impinged on the ceria rapidly diffuses to the Rh nanoparticles where it is bound more strongly and "captured" by the Rh. When methanol is adsorbed on reduced $\mathrm{Rh} / \mathrm{CeO}_{2-\mathrm{x}}(111)$ the $\mathrm{CO}$ that is produced through decomposition of methoxy on the Rh can undergo further decomposition to $\mathrm{C}+\mathrm{O}$ just as $\mathrm{CO}$ does directly on $\mathrm{Rh} / \mathrm{CeO}_{2-\mathrm{x}}(111) \cdot[76,279]$

Methanol was also studied on $\mathrm{Pt} / \mathrm{CeO}_{2}(111)$.[323] The principal observation was that the methanol decomposed in a manner similar to methanol on sputtered, i.e. roughened, $\mathrm{Pt}(111)$. Specifically the methoxy was bound more strongly than on flat $\mathrm{Pt}(111)$ and that a portion of the $\mathrm{C}-\mathrm{O}$ bonds were activated producing $\mathrm{C}$ on the $\mathrm{Pt}$. The similarity of the behavior on sputtered $\mathrm{Pt}(111)$ and $\mathrm{Pt} / \mathrm{CeO}_{2}(111)$ suggests that the morphology of the nanoparticles dictates the reactivity of methanol on the $\mathrm{Pt}$.

Formic acid was studied on $\mathrm{Pt} / \mathrm{CeO}_{2}(111)$.[62] TPD spectra from formic acid on $\mathrm{CeO}_{2}(111)$ without and with $\mathrm{Pt}$ are shown in Figure 22a and 22d, respectively. The presence of Pt increased the production of $\mathrm{CO}_{2}, \mathrm{CO}, \mathrm{H}_{2}$ and $\mathrm{H}_{2} \mathrm{O}$. The results were attributed to spillover 
from $\mathrm{Pt}$ to the ceria. The $\mathrm{H}_{2}$ desorption results from reverse spillover from ceria to the $\mathrm{Pt}$ as was observed for both water and methanol on $\mathrm{Rh} / \mathrm{CeO}_{\mathrm{x}}(111)$. In addition, methane was produced from $\mathrm{HCOOH} / \mathrm{Pt} / \mathrm{CeO}_{2}(111)$ which was not observed in the absence of Pt.

Ethanol has been studied experimentally on $\mathrm{Co} / \mathrm{CeO}_{2} / \mathrm{YSZ}(100)$ [324] and computationally on $\mathrm{Rh} / \mathrm{CeO}_{x}(111) \cdot[325,326]$ Martano and Vohs observed that Co supported on reducible $\mathrm{CeO}_{2}$ was more effective in the partial oxidation of ethanol to acetaldehyde compared to Co on non-reducible YSZ(100).[324] They attributed this behavior to the partial oxidation of $\mathrm{Co}^{0}$ to $\mathrm{Co}^{2+}$ by the ceria support. Ho et al have calculated the adsorption and decomposition of ethanol on $\mathrm{Rh}_{1} / \mathrm{CeO}_{2}(111)$ [325] and $\mathrm{Rh}_{4}$ clusters on $\mathrm{CeO}_{2}(111)$ [326]. They determined that the ethanol adsorbs preferentially at a Ce cation site as opposed to an $\mathrm{O}$ anion or the Rh metal. The ethoxy then forms a metallocycle, $\mathrm{Ce}-\mathrm{O}-\mathrm{CH}_{2}-\mathrm{CH}_{2}-\mathrm{Rh}$. From this configuration it undergoes dehydrogenation, $\mathrm{C}-\mathrm{C}$ bond scission and oxidation by surface $\mathrm{O}$ to produce $\mathrm{CO}_{2}, \mathrm{CO}, \mathrm{H}_{2} \mathrm{O}$ and $\mathrm{H}_{2}$.

\section{$6.2 .5-\mathrm{SO}_{2}$}

$\mathrm{SO}_{2}$ adsorption and decomposition has been investigated on $\mathrm{Cu},[327] \mathrm{Au},[327,328]$ and Pt[63] on $\mathrm{CeO}_{2}(111)$. The behavior in these three systems contrasts with $\mathrm{SO}_{2}$ on metal-free $\mathrm{CeO}_{2}(111)[191,193,196]$ and on $\mathrm{Cu}[329,330], \mathrm{Au}[331]$ and $\mathrm{Pt}[332-335]$ single crystal surfaces. $\mathrm{SO}_{2}$ reacts with the $\mathrm{O}$ anions on $\mathrm{CeO}_{2}(111)$ to form $\mathrm{SO}_{3}{ }^{2-}[191,196]$ or $\mathrm{SO}_{4}{ }^{2-}$.[193] These species desorb at higher temperatures as $\mathrm{SO}_{2}$ without decomposition to $\mathrm{S}^{0}$ or $\mathrm{S}^{2-}$ on the surface. $\mathrm{SO}_{2}$ adsorbs weakly as $\mathrm{SO}_{2}$ on $\mathrm{Au}(111)$ and leaves the surface upon annealing to 150 $\mathrm{K}$. [331] $\mathrm{SO}_{2}$ adsorbs molecularly in two different configurations, standing up and lying down, on $\mathrm{Pt}(111) \cdot[332,333]$ Streber et al concluded that the $\mathrm{SO}_{2}$ desorbed molecularly with little decomposition.[332] More highly stepped Pt surfaces led to the formation of $\mathrm{SO}_{3}{ }^{2-}$ and $\mathrm{S}^{0}$.[335]. $\mathrm{SO}_{2}$ interacted more strongly with $\mathrm{Cu}(111), \mathrm{Cu}(100)[329]$ and $\mathrm{Cu}(110)[330]$ with some of the $\mathrm{SO}_{2}$ decomposing to $\mathrm{S}^{0}$.

When the metals are supported on $\mathrm{CeO}_{2}(111)$ the interaction with $\mathrm{SO}_{2}$ strengthens. $\mathrm{SO}_{2}$ still doesn't decompose on $\mathrm{Au} / \mathrm{CeO}_{2}(111)$ but the $\mathrm{SO}_{2}$ persists to above $250 \mathrm{~K}$. [327,328] On $\mathrm{Cu} / \mathrm{CeO}_{2}(111)$ the decomposition to $\mathrm{S}^{0}$ is enhanced compared to $\mathrm{Cu}$ single crystals. The activity peaks at $\mathrm{Cu}$ coverages between 0.5 and $1.0 \mathrm{ML}$ and decays back toward the activity of $\mathrm{Cu}$ metal at higher coverages.[327] The behavior of $\mathrm{SO}_{2}$ on $\mathrm{Pt} / \mathrm{CeO}_{2}(111)$ is perhaps the most complex.[63] Upon adsorption at $150 \mathrm{~K}$ the $\mathrm{SO}_{2}$ adsorbs as sulfite, $\mathrm{SO}_{3}{ }^{2-}$, on the $\mathrm{CeO}_{2}(111)$ and as $\mathrm{SO}_{2}$ standing upright on the $\mathrm{Pt}$ nanoparticles based on the $\mathrm{S} 2 \mathrm{p}$ sXPS photoemission spectra. This is consistent with what was observed on metal-free $\mathrm{CeO}_{2}(111)[191]$ and on 
$\mathrm{Pt}(111)[332,333]$ except for the absence of lying down $\mathrm{SO}_{2}$ on the Pt nanoparticles. As the sample is heated $\mathrm{SO}_{3}{ }^{2-}$ and $\mathrm{SO}_{2}$ disappear and $\mathrm{S}^{0}$ is formed. At the highest temperatures the $\mathrm{S}^{0}$ is transformed into oxysulfide species on the ceria. These transformations are accompanied by changes in the Ce oxidation state. As the sample is heated from $150 \mathrm{~K}$ to $300 \mathrm{~K}^{2}$ the $\mathrm{Ce}^{3+}$ population increases. Upon further heating the $\mathrm{Ce}^{3+}$ population decreases. Hapel et al interpreted these results to indicate that negatively charged $\mathrm{SO}_{x}{ }^{8-}$ species migrated from the ceria onto the Pt nanoparticles. This led to an increase in $\mathrm{Ce}^{3+}$ and a loss of $\mathrm{SO}_{3}{ }^{2-}$ on the ceria. The $\mathrm{SO}_{\mathrm{x}}{ }^{\delta-}$ then decomposed on the $\mathrm{Pt}$ into $\mathrm{S}^{0}$ and the $\mathrm{O}$ returned to the ceria resulting in the oxidation of $\mathrm{Ce}^{3+}$ to $\mathrm{Ce}^{4+}$. At the highest temperatures the $\mathrm{S}$ spilled off of the $\mathrm{Pt}$ and reacted with the ceria to create the oxysulfide.

\subsection{6 - Hydrocarbons}

As noted in Section 5.2 non-functionalized hydrocarbons have not been extensively studied on clean cerium oxide surfaces. It appears that ethylene does not adsorb strongly nor react on $\mathrm{CeO}_{2}(111)$ [201] nor on $\mathrm{CeO}_{2} / \mathrm{YSZ}(100)$.[202] When $\mathrm{Rh}$ or Pt are supported on the ceria surfaces the ethylene adsorbs on the metal particles and decomposes. On Rh single crystal surfaces ethylene thermally decomposes to produce gaseous $\mathrm{H}_{2}$ leaving $\mathrm{C}$ on the surface.[336-338] The $\mathrm{H}_{2}$ desorbs from the $\mathrm{Rh}$ between $300 \mathrm{~K}$ and $500 \mathrm{~K}$. If $\mathrm{Rh}$ is supported on an inert substrate such as $\alpha-\mathrm{Al}_{2} \mathrm{O}_{3}(0001)$ the ethylene decomposes in a similar manner and $\mathrm{H}_{2}$ desorbs near 440 K.[170] When ethylene is adsorbed on $\mathrm{Rh} / \mathrm{CeO}_{2}(111)[201]$ or $\mathrm{Rh} / \mathrm{CeO}_{2} / \mathrm{\alpha}$ $\mathrm{Al}_{2} \mathrm{O}_{3}(0001)$ [170] $\mathrm{CO}$ is produced in addition to $\mathrm{H}_{2}$. The $\mathrm{CO}$ results from a reaction between $\mathrm{C}$ on the $\mathrm{Rh}$ particle and $\mathrm{O}$ on the ceria substrate. During successive cycles of ethylene adsorption followed by TPD the CO desorption temperature moves to progressively higher temperatures indicating that it becomes more difficult to remove $\mathrm{O}$ from an increasingly reduced surface.[170] On $\mathrm{Rh} / \mathrm{CeO}_{2} / \mathrm{YSZ}(100)$ ethylene decomposition produces $\mathrm{CO}_{2}$ in addition to $\mathrm{CO}$ and $\mathrm{H}_{2}$.[202] This demonstrates that the $\mathrm{YSZ}(100)$ substrate alters the reactivity of the $\mathrm{O}$ in the $\mathrm{CeO}_{2}$. Notably $\mathrm{H}_{2} \mathrm{O}$ is not observed in any of these $\mathrm{Rh} / \mathrm{CeO}_{2}$ systems indicating that the $\mathrm{H}$ atoms combine and desorb as $\mathrm{H}_{2}$ rather than react with $\mathrm{O}$ in the ceria.

Similar behavior is observed for ethylene adsorbed on $\mathrm{Pt} / \mathrm{CeO}_{2}(111)$.[339] The TPD was not reported but the $\mathrm{C}$ 1s sXPS indicated decomposition of the ethylene to $\mathrm{C}$ on the Pt followed by removal of the $C$ at high temperature. The removal of the $C$ coincided with an increase in the $\mathrm{Ce}^{3+}$ content indicating reduction of the ceria through the reaction of $\mathrm{O}$ with the C. Compared to $\mathrm{Pt}(111)$ the $\mathrm{Pt}$ nanoparticles on $\mathrm{CeO}_{2}(111)$ activated the dehydrogenation of the ethylene at a lower temperature. Enhanced dehydrogenation activity was also observed for 
methane on $\mathrm{Pt} / \mathrm{CeO}_{2}(111)$.[340,341] At temperatures near $100 \mathrm{~K}$ methane partially dehydrogenates to $\mathrm{CH}_{3}$ which is then stable on $\mathrm{Pt}(111)$. On Pt nanoparticles on $\mathrm{CeO}_{2}(111)$ the methane further dehydrogenates to $\mathrm{CH}$. $\mathrm{H}$ spillover was observed through the formation of $\mathrm{OH}$ on the ceria. Enhanced methane activation was also observed for model low-surface area Pd, $\mathrm{Pt}$ and $\mathrm{Rh}$ on $\mathrm{CeO}_{2}$ during methane steam reforming.[342]

\section{3 - Inverse Catalysts}

In a typical, conventional catalyst a metal is supported on an oxide substrate. In an inverse catalyst oxide nanoparticles are supported on a bulk metallic substrate (Figure 32).[343] The utility of an inverse catalyst may seem counterintuitive since a conventional catalyst is partly designed to maximize the surface area of the more active, and frequently more expensive, metallic component. However, as discussed by Rodriguez and Hrbek in their perspective article on inverse catalysts, these structures provide fundamental insight into the nature of the metal/oxide interface because the properties of oxide nanoparticles may be influenced by defects, edge and corner sites, strain, and electronic interactions with the metal which are absent on ideal, flat oxide surfaces.[343] Such studies therefore further close the gap between model systems and real catalysts. Reactions have been studied on ceria nanoparticles

supported on $\mathrm{Au}(111)[86,164,344], \quad \operatorname{Rh}(111)[345], \quad \operatorname{Pt}(111)[84,85,346,347]$ and $\mathrm{Cu}(111) .[87,107,347-350]$. In this section we will not focus on the structural characterization of these systems but rather discuss their reactivities and how they may differ from the conventional metal on ceria behavior.

Studies on inverse ceria on metal model catalysts have primarily focused on the CO oxidation reaction, $\mathrm{CO}+1 / 2 \mathrm{O}_{2} \rightarrow \mathrm{CO}_{2}$, and the water-gas shift reaction (WGS), $\mathrm{CO}+\mathrm{H}_{2} \mathrm{O} \rightarrow$ $\mathrm{CO}_{2}+\mathrm{H}_{2}$. These model catalysts have been studied both under reaction conditions as well as the adsorption properties of some of the individual components such as $\mathrm{CO}, \mathrm{O}_{2}$ and $\mathrm{H}_{2} \mathrm{O}$. One of the earliest studies examined the adsorption of $\mathrm{CO}$ on O-covered $\mathrm{Rh}(111)$ with and without ceria nanoparticles[345]. Eck et al observed that the adsorption of $\mathrm{CO}$ at $300 \mathrm{~K}$ proceeded more slowly on $\mathrm{O} / \mathrm{Rh}(111)$ compared to clean $\mathrm{Rh}(111)$. They attributed this to the rate limiting kinetics of the $\mathrm{CO}+\mathrm{O}$ oxidation reaction that inhibited $\mathrm{CO}$ uptake on the surface. However, when ceria was present on the $\mathrm{Rh}$ surface the $\mathrm{CO}+\mathrm{O}$ reaction was much faster. They attributed this to unique $\mathrm{CO}$ adsorption sites at the metal-ceria interface.

Weiss et al have studied CO adsorption and CO oxidation on the ceria / Pt(111) inverse catalyst. They observed that the Pt promoted the reduction of $\mathrm{CeO}_{2}$ via spillover of $\mathrm{CO}$ from the Pt surface to the ceria.[347] They also studied the oxidation of $\mathrm{CO}$ on $\mathrm{Pt}(111)$ and ceria / 
$\mathrm{Pt}(111)$ as a function of the $\mathrm{CO}$ partial pressure relative to $\mathrm{O}_{2}$. [84,85] As shown in Figure 33 the oxidation reaction shows a high-rate region and a low-rate region as the CO pressure is increased and also exhibits hysteresis when the $\mathrm{CO}$ pressure is reduced. This behavior is attributed to a poisoning effect of $\mathrm{CO}$ on the Pt which inhibits adsorption and dissociation of $\mathrm{O}_{2}$ on the surface. The presence of ceria on the surface has two effects. First the overall rate of reaction is enhanced despite the fact that the ceria blocks some of the adsorption sites on the Pt. In addition, the pressure at which the reaction shifts from high-rate to low-rate, $\mathrm{T}_{A}$, shifts to higher pressure when ceria is present. They attributed the enhanced activity to an increased $\mathrm{O}_{2}$ dissociation rate at the ceria / Pt interface. The shift in the transition pressure, $\mathrm{T}_{A}$, was attributed to $\mathrm{O}$ spillover from the ceria to the Pt which supplied $\mathrm{O}$ for the reaction after $\mathrm{CO}$ blocked the sites on the Pt surface.

Rodriguez et al have produced a number of studies involving inverse ceria catalysts on $\mathrm{Cu}(111)$ and $\mathrm{Au}(111)$. As a general observation they reported that the $\mathrm{CO}$ oxidation reaction[87,351] and the WGS reaction[86,351-353] was enhanced on the inverse catalysts. In both of the reactions the unique contribution of the ceria is to adsorb and dissociate either $\mathrm{O}_{2}$ or $\mathrm{H}_{2} \mathrm{O}$. This part of the reaction pathway is either slow or essentially non-existent on the clean $\mathrm{Cu}$ or Au surfaces. They observed that when water was adsorbed on ceria / $\mathrm{Au}(111)$ the water dissociated on partially reduced $\mathrm{CeO}_{2-x}$ and that the water was unable to fully oxidize the ceria particles which maintained their water dissociation activity.[344] Using synchrotron-based sXPS they studied the WGS reaction intermediates in UHV on ceria / Au(111)[164] and 90 mTorr CO / 30 mTorr $\mathrm{H}_{2} \mathrm{O}$ on ceria / $\mathrm{Cu}(111)$.[81] On ceria / $\mathrm{Au}(111)$ they determined that when the ceria was highly oxidized there was an absence of $\mathrm{OH}$ on the ceria and the primary surface species was carbonate $\left(\mathrm{CO}_{3}\right)^{2-}$, but when the ceria was reduced the presence of $\mathrm{OH}$ resulted in formate intermediates (HCOO-) on the surface. At elevated pressure under reaction conditions on ceria / $\mathrm{Cu}(111)$ they determined that the reactive intermediate was $\mathrm{CO}_{2}{ }^{\delta-}$.

\section{7 - Summary and Outlook}

Adsorption and reaction on cerium oxide surfaces are clearly related to the key concepts highlighted in the Introduction: 1) the coordination environment of the surface atoms; (2) the redox properties of the oxide; and (3) the oxidation state of the surface.[6] It was established in the earliest work on $\mathrm{CeO}_{x}(111)$ that reduced $\mathrm{CeO}_{2-x}(111)$ is much more chemically active than oxidized $\mathrm{CeO}_{2}(111)$. However, the reduction of $\mathrm{CeO}_{2}(111)$ alters all three of these important oxide characteristics. The removal of an $\mathrm{O}$ anion from the surface creates an additional coordination vacancy on the neighboring Ce cations, it becomes more difficult to remove 
subsequent $\mathrm{O}$ from the surface, and two $\mathrm{Ce}$ cations change from $\mathrm{Ce}^{4+}$ to $\mathrm{Ce}^{3+}$. We can postulate certain outcomes based on these changes which appear to be consistent with experimental observations. The change in the $\mathrm{Ce}$ coordination produces a more stable adsorption site for many reactants. However, the decrease in reducibility results in products containing less $\mathrm{O}$; in some cases resulting in unreacted elements such as $\mathrm{S}$ or $\mathrm{C}$ remaining on the surface.

The vast majority of experimental studies have been conducted on the (111) surface. However, it is clear from recent observations that the (100) surface behaves very differently. This is again to be expected since, as shown on the reconstructed surface in Figure $7 \mathrm{~b}$, both the $\mathrm{Ce}$ and the $\mathrm{O}$ have two coordination vacancies compared to only one coordination vacancy for the $\mathrm{Ce}$ and $\mathrm{O}$ on $\mathrm{CeO}_{2}(111)$ (Figure 6). The result is that for adsorbates such as water, $\mathrm{CO}_{2}$ and organic oxygenates, $\mathrm{CeO}_{2}(100)$ is more reactive in the sense that these reactants form much more stable surface species on $\mathrm{CeO}_{2}(100)$ compared to $\mathrm{CeO}_{2}(111)$. Further, it has been determined computationally that $\mathrm{CeO}_{2}(100)$ has a lower O-vacancy formation energy than $\mathrm{CeO}_{2}(111)$.[7-9] The observable result is a greater prevalence of O-containing reaction products from $\mathrm{CeO}_{2}(100)$. The more under-coordinated $\mathrm{O}$ on $\mathrm{CeO}_{2}(100)$ appears to make this surface more nucleophillic. Organic oxygenates adsorbed on $\mathrm{CeO}_{2}(100)$ are susceptible to a loss of $\mathrm{H}$ resulting in $\mathrm{CO}, \mathrm{CO}_{2}$ and water as reaction products.

To date there have been no experimental studies of adsorption and reaction on $\mathrm{CeO}_{2}(110)$. This surface may produce reaction properties that are an interesting hybrid between those observed on $\mathrm{CeO}_{2}(111)$ and $\mathrm{CeO}_{2}(100)$. The $\mathrm{Ce}$ on the $\mathrm{CeO}_{2}(110)$ surface (Figure 5) has two coordination vacancies as does the $\mathrm{Ce}$ on $\mathrm{CeO}_{2}(100)$ (Figure $7 \mathrm{~b}$ ). This suggests that many adsorbates will readily adsorb on the $\mathrm{CeO}_{2}(110)$ surface. However, the $\mathrm{O}$ only has one coordination vacancy, perhaps resulting in a less nucleophillic surface and more selective reaction products. This hypothesis needs to be tested.

There have been numerous computational studies on cerium oxide surfaces. This has enabled a direct comparison of theory and experiment. Ideally, as the computational tools become more wide spread they will enable guidance for experimental directions of investigation. While there have been many calculations on the $\mathrm{CeO}_{2}(111)$ surface there has been somewhat of a mismatch between theory and experiment regarding $\mathrm{CeO}_{2}(100)$ and $\mathrm{CeO}_{2}(110)$. There have been many calculations, but no experiments, on $\mathrm{CeO}_{2}(110)$, and, conversely, more experiments but fewer calculations on $\mathrm{CeO}_{2}(100)$. From the experimental end the lack of studies on $\mathrm{CeO}_{2}(110)$ presumably has been the result of the difficulty in preparing a suitable surface. $\mathrm{CeO}_{2}(100)$ is more difficult from a computational perspective as it is unclear what surface model 
to utilize to overcome the polarized surface problem. Advances from both the experimental and computational direction will presumably close this gap.

Reactions on metals supported on ceria surfaces have been somewhat limited and there have been essentially no studies on metals supported on $\mathrm{CeO}_{2}(100)$ and $\mathrm{CeO}_{2}(110)$. Early studies examined primarily NO, CO and simple hydrocarbons. Presumably these experiments were motivated by the application of ceria in automotive exhaust catalysts. More recent investigations have focused on the outstanding activity of ceria as a component in water-gas shift catalysts. Other, more complex, reactants would appear to be a fertile area for exploration on metal / ceria surfaces.

It also appears that many of the metal / ceria combinations operate as bi-functional catalysts, i.e. one reactant adsorbs on the metal while another adsorbs on the oxide. Utilizing ceria surfaces other than $\mathrm{CeO}_{2}(111)$ will presumably alter the activity as reactants will interact differently with the other ceria surfaces.

Finally, it is now possible to create high surface area cerium oxide nanocrystals that expose primarily specific, low-index crystallographic faces.[354-357] As shown in Figure 34, it is possible to synthesize cubes that expose $\mathrm{CeO}_{2}(100)$ facets (Figure 34c and 34d), and octahedra that expose $\mathrm{CeO}_{2}(111)$ facets (Figure 34e and 34f).[157] These nanoshapes are not ideal, however, and each shape exposes defects at edges and corners as well as an undetermined number of vacancies on their faces. These defects presumably become more pronounced as the sizes of the particles get smaller. Such complexities will need to be addressed by systematically incorporating defects into the well-defined experimental surfaces and computational models. These experiments will help elucidate the role of defects in the behavior of ceria-based "real world" catalysts.

\section{8 - Acknowledgments}

I wish to thank Peter Albrecht for his invaluable assistance in conducting the literature review for this report. This work was supported by the U.S. Department of Energy, Office of Science, Basic Energy Sciences, Chemical Sciences, Geosciences, and Biosciences Division. 


\section{9 - References}

[1] A. Trovarelli,Catalytic properties of ceria and CeO2-containing materials, Catalysis Reviews-Science and Engineering 38 (1996) 439-520.

[2] A. Trovarelli (Ed.) Catalysis by Ceria and Related Materials, London, Imperial College Press, 2002.

[3] A. Trovarelli (Ed.) Catalysis by Ceria and Related Materials (2nd Ed.), London, Imperial College Press, 2013.

[4] J.J. Delgado, E.d. Río, X. Chen, G. Blanco, J.M. Pintado, S. Bernal, J.J. Calvino, in, Catalysis by Ceria and Related Materials, pp. 47-138.

[5] L. Vivier, D. Duprez,Ceria-Based Solid Catalysts for Organic Chemistry, Chemsuschem 3 (2010) 654-678.

[6] M.A. Barteau,Organic reactions at well-defined oxide surfaces, Chemical Reviews 96 (1996) 1413-1430.

[7] T.X.T. Sayle, S.C. Parker, C.R.A. Catlow,SURFACE OXYGEN VACANCY FORMATION ON CEO2 AND ITS ROLE IN THE OXIDATION OF CARBON-MONOXIDE, Journal of the Chemical Society-Chemical Communications (1992) 977-978.

[8] M. Nolan, S.C. Parker, G.W. Watson,The electronic structure of oxygen vacancy defects at the low index surfaces of ceria, Surface Science 595 (2005) 223-232.

[9] J. Paier, C. Penschke, J. Sauer,Oxygen Defects and Surface Chemistry of Ceria: Quantum Chemical Studies Compared to Experiment, Chemical Reviews (2013).

[10] S.H. OVERBURY, D.R. MULLINS, in, Catalysis by Ceria and Related Materials, pp. 311341.

[11] H. Idriss, M.A. Barteau, in: B.C. Gates, H. Knozinger (Eds.), Advances in Catalysis, Vol 45: Impact of Surface Science on Catalysis, San Diego, 2000, pp. 261-331.

[12] J.M. Vohs, Site Requirements for the Adsorption and Reaction of Oxygenates on Metal Oxide Surfaces, Chemical Reviews (2013).

[13] M.V. Ganduglia-Pirovano, A. Hofmann, J. Sauer,Oxygen vacancies in transition metal and rare earth oxides: Current state of understanding and remaining challenges, Surface Science Reports 62 (2007) 219-270.

[14] Y.J. Kim, Y. Gao, G.S. Herman, S. Thevuthasan, W. Jiang, D.E. McCready, S.A. Chambers, Growth and structure of epitaxial $\mathrm{CeO} 2$ by oxygen-plasma-assisted molecular beam epitaxy, Journal of Vacuum Science \& Technology a-Vacuum Surfaces and Films 17 (1999) 926-935.

[15] D.R. Mullins, P.M. Albrecht, T.L. Chen, F.C. Calaza, M.D. Biegalski, H.M. Christen, S.H. Overbury,Water Dissociation on $\mathrm{CeO} 2(100)$ and $\mathrm{CeO} 2(111)$ Thin Films, Journal of Physical Chemistry C 116 (2012) 19419-19428.

[16] B. Kaemena, S.D. Senanayake, A. Meyer, J.T. Sadowski, J. Falta, J.I. Flege,Growth and Morphology of Ceria on Ruthenium (0001), Journal of Physical Chemistry C 117 (2013) 221232.

[17] H. Norenberg, G.A.D. Briggs,Surface structure of $\mathrm{CeO} 2(111)$ studied by low current STM and electron diffraction, Surface Science 402 (1998) 734-737.

[18] G.S. Herman,Surface structure determination of $\mathrm{CeO} 2(001)$ by angle-resolved mass spectroscopy of recoiled ions, Physical Review B 59 (1999) 14899-14902.

[19] S.H. Overbury, D.R. Huntley, D.R. Mullins, K.S. Ailey, P.V. Radulovic,Surface studies of model supported catalysts: NO adsorption on $\mathrm{Rh} / \mathrm{CeO} 2(001)$, Journal of Vacuum Science \& Technology a-Vacuum Surfaces and Films 15 (1997) 1647-1652.

[20] D.R. Mullins, P.V. Radulovic, S.H. Overbury,Ordered cerium oxide thin films grown on $\mathrm{Ru}(0001)$ and $\mathrm{Ni}(111)$, Surface Science 429 (1999) 186-198. 
[21] H. Norenberg, J.H. Harding, The surface structure of $\mathrm{CeO} 2(001)$ single crystals studied by elevated temperature STM, Surface Science 477 (2001) 17-24.

[22] H. Norenberg, G.A.D. Briggs, The surface structure of $\mathrm{CeO} 2(110)$ single crystals studied by STM and RHEED, Surface Science 433 (1999) 127-130.

[23] K. Fukui, Y. Namai, Y. Iwasawa,Imaging of surface oxygen atoms and their defect structures on $\mathrm{CeO} 2(111)$ by noncontact atomic force microscopy, Applied Surface Science 188 (2002) 252-256.

[24] Y. Namai, K. Fukui, Y. Iwasawa,Atom-resolved noncontact atomic force microscopic observations of $\mathrm{CeO} 2(111)$ surfaces with different oxidation states: Surface structure and behavior of surface oxygen atoms, Journal of Physical Chemistry B 107 (2003) 11666-11673.

[25] Y. Namai, K.I. Fukui, Y. Iwasawa,Atom-resolved noncontact atomic force microscopic and scanning tunneling microscopic observations of the structure and dynamic behavior of CeO2(111) surfaces, Catalysis Today 85 (2003) 79-91.

[26] S. Gritschneder, Y. Namai, Y. Iwasawa, M. Reichling,Structural features of CeO2(111) revealed by dynamic SFM, Nanotechnology 16 (2005) S41-S48.

[27] S. Gritschneder, M. Reichling,Structural elements of CeO2(111) surfaces, Nanotechnology 18 (2007) 044024.

[28] J.V. Lauritsen, M. Reichling,Atomic resolution non-contact atomic force microscopy of clean metal oxide surfaces, Journal of Physics-Condensed Matter 22 (2010).

[29] H.H. Pieper, C. Derks, M.H. Zoellner, R. Olbrich, L. Troger, T. Schroeder, M. Neumann, M. Reichling,Morphology and nanostructure of $\mathrm{CeO} 2(111)$ surfaces of single crystals and $\mathrm{Si}(111)$ supported ceria films, Physical Chemistry Chemical Physics 14 (2012) 15361-15368.

[30] S. Ma, X. Zhao, J.A. Rodriguez, J. Hrbek,STM and XPS study of growth of Ce on Au(111), Journal of Physical Chemistry C 111 (2007) 3685-3691.

[31] S.G. Ma, J. Rodriguez, J. Hrbek,STM study of the growth of cerium oxide nanoparticles on $\mathrm{Au}(111)$, Surface Science 602 (2008) 3272-3278.

[32] F. Dvorak, O. Stetsovych, M. Steger, E. Cherradi, I. Matolinova, N. Tsud, M. Skoda, T. Skala, J. Myslivecek, V. Matolin,Adjusting Morphology and Surface Reduction of CeO2(111) Thin Films on Cu(111), Journal of Physical Chemistry C 115 (2011) 7496-7503.

[33] P. Luches, F. Pagliuca, S. Valeri,Morphology, Stoichiometry, and Interface Structure of CeO2 Ultrathin Films on Pt(111), Journal of Physical Chemistry C 115 (2011) 10718-10726.

[34] J. Zhou, A.P. Baddorf, D.R. Mullins, S.H. Overbury,Growth and characterization of Rh and $\mathrm{Pd}$ nanoparticles on oxidized and reduced $\mathrm{CeOx}(111)$ thin films by scanning tunneling microscopy, Journal of Physical Chemistry C 112 (2008) 9336-9345.

[35] C. Castellarin-Cudia, S. Surnev, G. Schneider, R. Podlucky, M.G. Ramsey, F.P. Netzer,Strain-induced formation of arrays of catalytically active sites at the metal-oxide interface, Surface Science 554 (2004) L120-L126.

[36] S. Eck, C. Castellarin-Cudia, S. Surnev, M.G. Ramsey, F.P. Netzer,Growth and thermal properties of ultrathin cerium oxide layers on Rh(111), Surface Science 520 (2002) 173-185.

[37] J.L. Lu, H.J. Gao, S. Shaikhutdinov, H.J. Freund,Morphology and defect structure of the $\mathrm{CeO} 2(111)$ films grown on $\mathrm{Ru}(0001)$ as studied by scanning tunneling microscopy, Surface Science 600 (2006) 5004-5010.

[38] A. Pfau, K.D. Schierbaum, The Electronic-Structure of Stoichiometric and Reduced Ceo2 Surfaces - an Xps, Ups and Hreels Study, Surface Science 321 (1994) 71-80.

[39] E. Paparazzo, G.M. Ingo, N. Zacchetti,X-Ray-Induced Reduction Effects at Ceo2 Surfaces - an X-Ray Photoelectron-Spectroscopy Study, Journal of Vacuum Science \& Technology A 9 (1991) 1416-1420.

[40] M. Romeo, K. Bak, J. Elfallah, F. Lenormand, L. Hilaire,Xps Study of the Reduction of Cerium Dioxide, Surface and Interface Analysis 20 (1993) 508-512. 
[41] C. Hardacre, G.M. Roe, R.M. Lambert,STRUCTURE, COMPOSITION AND THERMALPROPERTIES OF CERIUM OXIDE-FILMS ON PLATINUM(111), Surface Science 326 (1995) 1-10.

[42] P. Burroughs, A. Hamnett, A.F. Orchard, G. Thornton,Satellite Structure in X-Ray Photoelectron-Spectra of Some Binary and Mixed Oxides of Lanthanum and Cerium, Journal of the Chemical Society-Dalton Transactions (1976) 1686-1698.

[43] D.R. Mullins, S.H. Overbury, D.R. Huntley,Electron spectroscopy of single crystal and polycrystalline cerium oxide surfaces, Surface Science 409 (1998) 307-319.

[44] O. Gunnarsson, K. Schonhammer,Electron Spectroscopies for Ce Compounds in the Impurity Model, Physical Review B 28 (1983) 4315-4341.

[45] A. Kotani, T. Jo, J.C. Parlebas,Many-Body Effects in Core-Level Spectroscopy of RareEarth Compounds, Advances in Physics 37 (1988) 37-85.

[46] Signorel.Aj, R.G. Hayes,X-Ray Photoelectron Spectroscopy of Various Core Levels of Lanthanide lons - Roles of Monopole Excitation and Electrostatic Coupling, Physical Review B 8 (1973) 81-86.

[47] S.P. Kowalczyk, N. Edelstein, F.R. Mcfeely, L. Ley, D.A. Shirley,X-Ray Photoemission Spectra of 4d Levels in Rare-Earth Metals, Chemical Physics Letters 29 (1974) 491-495.

[48] J.W. Allen,Valence Fluctuations in Narrow-Band Oxides, Journal of Magnetism and Magnetic Materials 47-8 (1985) 168-174.

[49] M. Matsumoto, K. Soda, K. Ichikawa, S. Tanaka, Y. Taguchi, K. Jouda, O. Aita, Y. Tezuka, S. Shin,Resonant Photoemission-Study of Ceo2, Physical Review B 50 (1994) 1134011346.

[50] V. Matolin, J. Libra, M. Skoda, N. Tsud, K.C. Prince, T. Skala,Methanol adsorption on a $\mathrm{CeO} 2(111) / \mathrm{Cu}(111)$ thin film model catalyst, Surface Science 603 (2009) 1087-1092.

[51] V. Matolin, et al.,Water interaction with $\mathrm{CeO} 2\left(\begin{array}{lll}1 & 1 & 1\end{array}\right) / \mathrm{Cu}\left(\begin{array}{lll}1 & 1 & 1\end{array}\right)$ model catalyst surface, Catalysis Today 181 (2012) 124-132.

[52] M. Skoda, J. Libra, F. Sutara, N. Tsud, Y. Skala, L. Sedlacek, V. Chab, K.C. Prince, V. Matolin,A resonant photoemission study of the $\mathrm{Ce}$ and Ce-oxide/ $\mathrm{Pd}(111)$ interfaces, Surface Science 601 (2007) 4958-4965.

[53] F. Sutara, M. Cabala, L. Sedlacek, T. Skala, M. Skoda, V. Matolin, K.C. Prince, V. Chab,Epitaxial growth of continuous $\mathrm{CeO} 2$ (111) ultra-thin films on $\mathrm{Cu}(111)$, Thin Solid Films 516 (2008) 6120-6124.

[54] M. Skoda, M. Cabala, I. Matolinova, K.C. Prince, T. Skala, F. Sutara, K. Veltruska, V. Matolin,Interaction of Au with $\mathrm{CeO}$ (111): A photoemission study, Journal of Chemical Physics 130 (2009) -.

[55] M. Skoda, M. Cabala, V. Chab, K.C. Prince, L. Sedlacek, T. Skala, F. Sutara, V. Matolin,Sn interaction with the $\mathrm{CeO}$ (111) system: Bimetallic bonding and ceria reduction, Applied Surface Science 254 (2008) 4375-4379.

[56] V. Matolin, I. Matolinova, L. Sedlacek, K.C. Prince, T. Skala,A resonant photoemission applied to cerium oxide based nanocrystals, Nanotechnology 20 (2009) -.

[57] V. Matolin, M. Cabala, V. Chab, I. Matolinova, K.C. Prince, M. Skoda, F. Sutara, T. Skala, K. Veltruska,A resonant photoelectron spectroscopy study of $\mathrm{Sn}(\mathrm{O}-\mathrm{x})$ doped $\mathrm{CeO} 2$ catalysts, Surface and Interface Analysis 40 (2008) 225-230.

[58] M.P. Seah, W.A. Dench, Quantitative electron spectroscopy of surfaces: A standard data base for electron inelastic mean free paths in solids, Surface and Interface Analysis 1 (1979) 2 11.

[59] S.H. Overbury, D.R. Mullins, D.R. Huntley, L. Kundakovic,Chemisorption and reaction of $\mathrm{NO}$ and $\mathrm{N} 2 \mathrm{O}$ on oxidized and reduced ceria surfaces studied by soft X-ray photoemission spectroscopy and desorption spectroscopy, Journal of Catalysis 186 (1999) 296-309.

[60] D.R. Mullins, Reactions on model emission control catalysts studied by soft X-ray photoemission, Journal of Electron Spectroscopy and Related Phenomena 114 (2001) 333-337. 
[61] D.R. Mullins, P.M. Albrecht,Acetaldehyde Adsorption and Reaction on CeO2(100) Thin Films, The Journal of Physical Chemistry C 117 (2013) 14692-14700.

[62] Y. Lykhach, M. Happel, V. Johanek, T. Skala, F. Kollhoff, N. Tsud, F. Dvorak, K.C. Prince, V. Matolin, J. Libuda,Adsorption and Decomposition of Formic Acid on Model Ceria and Pt/Ceria Catalysts, Journal of Physical Chemistry C 117 (2013) 12483-12494.

[63] M. Happel, Y. Lykhach, N. Tsud, T. Skala, V. Johanek, K.C. Prince, V. Matolin, J. Libuda,SO2 Decomposition on Pt/CeO2(111) Model Catalysts: On the Reaction Mechanism and the Influence of H-2 and CO, Journal of Physical Chemistry C 116 (2012) 10959-10967.

[64] C.J. Weststrate, R. Westerstrom, E. Lundgren, A. Mikkelsen, J.N. Andersen,Influence of Oxygen Vacancies on the Properties of Ceria-Supported Gold, Journal of Physical Chemistry C 113 (2009) 724-728.

[65] A. Bruix, J.A. Rodriguez, P.J. Ramirez, S.D. Senanayake, J. Evans, J.B. Park, D. Stacchiola, P. Liu, J. Hrbek, F. Illas,A New Type of Strong Metal-Support Interaction and the Production of $\mathrm{H}-2$ through the Transformation of Water on $\mathrm{Pt} / \mathrm{CeO} 2(111)$ and $\mathrm{Pt} / \mathrm{CeOx} / \mathrm{TiO} 2(110)$ Catalysts, Journal of the American Chemical Society 134 (2012) 8968-8974. [66] J.A. Rodriguez, X. Wang, P. Liu, W. Wen, J.C. Hanson, J. Hrbek, M. Perez, J. Evans,Gold nanoparticles on ceria: importance of $O$ vacancies in the activation of gold, Topics in Catalysis 44 (2007) 73-81.

[67] U. Berner, K. Schierbaum, G. Jones, P. Wincott, S. Haq, G. Thornton,Ultrathin ordered $\mathrm{CeO} 2$ overlayers on $\mathrm{Pt}(111)$ : interaction with NO2, NO, H2O and $\mathrm{CO}$, Surface Science 467 (2000) 201-213.

[68] L. Kundakovic, D.R. Mullins, S.H. Overbury,Adsorption and reaction of $\mathrm{H} 2 \mathrm{O}$ and $\mathrm{CO}$ on oxidized and reduced Rh/CeOx(111) surfaces, Surface Science 457 (2000) 51-62.

[69] J.J. Yeh, I. Lindau,Atomic Subshell Photoionization Cross-Sections and Asymmetry Parameters - 1 Less-Than-or-Equal-to Z Less-Than-or-Equal-to 103, Atomic Data and Nuclear Data Tables 32 (1985) 1-155.

[70] J. Stohr, NEXAFS Spectroscopy, New York, Springer-Verlag, 2003.

[71] S.D. Senanayake, D.R. Mullins,Redox pathways for $\mathrm{HCOOH}$ decomposition over $\mathrm{CeO} 2$ surfaces, Journal of Physical Chemistry C 112 (2008) 9744-9752.

[72] P.M. Albrecht, D.E. Jiang, D.R. Mullins,CO2 Adsorption As a Flat-Lying, Tridentate Carbonate on CeO2(100), Journal of Physical Chemistry C 118 (2014) 9042-9050.

[73] H. Ibach, D.L. Mills, Electron energy loss spectroscopy and surface vibrations, Academic Press, 1982.

[74] J.W. Niemantsverdriet, Spectroscopy in Catalysis: An Introduction, Wiley, 2008.

[75] J. Stubenrauch, E. Brosha, J.M. Vohs,Reaction of carboxylic acids on CeO2(111) and CeO2(100), Catalysis Today 28 (1996) 431-441.

[76] J. Stubenrauch, J.M. Vohs,Support effects in the dissociation of $\mathrm{CO}$ on $\mathrm{Rh} / \mathrm{CeO} 2(111)$, Catalysis Letters 47 (1997) 21-25.

[77] F.C. Calaza, Y. Xu, D.R. Mullins, S.H. Overbury,Oxygen Vacancy-Assisted Coupling and Enolization of Acetaldehyde on $\mathrm{CeO} 2(111)$, Journal of the American Chemical Society 134 (2012) 18034-18045.

[78] W.O. Gordon, Y. Xu, D.R. Mullins, S.H. Overbury,Temperature evolution of structure and bonding of formic acid and formate on fully oxidized and highly reduced $\mathrm{CeO}$ (111), Physical Chemistry Chemical Physics 11 (2009) 11171-11183.

[79] Z.L. Wu, M.J. Li, D.R. Mullins, S.H. Overbury,Probing the Surface Sites of $\mathrm{CeO} 2$ Nanocrystals with Well-Defined Surface Planes via Methanol Adsorption and Desorption, Acs Catalysis 2 (2012) 2224-2234.

[80] F.M. Hoffmann,Infrared reflection-absorption spectroscopy of adsorbed molecules, Surface Science Reports 3 (1983) 107-192. 
[81] K. Mudiyanselage, et al.,Importance of the Metal-Oxide Interface in Catalysis: In Situ Studies of the Water-Gas Shift Reaction by Ambient-Pressure X-ray Photoelectron Spectroscopy, Angewandte Chemie-International Edition 52 (2013) 5101-5105.

[82] D.A. King,Thermal desorption from metal surfaces: A review, Surface Science 47 (1975) 384-402.

[83] R.M. Ferrizz, G.S. Wong, T. Egami, J.M. Vohs,Structure sensitivity of the reaction of methanol on ceria, Langmuir 17 (2001) 2464-2470.

[84] Y. Suchorski, R. Wrobel, S. Becker, B. Strzelczyk, W. Drachsel, H. Weiss,Ceria nanoformations in $\mathrm{CO}$ oxidation on $\mathrm{Pt}(111)$ : Promotional effects and reversible redox behaviour, Surface Science 601 (2007) 4843-4848.

[85] Y. Suchorski, R. Wrobel, S. Becker, H. Weiss, CO Oxidation on a CeOx/Pt(111) Inverse Model Catalyst Surface: Catalytic Promotion and Tuning of Kinetic Phase Diagrams, Journal of Physical Chemistry C 112 (2008) 20012-20017.

[86] J.A. Rodriguez, S. Ma, P. Liu, J. Hrbek, J. Evans, M. Perez,Activity of CeOx and TiOx nanoparticles grown on $\mathrm{Au}(111)$ in the water-gas shift reaction, Science 318 (2007) 1757-1760.

[87] F. Yang, J. Graciani, J. Evans, P. Liu, J. Hrbek, J.F. Sanz, J.A. Rodriguez,CO Oxidation on Inverse $\mathrm{CeOx} / \mathrm{Cu}(111)$ Catalysts: High Catalytic Activity and Ceria-Promoted Dissociation of O-2, Journal of the American Chemical Society 133 (2011) 3444-3451.

[88] R.W.G. Wyckoff, Crystal Structures, New York, Interscience, 1963.

[89] L. Eyring, in: K.A. Gschneider, L. Eyring (Eds.), Handbook on the Physics and Chemistry of Rare Earths, New York, 1979, pp. 337-399.

[90] J. Zhang, Z.C. Kang, L. Eyring,The Binary Higher Oxides of the Rare-Earths, Journal of Alloys and Compounds 192 (1993) 57-63.

[91] A. Trovarelli, in: A. Trovarelli (Ed.), Catalysis by Ceria and Related Materials, London, 2002, pp. 15-50.

[92] P.W. Tasker,STABILITY OF IONIC-CRYSTAL SURFACES, Journal of Physics C-Solid State Physics 12 (1979) 4977-4984.

[93] J.C. Conesa,Computer Modeling of Surfaces and Defects on Cerium Dioxide, Surface Science 339 (1995) 337-352.

[94] M. Baudin, M. Wojcik, K. Hermansson,Dynamics, structure and energetics of the (111), (011) and (001) surfaces of ceria, Surface Science 468 (2000) 51-61.

[95] N.V. Skorodumova, M. Baudin, K. Hermansson,Surface properties of $\mathrm{CeO} 2$ from first principles, Physical Review B 69 (2004) -.

[96] Z.X. Yang, T.K. Woo, M. Baudin, K. Hermansson,Atomic and electronic structure of unreduced and reduced $\mathrm{CeO} 2$ surfaces: A first-principles study, Journal of Chemical Physics 120 (2004) 7741-7749.

[97] M. Nolan, S. Grigoleit, D.C. Sayle, S.C. Parker, G.W. Watson,Density functional theory studies of the structure and electronic structure of pure and defective low index surfaces of ceria, Surface Science 576 (2005) 217-229.

[98] Y. Jiang, J.B. Adams, M. van Schilfgaarde,Density-functional calculation of $\mathrm{CeO} 2$ surfaces and prediction of effects of oxygen partial pressure and temperature on stabilities, Journal of Chemical Physics 123 (2005).

[99] H.-T. Chen, Y.M. Choi, M. Liu, M.C. Lin,A theoretical study of surface reduction mechanisms of $\mathrm{CeO} 2$ (111) and (110) by H-2, Chemphyschem 8 (2007) 849-855.

[100] M. Nolan,Hybrid density functional theory description of oxygen vacancies in the $\mathrm{CeO} 2$ (110) and (100) surfaces, Chemical Physics Letters 499 (2010) 126-130.

[101] T. Desaunay, A. Ringuede, M. Cassir, F. Labat, C. Adamo,Modeling basic components of solid oxide fuel cells using density functional theory: Bulk and surface properties of $\mathrm{CeO}$, Surface Science 606 (2012) 305-311.

[102] A. Siokou, R.M. Nix, Interaction of methanol with well-defined ceria surfaces: Reflection/absorption infrared spectroscopy, X-ray photoelectron spectroscopy, and 
temperature-programmed desorption study, Journal of Physical Chemistry B 103 (1999) 69846997.

[103] F. Esch, S. Fabris, L. Zhou, T. Montini, C. Africh, P. Fornasiero, G. Comelli, R. Rosei,Electron localization determines defect formation on ceria substrates, Science 309 (2005) 752-755.

[104] S. Torbruegge, M. Cranney, M. Reichling,Morphology of step structures on $\mathrm{CeO}(2)(111)$, Applied Physics Letters 93 (2008).

[105] C. Muggelberg, M.R. Castell, G.A.D. Briggs, D.T. Goddard,The atomic structure of the UO2 $+x(110)$ surface and the effects of interstitial oxygen: an elevated-temperature STM study, Surface Science 402 (1998) 673-677.

[106] C.Y. Tian, Y. Du, S.W. Chan,Preparation and microstructural study of $\mathrm{CeO} 2$ thin films, Journal of Vacuum Science \& Technology a-Vacuum Surfaces and Films 15 (1997) 85-92.

[107] F. Yang, Y. Choi, S. Agnoli, P. Liu, D. Stacchiola, J. Hrbek, J.A. Rodriguez,CeO2 <-> $\mathrm{CuOx}$ Interactions and the Controlled Assembly of CeO2(111) and CeO2(100) Nanoparticles on an Oxidized Cu(111) Substrate, Journal of Physical Chemistry C 115 (2011) 23062-23066.

[108] Y.Y. Lin, Z.L. Wu, J.G. Wen, K.R. Poeppelmeier, L.D. Marks,Imaging the Atomic Surface Structures of CeO2 Nanoparticles, Nano Letters 14 (2014) 191-196.

[109] J. Kullgren, K. Hermansson, C. Castleton,Many competing ceria (110) oxygen vacancy structures: From small to large supercells, Journal of Chemical Physics 137 (2012).

[110] J.F. Jerratsch, X. Shao, N. Nilius, H.J. Freund, C. Popa, M.V. Ganduglia-Pirovano, A.M. Burow, J. Sauer,Electron Localization in Defective Ceria Films: A Study with ScanningTunneling Microscopy and Density-Functional Theory, Physical Review Letters 106 (2011).

[111] H. Norenberg, G.A.D. Briggs, Defect formation on CeO2(111) surfaces after annealing studied by STM, Surface Science 424 (1999) L352-L355.

[112] H. Norenberg, G.A.D. Briggs,Defect structure of nonstoichiometric $\mathrm{CeO} 2(111)$ surfaces studied by scanning tunneling microscopy, Physical Review Letters 79 (1997) 4222-4225.

[113] Y. Namai, K. Fukui, Y. Iwasawa,The dynamic behaviour of $\mathrm{CH} 3 \mathrm{OH}$ and $\mathrm{NO} 2$ adsorbed on CeO2(111) studied by noncontact atomic force microscopy, Nanotechnology 15 (2004) S49S54.

[114] S. Gritschneder, Y. Iwasawa, M. Reichling,Strong adhesion of water to CeO2(111), Nanotechnology 18 (2007) 044025.

[115] Z. Lu, R. Hiskes, S.A. Dicarolis, A. Nel, R.K. Route, R.S. Feigelson,Crystalline Quality and Surface-Morphology of (100)Ceo2 Thin-Films Grown on Sapphire Substrates by Solid Source Metalorganic Chemical-Vapor-Deposition, Journal of Crystal Growth 156 (1995) 227234.

[116] R. Lo Nigro, R.G. Toro, G. Malandrino, I.L. Fragala,Morphological and structural control of nanostructured $<100>$ oriented $\mathrm{CeO} 2$ films grown on random metallic substrates, Journal of Materials Chemistry 15 (2005) 2328-2337.

[117] J.R. Vargas-Garcia, L. Beltran-Romero, R. Tu, T. Goto,Highly (100)-oriented CeO2 films prepared on amorphous substrates by laser chemical vapor deposition, Thin Solid Films 519 (2010) 1-4.

[118] P. Zhao, A. Ito, R. Tu, T. Goto,Preparation of highly (100)-oriented CeO2 films on polycrystalline $\mathrm{Al} 2 \mathrm{O} 3$ substrates by laser chemical vapor deposition, Surface \& Coatings Technology 204 (2010) 3619-3622.

[119] P. Zhao, A. Ito, R. Tu, T. Goto,High-speed epitaxial growth of (100)-oriented CeO2 film on $r$-cut sapphire by laser chemical vapor deposition, Surface \& Coatings Technology 205 (2011) 4079-4082.

[120] S.Y. Wang, W. Wang, Q.C. Liu, M. Zhang, Y.T. Qian,Preparation and characterization of cerium (IV) oxide thin films by spray prolysis method, Solid State lonics 133 (2000) 211-215.

[121] G.S. Zafiris, R.J. Gorte,A Study of Co, No, and H2 Adsorption on Model Pt/Ceo2 Catalysts, Surface Science 276 (1992) 86-94. 
[122] K. Konstantinov, I. Stambolova, P. Peshev, B. Darriet, S. Vassilev, Preparation of ceria films by spray pyrolysis method, International Journal of Inorganic Materials 2 (2000) 277-280.

[123] T. Inoue, Y. Yamamoto, S. Koyama, S. Suzuki, Y. Ueda,Epitaxial-Growth of Ceo2 Layers on Silicon, Applied Physics Letters 56 (1990) 1332-1333.

[124] K.D. Schierbaum,Ordered ultra-thin cerium oxide overlayers on $\mathrm{Pt}(111)$ single crystal surfaces studied by LEED and XPS, Surface Science 399 (1998) 29-38.

[125] N. Yamada, Y. Oyama, T. Higuchi, S. Yamaguchi,Fabrication of $\mathrm{CeO} 2$ thin film on quartz glass and $\mathrm{MgO}(100)$ by electron beam evaporation, Solid State Ionics 172 (2004) 293-297.

[126] S.N. Jacobsen, U. Helmersson, R. Erlandsson, B. Skarman, L.R. Wallenberg,Sharp microfaceting of (001)-oriented cerium dioxide thin films and the effect of annealing on surface morphology, Surface Science 429 (1999) 22-33.

[127] D.N. Belton, S.J. Schmieg,Low-Temperature Oxidation and Reduction of Ceria Particles on $\mathrm{Rh}(111)$, Journal of Vacuum Science \& Technology a-Vacuum Surfaces and Films 11 (1993) 2330-2335.

[128] M. Paranthaman, et al.,Growth of biaxially textured buffer layers on rolled-Ni substrates by electron beam evaporation, Physica C 275 (1997) 266-272.

[129] M. Alexandrou, R.M. Nix,The Growth, Structure and Stability of Ceria Overlayers on Pd(111), Surface Science 321 (1994) 47-57.

[130] B. Hirschauer, G. Chiaia, M. Gothelid, U.O. Karlsson,Studies of highly oriented CeO2 films grown on $\mathrm{Si}(111)$ by pulsed laser deposition, Thin Solid Films 348 (1999) 3-7.

[131] W. Dmowski, E. Mamontov, T. Egami, S. Putna, R. Gorte,Energy-dispersive surface Xray scattering study of thin ceria overlayer on zirconia: Structural evolution with temperature, Physica B 248 (1998) 95-100.

[132] Y.J. Kim, S. Thevuthasan, V. Shutthananadan, C.L. Perkins, D.E. McCready, G.S. Herman, Y. Gao, T.T. Tran, S.A. Chambers, C.H.F. Peden,Growth and structure of epitaxial Ce1-xZrxO2 thin films on yttria-stabilized zirconia (111), Journal of Electron Spectroscopy and Related Phenomena 126 (2002) 177-190.

[133] M.A. Henderson, C.L. Perkins, M.H. Engelhard, S. Thevuthasan, C.H.F. Peden,Redox properties of water on the oxidized and reduced surfaces of $\mathrm{CeO} 2(111)$, Surface Science 526 (2003) 1-18.

[134] S.A. Maicaneanu, D.C. Sayle, G.W. Watson,Structural characterization of the $\mathrm{CeO} / \mathrm{YSZ}(111)$ catalytic system synthesized using simulated amorphization and recrystallization, Journal of Physical Chemistry B 105 (2001) 12481-12489.

[135] P. Luches, F. Pagliuca, S. Valeri, F. Boscherini,Structure of Ultrathin $\mathrm{CeO} 2$ Films on $\mathrm{Pt}(111)$ by Polarization-Dependent X-ray Absorption Fine Structure, Journal of Physical Chemistry C 117 (2013) 1030-1036.

[136] T. Staudt, Y. Lykhach, L. Hammer, M.A. Schneider, V. Matolin, J. Libuda,A route to continuous ultra-thin cerium oxide films on Cu(111), Surface Science 603 (2009) 3382-3388.

[137] V. Matolin, J. Libra, I. Matolinova, V. Nehasil, L. Sedlacek, F. Sutara,Growth of ultra-thin cerium oxide layers on Cu(111), Applied Surface Science 254 (2007) 153-155.

[138] T. Inoue, T. Ohsuna, L. Luo, X.D. Wu, C.J. Maggiore, Y. Yamamoto, Y. Sakurai, J.H. Chang,GROWTH OF (110)-ORIENTED CEO2 LAYERS ON (100) SILICON SUBSTRATES, Applied Physics Letters 59 (1991) 3604-3606.

[139] T. Inoue, Y. Yamamoto, M. Satoh,Low-temperature epitaxial growth of $\mathrm{CeO} 2(110) / \mathrm{Si}(100)$ structure by evaporation under substrate bias, Japanese Journal of Applied Physics Part 2-Letters 35 (1996) L1685-L1688.

[140] T. Inoue, Y. Yamamoto, M. Satoh,Low temperature epitaxial growth of CeO2(110) layers on $\mathrm{Si}(100)$ using electron beam assisted evaporation, Thin Solid Films 343 (1999) 594-597.

[141] T. Inoue, N. Igarashi, Y. Kanno, S. Shida,Two dimensional control of electron beam induced orientation selective epitaxial growth of (100) and (110)CeO2 regions on $\mathrm{Si}(100)$ substrates, Thin Solid Films 519 (2011) 5775-5779. 
[142] T. Inoue, S. Shida,Spatially varied orientation selective epitaxial growth of $\mathrm{CeO} 2(100)$ and (110) regions on $\mathrm{Si}(100)$ substrates by reactive magnetron sputtering utilizing electron beam irradiation, Thin Solid Films 520 (2012) 6179-6182.

[143] T. Inoue, M. Ohashi, N. Sakamoto, S. Shida,Orientation selective epitaxial growth of $\mathrm{CeO} 2$ layers on $\mathrm{Si}(100)$ substrates using reactive $\mathrm{DC}$ magnetron sputtering with substrate bias, Journal of Crystal Growth 271 (2004) 176-183.

[144] T. Inoue, T. Saito, S. Shida,Electron beam induced orientation selective epitaxial growth of $\mathrm{CeO} 2(100)$ layers on $\mathrm{Si}(100)$ substrates, Journal of Crystal Growth 304 (2007) 1-3.

[145] A. Laachir, et al.,Reduction of Ceo2 by Hydrogen - Magnetic-Susceptibility and FourierTransform Infrared, Ultraviolet and X-Ray Photoelectron-Spectroscopy Measurements, Journal of the Chemical Society-Faraday Transactions 87 (1991) 1601-1609.

[146] V. Perrichon, A. Laachir, G. Bergeret, R. Frety, L. Tournayan, O. Touret, Reduction of Cerias with Different Textures by Hydrogen and Their Reoxidation by Oxygen, Journal of the Chemical Society-Faraday Transactions 90 (1994) 773-781.

[147] H. Cordatos, R.J. Gorte,CO, NO, and H-2 adsorption on ceria-supported Pd, Journal of Catalysis 159 (1996) 112-118.

[148] B.H. Chen, Y.S. Ma, L.B. Ding, L.S. Xu, Z.F. Wu, Q. Yuan, W.X. Huang,Reactivity of Hydroxyls and Water on a CeO2(111) Thin Film Surface: The Role of Oxygen Vacancy, Journal of Physical Chemistry C 117 (2013) 5800-5810.

[149] M.B. Watkins, A.S. Foster, A.L. Shluger,Hydrogen cycle on $\mathrm{CeO}(2)$ (111) surfaces: Density functional theory calculations, Journal of Physical Chemistry C 111 (2007) 1533715341.

[150] G. Vicario, G. Balducci, S. Fabris, S. de Gironcoli, S. Baroni,Interaction of hydrogen with cerium oxide surfaces: a quantum mechanical computational study, Journal of Physical Chemistry B 110 (2006) 19380-19385.

[151] M.K. Alam, F. Ahmed, R. Miura, A. Suzuki, H. Tsuboi, N. Hatakeyama, A. Endou, H. Takaba, M. Kubo, A. Miyamoto,Study of reduction processes over cerium oxide surfaces with atomic hydrogen using ultra accelerated quantum chemical molecular dynamics, Applied Surface Science 257 (2010) 1383-1389.

[152] C. Doornkamp, V. Ponec,The universal character of the Mars and Van Krevelen mechanism, Journal of Molecular Catalysis a-Chemical 162 (2000) 19-32.

[153] P. Mars, D.W. van Krevelen,Oxidations carried out by means of vanadium oxide catalysts, Chemical Engineering Science 3, Supplement 1 (1954) 41-59.

[154] G. Praline, B.E. Koel, R.L. Hance, H.I. Lee, J.M. White,X-Ray Photoelectron Study of the Reaction of Oxygen with Cerium, Journal of Electron Spectroscopy and Related Phenomena 21 (1980) $17-30$.

[155] C.R. Helms, W.E. Spicer,Comparison of Oxidation Process in Strontium and Cerium by Ultraviolet Photoelectron Spectroscopy, Applied Physics Letters 21 (1972) 237-\&.

[156] T.L. Barr,Esca Study of Termination of Passivation of Elemental Metals, Journal of Physical Chemistry 82 (1978) 1801-1810.

[157] Z.L. Wu, M.J. Li, J. Howe, H.M. Meyer, S.H. Overbury,Probing Defect Sites on CeO2 Nanocrystals with Well-Defined Surface Planes by Raman Spectroscopy and O-2 Adsorption, Langmuir 26 (2010) 16595-16606.

[158] Y.M. Choi, H. Abernathy, H.T. Chen, M.C. Lin, M.L. Liu,Characterization of O-2-CeO2 interactions using in situ Raman spectroscopy and first-principle calculations, Chemphyschem 7 (2006) 1957-1963.

[159] Y. Zhao, B.T. Teng, X.D. Wen, Y. Zhao, Q.P. Chen, L.H. Zhao, M.F. Luo,Superoxide and Peroxide Species on $\mathrm{CeO} 2(111)$, and Their Oxidation Roles, Journal of Physical Chemistry C 116 (2012) 15986-15991.

[160] M. Nolan,Healing of oxygen vacancies on reduced surfaces of gold-doped ceria, Journal of Chemical Physics 130 (2009). 
[161] E.S. Putna, J.M. Vohs, R.J. Gorte,Evidence for weakly bound oxygen on ceria films, Journal of Physical Chemistry 100 (1996) 17862-17865.

[162] Y. Lykhach, et al.,Water Chemistry on Model Ceria and Pt/Ceria Catalysts, Journal of Physical Chemistry C 116 (2012) 12103-12113.

[163] G.S. Herman, Y.J. Kim, S.A. Chambers, C.H.F. Peden,Interaction of D2O with $\mathrm{CeO} 2(001)$ investigated by temperature-programmed desorption and X-ray photoelectron spectroscopy, Langmuir 15 (1999) 3993-3997.

[164] S.D. Senanayake, D. Stacchiola, J. Evans, M. Estrella, L. Barrio, M. Perez, J. Hrbek, J.A. Rodriguez, Probing the reaction intermediates for the water-gas shift over inverse $\mathrm{CeOx} / \mathrm{Au}(111)$ catalysts, Journal of Catalysis 271 (2010) 392-400.

[165] M. Fronzi, S. Piccinin, B. Delley, E. Traversa, C. Stampfl,Water adsorption on the stoichiometric and reduced $\mathrm{CeO}(2)(111)$ surface: a first-principles investigation, Physical Chemistry Chemical Physics 11 (2009) 9188-9199.

[166] D. Marrocchelli, B. Yildiz,First-Principles Assessment of $\mathrm{H} 2 \mathrm{~S}$ and $\mathrm{H} 2 \mathrm{O}$ Reaction Mechanisms and the Subsequent Hydrogen Absorption on the CeO2(111) Surface, Journal of Physical Chemistry C 116 (2012) 2411-2424.

[167] M. Molinari, S.C. Parker, D.C. Sayle, M.S. Islam,Water Adsorption and Its Effect on the Stability of Low Index Stoichiometric and Reduced Surfaces of Ceria, Journal of Physical Chemistry C 116 (2012) 7073-7082.

[168] D. Fernandez-Torre, K. Kosmider, J. Carrasco, M.V. Ganduglia-Pirovano, R. Perez,Insight into the Adsorption of Water on the Clean CeO2(111) Surface with van der Waals and Hybrid Density Functionals, Journal of Physical Chemistry C 116 (2012) 13584-13593.

[169] M.A. Henderson, The interaction of water with solid surfaces: fundamental aspects revisited, Surface Science Reports 46 (2002) 5-308.

[170] R.M. Ferrizz, T. Egami, J.M. Vohs,Temperature programmed desorption study of the reaction of $\mathrm{C} 2 \mathrm{H} 4$ and $\mathrm{CO}$ on $\mathrm{Rh}$ supported on alpha-Al2O3(0001), $\mathrm{YSZ}(100)$ and $\mathrm{CeO} 2$ thin films, Surface Science 465 (2000) 127-137.

[171] J. Stubenrauch, J.M. Vohs,Interaction of $\mathrm{CO}$ with Rh supported on stoichiometric and reduced $\mathrm{CeO} 2(111)$ and $\mathrm{CeO} 2(100)$ surfaces, Journal of Catalysis 159 (1996) 50-57.

[172] D.R. Mullins, K.Z. Zhang,Metal-support interactions between Pt and thin film cerium oxide, Surface Science 513 (2002) 163-173.

[173] S.D. Senanayake, J. Zhou, A.P. Baddorf, D.R. Mullins, The reaction of carbon monoxide with palladium supported on cerium oxide thin films, Surface Science 601 (2007) 3215-3223.

[174] C. Muller, C. Freysoldt, M. Baudin, K. Hermansson,An ab initio study of CO adsorption on ceria(110), Chemical Physics 318 (2005) 180-190.

[175] B. Herschend, M. Baudin, K. Hermansson, CO adsorption on CeO2(110) using hybridDFT embedded-cluster calculations, Chemical Physics 328 (2006) 345-353.

[176] C. Muller, B. Herschend, K. Hermansson, B. Paulus,Application of the method of increments to the adsorption of $\mathrm{CO}$ on the $\mathrm{CeO} 2(110)$ surface, The Journal of chemical physics 128 (2008) 214701-214701.

[177] C. Muller, B. Paulus, K. Hermansson, Ab initio calculations of $\mathrm{CO}$ physisorption on ceria(111), Surface Science 603 (2009) 2619-2623.

[178] Z.X. Yang, T.K. Woo, K. Hermansson,Strong and weak adsorption of $\mathrm{CO}$ on $\mathrm{CeO} 2$ surfaces from first principles calculations, Chemical Physics Letters 396 (2004) 384-392.

[179] F. Chen, D. Liu, J. Zhang, P. Hu, X.Q. Gong, G.Z. Lu,A DFT plus U study of the lattice oxygen reactivity toward direct $\mathrm{CO}$ oxidation on the $\mathrm{CeO} 2(111)$ and (110) surfaces, Physical Chemistry Chemical Physics 14 (2012) 16573-16580.

[180] M. Nolan, G.W. Watson, The surface dependence of CO adsorption on ceria, Journal of Physical Chemistry B 110 (2006) 16600-16606. 
[181] Y. Lykhach, T. Staudt, R. Streber, M.P. Lorenz, A. Bayer, H.P. Steinruck, J. Libuda,CO2 activation on single crystal based ceria and magnesia/ceria model catalysts, European Physical Journal B 75 (2010) 89-100.

[182] T. Staudt, Y. Lykhach, N. Tsud, T. Skala, K.C. Prince, V. Matolin, J. Libuda,Ceria reoxidation by CO2: A model study, Journal of Catalysis 275 (2010) 181-185.

[183] K.R. Hahn, M. Iannuzzi, A.P. Seitsonen, J. Hutter,Coverage Effect of the CO2 Adsorption Mechanisms on $\mathrm{CeO} 2(111)$ by First Principles Analysis, Journal of Physical Chemistry C 117 (2013) 1701-1711.

[184] Z. Cheng, B.J. Sherman, C.S. Lo,Carbon dioxide activation and dissociation on ceria (110): A density functional theory study, Journal of Chemical Physics 138 (2013).

[185] R.M. Ferrizz, T. Egami, G.S. Wong, J.M. Vohs, Reaction of $\mathrm{NO}$ on $\mathrm{CeO} 2$ and $\mathrm{Rh} / \mathrm{CeO} 2$ thin films supported on alpha-Al2O3(0001) and YSZ(100), Surface Science 476 (2001) 9-21.

[186] M. Daturi, N. Bion, J. Saussey, J.C. Lavalley, C. Hedouin, T. Seguelong, G. Blanchard,Evidence of a lacunar mechanism for deNO(x) activity in ceria-based catalysts, Physical Chemistry Chemical Physics 3 (2001) 252-255.

[187] Z. Yang, T.K. Woo, K. Hermansson,Adsorption of $\mathrm{NO}$ on unreduced and reduced $\mathrm{CeO} 2$ surfaces: A plane-wave DFT study, Surface Science 600 (2006) 4953-4960.

[188] J.A. Rodriguez, T. Jirsak, S. Sambasivan, D. Fischer, A. Maiti,Chemistry of NO2 on $\mathrm{CeO} 2$ and $\mathrm{MgO}$ : Experimental and theoretical studies on the formation of NO3, Journal of Chemical Physics 112 (2000) 9929-9939.

[189] M. Nolan, S.C. Parker, G.W. Watson, Reduction of NO2 on ceria surfaces, Journal of Physical Chemistry B 110 (2006) 2256-2262.

[190] C. Muller, K. Hermansson, B. Paulus, Electron correlation contribution to the N2O/ceria(111) interaction, Chemical Physics 362 (2009) 91-96.

[191] S.H. Overbury, D.R. Mullins, D.R. Huntley, L. Kundakovic,Chemisorption and reaction of sulfur dioxide with oxidized and reduced ceria surfaces, Journal of Physical Chemistry B 103 (1999) 11308-11317.

[192] M. Waqif, P. Bazin, O. Saur, J.C. Lavalley, G. Blanchard, O. Touret,Study of ceria sulfation, Applied Catalysis B-Environmental 11 (1997) 193-205.

[193] J.A. Rodriguez, T. Jirsak, A. Freitag, J.C. Hanson, J.Z. Larese, S. Chaturvedi,Interaction of $\mathrm{SO} 2$ with $\mathrm{CeO} 2$ and $\mathrm{Cu} / \mathrm{CeO} 2$ catalysts: photoemission, XANES and TPD studies, Catalysis Letters 62 (1999) 113-119.

[194] M.Y. Smirnov, A.V. Kalinkin, A.V. Pashis, A.M. Sorokin, A.S. Noskov, K.C. Kharas, V.I. Bukhtiyarov, Interaction of $\mathrm{Al} 2 \mathrm{O} 3$ and $\mathrm{CeO} 2$ surfaces with $\mathrm{SO} 2$ and $\mathrm{SO} 2+\mathrm{O}-2$ studied by X-ray photoelectron spectroscopy, Journal of Physical Chemistry B 109 (2005) 11712-11719.

[195] R.M. Ferriz, R.J. Gorte, J.M. Vohs,TPD and XPS investigation of the interaction of SO2 with model ceria catalysts, Catalysis Letters 82 (2002) 123-129.

[196] M. Happel, Y. Lykhach, N. Tsud, T. Skala, K.C. Prince, V. Matolin, J. Libuda,Mechanism of Sulfur Poisoning and Storage: Adsorption and Reaction of SO2 with Stoichiometric and Reduced Ceria Films on Cu(111), Journal of Physical Chemistry C 115 (2011) 19872-19882.

[197] Z.S. Lu, C. Muller, Z.X. Yang, K. Hermansson, J. Kullgren,SOx on ceria from adsorbed SO2, Journal of Chemical Physics 134 (2011).

[198] J. Kullgren, Z. Lu, Z. Yang, K. Hermansson,Sulfidation and Sulfur Recovery from SO2 over Ceria, The Journal of Physical Chemistry C 118 (2014) 17499-17504.

[199] H.T. Chen, Y.M. Choi, M.L. Liu, M.C. Lin,A first-principles analysis for sulfur tolerance of $\mathrm{CeO} 2$ in solid oxide fuel cells, Journal of Physical Chemistry C 111 (2007) 11117-11122.

[200] D.R. Mullins, T.S. McDonald,Adsorption and reaction of hydrogen sulfide on thin-film cerium oxide, Surface Science 601 (2007) 4931-4938.

[201] D.R. Mullins, K. Zhang,Interaction between NO and C2H4 on rh-loaded CeOx(111), Journal of Physical Chemistry B 105 (2001) 1374-1380. 
[202] R.M. Ferrizz, T. Egami, J.M. Vohs, The reaction of ethylene on a model automotive emissions control catalyst, Catalysis Letters 61 (1999) 33-38.

[203] G. Vile, B. Bridier, J. Wichert, J. Perez-Ramirez,Ceria in Hydrogenation Catalysis: High Selectivity in the Conversion of Alkynes to Olefins, Angewandte Chemie-International Edition 51 (2012) 8620-8623.

[204] J. Carrasco, G. Vilé, D. Fernández-Torre, R. Pérez, J. Pérez-Ramírez, M.V. GandugliaPirovano,Molecular-Level Understanding of $\mathrm{CeO} 2$ as a Catalyst for Partial Alkyne Hydrogenation, The Journal of Physical Chemistry C 118 (2014) 5352-5360.

[205] D.R. Mullins, P.M. Albrecht, F. Calaza,Variations in Reactivity on Different Crystallographic Orientations of Cerium Oxide, Topics in Catalysis 56 (2013) 1345 - 1362.

[206] M. Badlani, I.E. Wachs,Methanol: a "smart" chemical probe molecule, Catalysis Letters 75 (2001) 137-149.

[207] A. Beste, D.R. Mullins, S.H. Overbury, R.J. Harrison,Adsorption and dissociation of methanol on the fully oxidized and partially reduced (111) cerium oxide surface: Dependence on the configuration of the cerium $4 f$ electrons, Surface Science 602 (2008) 162-175.

[208] D.R. Mullins, M.D. Robbins, J. Zhou,Adsorption and reaction of methanol on thin-film cerium oxide, Surface Science 600 (2006) 1547-1558.

[209] D. Mei, N.A. Deskins, M. Dupuis, Q. Ge,Methanol adsorption on the clean CeO2(111) surface: A density functional theory study, Journal of Physical Chemistry C 111 (2007) 1051410522.

[210] D. Mei, N.A. Deskins, M. Dupuis, Q. Ge,Density functional theory study of methanol decomposition on the $\mathrm{CeO}(2)(110)$ surface, Journal of Physical Chemistry C 112 (2008) 42574266.

[211] P.M. Albrecht, D.R. Mullins,Adsorption and Reaction of Methanol over CeOx(100) Thin Films, Langmuir 29 (2013) 4559-4567.

[212] J.M. Tatibouet,Methanol oxidation as a catalytic surface probe, Applied Catalysis aGeneral 148 (1997) 213-252.

[213] D.R. Mullins, S.D. Senanayake, T.L. Chen,Adsorption and Reaction of C-1-C-3 Alcohols over CeOx(111) Thin Films, Journal of Physical Chemistry C 114 (2010) 17112-17119.

[214] D. Kulkarni, S.E. Wachs, Isopropanol oxidation by pure metal oxide catalysts: number of active surface sites and turnover frequencies, Applied Catalysis a-General 237 (2002) 121-137.

[215] T.L. Chen, D.R. Mullins, Ethylene Glycol Adsorption and Reaction over CeOx(111) Thin Films, Journal of Physical Chemistry C 115 (2011) 13725-13733.

[216] T.L. Chen, D.R. Mullins,Adsorption and Reaction of Acetaldehyde over CeOX(111) Thin Films, Journal of Physical Chemistry C 115 (2011) 3385-3392.

[217] S. Sato, R. Takahashi, T. Sodesawa, N.T. Honda,Dehydration of diols catalyzed by CeO2, Journal of Molecular Catalysis a-Chemical 221 (2004) 177-183.

[218] N. Ichikawa, S. Sato, R. Takahashi, T. Sodesawa, H. Fujita, T. Atoguchi, A. Shiga,Theoretical investigation of 1,3-butanediol adsorption on an oxygen-defected $\mathrm{CeO} 2$ (111) surface, Journal of Catalysis 239 (2006) 13-22.

[219] N. Ichikawa, S. Sato, R. Takahashi, T. Sodesawa,PIO study on 1,3-butanediol dehydration over $\mathrm{CeO} 2$ (111) surface, Journal of Molecular Catalysis a-Chemical 231 (2005) 181-189.

[220] G. Busca, V. Lorenzelli,Infrared Spectroscopic Indentification of Species Arising From Reactive Adsorption of Carbon Oxides on Metal Oxide Surfaces, Materials Chemistry 7 (1982) 89-126.

[221] C. Li, K. Domen, K. Maruya, T. Onishi,Spectroscopic Identification of Adsorbed Species Derived from Adsorption and Decomposition of Formic-Acid, Methanol, and Formaldehyde on Cerium Oxide, Journal of Catalysis 125 (1990) 445-455. 
[222] G.B. Deacon, R.J. Phillips,Relationships between the Carbon-Oxygen Stretching Frequencies of Carboxylato Complexes and the Type of Carboxylate Coordination, Coordination Chemistry Reviews 33 (1980) 227-250.

[223] J. Zhou, D.R. Mullins,Adsorption and reaction of formaldehyde on thin-film cerium oxide, Surface Science 600 (2006) 1540-1546.

[224] S.D. Senanayake, W.O. Gordon, S.H. Overbury, D.R. Mullins,Adsorption and Reaction of Acetone over CeOx(111) Thin Films, Journal of Physical Chemistry C 113 (2009) 6208-6214.

[225] F.C. Calaza, T.L. Chen, D.R. Mullins, S.H. Overbury,Structure and Reactivity of Alkyl Ethers Adsorbed on CeO2(111) Model Catalysts, Topics in Catalysis 54 (2011) 56-69.

[226] M.A. Henderson,Acetone chemistry on oxidized and reduced TiO2(110), Journal of Physical Chemistry B 108 (2004) 18932-18941.

[227] D.H. Mei, N.A. Deskins, M. Dupuis,A density functional theory study of formaldehyde adsorption on ceria, Surface Science 601 (2007) 4993-5001.

[228] J.T. Francis, A.P. Hitchcock,Inner-Shell Spectroscopy of Para-Benzoquinone, Hydroquinone, and Phenol - Distinguishing Quinoid and Benzenoid Structures, Journal of Physical Chemistry 96 (1992) 6598-6610.

[229] D.R. Mullins, T.S. McDonald,Adsorption and reaction of methanethiol on thin-film cerium oxide, Surface Science 602 (2008) 1280-1287.

[230] D.A. Chen, J.S. Ratliff, X.F. Hu, W.O. Gordon, S.D. Senanayake, D.R. Mullins, Dimethyl methylphosphonate decomposition on fully oxidized and partially reduced ceria thin films, Surface Science 604 (2010) 574-587.

[231] J.L. Lu, H.J. Gao, S. Shaikhutdinov, H.J. Freund,Gold supported on well-ordered ceria films: nucleation, growth and morphology in CO oxidation reaction, Catalysis Letters 114 (2007) 8-16.

[232] Y. Zhou, J.M. Perket, A.B. Crooks, J. Zhou,Effect of Ceria Support on the Structure of Ni Nanoparticles, Journal of Physical Chemistry Letters 1 (2010) 1447-1453.

[233] P. Luches, F. Pagliuca, S. Valeri, F. Illas, G. Preda, G. Pacchioni,Nature of Ag Islands and Nanoparticles on the CeO2(111) Surface, Journal of Physical Chemistry C 116 (2012) 1122-1132.

[234] J.A. Farmer, J.H. Baricuatro, C.T. Campbell,Ag Adsorption on Reduced CeO2(111) Thin Films, Journal of Physical Chemistry C 114 (2010) 17166-17172.

[235] M. Baron, O. Bondarchuk, D. Stacchiola, S. Shaikhutdinov, H.J. Freund, Interaction of Gold with Cerium Oxide Supports: CeO2(111) Thin Films vs CeOx Nanoparticles, Journal of Physical Chemistry C 113 (2009) 6042-6049.

[236] Y. Pan, Y. Cui, C. Stiehler, N. Nilius, H.J. Freund,Gold Adsorption on CeO2 Thin Films Grown on Ru(0001), Journal of Physical Chemistry C 117 (2013) 21879-21885.

[237] Y. Zhou, J. Zhou,Interactions of Ni Nanoparticles with Reducible CeO2(111) Thin Films, Journal of Physical Chemistry C 116 (2012) 9544-9549.

[238] Y. Zhou, J.M. Perket, J. Zhou,Growth of Pt Nanoparticles on Reducible CeO2(111) Thin Films: Effect of Nanostructures and Redox Properties of Ceria, Journal of Physical Chemistry C 114 (2010) 11853-11860.

[239] E.L. Wilson, R. Grau-Crespo, C.L. Pang, G. Cabailh, Q. Chen, J.A. Purton, C.R.A. Catlow, W.A. Brown, N.H. de Leeuw, G. Thornton,Redox behavior of the model catalyst $\mathrm{Pd} / \mathrm{CeO}_{2-x} / \mathrm{Pt}(111)$, Journal of Physical Chemistry C 112 (2008) 10918-10922.

[240] T. Skala, N. Tsud, K.C. Prince, V. Matolin,Formation of alumina-ceria mixed oxide in model systems, Applied Surface Science 257 (2011) 3682-3687.

[241] T. Skala, F. Sutara, M. Cabala, M. Skoda, K.C. Prince, V. Matolin,A photoemission study of the interaction of $\mathrm{Ga}$ with CeO2(111) thin films, Applied Surface Science 254 (2008) 68606864.

[242] Y. Zhou, J. Zhou,Ti/CeOx(111) interfaces studied by XPS and STM, Surface Science 606 (2012) 749-753. 
[243] G.S. Wong, J.M. Vohs,An XPS study of the growth and electronic structure of vanadia films supported on CeO2(111), Surface Science 498 (2002) 266-274.

[244] T. Skala, N. Tsud, K.C. Prince, V. Matolin, Interaction of tungsten with CeO2(111) layers as a function of temperature: a photoelectron spectroscopy study, Journal of PhysicsCondensed Matter 23 (2011).

[245] M.M. Branda, N.C. Hernandez, J.F. Sanz, F. Illas, Density Functional Theory Study of the Interaction of $\mathrm{Cu}, \mathrm{Ag}$, and $\mathrm{Au}$ Atoms with the Regular $\mathrm{CeO} 2$ (111) Surface, Journal of Physical Chemistry C 114 (2010) 1934-1941.

[246] L. Cui, Y. Tang, H. Zhang, L.G. Hector, Jr., C. Ouyang, S. Shi, H. Li, L. Chen,Firstprinciples investigation of transition metal atom $\mathrm{M}(\mathrm{M}=\mathrm{Cu}, \mathrm{Ag}, \mathrm{Au})$ adsorption on $\mathrm{CeO}(110)$, Physical Chemistry Chemical Physics 14 (2012) 1923-1933.

[247] Y. Tang, H. Zhang, L. Cui, C. Ouyang, S. Shi, W. Tang, H. Li, L. Chen,Electronic states of metal $(\mathrm{Cu}, \mathrm{Ag}, \mathrm{Au})$ atom on $\mathrm{CeO} 2(111)$ surface: The role of local structural distortion, Journal of Power Sources 197 (2012) 28-37.

[248] Y. Chen, P. Hu, M.-H. Lee, H. Wang,Au on (111) and (110) surfaces of CeO2: A densityfunctional theory study, Surface Science 602 (2008) 1736-1741.

[249] B.-T. Teng, F.-M. Wu, W.-X. Huang, X.-D. Wen, L.-H. Zhao, M.-F. Luo,A DFT Study of the Structures of Aux Clusters on a CeO2(111) Surface, Chemphyschem 13 (2012) 1261-1271.

[250] C. Zhang, A. Michaelides, D.A. King, S.J. Jenkins,Anchoring Sites for Initial Au Nucleation on CeO2\{111\}: O Vacancy versus Ce Vacancy, Journal of Physical Chemistry C 113 (2009) 6411-6417.

[251] Z.P. Liu, S.J. Jenkins, D.A. King,Origin and activity of oxidized gold in water-gas-shift catalysis, Physical Review Letters 94 (2005).

[252] N.C. Hernandez, R. Grau-Crespo, N.H. de Leeuw, J.F. Sanz,Electronic charge transfer between ceria surfaces and gold adatoms: a GGA plus $U$ investigation, Physical Chemistry Chemical Physics 11 (2009) 5246-5252.

[253] C.J. Zhang, A. Michaelides, D.A. King, S.J. Jenkins,Positive Charge States and Possible Polymorphism of Gold Nanoclusters on Reduced Ceria, Journal of the American Chemical Society 132 (2010) 2175-2182.

[254] Z. Lu, Z. Yang, K. Hermansson, in: Y. Zhang (Ed.), Advanced Materials Research, 2011, pp. 166-171.

[255] L. Szabova, M.F. Camellone, M. Huang, V. Matolin, S. Fabris,Thermodynamic, electronic and structural properties of $\mathrm{Cu} / \mathrm{CeO} 2$ surfaces and interfaces from first-principles DFT plus U calculations, Journal of Chemical Physics 133 (2010) -.

[256] Z.X. Yang, L.G. Xie, D.W. Ma, G.T. Wang,Origin of the High Activity of the CeriaSupported Copper Catalyst for H2O Dissociation, Journal of Physical Chemistry C 115 (2011) 6730-6740.

[257] Z. Yang, Z. Lu, G. Luo, K. Hermansson,Oxygen vacancy formation energy at the $\mathrm{Pd} / \mathrm{CeO} 2(111)$ interface, Physics Letters A 369 (2007) 132-139.

[258] Z. Lu, Z. Yang,Interfacial properties of $\mathrm{NM} / \mathrm{CeO} 2(111)$ (NM = noble metal atoms or clusters of Pd, Pt and Rh): a first principles study, Journal of Physics-Condensed Matter 22 (2010).

[259] B. Li, O.K. Ezekoye, Q. Zhang, L. Chen, P. Cui, G. Graham, X. Pan,Origin of Rh and Pd agglomeration on the CeO2(111) surface, Physical Review B 82 (2010).

[260] G.N. Vayssilov, et al.,Support nanostructure boosts oxygen transfer to catalytically active platinum nanoparticles, Nature Materials 10 (2011) 310-315.

[261] A. Bruix, F. Nazari, K.M. Neyman, F. Illas,On the adsorption and formation of Pt dimers on the CeO2(111) surface, Journal of Chemical Physics 135 (2011).

[262] A. Bruix, K.M. Neyman, F. Illas,Adsorption, Oxidation State, and Diffusion of Pt Atoms on the CeO2(111) Surface, Journal of Physical Chemistry C 114 (2010) 14202-14207. 
[263] W.Y. Song, C. Popa, A.P.J. Jansen, E.J.M. Hensen,Formation of a Rhodium Surface Oxide Film in Rh-n/CeO2(111) Relevant for Catalytic CO Oxidation: A Computational Study, Journal of Physical Chemistry C 116 (2012) 22904-22915.

[264] J.H. Larsen, J.T. Ranney, D.E. Starr, J.E. Musgrove, C.T. Campbell,Adsorption energetics of $\mathrm{Ag}$ on $\mathrm{MgO}(100)$, Physical Review B 63 (2001).

[265] J.A. Farmer, C.T. Campbell,Ceria Maintains Smaller Metal Catalyst Particles by Strong Metal-Support Bonding, Science 329 (2010) 933-936.

[266] S.D. Senanayake, J. Evans, S. Agnoli, L. Barrio, T.L. Chen, J. Hrbek, J.A. Rodriguez,Water-Gas Shift and CO Methanation Reactions over Ni-CeO2(111) Catalysts, Topics in Catalysis 54 (2011) 34-41.

[267] T. Skala, F. Sutara, M. Skoda, K.C. Prince, V. Matolin,Palladium interaction with CeO2, Sn-Ce-O and Ga-Ce-O layers, Journal of Physics-Condensed Matter 21 (2009) -.

[268] J. Matharu, G. Cabailh, R. Lindsay, C.L. Pang, D.C. Grinter, T. Skala, G. Thornton,Reduction of thin-film ceria on $\mathrm{Pt}(111)$ by supported Pd nanoparticles probed with resonant photoemission, Surface Science 605 (2011) 1062-1066.

[269] V. Nehasil, K. Sevcikova, T. Zahoranova, N. Tsud, T. Skala, J. Libra,Photoemission study of $\mathrm{Rh} / \mathrm{CeO} 2 / \mathrm{Cu}(111)$ system-Oxidation state, stability and interaction with adsorbed gases, Journal of Electron Spectroscopy and Related Phenomena 181 (2010) 229-233.

[270] A. Pfau, K.D. Schierbaum, W. Gopel,The Electronic-Structure of Ceo2 Thin-Films - the Influence of Rh Surface Dopants, Surface Science 333 (1995) 1479-1485.

[271] C.T. Campbell,Ultrathin metal films and particles on oxide surfaces: Structural, electronic and chemisorptive properties, Surface Science Reports 27 (1997) 1-111.

[272] H.L. Abbott, A. Aumer, Y. Lei, C. Asokan, R.J. Meyer, M. Sterrer, S. Shaikhutdinov, H.J. Freund,CO Adsorption on Monometallic and Bimetallic Au-Pd Nanoparticles Supported on Oxide Thin Films, Journal of Physical Chemistry C 114 (2010) 17099-17104.

[273] E.L. Wilson, Q. Chen, W.A. Brown, G. Thornton,CO adsorption on the model catalyst $\mathrm{Pd} / \mathrm{CeO}_{2-x}(111) / \mathrm{Rh}(111)$, Journal of Physical Chemistry C 111 (2007) 14215-14222.

[274] E.L. Wilson, W.A. Brown, G. Thornton,RAIRS studies of $\mathrm{CO}$ adsorption on $\mathrm{Pd} / \mathrm{CeO}_{2}$. $x(111) / P t(111)$, Surface Science 600 (2006) 2555-2561.

[275] M. Happel, J. Myslivecek, V. Johanek, F. Dvorak, O. Stetsovych, Y. Lykhach, V. Matolin, J. Libuda,Adsorption sites, metal-support interactions, and oxygen spillover identified by vibrational spectroscopy of adsorbed CO: A model study on Pt/ceria catalysts, Journal of Catalysis 289 (2012) 118-126.

[276] H. Cordatos, T. Bunluesin, J. Stubenrauch, J.M. Vohs, R.J. Gorte,Effect of ceria structure on oxygen migration for Rh/ceria catalysts, Journal of Physical Chemistry 100 (1996) 785-789.

[277] G.S. Zafiris, R.J. Gorte,EVIDENCE FOR A 2ND CO OXIDATION MECHANISM ON RH CERIA, Journal of Catalysis 143 (1993) 86-91.

[278] G.S. Zafiris, R.J. Gorte,EVIDENCE FOR LOW-TEMPERATURE OXYGEN MIGRATION FROM CERIA TO RH, Journal of Catalysis 139 (1993) 561-567.

[279] D.R. Mullins, S.H. Overbury, CO dissociation on Rh deposited on reduced cerium oxide thin films, Journal of Catalysis 188 (1999) 340-345.

[280] T. Bunluesin, E.S. Putna, R.J. Gorte,A comparison of CO oxidation on ceria-supported $\mathrm{Pt}, \mathrm{Pd}$, and Rh, Catalysis Letters 41 (1996) 1-5.

[281] T. Bunluesin, R.J. Gorte, G.W. Graham,CO oxidation for the characterization of reducibility in oxygen storage components of three-way automotive catalysts, Applied Catalysis B-Environmental 14 (1997) 105-115.

[282] S. Johansson, L. Osterlund, B. Kasemo,CO oxidation bistability diagrams for $\mathrm{Pt} / \mathrm{CeOx}$ and $\mathrm{Pt} / \mathrm{SiO} 2$ model catalysts prepared by electron-beam lithography, Journal of Catalysis 201 (2001) 275-285. 
[283] H.Y. Kim, G. Henkelman,CO Oxidation at the Interface of Au Nanoclusters and the Stepped-CeO2(111) Surface by the Mars-van Krevelen Mechanism, Journal of Physical Chemistry Letters 4 (2013) 216-221.

[284] H.Y. Kim, H.M. Lee, G. Henkelman,CO Oxidation Mechanism on CeO2-Supported Au Nanoparticles, Journal of the American Chemical Society 134 (2012) 1560-1570.

[285] D.G. Castner, G.A. Somorjai,Leed and Thermal-Desorption Studies of Small Molecules $(\mathrm{H}-2$, O2, Co, Co2, No, C2h4, C2h2 and C) Chemisorbed on the Stepped Rhodium (755) and (331) Surfaces, Surface Science 83 (1979) 60-82.

[286] M. Rebholz, R. Prins, N. Kruse,Adsorption and Dissociation of Co on Rh(210), Surface Science 259 (1991) L797-L803.

[287] M. Frank, et al.,Particle size dependent CO dissociation on alumina-supported Rh: a model study, Chemical Physics Letters 279 (1997) 92-99.

[288] S. Andersson, M. Frank, A. Sandell, A. Giertz, B. Brena, P.A. Bruhwiler, N. Martensson, J. Libuda, M. Baumer, H.J. Freund,CO dissociation characteristics on size-distributed rhodium islands on alumina model substrates, Journal of Chemical Physics 108 (1998) 2967-2974.

[289] A. Sandell, J. Libuda, M. Baumer, H.J. Freund,Metal deposition in adsorbate atmosphere: Growth and decomposition of a palladium carbonyl-like species, Surface Science 346 (1996) 108-126.

[290] J. Xu, D.R. Mullins, S.H. Overbury,CO desorption and oxidation on CeO2-supported Rh: Evidence for two types of Rh sites, Journal of Catalysis 243 (2006) 158-164.

[291] E.C. Akubuiro, X.E. Verykios,Effects of Dopants on Performance of Metal Crystallites .2. Further Characterization of Doped Supports and Catalysts, Journal of Catalysis 113 (1988) 106119.

[292] R.G. Sharpe, M. Bowker,The adsorption and decomposition of NO on Pd(110), Surface Science 360 (1996) 21-30.

[293] I. Nakamura, T. Fujitani, H. Hamada,Adsorption and decomposition of NO on Pd surfaces, Surface Science 514 (2002) 409-413.

[294] R.J. Gorte, L.D. Schmidt, J.L. Gland,Binding States and Decomposition of No on SingleCrystal Planes of Pt, Surface Science 109 (1981) 367-380.

[295] A. Siokou, R.M. van Hardeveld, J.W. Niemantsverdriet,Surface reactions of nitrogen oxide on rhodium(100), adsorption, dissociation and desorption, Surface Science 404 (1998) 110-114.

[296] E.I. Altman, R.J. Gorte,Temperature-Programmed Desorption Study of No on Pt Particles Supported on Alpha-Al2o3(0001), Journal of Physical Chemistry 93 (1989) 1993-1997. [297] S.H. Overbury, D.R. Mullins, L. Kundakovic,Enhancement of dissociation by metalsupport interaction: reaction of $\mathrm{NO}$ on $\mathrm{Rh}$ supported by ceria films of controlled oxidation state, Surface Science 470 (2001) 243-254.

[298] H.J. Borg, J.F.C.J.M. Reijerse, R.A. Vansanten, J.W. Niemantsverdriet,The Dissociation Kinetics of No on Rh(lii) as Studied by Temperature-Programmed Static Secondary-Ion MassSpectrometry and Desorption, Journal of Chemical Physics 101 (1994) 10052-10063.

[299] D.R. Mullins, S.H. Overbury,Coverage dependent dissociation of NO on Rh supported on cerium oxide thin films, Surface Science 511 (2002) L293-L297.

[300] V. Schmatloch, I. Jirka, N. Kruse,Surface-Reaction Kinetics of No on Rh(110), Journal of Chemical Physics 100 (1994) 8471-8482.

[301] M.J.P. Hopstaken, J.W. Niemantsverdriet,Lateral interactions in the dissociation kinetics of NO on Rh(100), Journal of Physical Chemistry B 104 (2000) 3058-3066.

[302] D.R. Mullins, L. Kundakovic, S.H. Overbury, The interaction between NO and CO on Rhloaded CeOx(111), Journal of Catalysis 195 (2000) 169-179.

[303] C.T. Campbell, J.M. White,Chemisorption and Reactions of Nitric-Oxide on Rhodium, Applied Surface Science 1 (1978) 347-359. 
[304] T.W. Root, L.D. Schmidt, G.B. Fisher,Nitric-Oxide Reduction by Co on Rh(111) Temperature Programmed Reaction, Surface Science 150 (1985) 173-192.

[305] C.H.F. Peden, D.N. Belton, S.J. Schmieg,Structure Sensitive Selectivity of the No-Co Reaction over $\mathrm{Rh}(110)$ and $\mathrm{Rh}(111)$, Journal of Catalysis 155 (1995) 204-218.

[306] D.N. Belton, S.J. Schmieg,Oxidation of Co by No over Rh(111), Journal of Catalysis 144 (1993) 9-15.

[307] V. Schmatloch, N. Kruse,Adsorption and Reaction of Co, No and Mixtures of Co/No on Rh(110), Surface Science 269 (1992) 488-494.

[308] L.H. Dubois, P.K. Hansma, G.A. Somorjai,Evidence for an Oxygen Intermediate in the Catalytic Reduction of No by Co on Rhodium Surfaces, Journal of Catalysis 65 (1980) 318-327.

[309] V.P. Zhdanov, B. Kasemo,Mechanism and kinetics of the NO-CO reaction on Rh, Surface Science Reports 29 (1997) 35-90.

[310] R.M. vanHardeveld, A.J.G.W. Schmidt, J.W. Niemantsverdriet,Surface reactions of nitrogen oxide and ethylene on rhodium(111), Catalysis Letters 41 (1996) 125-131.

[311] J. Kiss, F. Solymosi,Adsorption of $\mathrm{H} 2 \mathrm{O}$ on Clean and on Boron-Contaminated $\mathrm{Rh}$ Surfaces, Surface Science 177 (1986) 191-206.

[312] H.-L. Chen, W.-T. Peng, J.-J. Ho, H.-M. Hsieh,Density-functional calculation of the adsorption and reaction of $\mathrm{CO}$ and $\mathrm{H} 2 \mathrm{O}$ molecules over a $4 \mathrm{Rh} / \mathrm{CeO} 2(111)$ surface, Chemical Physics 348 (2008) 161-168.

[313] J.A. Rodriguez, P. Liu, J. Hrbek, J. Evans, M. Perez,Water gas shift reaction on Cu and $\mathrm{Au}$ nanoparticles supported on $\mathrm{CeO} 2(111)$ and $\mathrm{ZnO}(000(1)$ over-bar): Intrinsic activity and importance of support interactions, Angewandte Chemie-International Edition 46 (2007) 13291332.

[314] J.A. Rodriguez,Gold-based catalysts for the water-gas shift reaction: Active sites and reaction mechanism, Catalysis Today 160 (2011) 3-10.

[315] E.S. Putna, R.J. Gorte, J.M. Vohs, G.W. Graham,Evidence for enhanced dissociation of $\mathrm{CO}$ on Rh/ceria, Journal of Catalysis 178 (1998) 598-603.

[316] P. Liu, J.A. Rodriguez,Water-gas-shift reaction on metal nanoparticles and surfaces, Journal of Chemical Physics 126 (2007).

[317] S.D. Senanayake, J.A. Rodriguez, D. Stacchiola,Electronic Metal-Support Interactions and the Production of Hydrogen Through the Water-Gas Shift Reaction and Ethanol Steam Reforming: Fundamental Studies with Well-Defined Model Catalysts, Topics in Catalysis 56 (2013) 1488-1498.

[318] J. Zhou, D.R. Mullins, Rh-promoted methanol decomposition on cerium oxide thin films, Journal of Physical Chemistry B 110 (2006) 15994-16002.

[319] C. Houtman, M.A. Barteau,Reactions of Methanol on Rh(111) and Rh(111)-(2x2)O Surfaces - Spectroscopic Identification of Adsorbed Methoxide and Eta-1-Formaldehyde, Langmuir 6 (1990) 1558-1566.

[320] J.E. Parmeter, X.D. Jiang, D.W. Goodman,The Adsorption and Decomposition of Methanol on the Rh(100) Surface, Surface Science 240 (1990) 85-100.

[321] J. Libuda, H.J. Freund,Molecular beam experiments on model catalysts, Surface Science Reports 57 (2005) 157-298.

[322] M. Bowker, P. Stone, R. Bennett, N. Perkins,Formic acid adsorption and decomposition on TiO2(110) and on Pd/TiO2(110) model catalysts, Surface Science 511 (2002) 435-448.

[323] V. Matolin, V. Johanek, M. Skoda, N. Tsud, K.C. Prince, T. Skala, I. Matolinova,Methanol Adsorption and Decomposition on Pt/CeO2(111)/Cu(111) Thin Film Model Catalyst, Langmuir 26 (2010) 13333-13341.

[324] E. Martono, J.M. Vohs,Support effects in cobalt-based ethanol steam reforming catalysts: Reaction of ethanol on Co/CeO2/YSZ(l 0 l 0 ) model catalysts, Journal of Catalysis 291 (2012) 79-86. 
[325] H.-L. Chen, S.-H. Liu, J.-J. Ho, Theoretical calculation of the dehydrogenation of ethanol on a Rh/CeO2(111) surface, Journal of Physical Chemistry B 110 (2006) 14816-14823.

[326] H.-J. Li, H.-L. Chen, S.-F. Peng, J.-J. Ho,Dehydrogenation of ethanol on an O-24Rh/ $\mathrm{CeO}_{2-x}(111)$ surface: A computational study, Chemical Physics 359 (2009) 141-150.

[327] J.A. Rodriguez, P. Liu, M. Perez, G. Liu, J. Hrbek,Destruction of SO2 on An and Cu Nanoparticles Dispersed on $\mathrm{MgO}(100)$ and $\mathrm{CeO} 2(111)$, Journal of Physical Chemistry A 114 (2010) 3802-3810.

[328] J.A. Rodriguez, M. Perez, J. Evans, G. Liu, J. Hrbek,Reaction of SO2 with $\mathrm{Au} / \mathrm{CeO} 2(111)$ : Importance of $\mathrm{O}$ vacancies in the activation of gold, Journal of Chemical Physics 122 (2005).

[329] M. Polcik, L. Wilde, J. Haase, B. Brena, D. Cocco, G. Comelli, G. Paolucci,Adsorption and temperature-dependent decomposition of $\mathrm{SO} 2$ on $\mathrm{Cu}(100)$ and $\mathrm{Cu}(111)$ : A fast and highresolution core-level spectroscopy study, Physical Review B 53 (1996) 13720-13724.

[330] A.R. Alemozafar, X.C. Guo, R.J. Madix,Adsorption and reaction of sulfur dioxide with $\mathrm{Cu}(110)$ and $\mathrm{Cu}(110)-\mathrm{p}(2 \times 1)-\mathrm{O}$, Journal of Chemical Physics 116 (2002) 4698-4706.

[331] G. Liu, J.A. Rodriguez, J. Dvorak, J. Hrbek, T. Jirsak,Chemistry of sulfur-containing molecules on $\mathrm{Au}(111)$ : thiophene, sulfur dioxide, and methanethiol adsorption, Surface Science 505 (2002) 295-307.

[332] R. Streber, C. Papp, M.P.A. Lorenz, O. Hofert, E. Darlatt, A. Bayer, R. Denecke, H.P. Steinruck,SO2 adsorption and thermal evolution on clean and oxygen precovered $\mathrm{Pt}(111)$, Chemical Physics Letters 494 (2010) 188-192.

[333] M. Polcik, L. Wilde, J. Haase, B. Brena, G. Comelli, G. Paolucci,High-resolution XPS and NEXAFS study of SO2 adsorption on Pt(111): Two surface SO2 species, Surface Science 381 (1997) L568-L572.

[334] P. Zebisch, M. Stichler, P. Trischberger, M. Weinelt, H.P. Steinruck,Adsorption and thermal evolution of SO2 on the Pt(110) surface, Surface Science 371 (1997) 235-244.

[335] R. Streber, C. Papp, M.P.A. Lorenz, O. Hofert, W. Zhao, S. Wickert, E. Darlatt, A. Bayer, R. Denecke, H.P. Steinruck, Influence of Steps on the Adsorption and Thermal Evolution of SO2 on Clean and Oxygen Precovered Pt Surfaces, Journal of Physical Chemistry C 114 (2010) 19734-19743.

[336] D.G. Castner, B.A. Sexton, G.A. Somorjai,Leed and Thermal Desorption Studies of Small Molecules (H2,O2,Co,Co2,No,C2h4,C2h2 and C) Chemisorbed on Rhodium (111) and (100) Surfaces, Surface Science 71 (1978) 519-540.

[337] L.H. Dubois, D.G. Castner, G.A. Somorjai, The Chemisorption of Acetylene and Ethylene on $\mathrm{Rh}(111)$ - a Low-Energy Electron-Diffraction (Leed), High-Resolution Electron-Energy Loss (Els), and Thermal-Desorption Mass-Spectrometry (Tds) Study, Journal of Chemical Physics 72 (1980) 5234-5240.

[338] A.J. Slavin, B.E. Bent, C.T. Kao, G.A. Somorjai,Thermal Fragmentation of Ethylene on the $\mathrm{Rh}(100)$ Single-Crystal Surface in the Temperature-Range of 200-800 K, Surface Science 206 (1988) 124-144.

[339] Y. Lykhach, T. Staudt, N. Tsud, T. Skala, K.C. Prince, V. Matolin, J. Libuda,Enhanced reactivity of $\mathrm{Pt}$ nanoparticles supported on ceria thin films during ethylene dehydrogenation, Physical Chemistry Chemical Physics 13 (2011) 253-261.

[340] Y. Lykhach, T. Staudt, M.P.A. Lorenz, R. Streber, A. Bayer, H.P. Steinruck, J. Libuda,Microscopic Insights into Methane Activation and Related Processes on Pt/Ceria Model Catalysts, Chemphyschem 11 (2010) 1496-1504.

[341] F. Vines, Y. Lykhach, T. Staudt, M.P.A. Lorenz, C. Papp, H.P. Steinruck, J. Libuda, K.M. Neyman, A. Gorling,Methane Activation by Platinum: Critical Role of Edge and Corner Sites of Metal Nanoparticles, Chemistry-a European Journal 16 (2010) 6530-6539.

[342] R. Craciun, B. Shereck, R.J. Gorte, Kinetic studies of methane steam reforming on ceriasupported Pd, Catalysis Letters 51 (1998) 149-153. 
[343] J.A. Rodriguez, J. Hrbek,Inverse oxide/metal catalysts: A versatile approach for activity tests and mechanistic studies, Surface Science 604 (2010) 241-244.

[344] X.E. Zhao, S.G. Ma, J. Hrbek, J.A. Rodriguez,Reaction of water with $\mathrm{Ce}-\mathrm{Au}(111)$ and $\mathrm{CeOx} / \mathrm{Au}(111)$ surfaces: Photoemission and STM studies, Surface Science 601 (2007) 24452452.

[345] S. Eck, C. Castellarin-Cudia, S. Surnev, K.C. Prince, M.G. Ramsey, F.P. Netzer,Adsorption and reaction of $\mathrm{CO}$ on a ceria-Rh(111) "inverse model catalyst" surface, Surface Science 536 (2003) 166-176.

[346] C. Hardacre, R.M. Ormerod, R.M. Lambert,PLATINUM-PROMOTED CATALYSIS BY CERIA - A STUDY OF CARBON-MONOXIDE OXIDATION OVER PT(111)/CEO2, Journal of Physical Chemistry 98 (1994) 10901-10905.

[347] R. Wrobel, Y. Suchorski, S. Becker, H. Weiss,Cerium oxide layers on the Cu(111) surface: Substrate-mediated redox properties, Surface Science 602 (2008) 436-442.

[348] V. Matolin, L. Sedlacek, I. Matolinova, F. Sutara, T. Skala, B. Smid, J. Libra, V. Nehasil, K.C. Prince,Photoemission spectroscopy study of $\mathrm{Cu} / \mathrm{CeO} 2$ systems: $\mathrm{Cu} / \mathrm{CeO} 2$ nanosized catalyst and $\mathrm{CeO} 2(111) / \mathrm{CU}(111)$ inverse model catalyst, Journal of Physical Chemistry C 112 (2008) 3751-3758.

[349] J.A. Rodriguez, et al.,Water-Gas Shift Reaction on a Highly Active Inverse $\mathrm{CeOx} / \mathrm{Cu}(111)$ Catalyst: Unique Role of Ceria Nanoparticles, Angewandte Chemie-International Edition 48 (2009) 8047-8050.

[350] S.D. Senanayake, J.T. Sadowski, J. Evans, S. Kundu, S. Agnoli, F. Yang, D. Stacchiola, J.I. Flege, J. Hrbek, J.A. Rodriguez,Nanopattering in $\mathrm{CeOx} / \mathrm{Cu}(111)$ : A New Type of Surface Reconstruction and Enhancement of Catalytic Activity, Journal of Physical Chemistry Letters 3 (2012) 839-843.

[351] S.D. Senanayake, D. Stacchiola, J.A. Rodriguez,Unique Properties of Ceria Nanoparticles Supported on Metals: Novel Inverse Ceria/Copper Catalysts for CO Oxidation and the Water-Gas Shift Reaction, Accounts of Chemical Research 46 (2013) 1702-1711.

[352] J.A. Rodriguez, et al.,Water-Gas Shift Reaction on a Highly Active Inverse $\mathrm{CeOx} / \mathrm{Cu}(111)$ Catalyst: Unique Role of Ceria Nanoparticles, Angewandte Chemie-International Edition 48 (2009) 8047-8050.

[353] J.A. Rodriguez, S.D. Senanayake, D. Stacchiola, P. Liu, J. Hrbek, The Activation of Gold and the Water-Gas Shift Reaction: Insights from Studies with Model Catalysts, Accounts of Chemical Research 47 (2014) 773-782.

[354] K.B. Zhou, X. Wang, X.M. Sun, Q. Peng, Y.D. Li,Enhanced catalytic activity of ceria nanorods from well-defined reactive crystal planes, Journal of Catalysis 229 (2005) 206-212.

[355] H.X. Mai, L.D. Sun, Y.W. Zhang, R. Si, W. Feng, H.P. Zhang, H.C. Liu, C.H. Yan,Shapeselective synthesis and oxygen storage behavior of ceria nanopolyhedra, nanorods, and nanocubes, Journal of Physical Chemistry B 109 (2005) 24380-24385.

[356] L. Yan, R.B. Yu, J. Chen, X.R. Xing,Template-free hydrothermal synthesis of $\mathrm{CeO} 2$ nano-octahedrons and nanorods: Investigation of the morpholog evolution, Crystal Growth \& Design 8 (2008) 1474-1477.

[357] E. Aneggi, J. Llorca, M. Boaro, A. Trovarelli,Surface-structure sensitivity of CO oxidation over polycrystalline ceria powders, Journal of Catalysis 234 (2005) 88-95.

[358] M.K. Templeton, W.H. Weinberg,Adsorption and Decomposition of Dimethyl Methylphosphonate on an Aluminum-Oxide Surface, Journal of the American Chemical Society 107 (1985) 97-108.

[359] C.N. Rusu, J.T. Yates,Adsorption and decomposition of dimethyl methylphosphonate on TiO2, Journal of Physical Chemistry B 104 (2000) 12292-12298.

[360] D.A. Panayotov, J.R. Morris, Uptake of a Chemical Warfare Agent Simulant (DMMP) on TiO2: Reactive Adsorption and Active Site Poisoning, Langmuir 25 (2009) 3652-3658. 
[361] D.A. Panayotov, J.R. Morris, Catalytic degradation of a chemical warfare agent simulant: Reaction mechanisms on TiO2-supported Au nanoparticles, Journal of Physical Chemistry C 112 (2008) 7496-7502. 


\section{Figure Captions}

Figure 1 - Ce 3d XPS spectra excited by Mg ka x-rays. A) Fully oxidized $\mathrm{CeO}_{2}(111)$, B) partially reduced $\mathrm{CeO}_{2}(111)$, and $\mathrm{C}$ ) fully reduced $\mathrm{Ce}(\mathrm{III})$ oxide. The dotted line over (B) is the best-fit from a linear combination of $(A)$ and $(C)$. Reprinted from Ref. [43] with permission from Elsevier.

Figure 2 - Ce 4d XPS spectra excited at 350 eV. A) Fully oxidized $\mathrm{CeO}_{2}(110)$, B) partially reduced $\mathrm{CeO}_{2}(110)$, and $\mathrm{C}$ ) fully reduced $\mathrm{Ce}$ (III) oxide. The dotted line over (B) is the best-fit from a linear combination of $(A)$ and $(C)$. Reprinted from Ref.[43] with permission from Elsevier.

Figure 3 - Valence level photoemission spectra record from clean, fully oxidized $\mathrm{CeO}_{2}(111)(\mathrm{A})$ and partially reduced $\mathrm{CeO}_{2-x}(111)(\mathrm{B})$. The spectra were recorded using photon energies offresonance $\left(115.0 \mathrm{eV}\right.$, black), at the $\mathrm{Ce}^{3+}$ resonance $\left(121.4 \mathrm{eV}\right.$, red) and at the $\mathrm{Ce}^{4+}$ resonance (124.8 eV, green). Reprinted from Ref. [51] with permission from Elsevier.

Figure 4- The unit cell of $\mathrm{CeO}_{2}$. The black spheres are $\mathrm{Ce}$ and the white spheres are $\mathrm{O}$. Note that the spheres have been drawn at $50 \%$ space-filling so that the $\mathrm{Ce}-\mathrm{O}$ bonding could be shown.

Figure $5-\mathrm{CeO}_{2}(110)$ depicted as an unreconstructed Tasker Type 1 surface.[92] The black spheres are $\mathrm{Ce}$ and the white spheres are $\mathrm{O}$. The spheres have been drawn at $100 \%$ spacefilling to indicate accessibility to subsurface sites. CV refers to the number of coordination vacancies around the $\mathrm{Ce}$ and $\mathrm{O}$ ions in the top layer.

Figure $6-\mathrm{CeO}_{2}(111)$ depicted as an unreconstructed Tasker Type 2 surface.[92] The black spheres are $\mathrm{Ce}$ and the white spheres are $\mathrm{O}$. The spheres have been drawn at $100 \%$ spacefilling to indicate accessibility to subsurface sites. CV refers to the number of coordination vacancies around the $\mathrm{Ce}$ in the second layer and $\mathrm{O}$ in the top layer.

Figure 7a - $\mathrm{CeO}_{2}(100)$ depicted as an unreconstructed Tasker Type 3 surface.[92] The black spheres are $\mathrm{Ce}$ and the white spheres are $\mathrm{O}$. The spheres have been drawn at $100 \%$ spacefilling to indicate accessibility to subsurface sites. CV refers to the number of coordination vacancies around the $\mathrm{Ce}$ in the second layer and $\mathrm{O}$ in the top layer.

Figure $7 \mathrm{~b}-\mathrm{CeO}_{2}(100)$ depicted as a reconstructed surface. The black spheres are $\mathrm{Ce}$ and the white spheres are $\mathrm{O}$. The spheres have been drawn at $100 \%$ space-filling to indicate accessibility to subsurface sites. CV refers to the number of coordination vacancies around the $\mathrm{Ce}$ in the second layer and $\mathrm{O}$ in the top layer.

Figure 8 - (a) Topographic SFM images of the $\mathrm{CeO}_{2}(111)$ surface morphology observed directly after preparation. (b) Height profile taken along the straight line in $(\mathrm{a}(\mathrm{i})$ ) revealing steps of triplelayer height. (c) Atomically resolved image together with a schematic model (d) of the stoichiometric oxygen terminated (111) surface. (e) Height profile as indicated in (a(ii)). Imaging parameters: $f_{0}=296698 \mathrm{~Hz}, k=42 \mathrm{~N} / \mathrm{m}, \mathrm{A}=42.8 \mathrm{~nm}$, (a) image size $(100 \times 100) \mathrm{nm}^{2}, \Delta f=-1 \mathrm{~Hz}$. (c) image size $(2.3 \times 2.3) \mathrm{nm}^{2}, \Delta f=-5 \mathrm{~Hz}$. Reprinted with from Ref.[104] . Copyright 2008, AIP Publishing LLC.

Figure 9 - (a) Large-scale and (b) atomic-scale resolution STM images of a 3-nm-thick $\mathrm{CeO}_{2}(111)$ film on $\mathrm{Ru}(0001)$; Inset in panel (a) is a LEED pattern taken from $\mathrm{CeO}_{2}(111)$. (c) 
Atomic-scale resolution STM image of a 3-nm-thick reduced $\mathrm{CeO}_{1.75}(111)$ on $\mathrm{Ru}(0001)$. Images were taken with a constant current STM mode (3-4 V and 0.5-1.0 nA). Reprinted with permission from Ref.[34]. Copyright 2008 American Chemical Society.

Figure 10 - Constant current topographic STM images of $\sim 0.5$ monolayer (ML) of $\mathrm{CeO}_{2}$ on Rh(111). (a) $1850 \times 1850 \AA^{2}$; sample bias: $1.99 \mathrm{~V}$; tunneling current $1 \mathrm{nA}$. (b) $200 \times 200 \AA^{2} ; 0.89$ $\mathrm{V} ; 0.83 \mathrm{nA}$. (c) $93 \times 57 \AA^{2}$; $0.78 \mathrm{~V} ; 0.83 \mathrm{nA}$. $\mathrm{A} \mathrm{CeO}_{2}(111) 1 \times 1$ unit cell $(\mathrm{u})$ is indicated on the image (c). The insert to (a) shows a corresponding LEED pattern (electron energy $=77 \mathrm{eV}$ ). Reprinted from Ref. [35] with permission from Elsevier.

Figure 11 - A) O 1s core level spectra and B) TPD spectra from water adsorbed on oxidized $\mathrm{CeO}_{2}(111)$ (black) and $\mathrm{CeO}_{2}(100)$ (blue) at $180 \mathrm{~K}$. Adapted with permission from Ref.[15]. Copyright 2012 American Chemical Society.

Figure 12 - A) O 1s core level spectra and B) TPD spectra from water adsorbed on reduced $\mathrm{CeO}_{1.7}(111)$ (black) and $\mathrm{CeO}_{1.7}(100)$ (blue) at $180 \mathrm{~K}$. Adapted with permission from Ref.[15]. Copyright 2012 American Chemical Society.

Figure $13-\mathrm{CO}_{2}$ TPD following exposure at $180 \mathrm{~K}$ on oxidized $\mathrm{CeO}_{1.7}(111)$ (black) and reduced $\mathrm{CeO}_{1.7}(100)$ (blue). Reprinted with permission from Ref.[72]. Copyright 2014 American Chemical Society.

Figure 14 - Near-edge X-ray absorption fine structure (NEXAFS) spectra at the $\mathrm{C}$ k-edge following the adsorption of 5 Langmuirs of $\mathrm{CO}_{2}$ at $180 \mathrm{~K}$ and annealed as indicated on oxidized $\mathrm{CeO}_{2}(100)$. The inset at the bottom depicts the preferred adsorption site as determined by DFT+U calculations. Adapted with permission from Ref.[72]. Copyright 2014 American Chemical Society.

Figure 15 - The most stable $\mathrm{CO}_{2}$ adsorption configuration on reduced ceria (110) with (a) an inplane vacancy $(\mathbf{R v}(\operatorname{InP}))$ and (b) a split vacancy (Rp5). The surface oxygen nearest the vacancy is labeled as $\mathrm{O} v$. Both structural parameters and energies of adsorption are indicated. Reprinted with permission from Ref.[184] . Copyright 2013, AIP Publishing LLC.

Figure 16 - Temperature programmed desorption following exposure of ${ }^{15} \mathrm{NO}$ on oxidized $\mathrm{CeO}_{2}(111)$ (bottom) and sputter reduced $\mathrm{CeO}_{2-\mathrm{x}}(111)$ (top). On the oxidized surface the ${ }^{15} \mathrm{NO}$ was exposed at $90 \mathrm{~K}$. On the reduced surface the ${ }^{15} \mathrm{NO}$ was exposed at different temperatures as indicated and then the sample was cooled to $90 \mathrm{~K}$ before the TPD. Reprinted from Ref. [59]. Copyright 1999 with permission from Elsevier.

Figure $17-\mathrm{N}$ 1s XPS spectra following exposure of ${ }^{15} \mathrm{NO}$ on $\mathrm{A}$ ) oxidized $\mathrm{CeO}_{2}(111)$ and $\mathrm{B}$ ) sputter reduced $\mathrm{CeO}_{2-\mathrm{x}}(111)$. On the oxidized surface the ${ }^{15} \mathrm{NO}$ was exposed at $100 \mathrm{~K}$. On the reduced surface the ${ }^{15} \mathrm{NO}$ was exposed at different temperatures as indicated. Adapted from Ref. [59]. Copyright 1999 with permission from Elsevier.

Figure 18 - S 2p XPS spectra following exposure of $\mathrm{SO}_{2}$ on A) oxidized $\mathrm{CeO}_{2}(111) / \mathrm{Cu}(111)$ and $\mathrm{B}$ ) reduced $\mathrm{CeO}_{2-\mathrm{x}}(111) / \mathrm{Cu}(111)$. The $\mathrm{SO}_{2}$ was exposed at $300 \mathrm{~K}$ and then annealed as 
indicated. Reprinted with permission from Ref.[196]. Copyright 2011 American Chemical Society.

Figure $19-A) S 2 p$ and $B) O$ 1s XPS spectra following exposure of $\mathrm{H}_{2} \mathrm{~S}$ on oxidized $\mathrm{CeO}_{2}(111)$ / $\mathrm{Ru}(0001)$. The $\mathrm{H}_{2} \mathrm{~S}$ was exposed at $100 \mathrm{~K}$ and then annealed as indicated. Reprinted from Ref. [200]. Copyright 2007 with permission from Elsevier.

Figure 20 - TPD following methanol adsorption at $180 \mathrm{~K}$ on oxidized $\mathrm{CeO}_{2}(111)$ (black lines) and $\mathrm{CeO}_{2}(100)$ (blue lines). Reprinted from Ref.[205] . Copyright 2013 with kind permission from Springer Science and Business Media.

Figure 21 - TPD following methanol adsorption at $180 \mathrm{~K}$ on reduced $\mathrm{CeO}_{2-x}(111)$ (black lines) and $\mathrm{CeO}_{2-x}(100)$ (blue lines). Reprinted from Ref.[205] . Copyright 2013 with kind permission from Springer Science and Business Media.

Figure 22 -TPD from selectively deuterated formic acid, $\mathrm{DCOOH}$, on (a) oxidized $\mathrm{CeO}_{2}$ (111), (c) reduced $\mathrm{CeO}_{2-x}(111)$, and (d) Pt supported on oxidized $\mathrm{CeO}_{2}$ (111). Reprinted with permission from Ref.[62]. Copyright 2013 American Chemical Society.

Figure 23 - Acetic acid TPD on A) oxidized and $\mathrm{B}$ ) reduced $\mathrm{CeO}_{x}$ surfaces. The black lines are from $\mathrm{CeO}_{x}(111)$ and the blue lines are from $\mathrm{CeO}_{x}(100)$. Reprinted from Ref.[205] . Copyright 2013 with kind permission from Springer Science and Business Media.

Figure 24 - Acetaldehyde TPD on oxidized (black lines) and reduced (blue lines) $\mathrm{CeO}_{x}(111)$ surfaces. Reprinted with permission from Ref.[216]. Copyright 2011 American Chemical Society.

Figure $25-C$ 1s XPS (A) and C k-edge NEXAFS (B) of acetaldehyde adsorbed on reduced $\mathrm{CeO}_{2-\mathrm{x}}(111)$ at $175 \mathrm{~K}$ and .annealed as indicated.

Figure 26 - A proposed reaction scheme for DMMP decomposition on $\mathrm{CeO}_{2}(111)$ showing the main surface species at various temperatures. Although the structures of all the intermediates have not been conclusively identified in this work, reasonable structures have been proposed based on literature studies of DMMP decomposition on other oxide surfaces.[358-361] Reprinted from Ref. [230]. Copyright 2010 with permission from Elsevier.

Figure 27 - STM image of $0.1 \mathrm{ML}$ of Au deposited on (a) fully oxidized and (b) partially reduced $\mathrm{CeO}_{2}(111)$ films grown on $\mathrm{Ru}(0001)$ at $300 \mathrm{~K}$. On the fully oxidized surface the Au particles nucleate almost exclusively at the step edges, whereas more of the Au nucleates at defects on the terraces of the partially reduced surface. Image size is $150 \times 150 \mathrm{~nm}^{2}$. Reprinted from Ref.[231]. Copyright 2007 with kind permission from Springer Science and Business Media. 
Figure 28 - STM images of $0.25 \mathrm{ML}$ of $\mathrm{Ni}$ on (a) $\mathrm{CeO}_{2}(111)$, (b) $\mathrm{CeO}_{1.88}(111)$ and (c) $\mathrm{CeO}_{1.77}(111)$. The Ni nanoparticles are uniformly distributed on all of the surfaces. The particles are smaller and have a larger density of the reduced surfaces. Image sizes are $100 \times 100 \mathrm{~nm}^{2}$. Reprinted with permission from Ref.[232]. Copyright 2010 American Chemical Society.

Figure 29 - TPD spectra obtained after exposing Rh particles supported on nearly stoichiometric $\mathrm{Ce}^{16} \mathrm{O}_{2}(111)$ (lower panel) and partially reduced $\mathrm{Ce}^{16} \mathrm{O}_{2}(111)$ (upper panel) to a saturation dose of ${ }^{13} \mathrm{C}^{18} \mathrm{O}$. Reprinted from Ref.[76]. Copyright 1994 with kind permission from Springer Science and Business Media.

Figure 30 - C 1s sXPS spectra obtained after exposing Rh particles supported on oxidized $\mathrm{CeO}_{2}(111)$ (lower panel) and partially reduced $\mathrm{CeO}_{\mathbf{X}}(111)$ (upper panel) to a saturation dose of $\mathrm{CO}$.

Figure 31 - TPD spectra obtained after exposing Rh particles supported on (a) oxidized and (b) partially reduced $\mathrm{CeO}_{x}(111)$ to methanol at $100 \mathrm{~K}$. Reprinted with permission from Ref.[318]. Copyright 2006 American Chemical Society.

Figure 32 - Structures of a conventional metal / oxide model catalyst and an inverse oxide / metal model catalyst. Adapted from Ref. [343]. Copyright 2010 with permission from Elsevier.

Figure 33 - Hysteresis in the $\mathrm{CO}_{2}$ production rate as obtained upon cyclic variation of the $\mathrm{CO}$ partial pressure at constant oxygen pressure. Results are shown on clean $\mathrm{Pt}(111)$ and on ceria particles supported on $\mathrm{Pt}(111)$. The reaction transitions from high reactivity $(\mathrm{HR})$ to low reactivity (LR) at transition pressures, $\tau_{\mathrm{A}}$. Reprinted from Ref. [84]. Copyright 2007 with permission from Elsevier.

Figure 34 - TEM and HRTEM images of as-synthesized ceria rods (a, b), cubes (c, d), and octahedra (e, f). Reprinted with permission from ref.[157] . Copyright 2010 American Chemical Society 


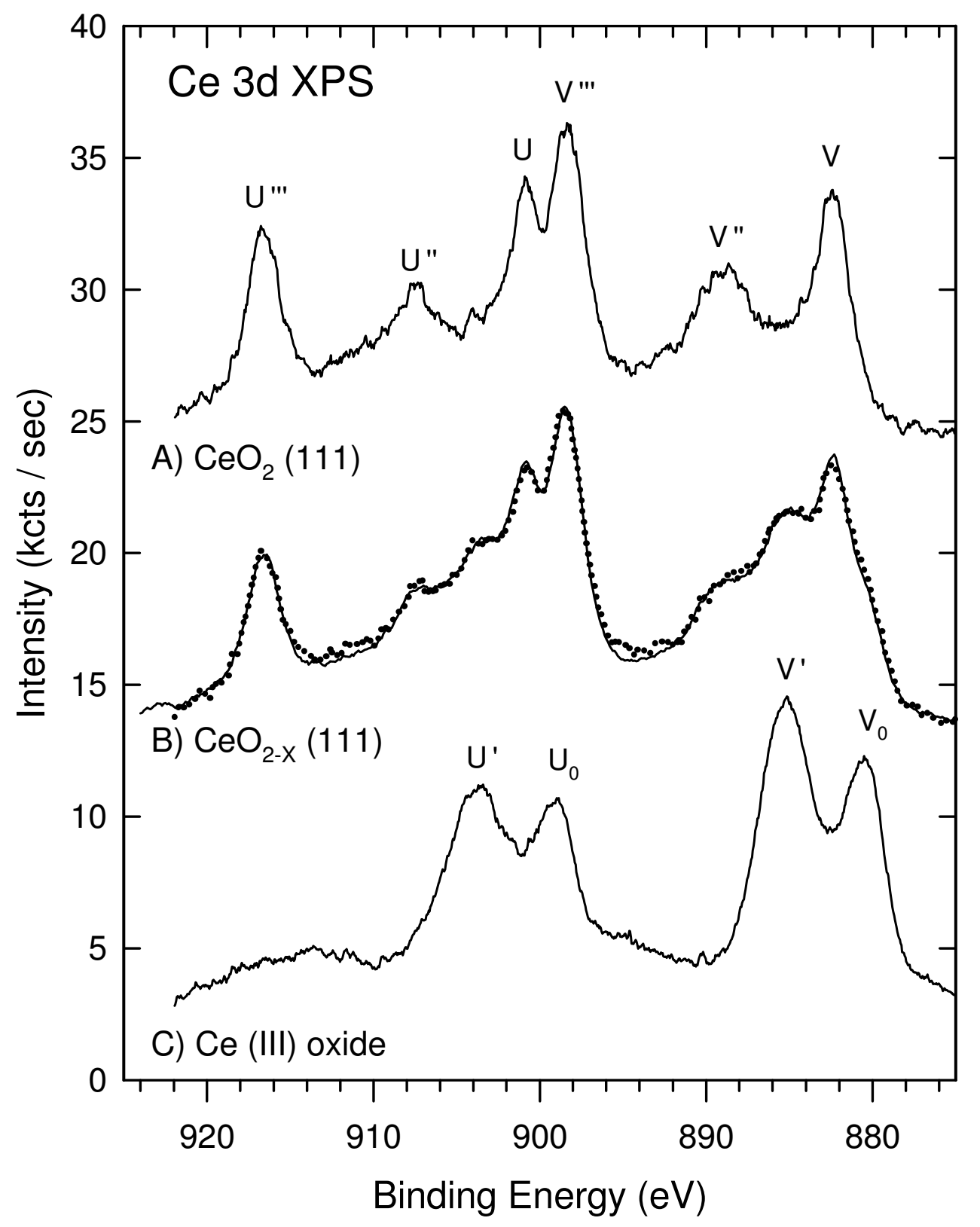

Figure 1 - Ce 3d XPS spectra excited by Mg ka x-rays. A) Fully oxidized $\mathrm{CeO}_{2}(111)$, B) partially reduced $\mathrm{CeO}_{2}(111)$, and $\mathrm{C}$ ) fully reduced $\mathrm{Ce}(\mathrm{III})$ oxide. The dotted line over $(\mathrm{B})$ is the best-fit from a linear combination of $(A)$ and $(C)$. Reprinted from Ref. [43] with permission from Elsevier. 


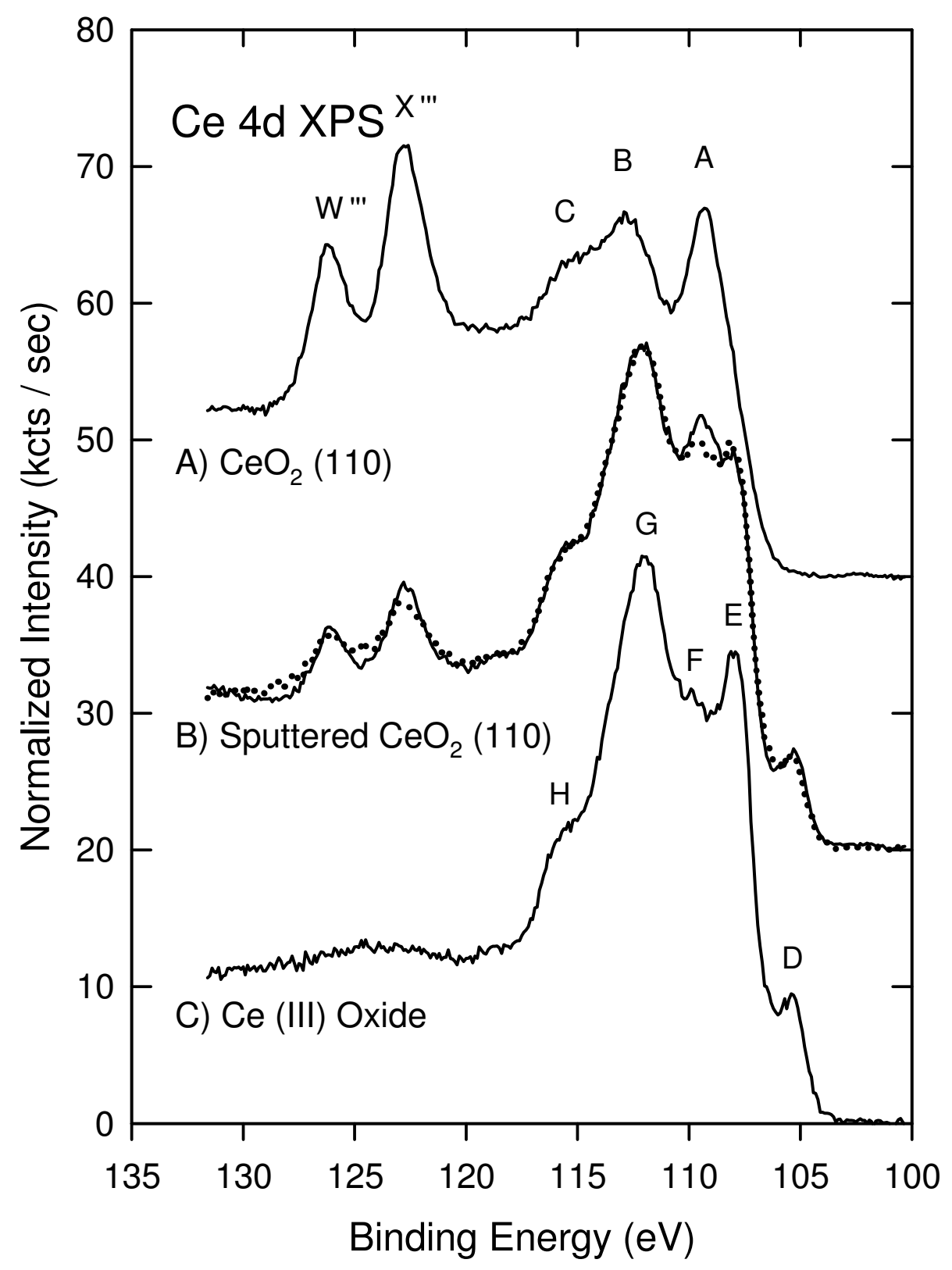

Figure 2 - Ce 4d XPS spectra excited at $350 \mathrm{eV}$. A) Fully oxidized $\mathrm{CeO}_{2}(110)$, B) partially reduced $\mathrm{CeO}_{2}(110)$, and $\mathrm{C}$ ) fully reduced $\mathrm{Ce}$ (III) oxide. The dotted line over (B) is the best-fit from a linear combination of $(A)$ and $(C)$. Reprinted from Ref.[43] with permission from Elsevier. 

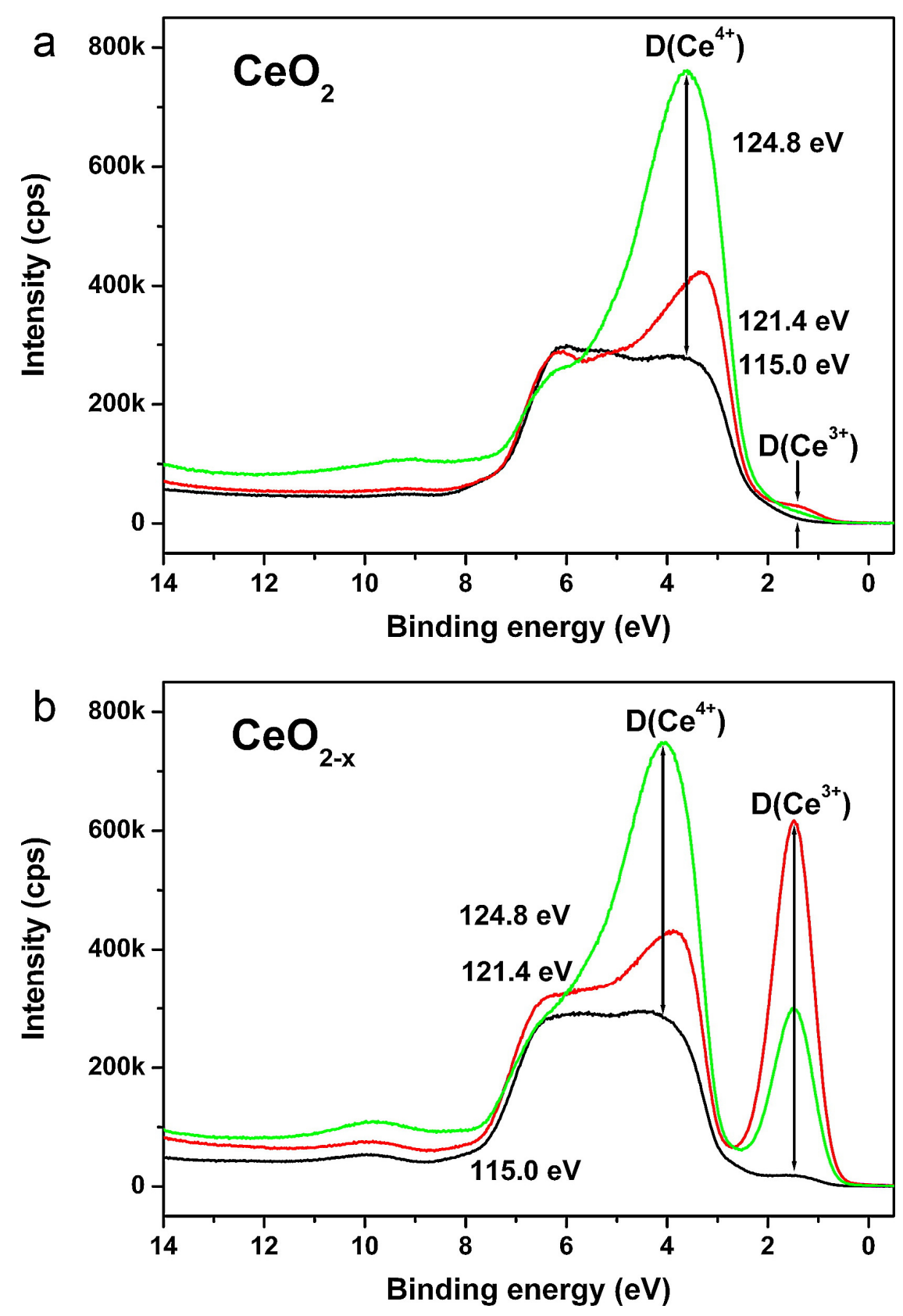

Figure 3 - Valence level photoemission spectra record from clean, fully oxidized $\mathrm{CeO}_{2}(111)(\mathrm{A})$ and partially reduced $\mathrm{CeO}_{2-x}(111)(\mathrm{B})$. The spectra were recorded using photon energies offresonance (115.0 eV, black), at the $\mathrm{Ce}^{3+}$ resonance $\left(121.4 \mathrm{eV}\right.$, red) and at the $\mathrm{Ce}^{4+}$ resonance (124.8 eV, green). Reprinted from Ref. [51] with permission from Elsevier. 


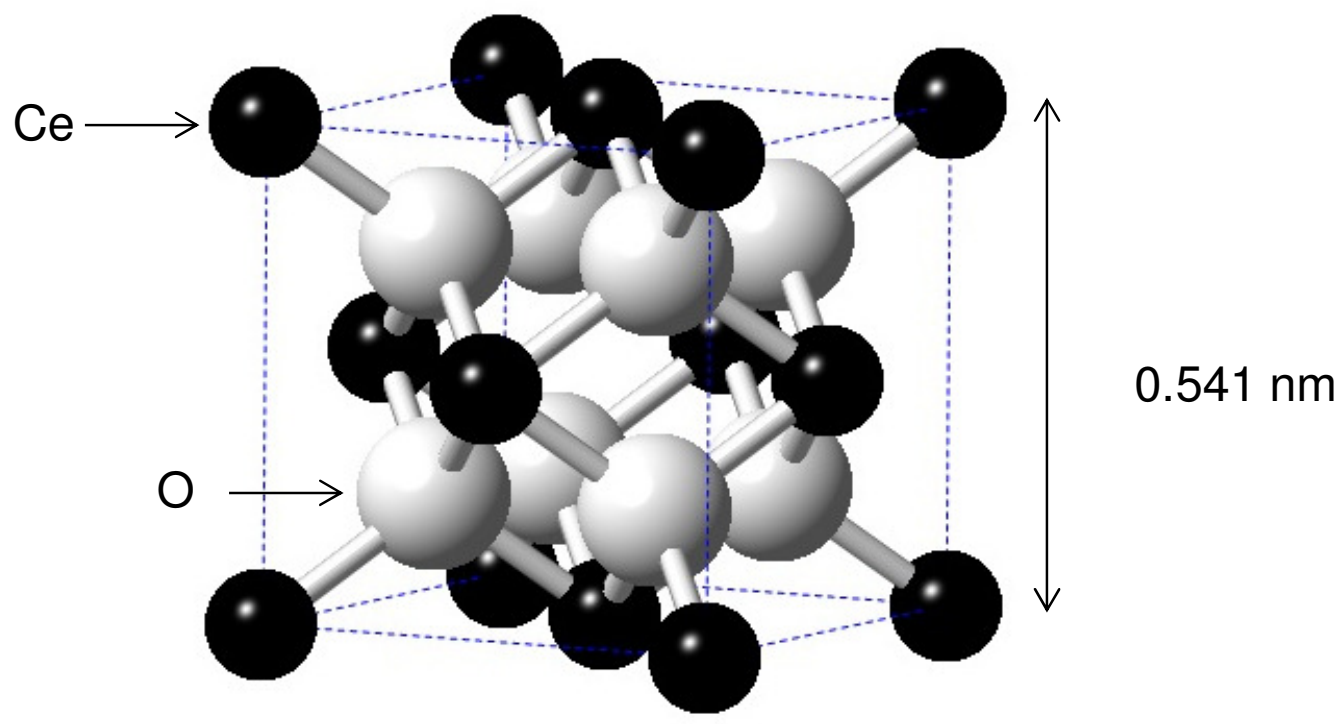

Figure 4 - The unit cell of $\mathrm{CeO}_{2}$. The black spheres are $\mathrm{Ce}$ and the white spheres are $\mathrm{O}$. Note that the spheres have been drawn at $50 \%$ space-filling so that the $\mathrm{Ce}-\mathrm{O}$ bonding could be shown. 


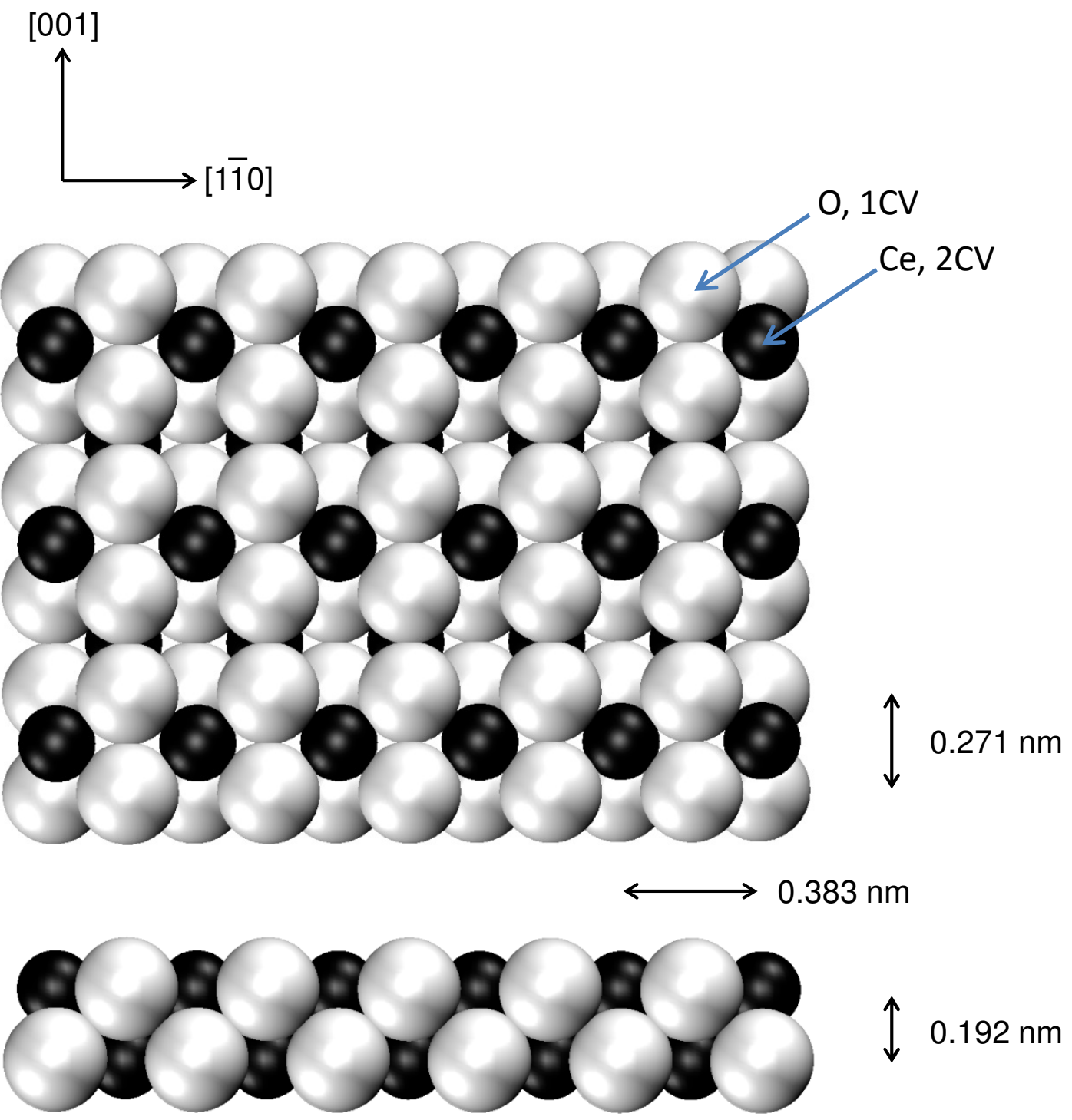

Figure $5-\mathrm{CeO}_{2}(110)$ depicted as an unreconstructed Tasker Type 1 surface.[92] The black spheres are $\mathrm{Ce}$ and the white spheres are $\mathrm{O}$. The spheres have been drawn at $100 \%$ spacefilling to indicate accessibility to subsurface sites. CV refers to the number of coordination vacancies around the $\mathrm{Ce}$ and $\mathrm{O}$ ions in the top layer. 




Figure $6-\mathrm{CeO}_{2}(111)$ depicted as an unreconstructed Tasker Type 2 surface.[92] The black spheres are $\mathrm{Ce}$ and the white spheres are $\mathrm{O}$. The spheres have been drawn at $100 \%$ spacefilling to indicate accessibility to subsurface sites. CV refers to the number of coordination vacancies around the $\mathrm{Ce}$ in the second layer and $\mathrm{O}$ in the top layer. 


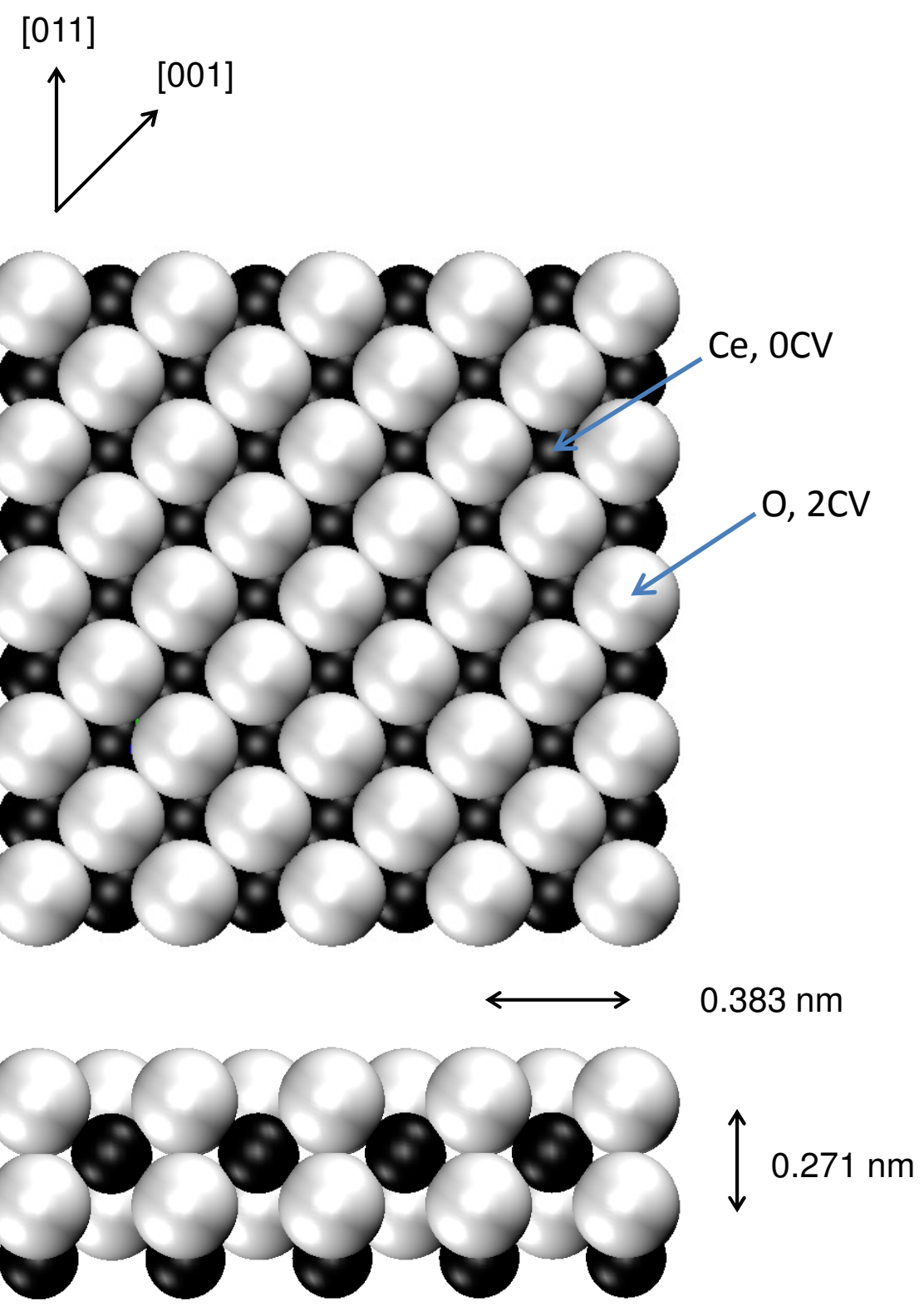

Figure 7a $-\mathrm{CeO}_{2}(100)$ depicted as an unreconstructed Tasker Type 3 surface.[92] The black spheres are $\mathrm{Ce}$ and the white spheres are $\mathrm{O}$. The spheres have been drawn at $100 \%$ spacefilling to indicate accessibility to subsurface sites. CV refers to the number of coordination vacancies around the $\mathrm{Ce}$ in the second layer and $\mathrm{O}$ in the top layer. 

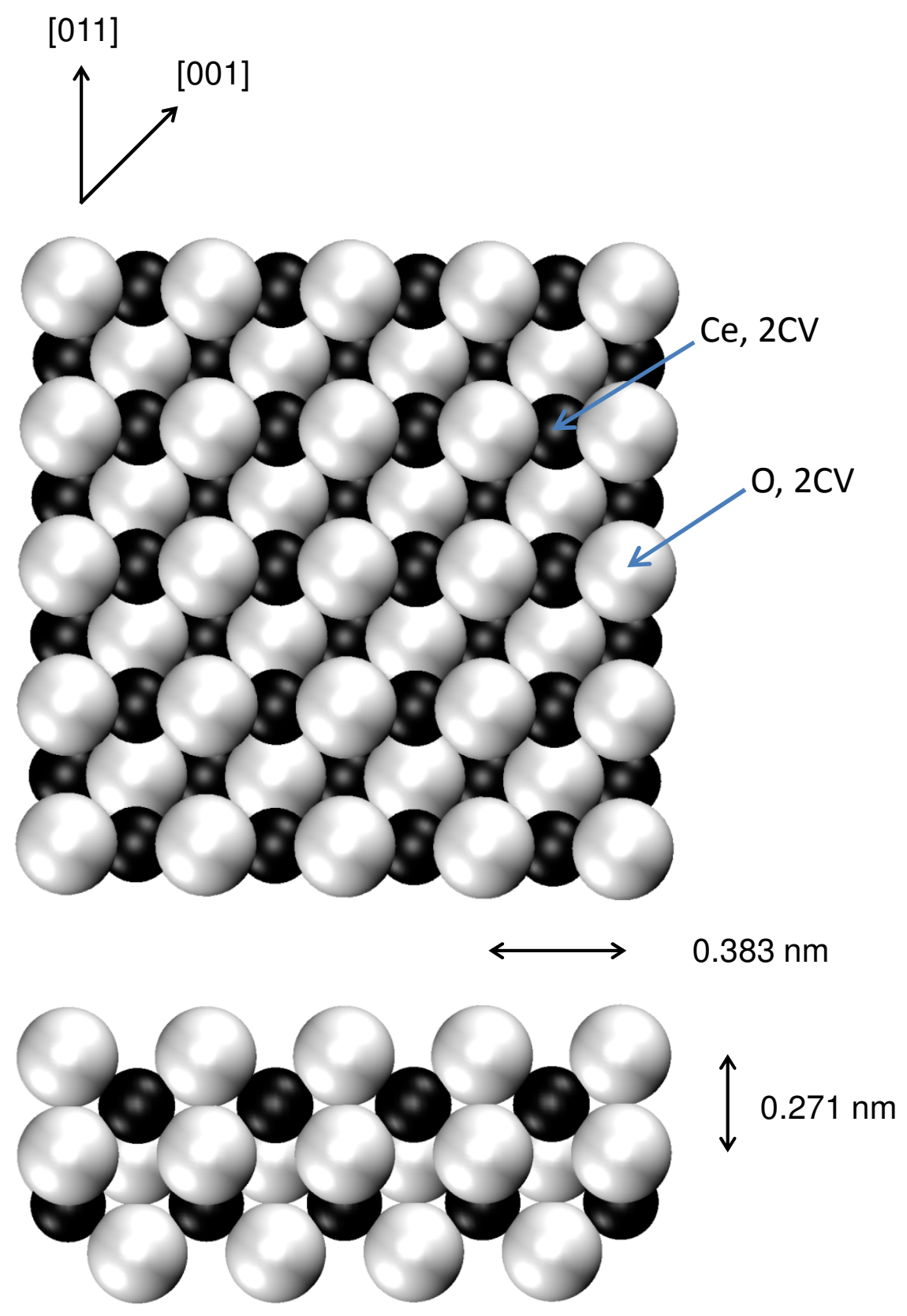

Figure $7 \mathrm{~b}-\mathrm{CeO}_{2}(100)$ depicted as a reconstructed surface. The black spheres are $\mathrm{Ce}$ and the white spheres are $O$. The spheres have been drawn at $100 \%$ space-filling to indicate accessibility to subsurface sites. CV refers to the number of coordination vacancies around the $\mathrm{Ce}$ in the second layer and $\mathrm{O}$ in the top layer. 


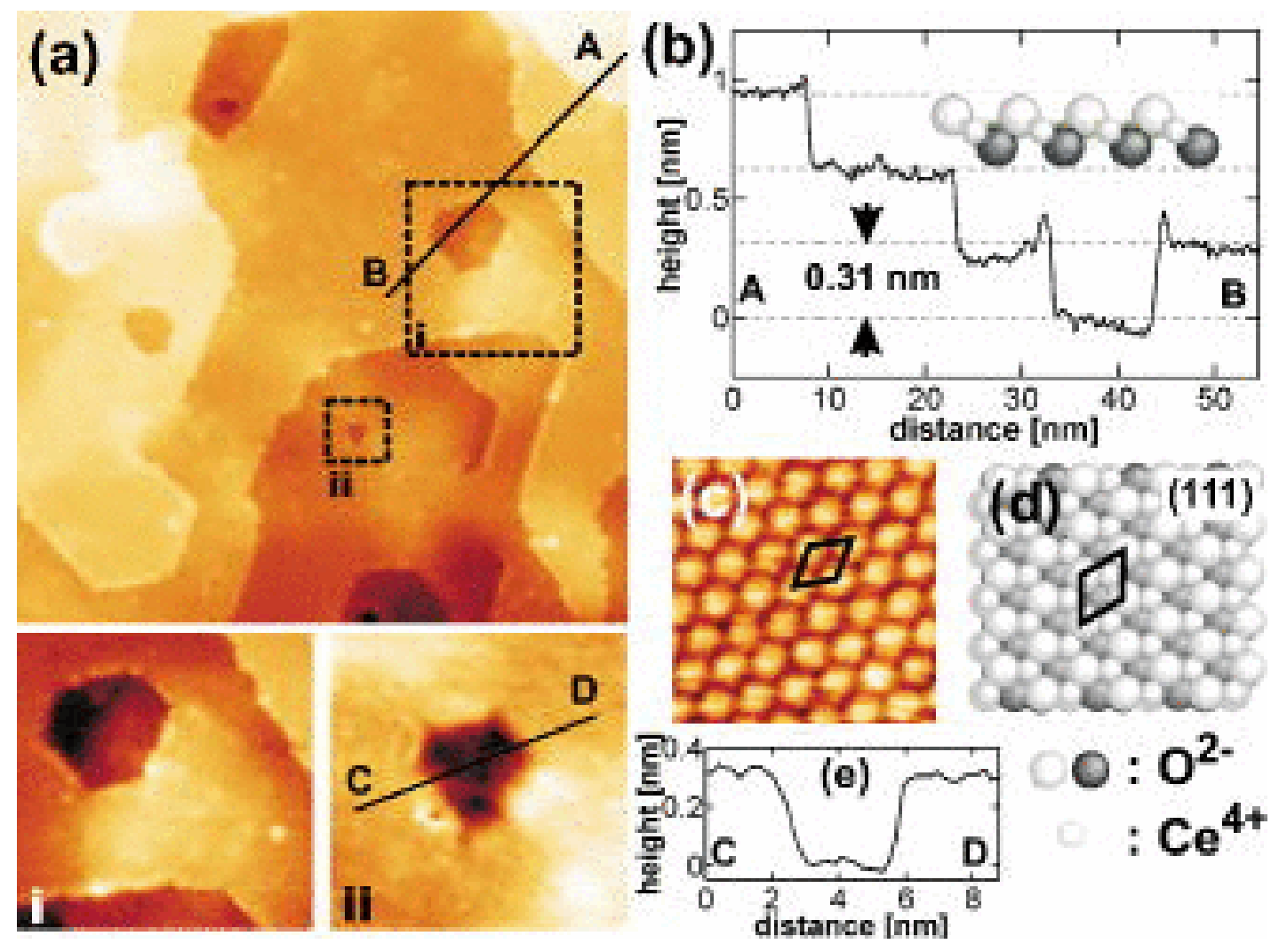

Figure 8 - (a) Topographic SFM images of the $\mathrm{CeO}_{2}(111)$ surface morphology observed directly after preparation. (b) Height profile taken along the straight line in $(\mathrm{a}(\mathrm{i}))$ revealing steps of triplelayer height. (c) Atomically resolved image together with a schematic model (d) of the stoichiometric oxygen terminated (111) surface. (e) Height profile as indicated in (a(ii)). Imaging parameters: $f_{0}=296698 \mathrm{~Hz}, k=42 \mathrm{~N} / \mathrm{m}, \mathrm{A}=42.8 \mathrm{~nm}$, (a) image size $(100 \times 100) \mathrm{nm}^{2}, \Delta f=-1 \mathrm{~Hz}$. (c) image size (2.3x2.3) $\mathrm{nm}^{2}, \Delta f=-5 \mathrm{~Hz}$. Reprinted with from Ref.[104] . Copyright 2008, AIP Publishing LLC. 

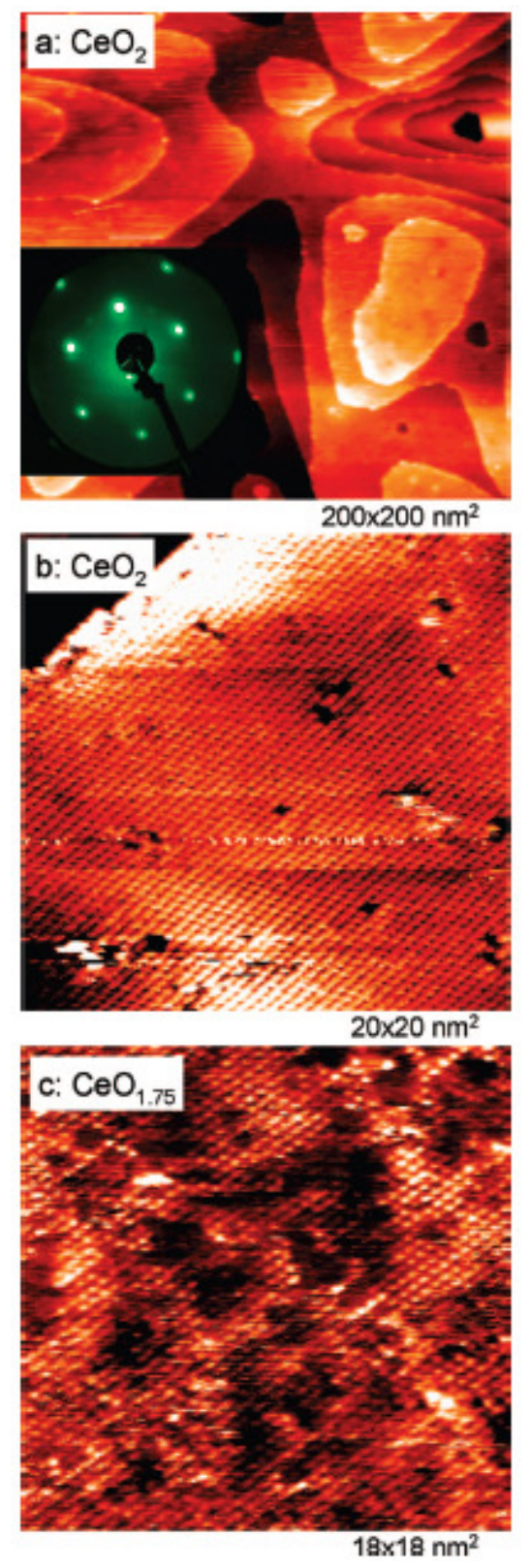

Figure 9 - (a) Large-scale and (b) atomic-scale resolution STM images of a 3-nm-thick $\mathrm{CeO}_{2}(111)$ film on $\mathrm{Ru}(0001)$; Inset in panel (a) is a LEED pattern taken from the $\mathrm{CeO}_{2}(111)$ film. (c) Atomic-scale resolution STM image of a 3-nm-thick reduced $\mathrm{CeO}_{1.75}(111)$ on $\mathrm{Ru}(0001)$. Images were taken with a constant current STM mode (3-4 V and 0.5-1.0 nA). Reprinted with permission from Ref.[34]. Copyright 2008 American Chemical Society. 

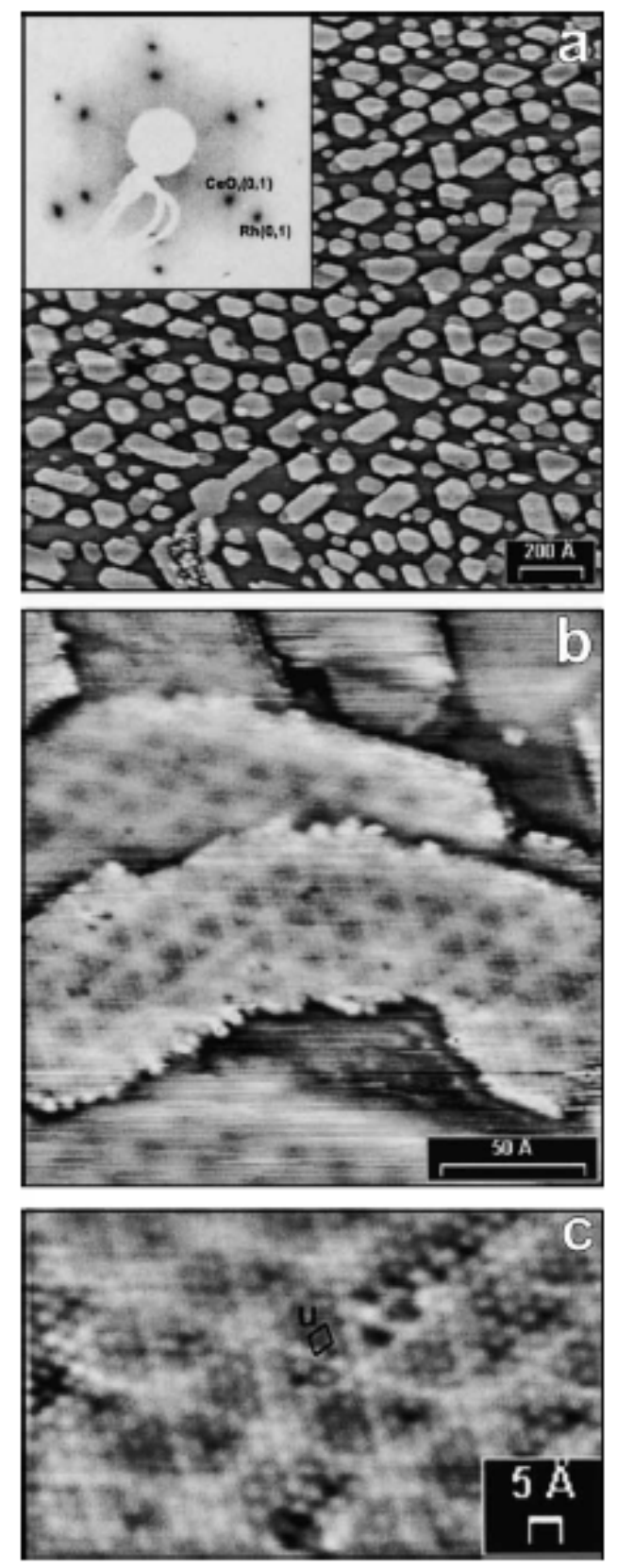

Figure 10 - Constant current topographic STM images of $\sim 0.5$ monolayer (ML) of $\mathrm{CeO}_{2}$ on Rh(111). (a) $1850 \times 1850 \AA^{2}$; sample bias: $1.99 \mathrm{~V}$; tunneling current $1 \mathrm{nA}$. (b) $200 \times 200 \AA^{2} ; 0.89$ $\mathrm{V} ; 0.83 \mathrm{nA}$. (c) $93 \times 57 \AA^{2}$; $0.78 \mathrm{~V} ; 0.83 \mathrm{nA}$. $\mathrm{A} \mathrm{CeO}_{2}(111) 1 \times 1$ unit cell $(\mathrm{u})$ is indicated on the image (c). The insert to (a) shows a corresponding LEED pattern (electron energy $=77 \mathrm{eV}$ ). Reprinted from Ref. [35] with permission from Elsevier. 

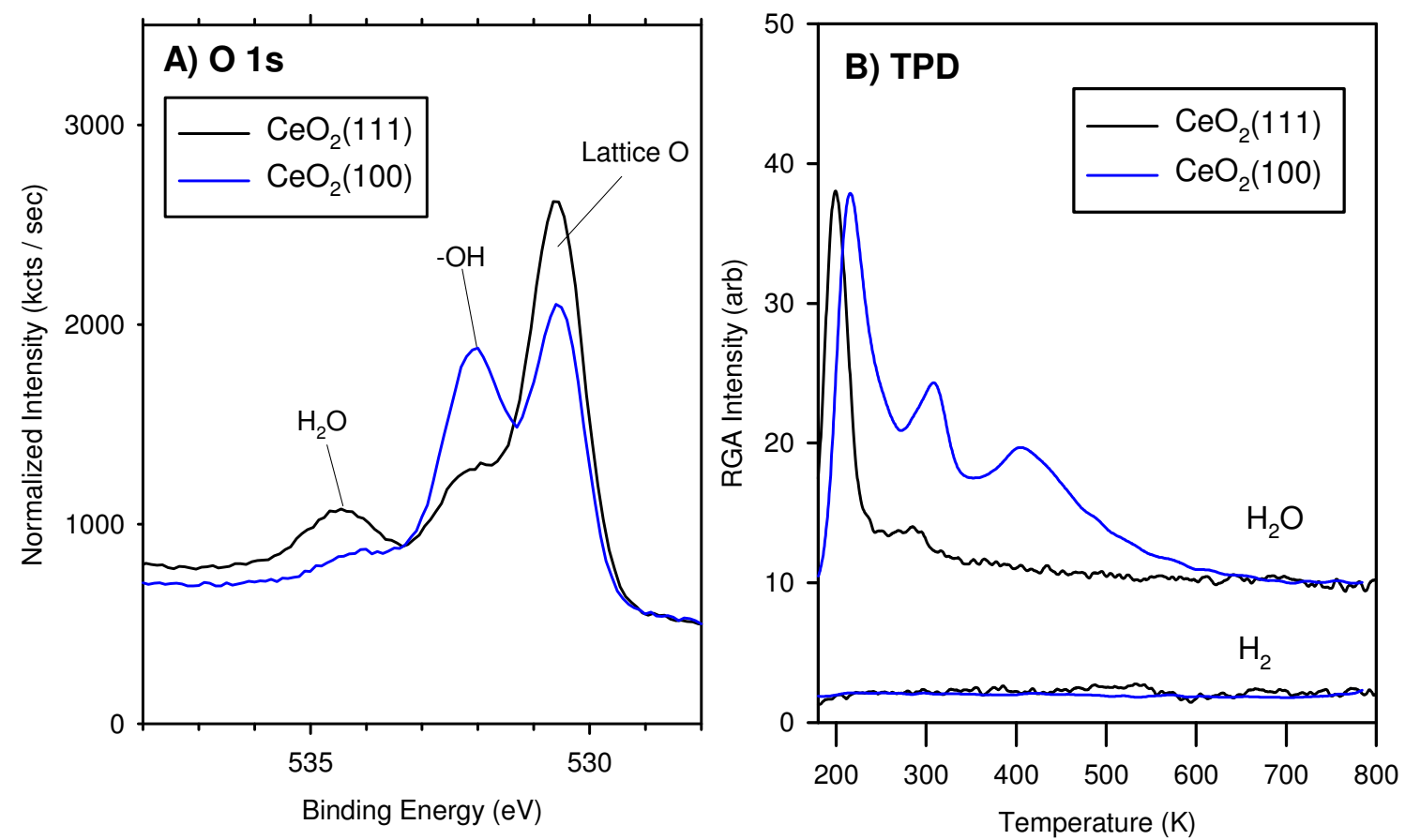

Figure 11 - A) O 1s core level spectra and B) TPD spectra from water adsorbed on oxidized $\mathrm{CeO}_{2}(111)$ (black) and $\mathrm{CeO}_{2}(100)$ (blue) at $180 \mathrm{~K}$. Adapted with permission from Ref.[15]. Copyright 2012 American Chemical Society. 

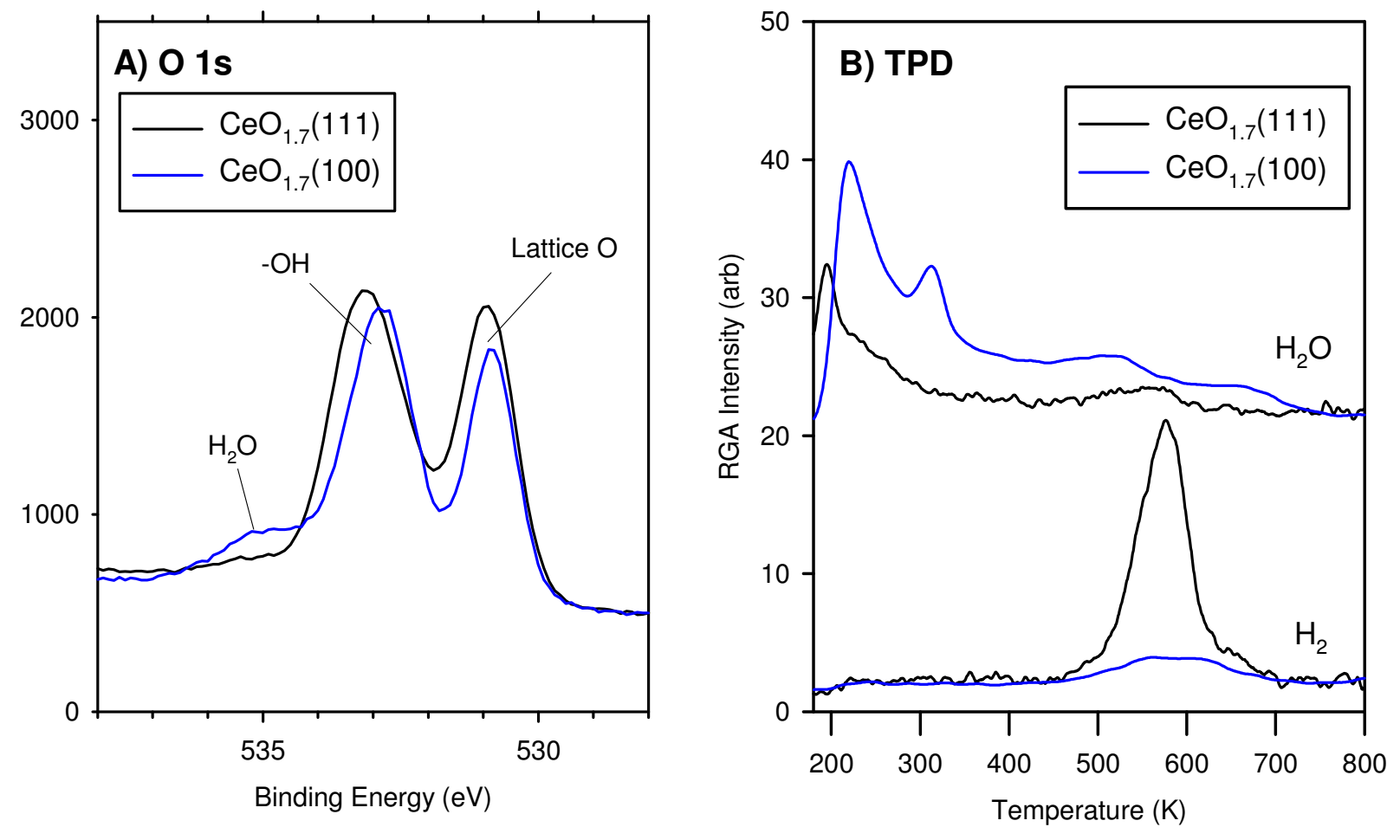

Figure 12 - A) O 1s core level spectra and B) TPD spectra from water adsorbed on reduced $\mathrm{CeO}_{1.7}(111)$ (black) and $\mathrm{CeO}_{1.7}(100)$ (blue) at $180 \mathrm{~K}$. Adapted with permission from Ref.[15]. Copyright 2012 American Chemical Society. 


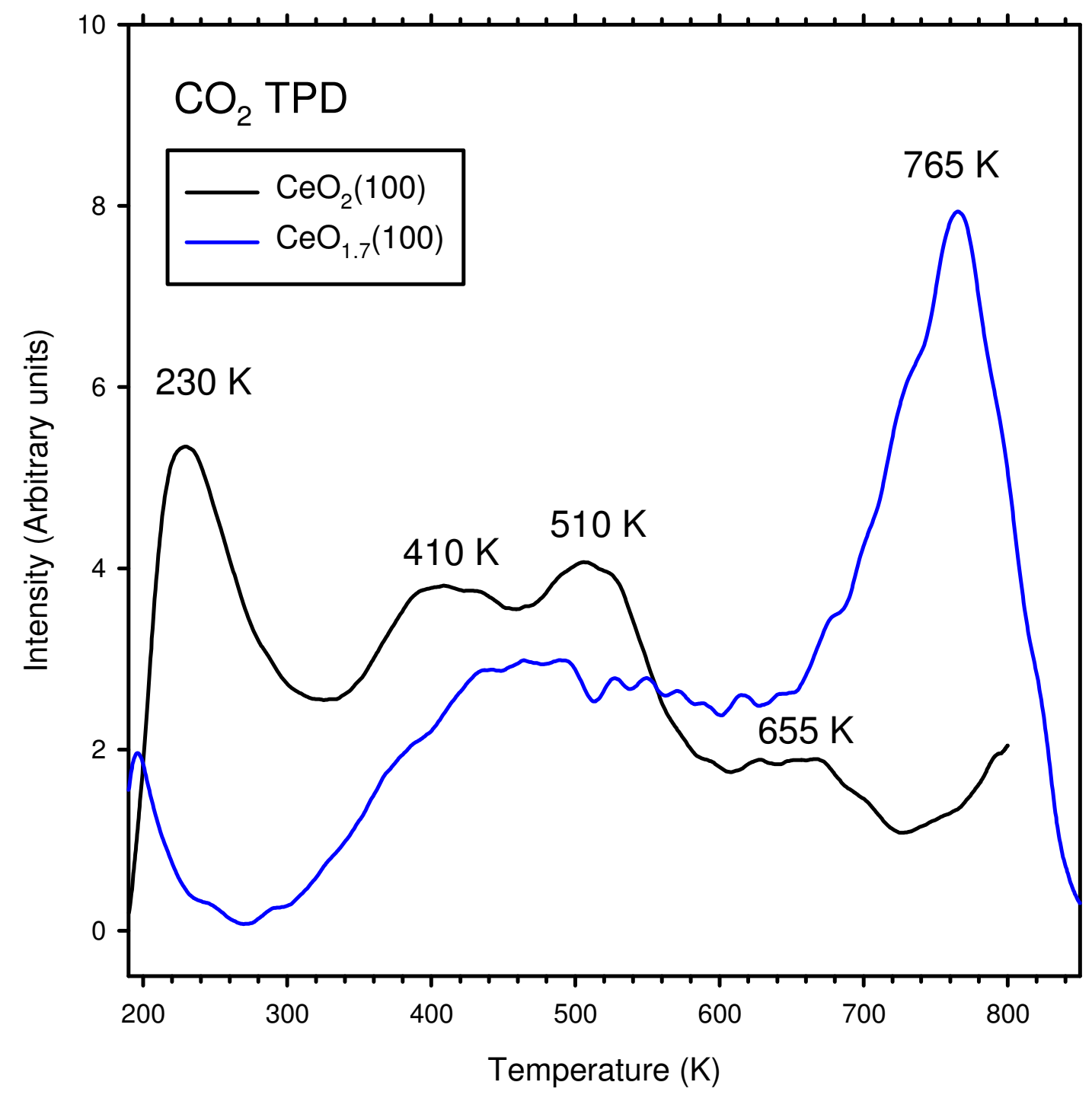

Figure $13-\mathrm{CO}_{2}$ TPD following exposure at $180 \mathrm{~K}$ on oxidized $\mathrm{CeO}_{1.7}(111)$ (black) and reduced $\mathrm{CeO}_{1.7}(100)$ (blue). Reprinted with permission from Ref.[72]. Copyright 2014 American Chemical Society. 


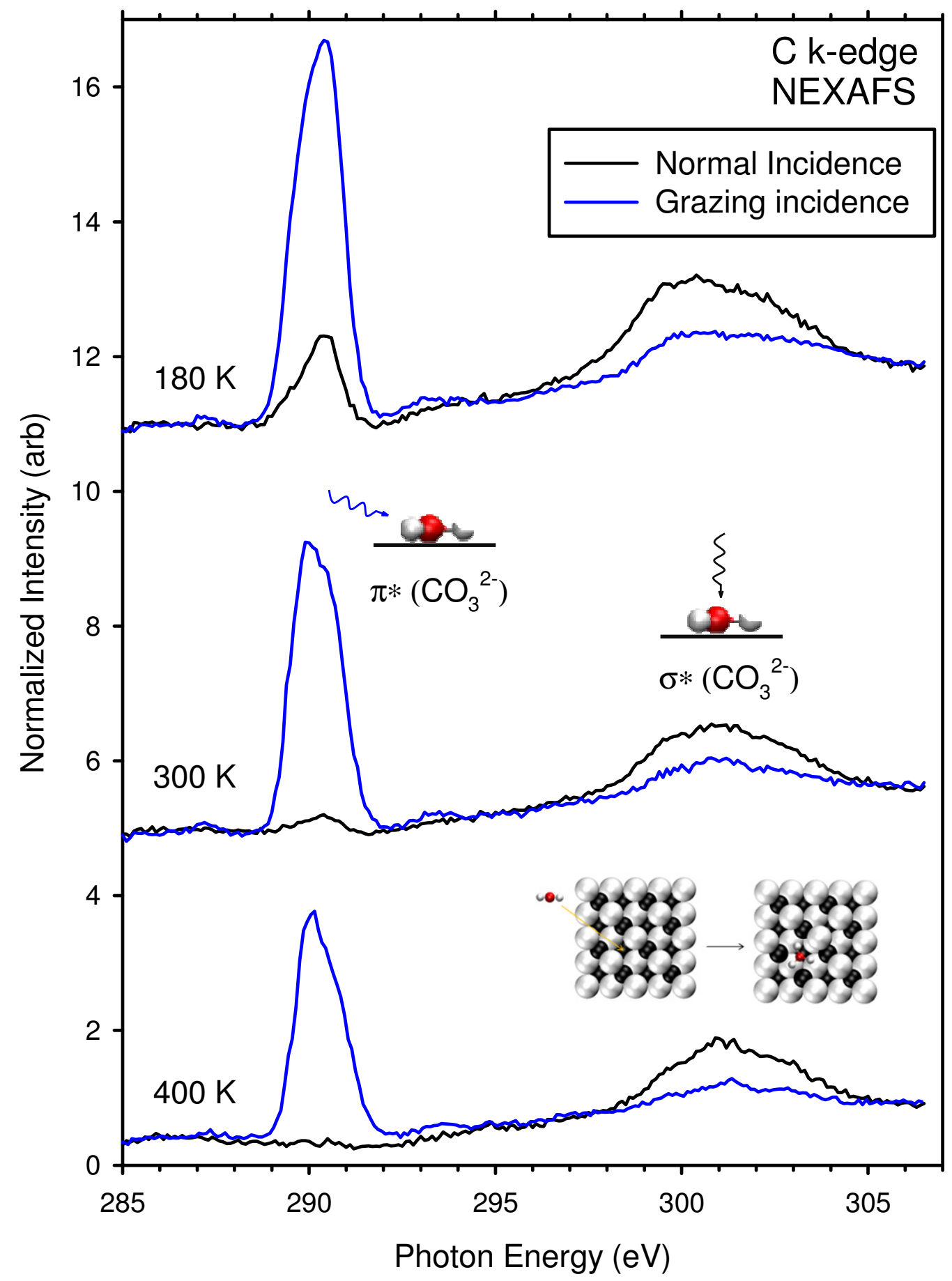

Figure 14 - Near-edge X-ray absorption fine structure (NEXAFS) spectra at the $\mathrm{C}$ k-edge following the adsorption of 5 Langmuirs of $\mathrm{CO}_{2}$ at $180 \mathrm{~K}$ and annealed as indicated on oxidized $\mathrm{CeO}_{2}(100)$. The inset at the bottom depicts the preferred adsorption site as determined by DFT+U calculations. Adapted with permission from Ref.[72]. Copyright 2014 American Chemical Society. 


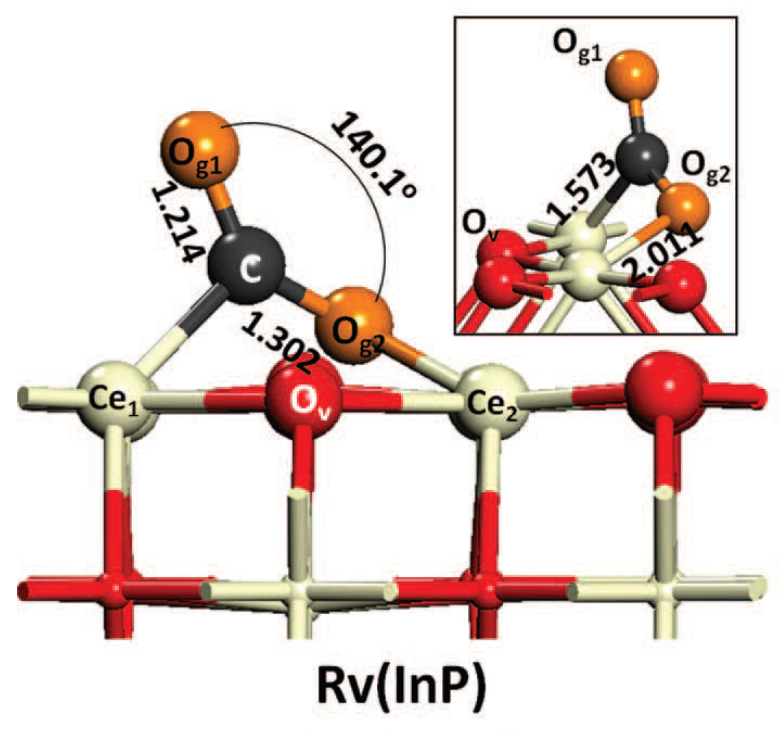

$E=-1.043 \mathrm{eV}$

(a)

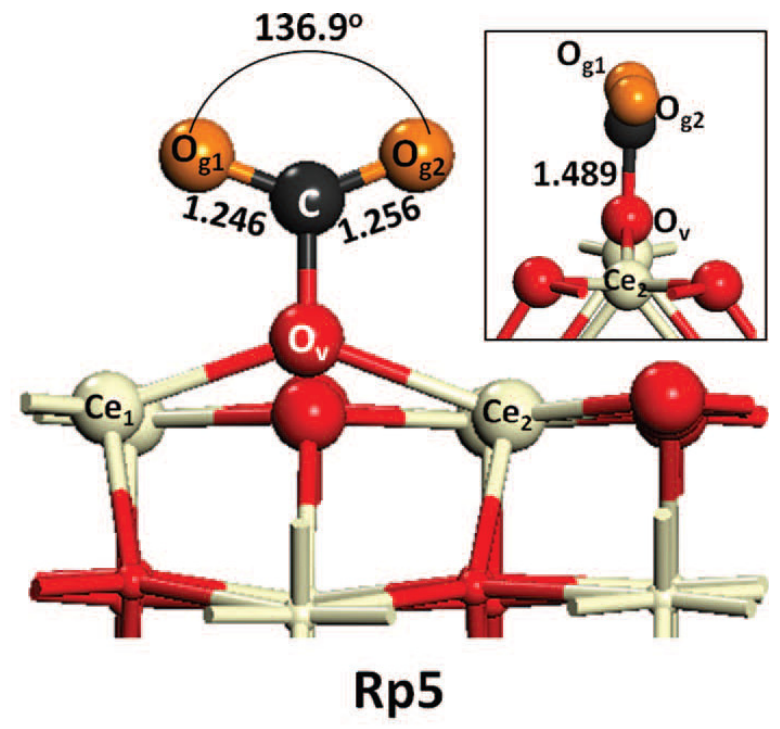

$E=-1.223 \mathrm{eV}$

(b)

Figure 15 - The most stable $\mathrm{CO}_{2}$ adsorption configuration on reduced ceria (110) with (a) an inplane vacancy $(\mathbf{R v}(\operatorname{InP}))$ and (b) a split vacancy $(\mathbf{R p 5})$. The surface oxygen nearest the vacancy is labeled as Ov . Both structural parameters and energies of adsorption are indicated.

Reprinted with permission from Ref.[184] . Copyright 2013, AIP Publishing LLC. 




Figure 16 - Temperature programmed desorption following exposure of ${ }^{15} \mathrm{NO}$ on oxidized $\mathrm{CeO}_{2}(111)$ (bottom) and sputter reduced $\mathrm{CeO}_{2-x}(111)$ (top). On the oxidized surface the ${ }^{15} \mathrm{NO}$ was exposed at $90 \mathrm{~K}$. On the reduced surface the ${ }^{15} \mathrm{NO}$ was exposed at different temperatures as indicated and then the sample was cooled to $90 \mathrm{~K}$ before the TPD. Reprinted from Ref. [59]. Copyright 1999 with permission from Elsevier. 




Figure $17-\mathrm{N}$ 1s XPS spectra following exposure of ${ }^{15} \mathrm{NO}$ on $\mathrm{A}$ ) oxidized $\mathrm{CeO}_{2}(111)$ and $\mathrm{B}$ ) sputter reduced $\mathrm{CeO}_{2-x}(111)$. On the oxidized surface the ${ }^{15} \mathrm{NO}$ was exposed at $100 \mathrm{~K}$. On the reduced surface the ${ }^{15} \mathrm{NO}$ was exposed at different temperatures as indicated. Adapted from Ref. [59]. Copyright 1999 with permission from Elsevier. 

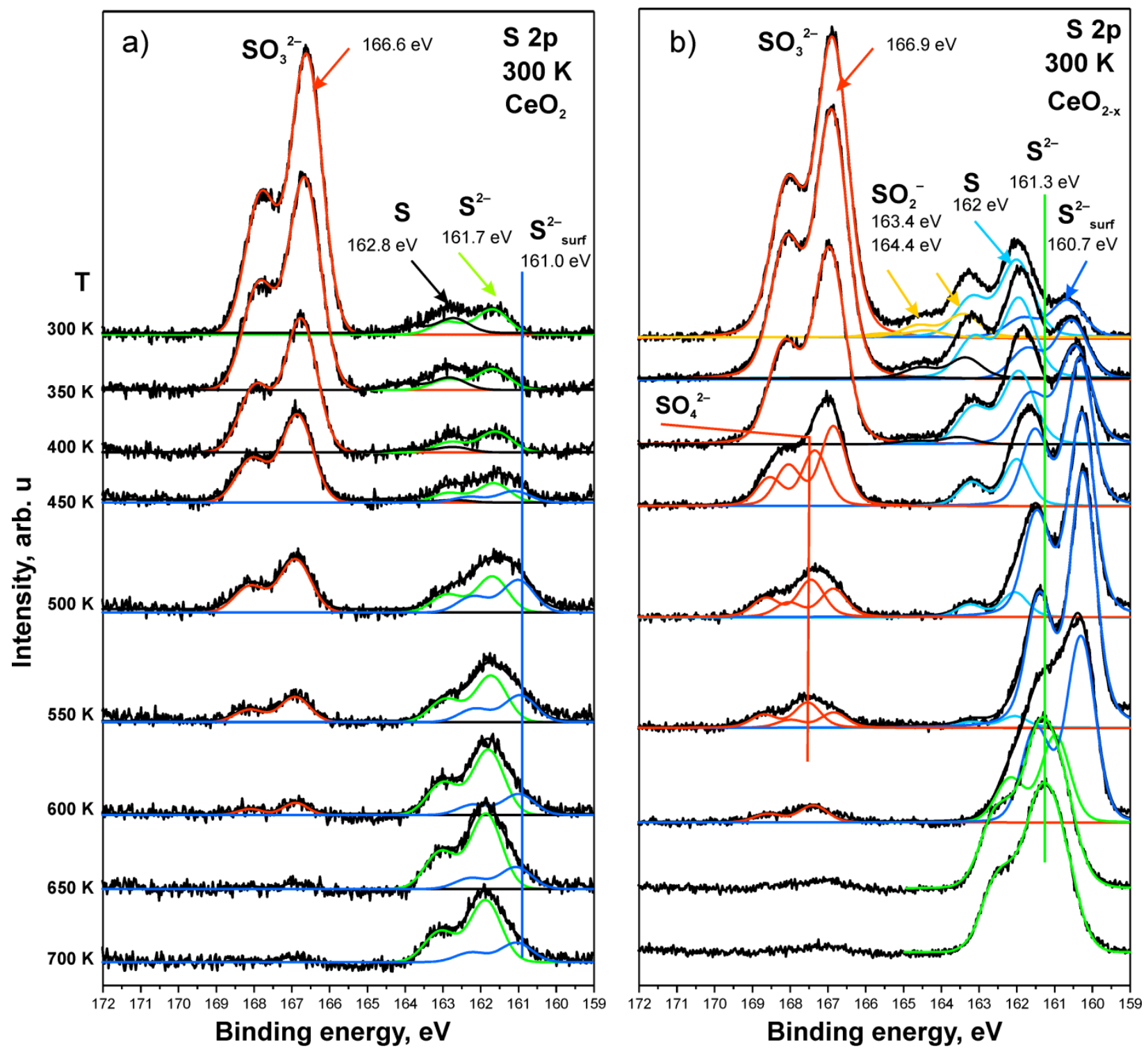

Figure 18 - S 2p XPS spectra following exposure of $\mathrm{SO}_{2}$ on A) oxidized $\mathrm{CeO}_{2}(111) / \mathrm{Cu}(111)$ and $\mathrm{B}$ ) reduced $\mathrm{CeO}_{2-\mathrm{x}}(111) / \mathrm{Cu}(111)$. The $\mathrm{SO}_{2}$ was exposed at $300 \mathrm{~K}$ and then annealed as indicated. Reprinted with permission from Ref.[196]. Copyright 2011 American Chemical Society. 

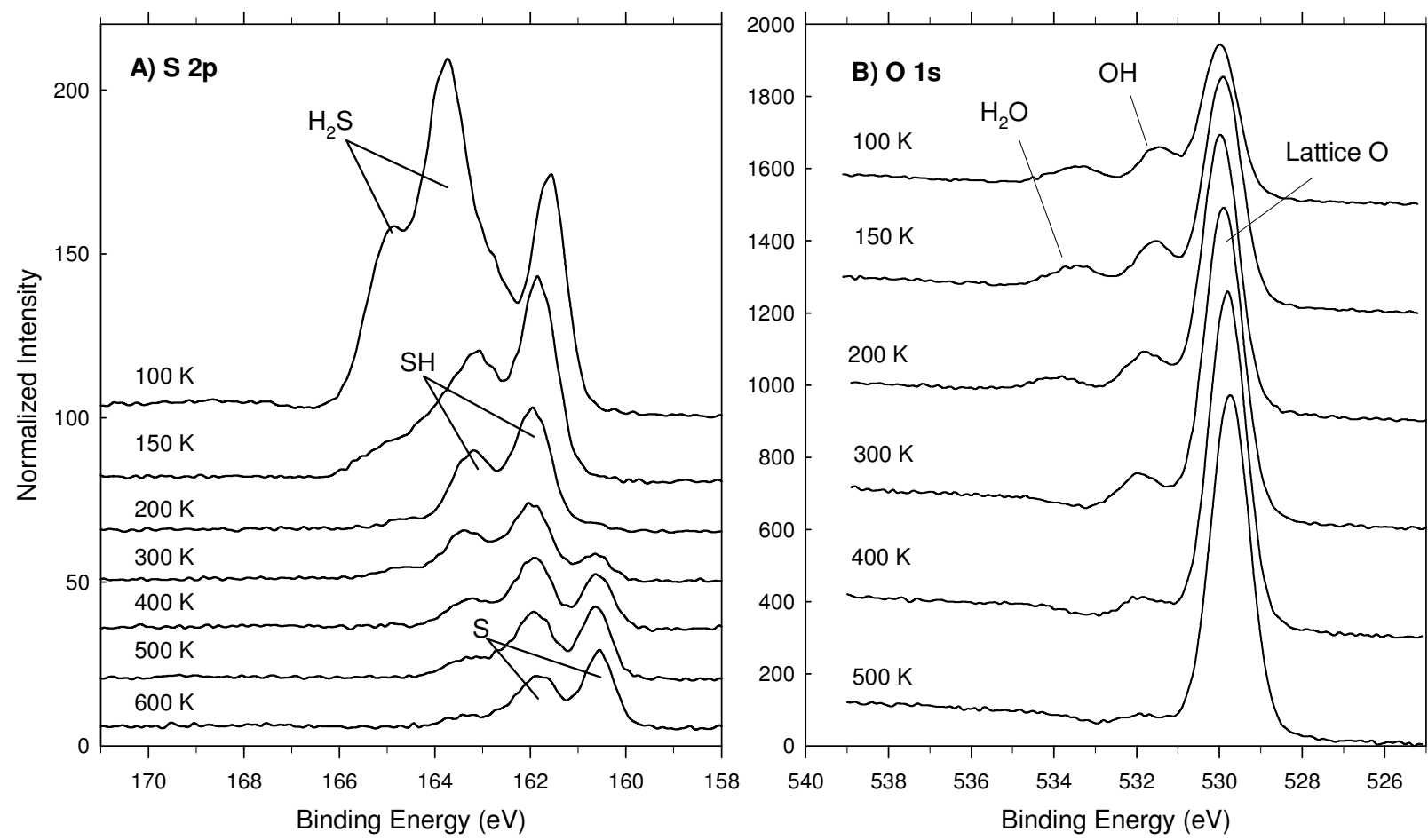

Figure $19-$ A) S 2p and B) O 1s XPS spectra following exposure of $\mathrm{H}_{2} \mathrm{~S}$ on oxidized $\mathrm{CeO}_{2}(111)$ / $\mathrm{Ru}(0001)$. The $\mathrm{H}_{2} \mathrm{~S}$ was exposed at $100 \mathrm{~K}$ and then annealed as indicated. Reprinted from Ref. [200]. Copyright 2007 with permission from Elsevier. 


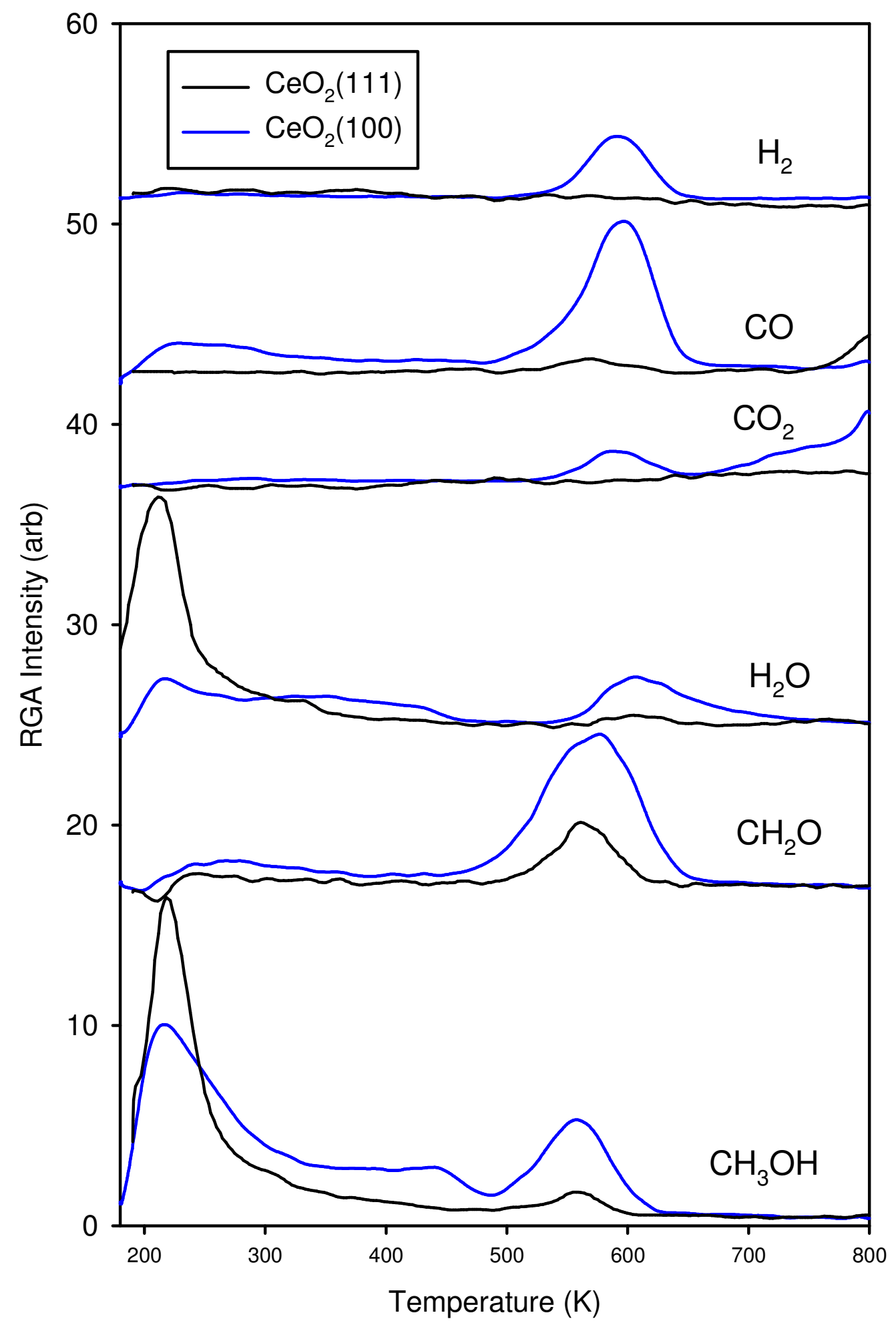

Figure 20 - TPD following methanol adsorption at $180 \mathrm{~K}$ on oxidized $\mathrm{CeO}_{2}(111)$ (black lines) and $\mathrm{CeO}_{2}(100)$ (blue lines). Reprinted from Ref.[205] . Copyright 2013 with kind permission from Springer Science and Business Media. 


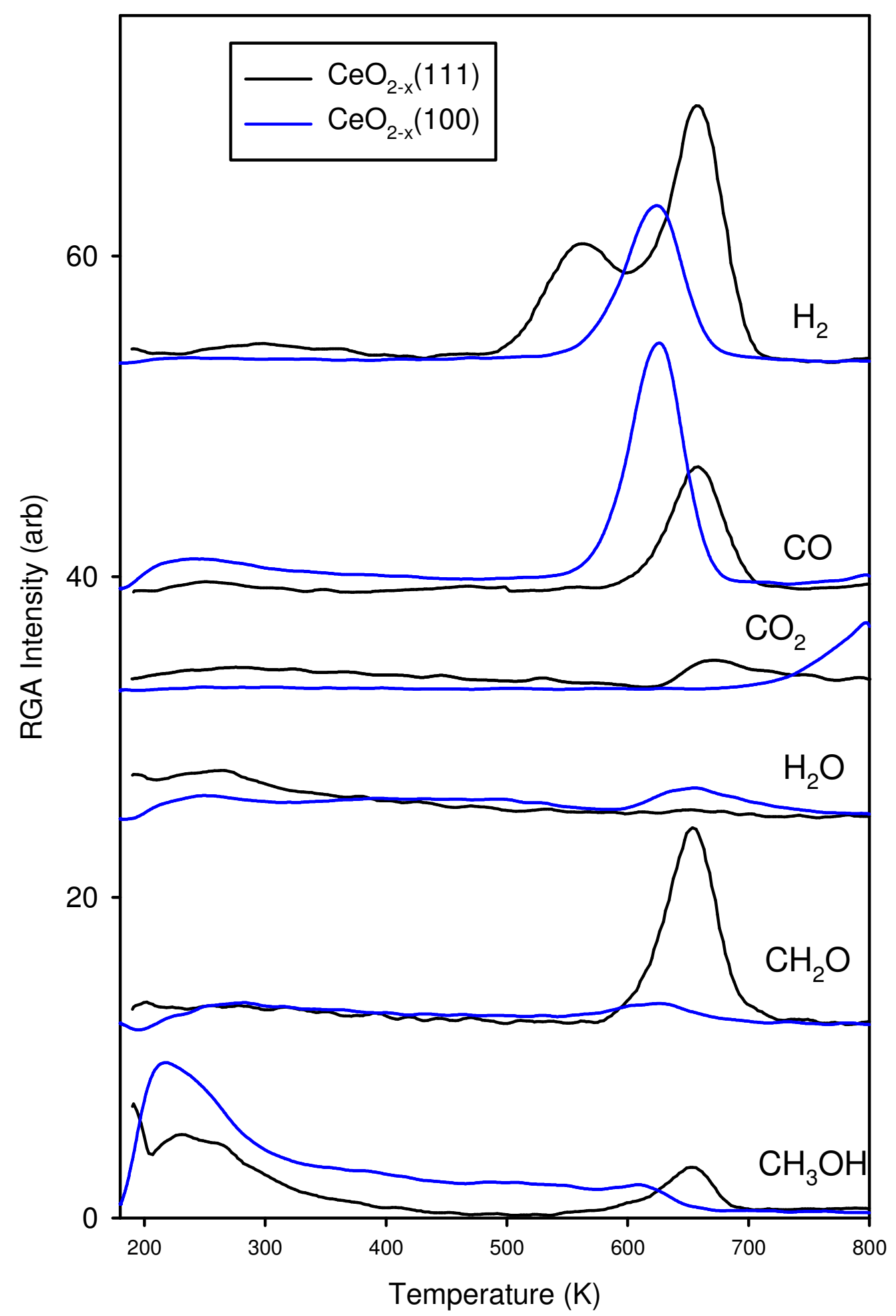

Figure 21 - TPD following methanol adsorption at $180 \mathrm{~K}$ on reduced $\mathrm{CeO}_{2-x}(111)$ (black lines) and $\mathrm{CeO}_{2-\mathrm{x}}(100)$ (blue lines). Reprinted from Ref.[205] . Copyright 2013 with kind permission from Springer Science and Business Media. 

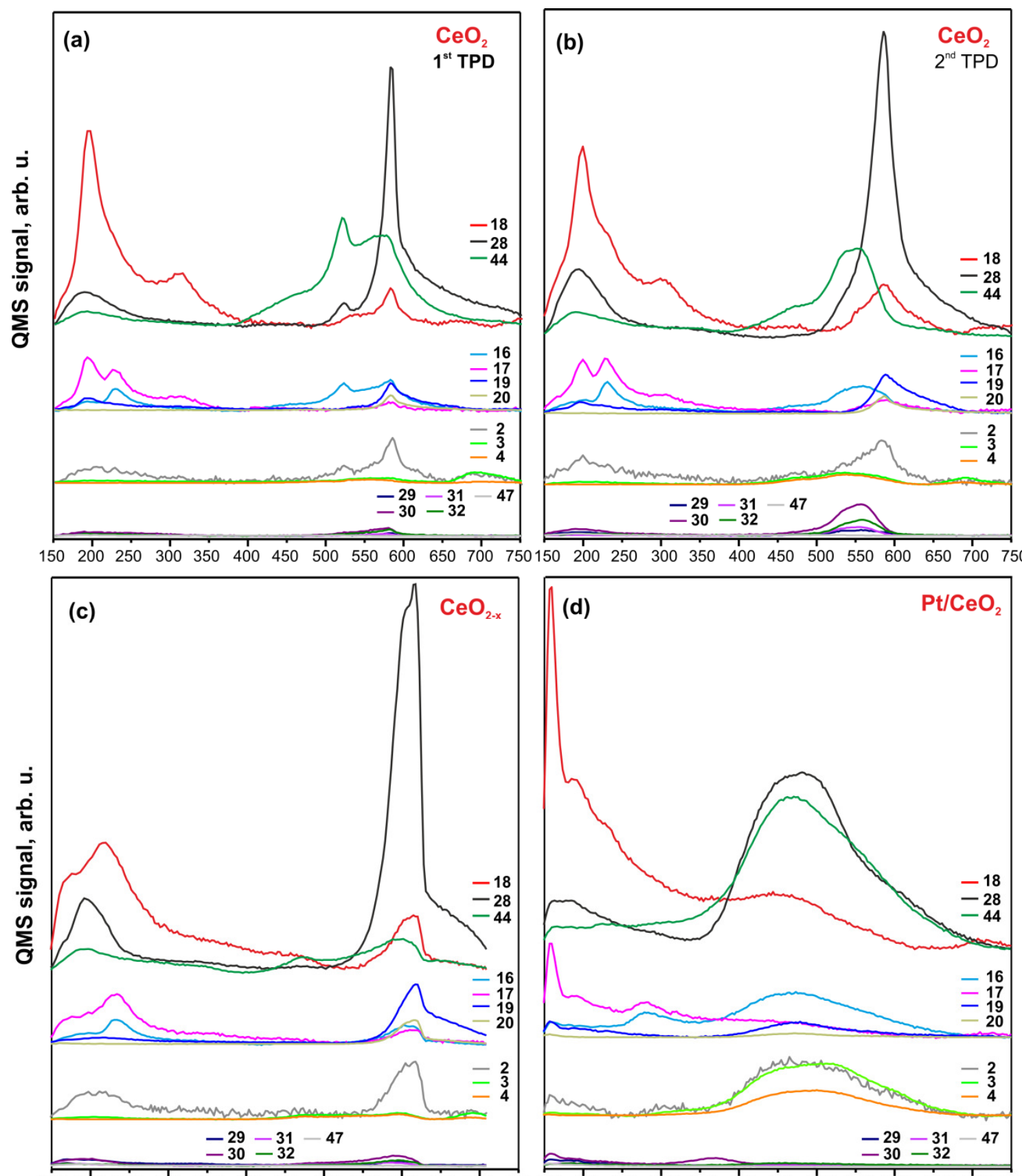

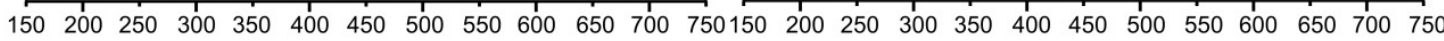

Temperature, $\mathbf{K}$

Temperature, $\mathbf{K}$

Figure 22 -TPD from selectively deuterated formic acid, $\mathrm{DCOOH}$, on (a) oxidized $\mathrm{CeO}_{2}(111)$, (c) reduced $\mathrm{CeO}_{2-x}(111)$, and (d) Pt supported on oxidized $\mathrm{CeO}_{2}(111)$. Reprinted with permission from Ref.[62]. Copyright 2013 American Chemical Society. 

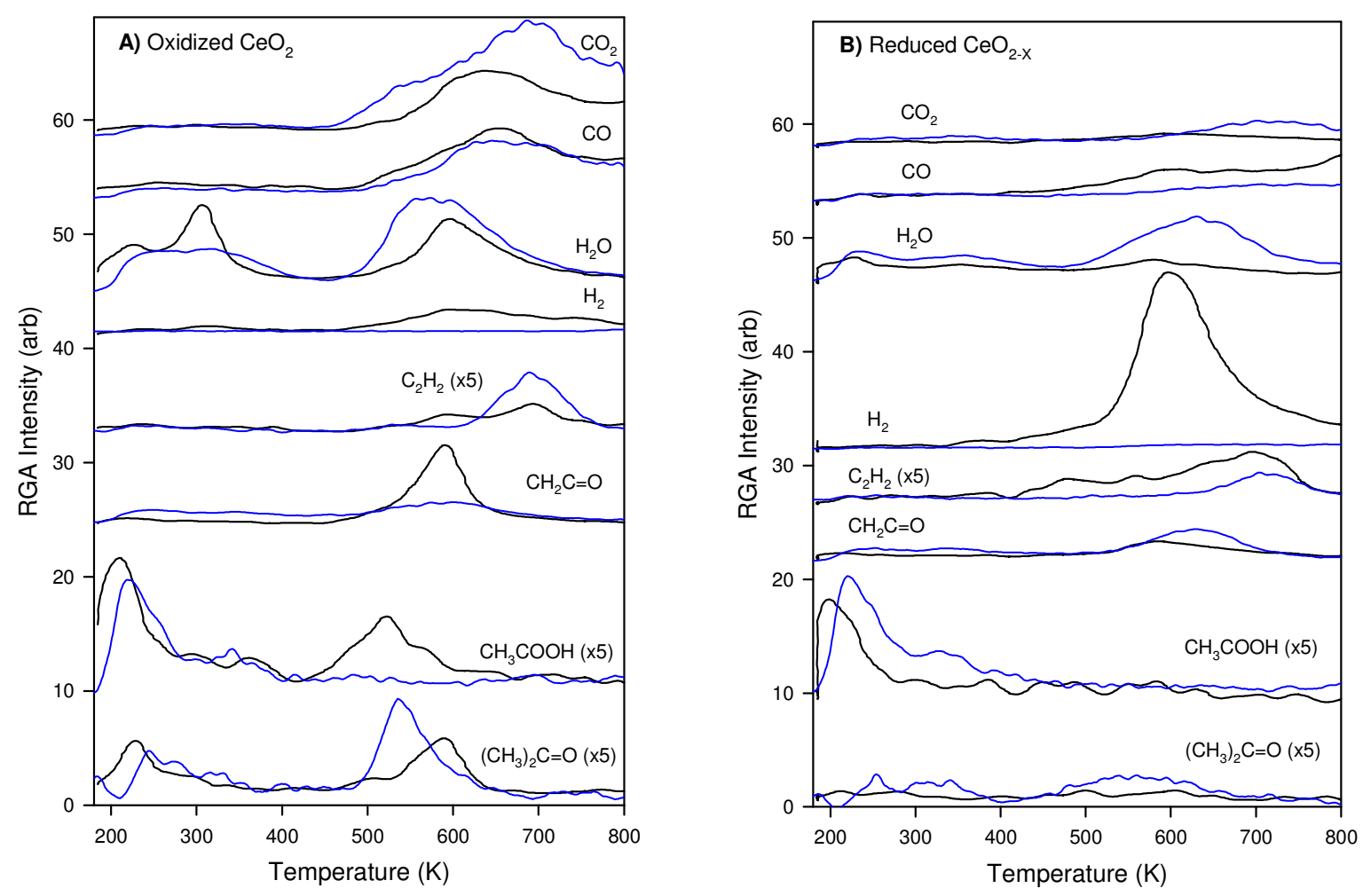

Figure 23 - Acetic acid TPD on A) oxidized and $\mathrm{B}$ ) reduced $\mathrm{CeO}_{x}$ surfaces. The black lines are from $\mathrm{CeO}_{x}(111)$ and the blue lines are from $\mathrm{CeO}_{x}(100)$. Reprinted from Ref.[205] . Copyright 2013 with kind permission from Springer Science and Business Media. 




Figure 24 - Acetaldehyde TPD on oxidized (black lines) and reduced (blue lines) $\mathrm{CeO}_{\mathrm{x}}(111)$ surfaces. Reprinted with permission from Ref.[216]. Copyright 2011 American Chemical Society. 

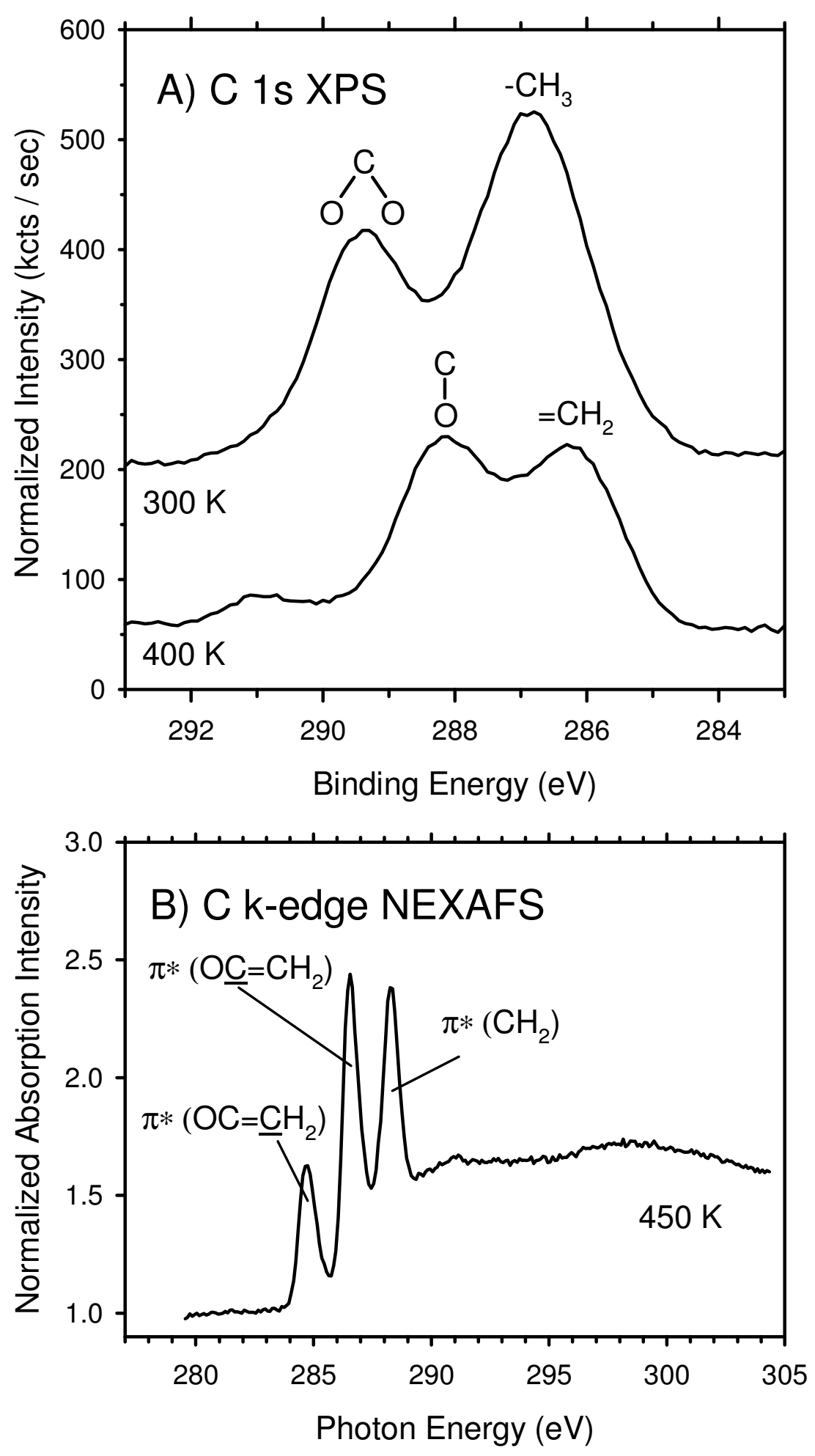

Figure $25-\mathrm{C}$ 1s XPS (A) and C k-edge NEXAFS (B) of acetaldehyde adsorbed on reduced $\mathrm{CeO}_{2-\mathrm{x}}(111)$ at $175 \mathrm{~K}$ and .annealed as indicated. 


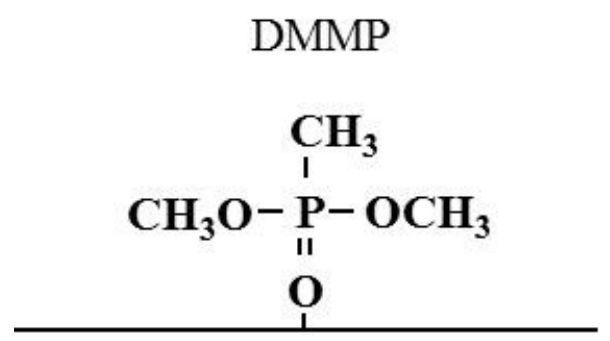

$200 \mathrm{~K}$

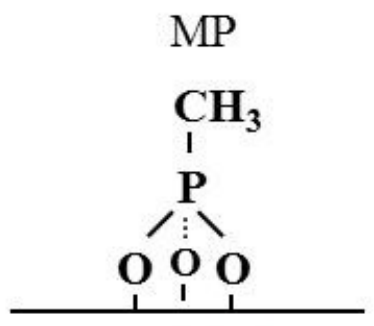

$700 \mathrm{~K}$

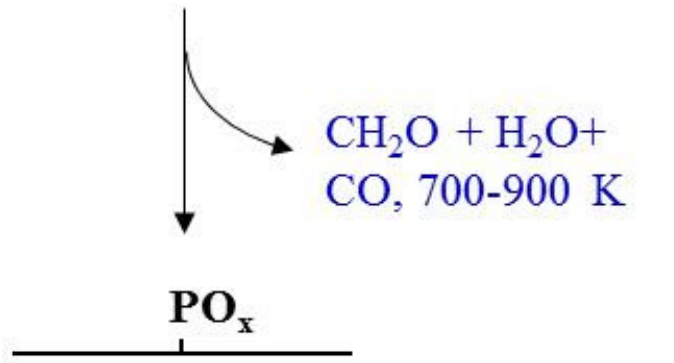

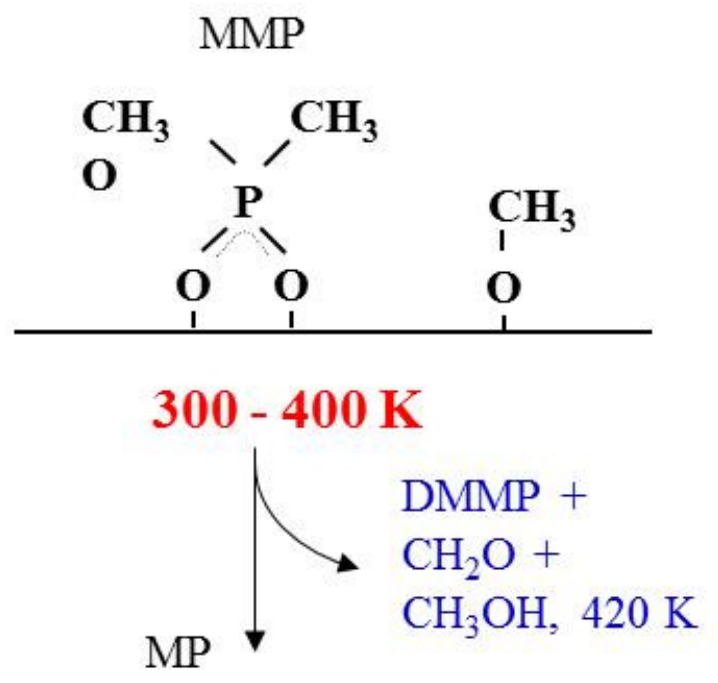



$500 \mathrm{~K}$

\section{$900 \mathrm{~K}$}

Figure 26 - A proposed reaction scheme for DMMP decomposition on $\mathrm{CeO}_{2}(111)$ showing the main surface species at various temperatures. Although the structures of all the intermediates have not been conclusively identified in this work, reasonable structures have been proposed based on literature studies of DMMP decomposition on other oxide surfaces.[358-361] Reprinted from Ref. [230]. Copyright 2010 with permission from Elsevier. 

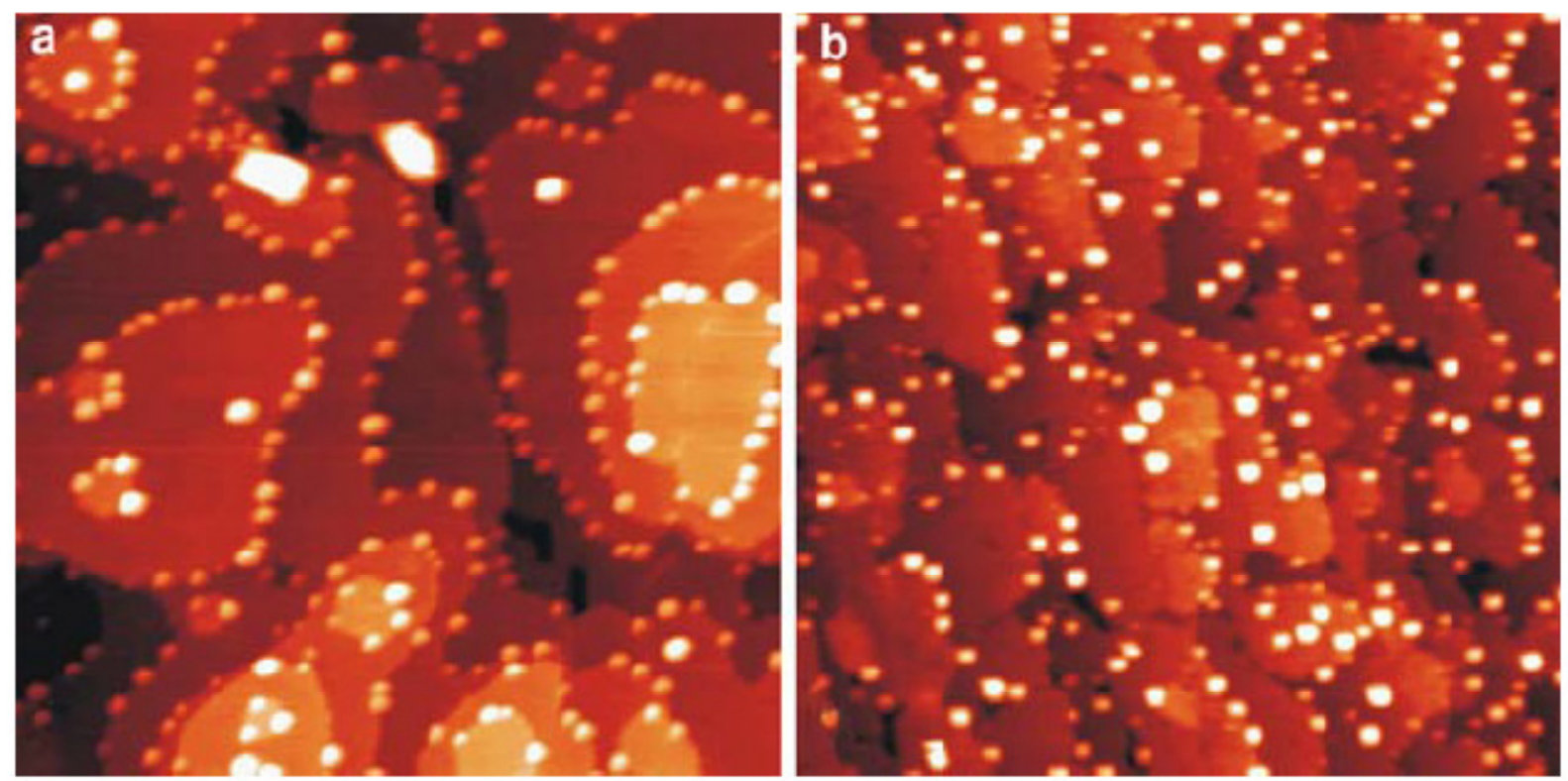

Figure 27 - STM image of $0.1 \mathrm{ML}$ of Au deposited on (a) fully oxidized and (b) partially reduced $\mathrm{CeO}_{2}(111)$ films grown on $\mathrm{Ru}(0001)$ at $300 \mathrm{~K}$. On the fully oxidized surface the Au particles nucleate almost exclusively at the step edges, whereas more of the Au nucleates at defects on the terraces of the partially reduced surface. Image size is $150 \times 150 \mathrm{~nm}^{2}$. Reprinted from Ref.[231]. Copyright 2007 with kind permission from Springer Science and Business Media. 

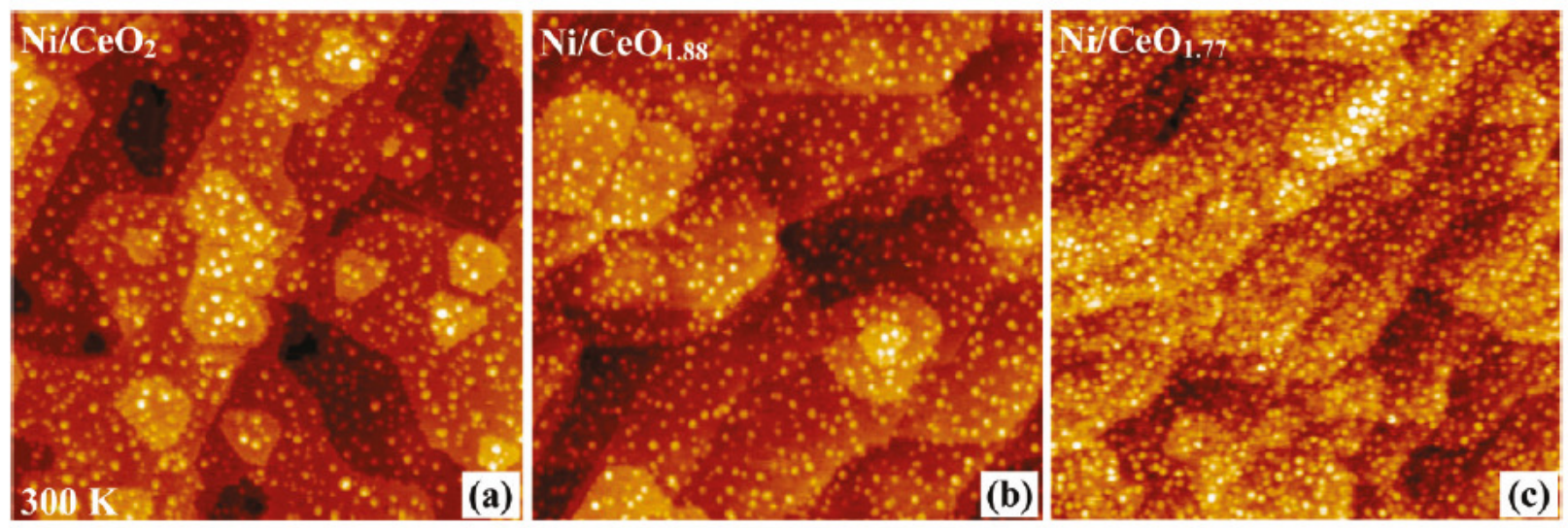

Figure 28 - STM images of $0.25 \mathrm{ML}$ of $\mathrm{Ni}$ on (a) $\mathrm{CeO}_{2}(111)$, (b) $\mathrm{CeO}_{1.88}(111)$ and (c) $\mathrm{CeO}_{1.77}(111)$. The Ni nanoparticles are uniformly distributed on all of the surfaces. The particles are smaller and have a larger density of the reduced surfaces. Image sizes are $100 \times 100 \mathrm{~nm}^{2}$. Reprinted with permission from Ref.[232]. Copyright 2010 American Chemical Society. 


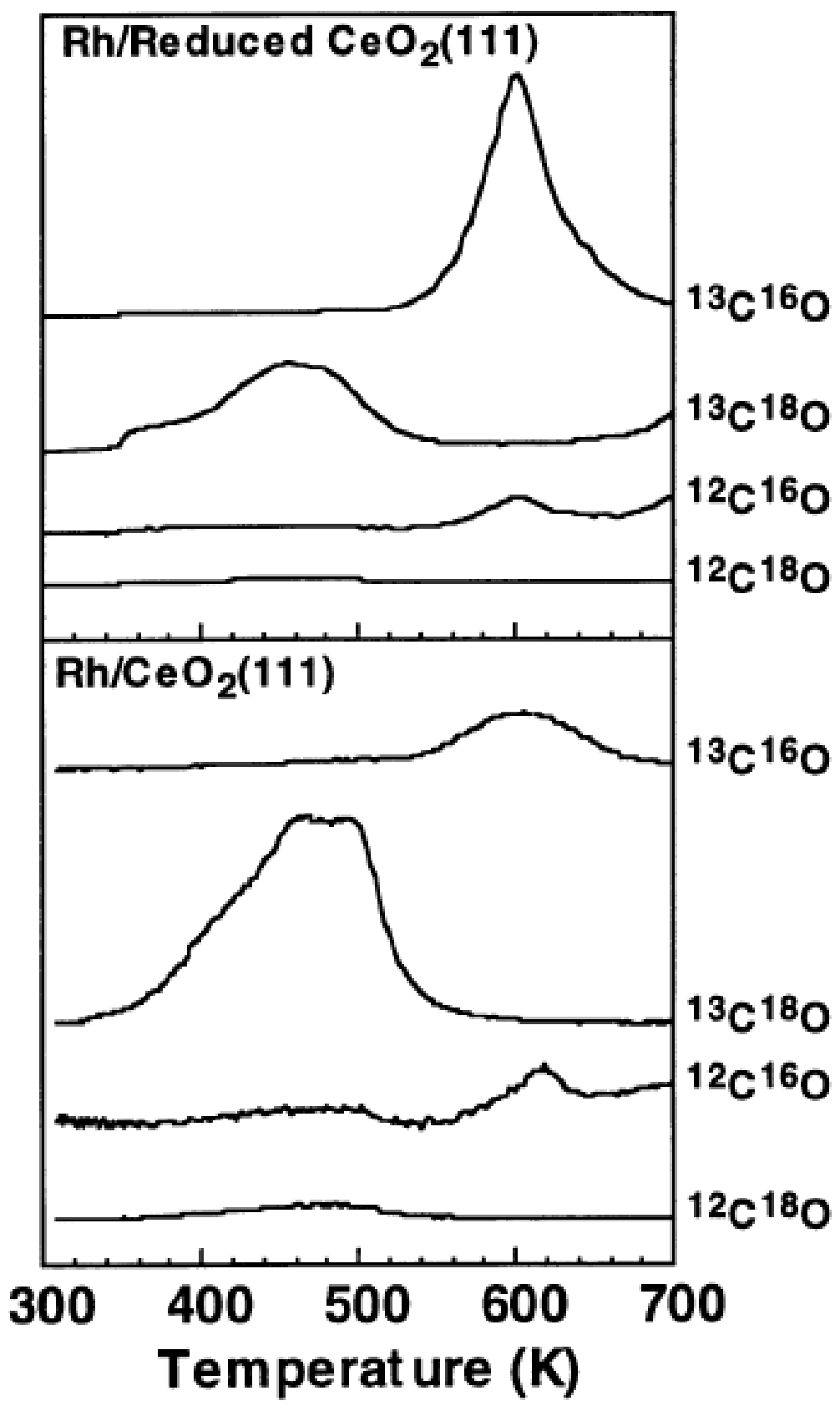

Figure 29 - TPD spectra obtained after exposing Rh particles supported on nearly stoichiometric $\mathrm{Ce}^{16} \mathrm{O}_{2}(111)$ (lower panel) and partially reduced $\mathrm{Ce}^{16} \mathrm{O}_{2}(111)$ (upper panel) to a saturation dose of ${ }^{13} \mathrm{C}^{18} \mathrm{O}$. Reprinted from Ref.[76]. Copyright 1994 with kind permission from Springer Science and Business Media. 


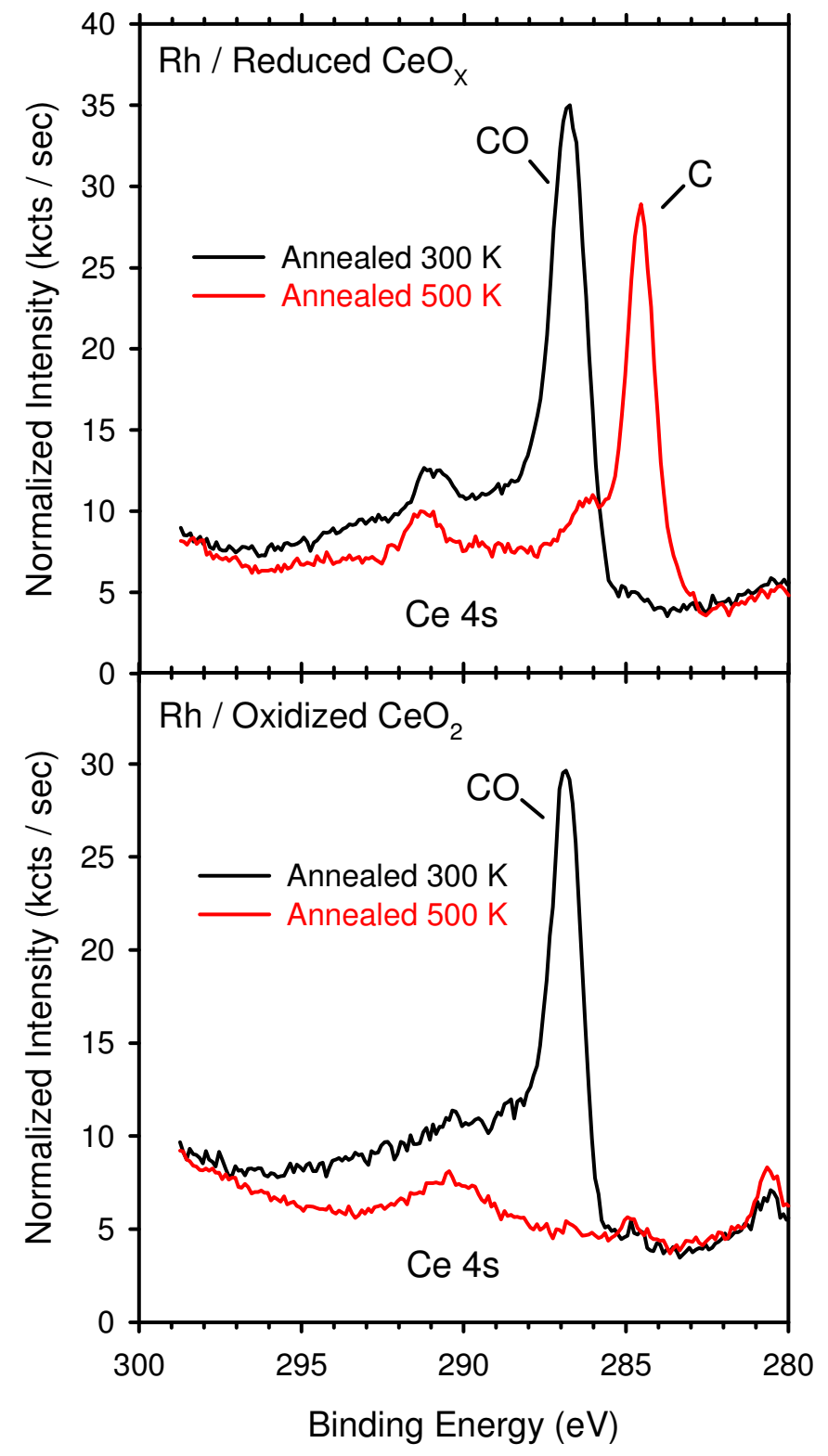

Figure 30 - C 1s sXPS spectra obtained after exposing Rh particles supported on oxidized $\mathrm{CeO}_{2}(111)$ (lower panel) and partially reduced $\mathrm{CeO}_{x}(111)$ (upper panel) to a saturation dose of $\mathrm{CO}$. 

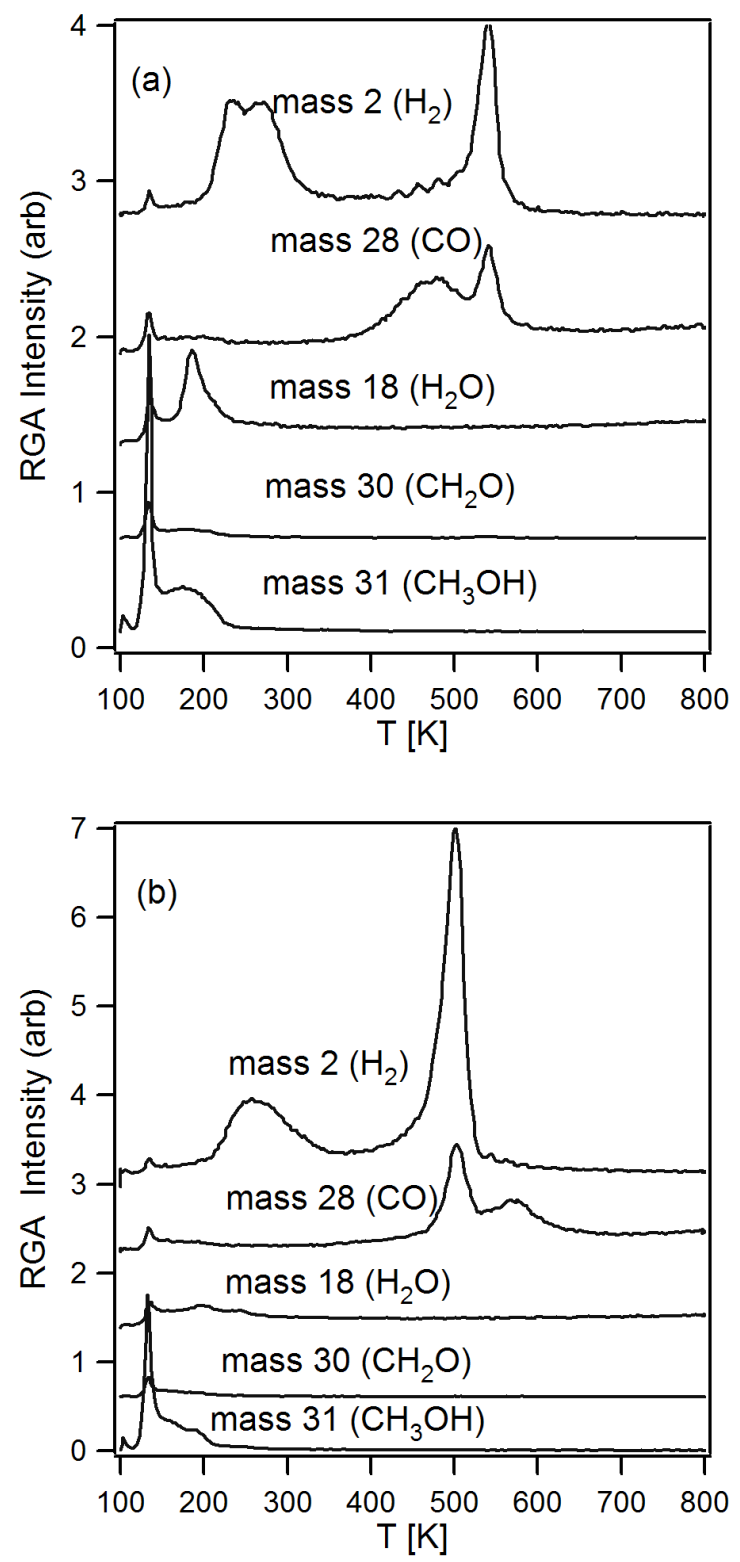

Figure 31 - TPD spectra obtained after exposing Rh particles supported on (a) oxidized and (b) partially reduced $\mathrm{CeO}_{x}(111)$ to methanol at $100 \mathrm{~K}$. Reprinted with permission from Ref.[318]. Copyright 2006 American Chemical Society. 


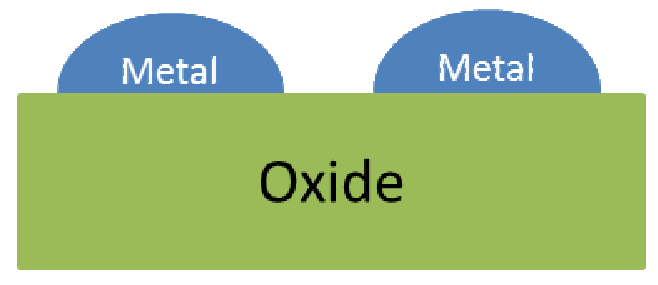

Conventional Catalyst

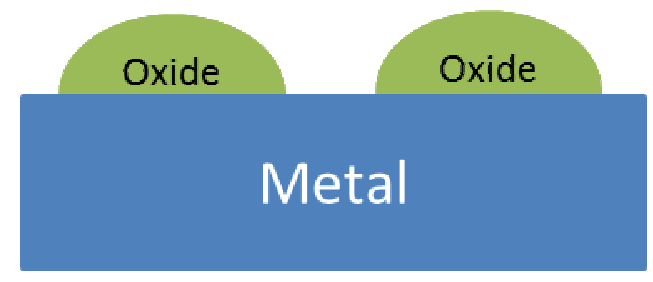

Inverse Catalyst

Figure 32 - Structures of a conventional metal / oxide model catalyst and an inverse oxide / metal model catalyst. Adapted from Ref. [343]. Copyright 2010 with permission from Elsevier. 


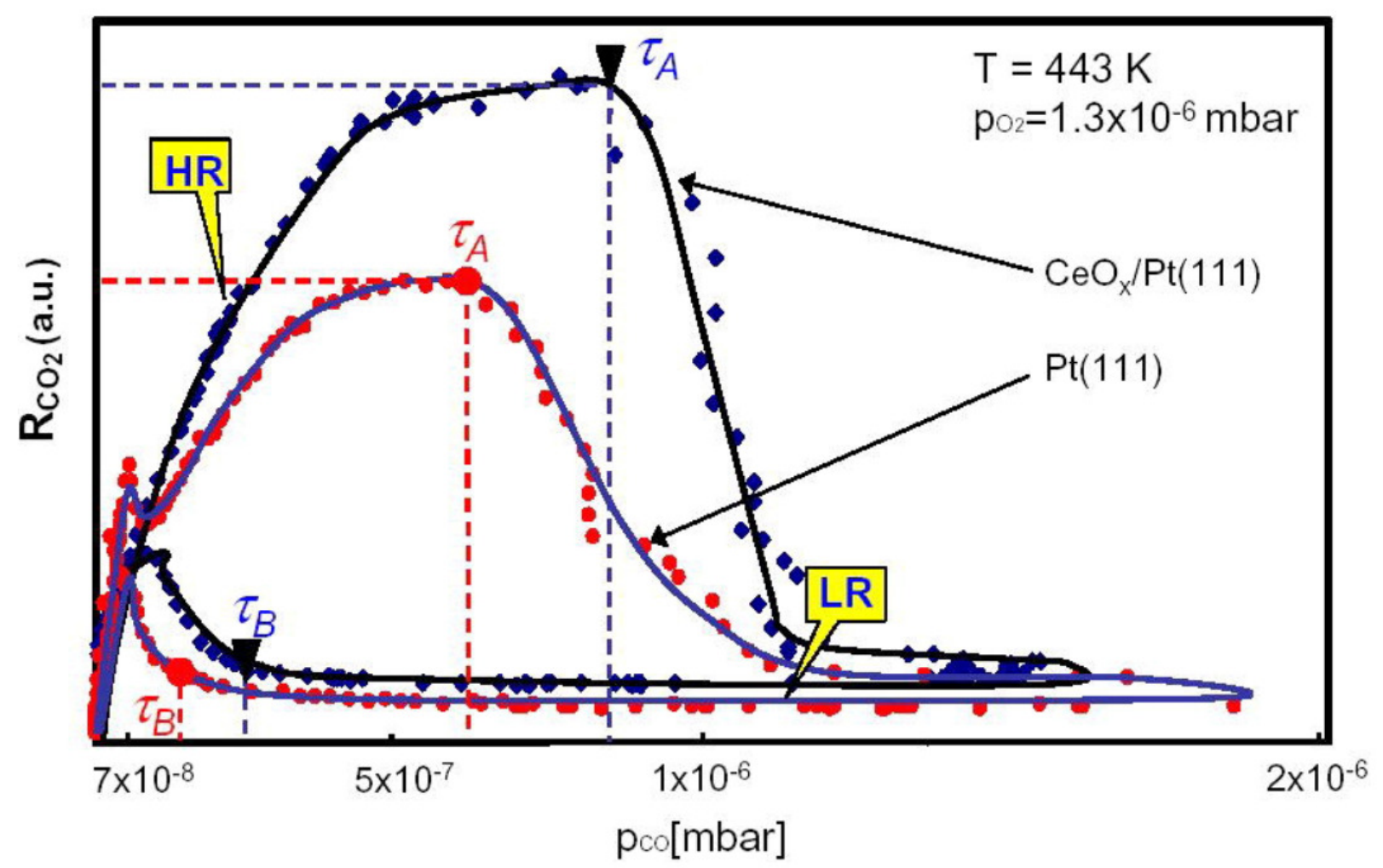

Figure 33 - Hysteresis in the $\mathrm{CO}_{2}$ production rate as obtained upon cyclic variation of the $\mathrm{CO}$ partial pressure at constant oxygen pressure. Results are shown on clean $\mathrm{Pt}(111)$ and on ceria particles supported on $\mathrm{Pt}(111)$. The reaction transitions from high reactivity $(\mathrm{HR})$ to low reactivity $(\mathrm{LR})$ at transition pressures, $\tau_{\mathrm{A}}$. Reprinted from Ref. [84]. Copyright 2007 with permission from Elsevier. 


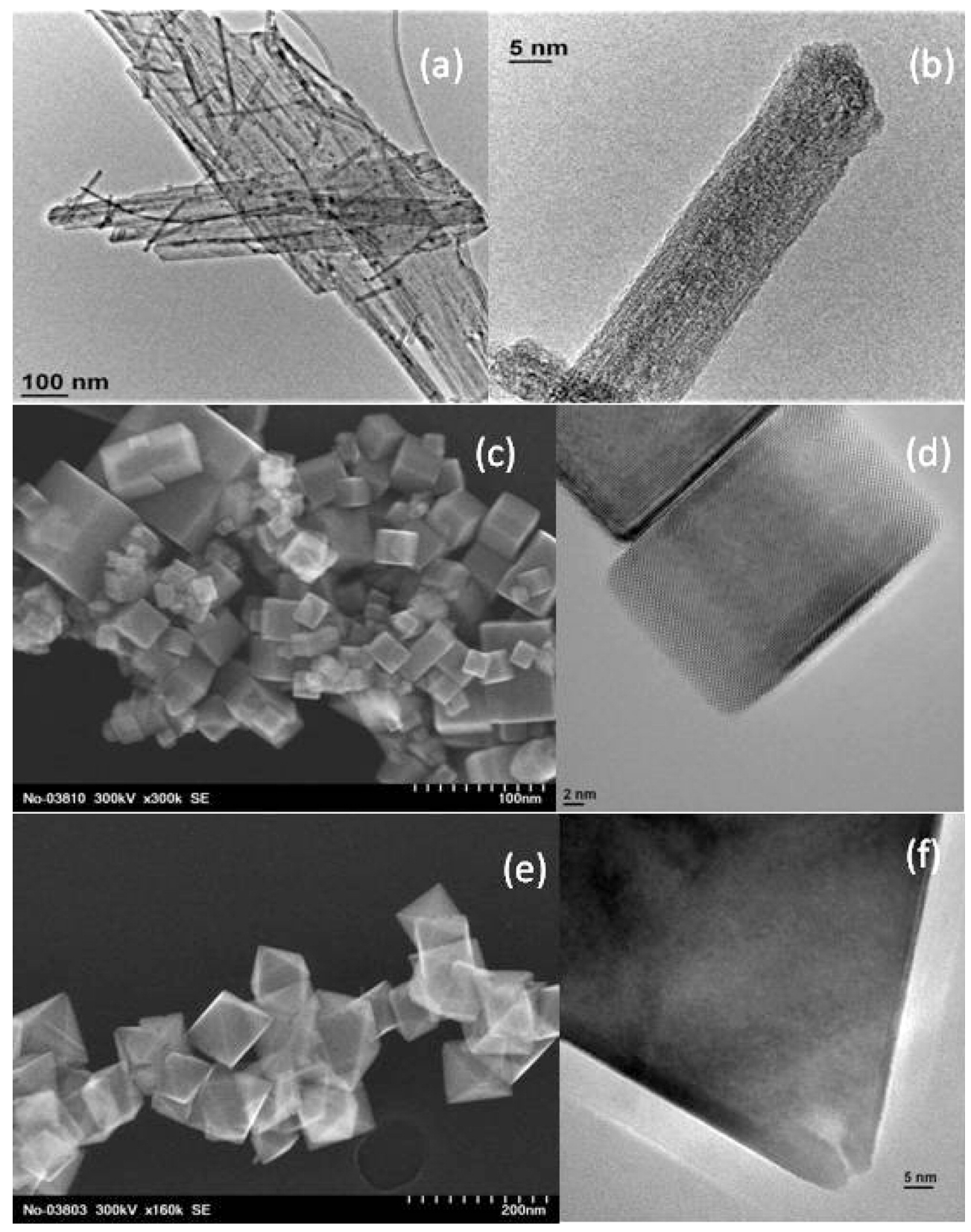

Figure 34 - TEM and HRTEM images of as-synthesized ceria rods (a, b), cubes (c, d), and octahedra (e, f). Reprinted with permission from ref.[157] . Copyright 2010 American Chemical Society 